\title{
Exploring the long-term social and land management impacts on participants of the Entry Level Stewardship Scheme
}

\section{George Cusworth}

A thesis submitted to The University of Gloucestershire in accordance with the requirements of the degree of Doctor of Philosophy in the School of Natural and Social Sciences

A research project co-funded by the Countryside and Community Research Institute of The University of Gloucestershire and Natural England.

April 2019 

Abstract:

Agri-environment schemes (AESs) offer remuneration for land managers who implement environmental management techniques onto their farms. Participation is voluntary, and the schemes are designed to go beyond the agri-environmental management standards placed on farmers by other policies. Between 2005 and 2014, Environmental Stewardship (ES) was England's main agri-environment scheme. It was itself split into two tiers - Higher Level Stewardship and Entry Level Stewardship (ELS). This research project assesses the long-term impacts of the ELS tier of ES and focusses on the social, attitudinal and behavioural features of the scheme's extended impact. The data was collected through 40 in-depth interviews, 24 of which also had a longitudinal, repeat interview component. The interviews took place in two different case-studies with contrasting agricultural profiles (landscape characteristics, representation of different farm systems). An important element of the research relates to the long-term management changes that participation has effected - specifically whether the participants had elected to preserve the management practices promoted by their scheme contracts. Interviews were conducted with contract holders at the end of their involvement with ELS and then shortly after the termination of their contracts as a means of attending to this particular research objective. For many participants, the scheme's intervention has functioned as a habit-breaking force and has catalysed the long-term adoption of the scheme practices, beyond the extent of the contract's duration. The research also contributes to the sociological study of environmental attitudes represented in the agricultural industry. Bourdieu's social theory, along with the good farmer concept, are used to help understand the non-economic capitals associated with the implementation of agri-environmental practices. A small but valuable literature exists that centres around a Bourdieusian analysis of agri-environmental behaviours and attitudes, and this project is adding to that lineage. Participation in the ELS scheme, along with other wider cultural and economic forces are changing the position that environmental management occupies in the psychologies of the farmers. In managing a farm, the absence - rather than the adoption - of environmental management practices emerged as the approach more likely to attract the criticism of other members of the farming community. The bad farmer concept is developed to help account for the criticism and distaste for environmentally negligent behaviour, and the motivational force this exerts on the manager's decision-making processes. 
Author's declaration

I declare that the work in this thesis was carried out in accordance with the regulations of The University of Gloucestershire and is original except where indicated by specific reference in the text. No part of the thesis has been submitted as part of any other academic award. The thesis has not been presented to any other education institution in the United Kingdom or overseas.

Any views expressed in the thesis are those of the author and in no way represent those of the University

\section{George Cusworth}

April 2019

doi:10.46289/HNDS2486 
Acknowledgements

Thanks firstly to my two supervisors at the CCRI - Jane Mills and Pete Gaskell and to Stephen Chaplin at Natural England. Without their personal encouragement and expertise, and without the funding from their respective institutions, the $\mathrm{PhD}$ would not have been possible. Thanks also to Ben and Noni for sheltering me whilst out collecting data. To Alex Cox, not only for his hospitality, but for his friendship long before the $\mathrm{PhD}$ was started. To my family, all of whom have offered their own unique contributions, support and distractions. And to Holly, who has been able to make me smile, throughout. 


\section{Contents}

Abstract

Author's declaration $\quad$ ii

Acknowledgements

Contents iv

List of Figures viii

List of Tables viii

List of Appendices viii

List of Abbreviations $\quad$ ix

1. Introduction to the thesis $\quad 1$

$\begin{array}{ll}1.1 \text { Chapter introduction } & 1\end{array}$

1.2 Research aims and objectives $\quad 5$

$\begin{array}{ll}1.3 \text { Structure of the thesis } & 6\end{array}$

$\begin{array}{ll}\text { 2. Literature review } & 8\end{array}$

$\begin{array}{ll}2.1 \text { Chapter introduction } & 8\end{array}$

2.2 AES design $\quad 8$

2.3 AES - where they came from, and where they sit in today's legislative landscape 12

$\begin{array}{ll}2.4 \text { Analysing AESs } & 18\end{array}$

2.4.1 Self-identity, the good farmer, and Bourdieu's social theory 20

2.4.2 Changing attitudes and values 25

2.4.3 Post-scheme behaviour 29

$\begin{array}{ll}2.5 \text { Chapter conclusion } & 31\end{array}$

3. Research theory

3.1 Chapter introduction 33

3.2 Choosing a research theory 33

3.3 The theory, in-depth $\quad 38$

3.3.1 Field 39

3.3.2 Habitus $\quad 41$

3.3.3 Capital 49

3.3.4 Practice $\quad 54$

3.4 Deploying the theory in this research project

3.4.1 Epistemological considerations in adopting Bourdieu's theory 55

3.4.2 Field, in the context of this project 57

3.4.3 Habitus, in the context of this project 59 
3.4.4 Capital, in the context of this project

3.4.5 Conceptualising the good farmer

3.5 Conceptualising environmental management practices 66

$\begin{array}{ll}3.6 \text { Conceptualising post-scheme behaviour } & 69\end{array}$

3.7 Conceptualising multifunctional agriculture $\quad 71$

$\begin{array}{ll}3.8 \text { Problems with Bourdieu's theory } & 72\end{array}$

$\begin{array}{ll}3.9 \text { Chapter conclusion } & 75\end{array}$

$\begin{array}{ll}\text { 4. Research methodology } & 76\end{array}$

$\begin{array}{ll}\text { 4.1 Chapter introduction } & 76\end{array}$

$\begin{array}{ll}4.2 \text { Research design } & 76\end{array}$

4.2.1 Selecting a qualitative methodology $\quad 77$

4.2.2 Considerations for researching post-scheme behaviour $\quad 79$

4.2.3 Selecting a follow-up methodology $\quad 81$

4.2.4 The comparative case-study approach $\quad 84$

4.2.5 Realising the comparative, follow-up case-study methodology 87

4.2.6 A note on ELS, and ES 90

$\begin{array}{ll}\text { 4.2.7 The case-studies } & 92\end{array}$

4.2.8 Bourdieu's theory and interview questions 94

4.2.9 Interview schedules 96

4.2.10 Privacy and ethics provisions 98

4.2.11 Data analysis 99

4.2.12 Reflexivity and Bourdieu's epistemic break 103

4.2.13 Data presentation 106

4.2.14 A note on the case-study method and the generalisability of the project's findings 107

4.3 Chapter conclusion

5. Contextualising the research 111

5.1 Chapter introduction $\quad 111$

5.2 Description of case-studies 111

5.3 Description of the policy landscape 118

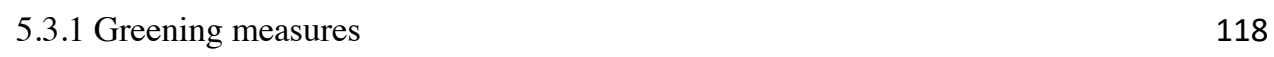

5.3.2 Post-Brexit agricultural policy 119

$\begin{array}{ll}\text { 5.3.3 Countryside Stewardship Scheme } & 120\end{array}$

$\begin{array}{ll}5.4 \text { Chapter conclusion } & 121\end{array}$

6. Analysis of data and discussion - phase 1 interviews 123

$\begin{array}{ll}\text { 6.1 Chapter introduction } & 123\end{array}$ 
$\begin{array}{ll}\text { 6.3 Theme by theme analysis } & 124\end{array}$

6.3.1 Good farmers, bad farmers, and the reproduction of cultural capital $\quad 124$

6.3.1.1 The productivist identity and good farming 125

$\begin{array}{ll}\text { 6.3.1.2 The good farmer and the middle ground } & 127\end{array}$

6.3.1.3 Business-orientated environmental behaviour $\quad 131$

6.3.1.4 Environmental behaviour and cultural capital 138

$\begin{array}{ll}\text { 6.1.3.5 Policy influence and attitude change } & 141\end{array}$

$\begin{array}{ll}\text { 6.1.3.6 The bad farmer } & 144\end{array}$

6.3.2 Hysteresis, habitus change and new attitudes 153

$\begin{array}{ll}\text { 6.3.2.1 ELS experience and attitude change } & 158\end{array}$

$\begin{array}{ll}\text { 6.3.2.2 Normalisation of AES participation } & 164\end{array}$

6.3.3 Scheme-inspired management changes, and post-scheme behaviour 177

6.3.3.1 deadweight or actual management change 178

$\begin{array}{ll}\text { 6.3.3.2 Post-scheme behaviour } & 182\end{array}$

6.3.3.2.1 Removal of ELS options 186

6.3.3.2.2 Upkeep of ELS options through CS 187

6.3.3.2.3 Voluntary Upkeep of ELS options 188

$\begin{array}{ll}\text { 6.3.3.3 Analysis of post-scheme behaviour } & 192\end{array}$

6.3.4 Regional comparisons 193

$\begin{array}{ll}6.3 .5 \text { Brexit } & 199\end{array}$

$\begin{array}{ll}\text { 6.4 Chapter conclusion } & 201\end{array}$

7. Analysis and discussion phase $2 \quad 202$

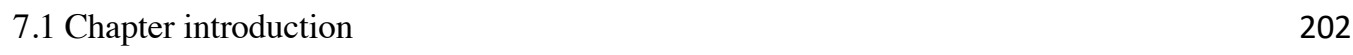

7.2 Phase 2 interviews research sample $\quad 202$

7.3 Theme by theme analysis $\quad 204$

7.3.1 Post-scheme management 204

7.3.1.1 Entry into CS, and use of ELS land for CS purposes 205

7.3.1.2 Maintenance of options in no-CS settings 208

7.3.1.2.1 Economic motivations 208

7.3.1.2.2 Ease of management motivations $\quad 210$

7.3.1.2.3 Environmental motivations $\quad 212$

$\begin{array}{ll}\text { 7.3.1.2.4 Policy motivations } & 213\end{array}$

7.3.1.2.5 Combined motivations $\quad 214$

7.3.1.2.6 Additionality and deadweight 218

7.3.1.3 Removal of ELS options, re-entry into agricultural production 221

7.3.1.4 Generalising the project's findings 226 
7.3.1.5 Reintroducing Bourdieu's thinking tools

7.3.1.5.1 The rules of the game

7.3.1.5.2 Multifunctionality in the rules of the game

7.3.1.6 Crowding out, crowding in

7.3.2 Provision of public goods and Brexit

7.3.2.1 Brexit, AES participation, and agri-environmental practices

8.3 Revisiting the project's research questions, and a future research agenda 


\section{List of Figures}

$\begin{array}{ll}\text { Figure 2.1 Infographic on the history of AESs in England } & 17\end{array}$

Figure 3.1 Schematic of capital $\quad 52$

$\begin{array}{ll}\text { Figure 4.1 Methodological schema } & 83\end{array}$

Figure 4.2 Swanwick’s typology map $\quad 86$

Figure 4.3 Map of case-studies $\quad 92$

Figure 5.1 Representation of arable farms 112

Figure 5.2 Representation of livestock farms 113

Figure 5.3 Representation of mixed farms 114

Figure 5.4 Uptake of grassland ELS options (Hodge and Reeder 2010), with case-study maps 115

Figure 5.5 Uptake of boundary ELS options (Hodge and Reeder 2010), with case-study maps 116

Figure 5.6 Uptake of ELS scheme (Hodge and Reeder 2010), with case-study maps 117

\section{Table of Figures}

Table 3.1 Table depicting environmental practices, relevant to arable land, as per the ELS scheme 69

Table 3.2 Table depicting environmental practices, relevant to grazing land, as per the ELS scheme 69

Table 3.3 Table depicting environmental practices, relevant to agricultural land, as per the ELS scheme

\section{List of Appendices}

Appendix A - Screenshots of NVivo coding process 305

Appendix B - Interviewee details 307

Appendix C - Phase 1 interview schedule 309

Appendix D - Phase 2 interview schedule 316

$\begin{array}{ll}\text { Appendix E - Interview request letter } & 320\end{array}$ 
List of Abbreviations

$\begin{array}{ll}\text { AES } & \text { Agri-environment scheme } \\ \text { BPS } & \text { Basic Payment Scheme } \\ \text { CAC } & \text { Command and Control } \\ \text { CAP } & \text { Common Agricultural Policy } \\ \text { CAQDAS } & \text { Computer-Assisted Qualitative Data Analysis Software } \\ \text { CCRI } & \text { Countryside and Community Research Institute } \\ \text { CS } & \text { Countryside Stewardship } \\ \text { Defra } & \text { Department for the environment, food and rural affairs } \\ \text { EFA } & \text { Ecological Focus Area } \\ \text { ELS } & \text { Entry Level Stewardship } \\ \text { ELM } & \text { Environmental Land Management } \\ \text { ES } & \text { Environmental Stewardship } \\ \text { EEC } & \text { European Economic Community } \\ \text { EU } & \text { European Union } \\ \text { GAEC } & \text { Good Agricultural Environmental Condition } \\ \text { GDPR } & \text { General Data Protection Regulations } \\ \text { GWCT } & \text { Game and Conservation Wildlife Trust } \\ \text { HLS } & \text { Higher Level Stewardship } \\ \text { IEEP } & \text { Institute for European Environmental Policy } \\ \text { NCA } & \text { National Character Area } \\ \text { NVZ } & \text { Nitrate Vulnerable Zone } \\ \text { NE } & \text { Natural England } \\ \text { OELS } & \text { Organic Entry Level Stewardship } \\ \text { PES } & \text { Payment for Ecosystem Services } \\ \text { SCU } & \text { Survey Control Unit } \\ \text { SFP } & \text { Single Farm Payment } \\ \text { SMR } & \text { Statutory Management Requirement } \\ \text { UK } & \text { United Kingdom } \\ \text { UELS } & \text { Uplands Entry Level Stewardship } \\ & \end{array}$



1. Introduction to the thesis

\subsection{Chapter introduction}

Agri-environmental schemes (AESs) are one of the main policy tools used to tackle the different environmental pressures put on the rural environment by agricultural systems in the United Kingdom (UK), and in England specifically (Smallshire et al. 2004). The schemes offer payments to farmers who adopt environmentally friendly farm management techniques from a pre-determined list of management prescriptions, in exchange for the environmental value that the land management practices will deliver (Kleijn and Sutherland 2003). The management techniques are recognised as reducing the productive output of the land, and so scheme payments are calibrated to compensate for the income the farmers forego in adopting the prescribed practices (Moxey et al. 2008). In this way, AESs pay the farmers for the ecosystem services or public goods provided by their new farming techniques: the provision of safeguarded habitats for birds, insects or land mammals who have historically relied on agricultural land for food and shelter; reduced levels of fertiliser and pesticide application to help secure cleaner water systems; and the provision of cultural-historical landscape features such as stone walls and hedgerows (see Jones 2012 for a full account of the calculations that predict the scale of income foregone through the adoption of some ELS management technique, and a justification of the payments offered for to participants adopting the practice).

In England there are a number of other policies that make environmental demands on the way farmers manage their land. For them to receive the full money available through the European Union's (EU) Basic Payment Scheme (BPS), they must meet a list of 'Good Agricultural Environmental Conditions' (GAECs), 'Statutory Management Requirements' (SMRs) and the new 'Greening Measures'. If these are not met, then through the cross-compliance mechanism of the Common Agricultural Policy (CAP) - through which European agricultural and agri-environmental policies are designed and financed - their payments are either reduced or forfeited entirely. The environmental value provided by the land management options of AESs across Europe are designed, therefore, to build on the environmental value secured by those other, mandatory requirements. In this way, AESs are designed to be voluntary - 
whereby additional environmental value is provided by the supererogatory decision to participate in an AES (Ruto and Garrod 2009).

This voluntarism represents a departure from the traditional 'Command and Control' (CAC) style design of most environmental legislation (Gunningham and Sinclair 2005). Instead, that is, of setting environmental limits or minimum technology standards for target actors to meet, and enforcing those requirements with criminal or financial punishments, AESs seek to promote environmental behaviour through the voluntary (although reimbursed) adoption of specific behaviours. In policy design terms, AESs represent a departure from the 'polluter pays principle' towards the 'provider gets' principle (Mauerhofer et al. 2013).

In the 1960s the first incarnation of the EU's CAP provided market support for agricultural produce, through which farmers were assured reliable payment for all the food they produced. Over the 70s and 80s farmers, with the widening availability of agricultural technologies and agro-chemicals, agriculture became so productive that food surpluses were being achieved. The CAP responded, and in the 1992 CAP reforms, subsidies were shifted away from 'produce support' and towards 'producer support' to better calibrate the amount of food produced to the amount of market demand there was. The changes were designed to attend to the environmental damage that the over-production was causing in biodiversity, landscape and resource terms. Under this altered payment systems, farmers were not paid exclusively for the quantity of food they produced, but also received payments directly according to the size of their farm holding (Garzon 2006). The 1992 reforms also required all EU Member States to include provisions for AESs to help address the environmental impacts of the intensifying agricultural systems across Europe, and to help proliferate the adoption of environmentally friendly farming techniques (Kleijn and Sutherland 2003, Batary et al. 2015).

Although AESs represent only a modest percentage of the total CAP budget, they are one of the key tools deployed to tackle the negative environmental externalities associated with agriculture, and to reward those individuals already adopting environmentally friendly farming practices (Pe'er et al. 2014). The extent to which 
they have been able to deliver sizeable environmental improvements has received considerable attention. Scheper et al. 2013, Lastra-Bravo et al. 2015, Batary et al. 2010, for example, are three meta-analyses studies, each considering multiple papers looking into different aspects of AES design and impact. Such research focuses on whether the schemes have succeeded in meeting their biodiversity, soil quality and water quality targets, and whether they provide good policy value for money.

Relative to such ecological or environmental assessments, inspecting the extent to which AES participation has influenced the attitudes and long-term practices of participants has received less attention. Does exposure to the environmental information and management techniques of an AES augment participants' environmental attitudes? Does this have a bearing on the practices that managers adopt once the AES payments come to an end? If so, then the AES schemes have the potential to hold double treasures for policy makers: they can stimulate immediately improved environmental activity in farmers, whilst simultaneously ensuring the farmers' long-lasting commitment to their environmental responsibilities outside of the scheme's duration (Kuhfuss et al. 2016). If, however, AESs are shown to have no impact on the environmental attitudes of farmers, and if their commitment to the environmentally friendly practices promoted by their AES contracts ends as soon as the scheme payments stop, then the scheme's value for money assumes a less flattering profile.

To this end, this research project is designed to contribute to the body of research aimed at analysing the attitudinal impacts of AESs engagement, and whether the schemes are able to stimulate the long-term adoption environmental management practices, beyond the extent of a given AES contract.

One of the most revealing strands of research in the above bracket has deployed Bourdieu's theory of capital, to help explain possible incompatibilities with AES participation and the farming community's values and identity preferences. Briefly put, Bourdieu's theory demonstrates how, contrary to its usual linguistic usage, there are three types of capital: social capital and cultural capital, along with the more familiar economic capital. Whilst the latter is a widely understood motivational 
factor, individual actors, according to the theory, are also motivated by the prospect of generating cultural and social capital. Within these papers, the idea of the 'good farmer' has been developed to conceptualise which practices are best able to generate the different capitals, and so which management practices are culturally as well as economically attractive (Burton 2004). The good farmer has, for instance, been historically associated with land management techniques that maximise the farm's agricultural production, and with management practices tied up with agricultural intensification.

This research project will similarly employ Bourdieu's social theory. It will operationalise a methodology that inspects the shifting profile of the good farmer, and will assess the attitudes of land managers towards the adoption of agrienvironmental management. The research will ask whether land managers have experienced an integration of environmental ideas into their psychologies, and whether agri-environmental management techniques are becoming more capable of earning farmers changed levels of capital.

The PhD studentship is being completed at the Countryside and Community Research Institute (CCRI) who, along with Natural England (NE) are co-funding the research. NE is the governmental body tasked with the design and delivery of AESs in England and, in the context of this studentship, are interested in the scale of behavioural change effected through participation in the Entry Level Scheme (ELS) component of the Environmental Stewardship (ES). ES was the AES available in England between 2005-2014, and its ELS tier offered payments for less demanding environmental management options. This 'broad and shallow' approach was intended to attract large numbers of participants, and offer an easy access point into environmentally friendly farming techniques (Hodge and Reader 2010). In light of the dramatic changes to agricultural and agri-environmental policies (with the ES scheme being phased out for the new Countryside Stewardship Scheme (CS), and with the overhaul of agricultural subsidies catalysed by the Brexit process), NE is seeking to understand the different and potentially lasting impacts of the ELS on farm management practices. 


\subsection{Research aims and objectives}

The main research aim is expressed in the title of the thesis: What are the long-term social and land management impacts of participation in ELS? The aim has two clear components - relating firstly to the social impacts (attitudes, beliefs) and secondly to the changes in land management practice the scheme has catalysed.

The importance of the research primarily revolves around the assessment it will offer of the policy's long-term value. What level of behavioural change has ELS helped inspire; what does this mean for an assessment of the environmental improvements delivered by the scheme? Beyond a strictly policy-orientated analysis, the research project will also develop the sociological understanding we have of the attitudes and behaviours of the agricultural industry. What are the attitudes represented in the agricultural industry: how and why are these attitudes changing; what role has ELS played in these developments; and how do these attitudes influence the adoption of agri-environmental practices? These research objectives were developed with NE to ensure they had both academic relevance and academic originality.

The project's precise research questions, developed to attend to the project's overall research objective, are as follows:

1) What are the recent developments of land managers' agri-environmental attitudes, and how can Bourdieu's theory of capital, field and habitus inform our understanding of this development?

2) How effective, as a policy tool for securing environmental action from the farming community has ELS been (including the environmental activity beyond the individual contracts' duration)?

3) What are the minimum environmental standards managers are expecting of each other, how can Bourdieu's thinking tools help understand this process, and how can the concept of the bad farmer be developed to account for this process? 
4) What impacts will the Brexit process have on managers' willingness to engage in agri-environmental management?

The project consisted of two rounds of interviews and the latter two research questions were added to the project after the first round of the interviews. Those questions emerged as important themes that needed to be considered to fully attend to the project's research objectives.

\subsection{Structure of the thesis}

Chapter 2 consists of a review of the relevant literature. This provides a stable basis from which the rest of the project is designed and launched, as well as a clearer understanding of the research gaps that this project is able to fill.

Chapter 3 is dedicated to a review of the project's research theory. Question 1, above, is framed around Bourdieu's research theory, and the chapter explains why his theory has been selected for this project, as well as a fine-grained description of what his theory is and how it has been mobilised in this empirical research project.

Chapter 4 develops the project's methodology. This includes an account of the project's data collection methods and analysis process.

Chapter 5 contextualises the research project and offers a descriptive account of the project's case-study areas. This includes a description of the areas, in terms of their farm system make-up and the uptake of the ELS scheme, and a description of the policy landscape in which the research samples are located.

Chapter 6 presents the project's research findings, arising from the first phase of data collection. These findings are presented in terms of Bourdieu's research theory. 
Chapter 7 presents the findings arising from the second phase of data collection: the follow-up interviews conducted with a cohort of interviewees from the phase 1 data collection.

Chapter 8, the final chapter, gives an overview of the findings in terms of the project's research questions. The chapter considers the extent to which they have they been successfully answered, and whether the project has identified any research questions that would benefit from future research. A reflection on the project's methodology and research theory is also be given. 


\section{Literature review}

\subsection{Chapter introduction}

As the topic of this thesis implicates a number of different academic fields, it will serve to present the research covered by the literature review according to their respective areas of focus. These areas will each form their own section, and will be organised in such a way as to best frame this research project's objectives.

The chapter will begin with an overview of what AESs are, where they sit in today's legislative landscape, and the environmental-social backdrop that lead to their being implemented. This will include a timeline of the changes in the agricultural sector in the EU, on the effects that this had on the environmental welfare of rural Europe, and on the development of the policies designed to address the problems associated with intensive agriculture.

The review will then turn to the body of research dedicated to understanding the social and psychological factors of AESs - how the farming community's environmental attitudes impacts the uptake of AESs; and how the perceived selfidentities of farmers stand to dissuade them from participating in pro-environmental farming practices. This body of work introduces theories that will be of central importance to the $\mathrm{PhD}$ - that of the 'good farmer' and Bourdieu's social theory. In reviewing this body of work important research omissions will emerge in relation to the possibility of the shifting values in the farming community with regards to their self-identity and their willingness to adopt environmental management practices. This gap in the literature will point to the need for research dedicated to understanding how AESs have changed the environmental values of farmers, and how these effects are liable to play out on farmland after an AES has finished.

\subsection{AES design}

AESs are a policy tool designed to address the market failure of the agricultural and food sectors in promoting a farming system that provides both the desired level of 
food production and an adequately maintained rural environment (Whitby 2000). Schemes offer payments to farmers for the adoption of farming techniques that are calculated to have a positive impact on the rural environment in comparison to the land management techniques they would otherwise have pursued, or for the removal of land from production altogether (Guningham and Sinclair 2005). The payments are designed to reflect the 'income foregone' of the participating farmers: if the adoption of some environmentally friendly farming technique - e.g. a low input style of farming - is estimated to lose the relevant farmer $£ x /$ ha through yield losses, they will be paid $£ x / h a$ of land committed to that land management technique (see Jones 2012 for full calculations made for the ELS scheme) (Jones 2012).

The way that schemes are designed and delivered varies greatly. Schemes can be zonal (targeting specific areas of high environmental value) or horizontal (available throughout a country or administrative unit); they can be targeted to specific goals (improving say a single species, or one specific environmental resource such as water pollution), or designed to improve a wider range of environmental or cultural targets (from historic landscapes, features of historical or cultural importance, and a range of environmental and biodiversity features); participation can be wholly voluntary, or in some cases target actors are encouraged to participate in a scheme by making access to other subsidies contingent on participation (Batary et al. 2015, Ekroos et al. 2014, Pe'er et al. 2014). ELS is a voluntary, horizontal scheme available throughout the country, with options that target a wide range of biodiversity and cultural features.

The basic AES blueprint represents a departure from the 'Polluter Pays' principle (which forms the mainstay of many pieces of European environmental legislation, through the Directive 2004/35EC) in which the polluting actors are reprimanded for their polluting activity, and towards a 'provider gets' principle in which the target actors are paid for the protection or provision of some natural resource or environmental asset (Hanley 2001). This difference in policy style also represents a departure from the CAC design. In CAC style laws, the body that governs the relevant natural resource places minimum technology standards on the actors who use the resource or by placing emission or pollution limits on the target actors 
(command) and enforces those regulations through the threat and subsequent application of criminal or economic punishments (control). AESs do not follow this policy design, but instead attempt to voluntarily coax improved environmental behaviour out of the agricultural sector by offering rewards for the farmers who participate in the AES and its prescribed land management techniques (Klein and Sutherland 2003). Since their widespread introduction from the early 1990s they have become the policy tool of choice in England (and the EU more generally) for tackling a variety of environmental and biodiversity issues associated with agricultural (Burton and Wilson 2006).

In the EU context, the land management techniques promoted by AESs are also specifically designed to go beyond the environmental value of the other environmental obligations that farmers are under, with respect to how they manage their land. Through the CAP's system of cross-compliance, they are, for example, obliged to observe a list GAECs and SMRs if they are to receive the full payments offered to them through CAP's Pillar 1 payment systems (Latacz-Lohmann and Hodge 2003). The AESs, in this way, are designed to go above and beyond the obligatory environmental standards, and provide the land under AES management with additional environmental benefits (European Commission 2015). A fuller account of cross-compliance, GAECs and SMRs will be given, below.

England's first national AES was the 1987 Environmentally Sensitive Areas scheme, that aimed to protect the historical and natural landscape of target areas with particular cultural or environmental value (Ovenden et al. 1998). There have since been three main schemes with largely overlapping objectives and policy mechanics. The first was the first CS running from 1991 to 2004; between 2005 and 2014 the ES; and from 2015 onwards new AES contracts have been given to the second incarnation of CS. Each scheme has had a slightly different character, with different options available, different contract lengths and slightly different environmental targets. Because this research project is focussing primarily on ES's ELS it will suffice to provide a full description of that scheme, alone. 
ES initially offered contracts from two different tiers. The first, ELS, was designed as a "non-competitive, high-uptake, whole farm, broad and shallow scheme" and the HLS tier, a "competitive, targeted, narrow and deep scheme" (Davey et al. 2010 p.460). The ELS tier was designed to attract large numbers of participants from a variety of different farm types with easily adopted land management techniques. The HLS tier, on the other hand, was designed to attract smaller numbers of farmers with contracts mandating the adoption of more technically difficult and more environmentally beneficial farm practices in exchange for a higher level of reimbursement (Quillérou et al. 2010). ELS contracts lasted five years, and HLS contracts, 10. From 2010, an Organic Entry Level Stewardship' (OELS) strand and an 'Uplands Entry Level Stewardship' (UELS) strand was added to the ELS tier. These offered slightly higher payments for the adoption of management techniques relevant to organic farming and uplands farming, whilst still maintaining ELS' 'broad and shallow' profile.

The scheme was a whole-farm scheme, and to enter into it, 30 scheme points had to be secured per hectare of the full holding. Farmers could decide how this requirement was met by choosing from a list of management options, targeting a wide range of cultural and environmental issues. Once the 30 points/ha target had been met, applicants were automatically eligible for the scheme, without having to compete for a limited amount of scheme financing with other potential participants. This represented a departure from previous AES design, and was an important feature of the attempt to attract a large number of participants (Hodge and Reeder 2010).

Participants could earn 300 scheme points per hectare of land set-aside in the form of $2 \mathrm{~m}$-wide riparian buffer strips to reduce the run-off of agricultural chemicals into waterways; they could earn 22 points per $100 \mathrm{~m}$ of hedgerow that they managed in accordance with ELS regulations, to help deliver the biodiversity and habitat value they confer; they could earn 450 scheme points per hectare of land they distributed with a mixed bird feed for the improvements the technique would have in avian populations; or they could earn 2 points for every square metre of a historic farm building's roof that they waterproofed. On top of these options, farmers were also 
required to create a Farm Environment Record for the whole farm, for which they received 3 scheme points per hectare. The record included an account of field boundaries, on-farm features (trees, hedgerows), and was designed to facilitate the selection of appropriate management options, and to provide NE with a detailed account of the land being committed to the different scheme options (Natural England 2013).

Over the course of ES's lifecycle, the points awarded for the adoption of different options subtly changed. This was done as a means of encouraging the selection of a more diverse range of options. Different versions of the ELS handbook (which detail the point allocation for the scheme options at different points in its lifecycle) can be found at the NE web archive.

2.3 AES - where they came from, and where they sit in today's legislative landscape

The need for a particular policy initiative to address the environmental damage caused by the agricultural sector is tied up with the food shortages in post-WWII Europe, the subsequent policy responses, and with the problems associated with the last 60 years' worth of advances in the agri-technology and agri-chemical industries. This socio-political backstory will be sketched below.

In the late 1950s and early 60s, through the auspices of European Economic Community (EEC), proposals were made and decisions taken to establish a shared agricultural policy for the then 6 members of the EEC. The CAP came into effect in 1962 with the three explicit aims of market unity, community preference (for the buying and selling of agricultural produce) and financial solidarity (Van Oudenaren 2004). Through the European Agricultural Guidance and Guarantee Fund, a common market was established within the participating countries facilitating the trade of agricultural goods across their respective borders to ensure a stable and buoyant market for agricultural produce. Farmers were also given price guarantees for their produce. The policies were designed to catalyse an increased level of foodproduction to tackle the large-scale food shorted being felt across post-war Europe 
(Whitby and Lowe 1994), and to ensure the economic welfare of the rural population (Potter 1998).

These policy shifts combined with wider capitalist forces at play in the agricultural industry. Technological and chemical advances meant that there was an increased availability and cheapness of agricultural machinery, fertilisers and pesticides that changed the way agricultural enterprises were managed, and the way the sector produced food (Wilson 2001, Marsden et al. 1989). There was a widespread adoption of agro-chemicals and machinery as a means of increasing production; farms were employing smaller numbers of farm hands due to the increased efficiency and availability of farm machinery; field sizes were increased to accommodate and optimise the usage of the new technologies; and farms became specialised, and limited their operation to a smaller diversity of produce in order to increase the overall output of farm (Whitby and Lowe 1994, Potter 1998, Ilbery and Bowler 1998).

To help understand these market and policy conditions, and the changes in the agricultural sector that they prompted, academics have developed the term 'productivism'. Productivism is “a commitment to an intensive, industrially driven and expansionist agriculture with state support based primarily on output and increased productivity" (Lowe et al. 1993 p. 221). The term has also been usefully unpacked as the combination of three interlocking processes (Bowler 1985): concentration - in which the number of farms decreases, such that the percentage of total agricultural land is being held by an increasingly smaller number of increasingly larger farms; intensification - in which farmers seek to increase the output of their farm land by increasing the input of agri-chemicals and reliance on farm machinery (Pretty 1998); and specialisation - in which farmers reduce the diversity of production, and employed smaller, more technically skilled, work-forces on the farm (Marsden et al. 1993). The concept will be referred to over the course of the project, and when the term is used it will denote Lowe's (1993) definition, above.

In the CAP's 'crisis years' during the 70s and 80s, the above policy changes and the productivist land management techniques they catalysed across Europe had serious 
and unintended consequences. The prices promised to farmers for their produce, combined with the widespread adoption of 'productivist' management techniques lead to mass overproduction of farm produce and huge budgetary overspends (Ilbery and Bowler 1998).

Although less well understood at the time, the proliferation of productivist land management techniques also had serious environmental consequences. The removal of hedgerows to increase field sizes and facilitate the usage of agricultural machinery has had serious effects on the levels of on-farm biodiversity (Le Coeur et al. 2002); committing previously unused land to production - including meadowland, grassland and wooded areas -had knock-on effects for biodiversity levels in rural Europe (Reidsma et al. 2006); and the increased usage of agri-chemicals and agri-machinery has had effects on the quality of water bodies and courses near farm land (NAO 2010), and on the stability of plant and insect biodiversity (Batary et al. 2012).

It was not until the 1992 MacSharry reforms that meaningful changes were witnessed in the CAP's payment systems and policy initiatives that would help address the problems of overproduction, overspending and the environmental degradation of rural Europe. The 1992 reforms saw the CAP's system of product support formed in favour of a system of producer support, through which farmers began to be paid in accordance with the size of their farm operation, as well as in accordance with their level of production - although livestock payments were still tied to headage numbers. Decoupling the farm payments in this way was intended to re-establish the connection between agricultural production and market demand for farm produce so as to reduce budgetary spending and undermine the pseudo-market conditions that had prompted the overproduction of the 70s and 80s. The 1992 reforms also made the introduction of AESs mandatory for all the EU Member States (although some states, England included, had already had an AES initiative in place by 1992) as a means of promoting the adoption of environmentally friendly land management techniques. 
The 'Agenda 2000' reforms then saw the formal inclusion of the CAP's environmental objectives into its newly formed 'Pillar 2'. The second 'rural development' pillar is concerned with ensuring the welfare of the rural population, and the environmental sustainability of the agricultural sector; whilst the first pillar covers the policy tools and objectives already associated with the CAP supplementing farmer income to ensure the agricultural sector's economic viability. The division of the CAP into the two pillars was partially a means of dividing the policy objectives into two distinct categories, each drawing from their own budget, but it also serves as a demonstration of the increasing importance of environmental and social concerns within the CAP (Gay et al. 2005). The AESs introduced in the 1992 reforms fell into the funding structure of the new second pillar.

The next critical development came in the form of the system of cross-compliance, and the complete decoupling of pillar 1 payments from product support, both effected in the 2003 reforms. The decoupling of farm payments (i.e. untangling farm payments from the volume of agricultural production) was enacted with the introduction of the Single Farm Payment (SFP) whereby farmers were paid exclusively in accordance with the size of their farm operation, and was the conclusion of the process started in the 1992 reforms. These newly decoupled pillar 1 payments had their environmental credentials bolstered through the system of crosscompliance (Kristensen and Primdahl 2006).

Cross-compliance is the system through which farmer subsidies are reduced or withheld in instances where farmers fail to meet certain land management requirements. Although the specific requirements that the farmers are under has changed over the last 15 years, along with the payments that are offered to them (and by extension the payments that the farmers stand to lose if they are non-compliant with their obligations), the general principle has remained unchanged. Farmers have their pillar one payments reduced if they do not meet the list of GAECs and SMRs. Although both lists are being constantly updated, the overall type of requirement contained in each list remains the same: the set of GAECs a farmer must observe relate to the conditions in which a farmer's land must be kept, technologies they 
must use or not use, and farming practices they must or must not adopt; whilst the SMRs are the list of obligations they are placed under by other legislative initiatives.

By way of example, in England, GAEC 1 requires the establishment of a small buffer strip alongside a waterway. No cultivation or application of agricultural chemicals can be done on the buffer strip. SMR 1 sets out the legal limits applied to the levels of application that can be done on agricultural land in Nitrate Vulnerable Zones (NVZ) - areas with water systems that have been identified as being particularly at risk from diffuse pollution from agricultural chemicals. For each SMR or GAEC not met, the respective manager's BPS payment is reduced by $1-5 \%$, depending on whether it is a repeat offence, by how much the rule has been broken, and the scale of environmental damage associated with the broken rule (full details of SMRs, cross-compliance and GAECs available at Defra 2019).

In 2015, the pillar 1 SFP payment shifted to the new Basic Payment Scheme (BPS). To secure their full BPS allowance, farmers not only had to meet the above GAECs and SMRs, but also a set of new Greening requirements. These required farmers to achieve certain levels of crop diversification, to have a certain amount of land dedicated to permanent grassland, and an amount of land committed to Ecological Focus Areas (EFAs). As with the above cross-compliance mechanism, if these targets are not met, then financial penalties are taken out of their BPS subsidy.

For the crop diversification rule, farmers who manage 10-30 hectares of arable land must grow two crops, and those with 30 or more hectares, three. No single crop can account for more than $75 \%$ of the arable land. Farmers with 15 hectares of arable land must also commit $5 \%$ of their total arable land to EFAs. These can include buffer strips, catch crops or over crops. A fuller account of these instruments will be given in Chapter 5.

England's AESs have existed in a number of different incarnations. The time-limited lifecycle of each scheme is used as a means to re-adjust the design of the scheme, and to target different priorities. Figure 2.1, taken from the NE archive, provides a valuable overview of England's successive AESs. 


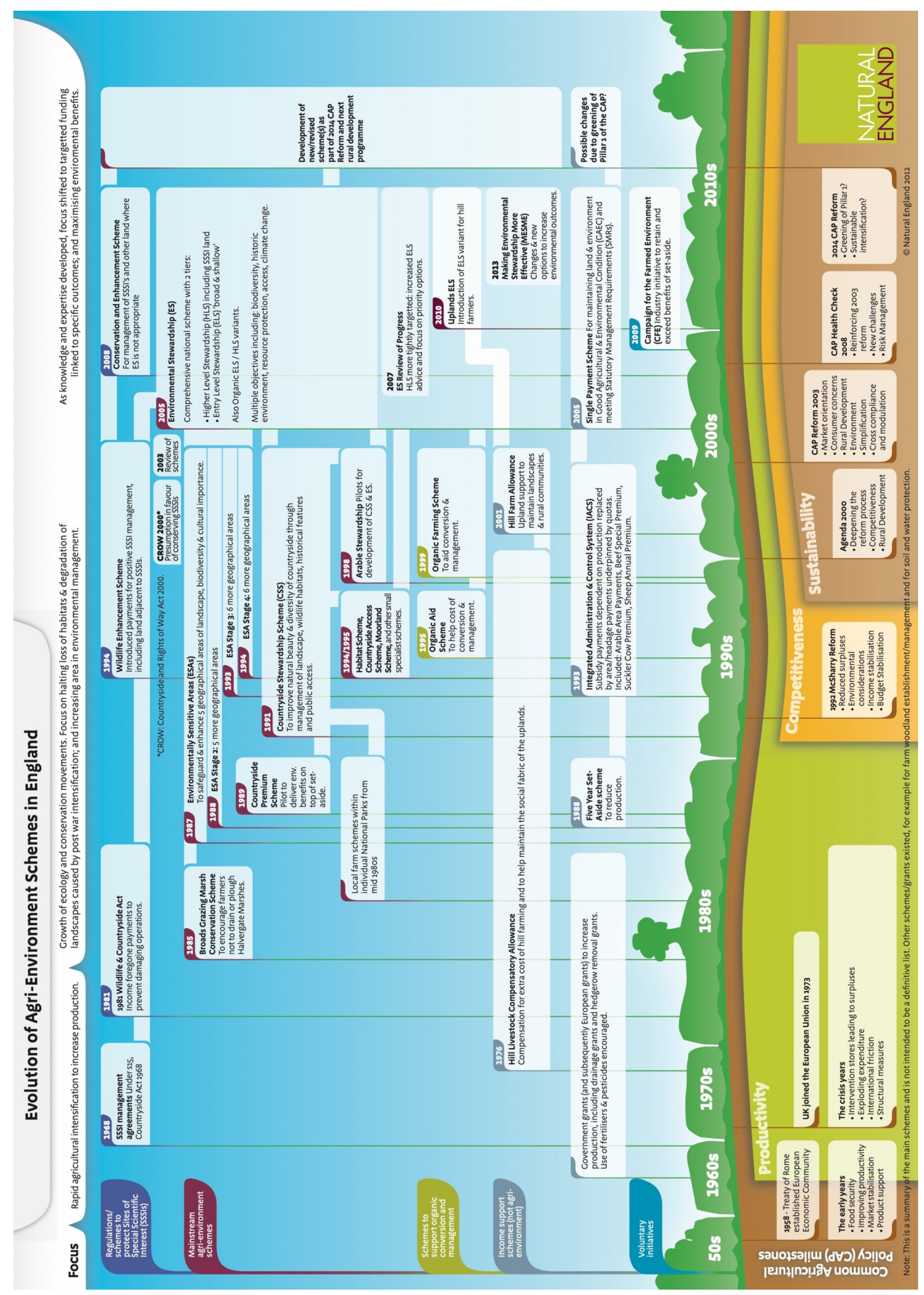

Figure 2.1 Infographic on the history of AESs in England (Natural England 2015) 
As can be seen from the figure, ELS - the focus of this research project - adopted a 'broad and shallow' profile. Broad, insofar as it was designed to attract large numbers of participants from across the country, and shallow insofar as the scale of management changes it was expected to effect on the respective contract holders' land was modest relative to previous schemes (or, indeed, rewarding the farmers already availing of such practices). These characteristics represent a significant departure from previous AES design in England. Schemes have historically had a more targeted approach, requiring the adoption of management practices that significantly deviated from pre-scheme behaviours - behaviours which were expected to be able to deliver significant environmental gains. Whilst there are ongoing concerns about the extent to which these 'shallow' interventions can catalyse meaningful environmental improvements (Hodge and Reader 2010) it did ensure the scheme's widespread uptake. At its peak in 2013, ELS covered $6.2 \mathrm{~m}$ hectares of land, $72 \%$ of all utilisable agricultural land in the country (JNCC 2017) The design of ELS, and the options available to participants is given fuller attention in 3.5, and then in 4.2.6.

Despite the growing importance of environmental and social objectives in the design the CAP, it is still the Pillar 1, producer support component that enjoys the bulk of the budget. Over the 2007-2013 budget cycle, $80 \%$ of the total CAP budget was directed to Pillar 1 (Parliamentary Publications 2011). For the 2014-2020 funding cycle, the figure is falling slightly to $75 \%$ (European Parliament Briefings 2016).

\subsection{Analysing AESs}

AESs are one of the major policy tools used to address the environmental problems associated with an intensive agricultural sector - as well as means of rewarding those already adopting environmentally sensitive farming practices. By 2000, the Institute for European Environmental Policy (IEEP) reported that they covered 20\% of the Utilisable Agricultural Area (UAA) in the EU (IEEP 2000). In 2009, when the ELS scheme was in full effect, it covered $66 \%$ of England's UAA (Natural England 
2009). They also represent a significant outlay for the CAP budget. Between 2007 and 2013, AESs cost the EU $€ 20 \mathrm{bn}$, or $22 \%$ of the entire pillar two budget for the period (European Commission 2015).

For these reasons, a great deal of effort has gone into evaluating their effectiveness at delivering on their environmental targets. A complete analysis of such projects is, however, out of the scope of the review. As AESs have been implemented across EU MSs - as well as other nations - for over 25 years, the body of research is too large to properly present here. Even more important, though, is the relevance of such research in the context of this project. As per the research questions described in Chapter 1, the project is interested in the long-term impacts of participation in ELS, in terms of the participant's attitudes and management practices and so a review of the research looking into the environmental impacts of AESs is not needed.

The review will also be limited by other constraints. It will, for example, exclude research based outside of the global north. Research looking into the management practices, attitudes and AES participation of farmers in the global south (Africa, South America, Asia) will be rooted in those actors' agricultural, social and economic situations. As a result, the transferability of their findings to our own research context is undermined. Where appropriate research papers exist from Europe, North America and Australasia, however, they will be included, because of the overlapping economic and legal contexts of the relevant actors to in relation to this project's research objectives (i.e. to ELS).

With respect to the above limitations, the review will present the research that attends to the following questions. What sociological and psychological research exists to help understand the adoption of environmental practices or participation in AESs; do schemes help effect long-term pro-environmental attitude shifts in farmers; what impacts does participation have on the long-term management of farmland previously under scheme coverage? Looking at such research will help understand what is currently known about the agri-environmental attitudes represented in the agricultural industry, and what the long-term impacts of AESs are. This review will 
then inform the project about possible gaps in the literature, and how the project can build on the most up-to-date research.

\subsubsection{Self-identity, the good farmer, and Bourdieu's social theory}

The concept of the good farmer, Bourdieu's social theory and theories of farming self-identity emerged over the review as prominent features of some of the most revealing research into the adoption of agri-environmental practices, and the representation of environmental attitudes in the industry. Although they are distinct phenomena, their shared conceptual heritage and related impacts lends itself to being the subject of a single, joint, subsection.

Self-identity in the context of the agricultural sector refers to the conception that a farmer has of their roles and responsibilities in their capacity as a 'farmer' (Burton and Wilson 2006). A number of researchers have deployed the concept to illuminate AES participation, and have shown how farmers' self-identities can steer them away from engaging in AESs (Burgess et al. 2000, Dwyer et al. 2007, Burton, et al. 2008, Blackstock et al. 2010). These identities have crystallised around a notion of an idealised good farmer who seeks to pursue the productivist ideals of intensification and increased production - goals that are perceived as incompatible with the land management options mandated by many AESs. In such instances, the perceived loss of self-identity acts as a motivational deterrent from participating in the AES.

The need to employ socially and psychologically nuanced theories when researching agricultural behaviour is motivated by a recognition of the shortcomings of the methodologies that depicted agricultural behaviour as the expression of economically rational decision-making processes (Burton 2004, Burton 2004a). Watkins et al. (1996) were one of the first to make this academic link and included in their analysis of agro-forestry decision-making, a recognition of non-economic motivational determinants. They showed how the different reasons farmers gave for their resistance towards an early forest management AES were underpinned by the sense that they were farmers, and not foresters, and that an AES that demanded they carry out forest management activities represented an unacceptable deviation from their 
sense of being a farmer. The misfit between farming self-identities and AES participation has since been echoed in numerous other studies. In relation to a local Wetlands AES, for example, Burgess et al. (2000) showed that farmers have resisted political and social attempts to reframe them as environmental stewards, and that their ongoing resistance to agri-environmental initiatives is born of a desire to live out the image they have of themselves as food producers.

Burton (2004) asserts that agriculturally managed landscapes are reflections or portraits of farmers' activities, and so are arenas in which they are able to communicate their identities to the local community. Through a series of semistructured interviews, he shows how the 'good farmer' concept has moulded around the productivist ideals, and that "farmers may... resist change [to their farming practices] on the basis of an anticipated loss of identity or social/cultural rewards traditionally conferred through existing commercial agricultural behaviour." (Burton 2004 p.196) If, so such arguments go, a farmer's self-identity is tied up with striving to imitate the productivist behaviour of the idealised 'good farmer', then a subsidy system that pays out for non-production or reduced-production, will represent an unpalatable departure from the ideals associated with their self-identity. Participating in an AES, in such situations, may well represent an economically rational decision (if, say, the profits forgone are well matched by the subsidies received), but will nevertheless be culturally unattractive to the farmer (Burton et al. 2008).

To help unpack the phenomenon of self-identity, and the impact it has on AES participation, Bourdieu's theory of capital (Bourdieu 1986) has been used to great extent and to great effect. Bourdieu's theory seeks to reframe our understanding of capital as having more than strictly economic implications. Capital, Bourdieu contends, comes in three distinct manifestations: economic capital, social capital, and cultural capital. Due to the intuitively understandable character of financial exchanges and monetary value, when we talk of capital the dialogue tends to be reduced to a discussion of economic capital. As we will see, however, we can be motivated to act not just by the prospect of earning economic capital, but by the two types-cultural and social - as well (Bourdieu 1986). 
Cultural capital is, itself, broken down into a further three forms. Embodied cultural capital are enduring physical or mental habits or dispositions that reflect onto the owner the accumulated labour associated with the acquisition of those dispositions; objectified cultural capital, which are objects that chart the realisation of an individual's hard work, skill or expertise; and institutionalised cultural capital, which comes in the form of educational qualifications that relay the expertise and technical understanding of the owner (Bourdieu 1986).

Embodied cultural capital, derives its value from its capacity to communicate the owner's accumulation of expertise, hard work or understanding to those around them. Skill at an instrument, for example, reproduces embodied cultural capital for the owner, because of the associated accumulation of hard work (e.g. time spent practicing). The objectified form of cultural capital comes in the form of objects that indicate the owner's expertise and understanding of the objects, and the arena in which they are relevant and respected. The musical instrument itself of the expert player (i.e. not just the act of playing it) reproduces objectified because it is a physical embodiment of the owner's accumulated expertise and technical skill. Institutionalised capital, are the qualifications that demonstrate the owner's expertise in the given field, as confirmed by an independent and external body. Having achieved a high musical qualification, for example, confirms the player's expertise in perpetuity, without having to continually reaffirm their skill by playing.

Social capital, is the "aggregate of the actual or potential resources which are linked to the possession of a durable network of more or less institutionalised relationships of mutual acquaintance and recognition - or in other words, to membership in a group - which provides each of its members with the backing of the collectivelyowned capital.” (Bourdieu 1986 p.21) The volume of social capital associated with membership of a social or professional grouping is calibrated to the "size of the network of connections he can effectively mobilise and on the volume of the capital possessed in his own right by each of those to whom he is connected." (Bourdieu 1986 p.21) Social capital is reproduced by continuing social interactions (greetings, conversation events, social/professional occasions) that affirm and reaffirm each member's integrated and continued membership. 
The activities that reproduce (generate, earn) the different forms of capital is dependent on the field in which the activities are taking place. The concept of field is a central one to Bourdieu's theory, and broadly speaking, relates to different social arenas/groupings to which people belong, and in which they strive to achieve good standing. People exist in a number of different fields at any one time (for example, as members of specific professional fields, of local communities and as family members), and they compete to earn capital according to the different rules and preferences in operation in the respective fields as a means of achieving a good position in the field's hierarchy. In this way, the reproduction of cultural and social capital is always done with respect to a given field, and is mediated by its social codes - its preferences, values, rules and tastes. Activities that generate some capital in one field, therefore, are not guaranteed to earn capital in another.

Once an individual has reproduced any one of the three types of capital, they can convert it into a different form. An individual, for example, with vast quantities of social capital (i.e. an individual who is well integrated in a large group with a collectively large amount of capital), for example, can employ their social ties for their own economic gains (investment from group members, loans); whilst individuals with large amounts of economic capital can, through mercantile means, immerse themselves in social groupings and exchange their economic capital into social capital. Understanding these means of capital conversion, individuals are motivated to act in ways that can earn them economic capital, as well as in ways that reproduce social and cultural capital.

Although Bourdieu's theory of capital was initially provided as a theoretical underpinning to his analysis of how the bourgeoisie hold onto power through the mobilisation of their economic, cultural or social capital, the theory has since been employed in a number of different academic fields. Importantly for the research project, the conceptual and linguistic taxonomy has been utilised in a number of rural studies papers to better understand the motivations of farmers with respect to their agri-environmental behaviour and AES participation. 
Burton et al. (2008), for example, used the theory to explain why farmers were demotivated to participate in an AES. They found there was a perceived inability to earn the desired levels of cultural capital through the land management options prescribed by a scheme, relative to the productivist techniques they would otherwise pursue. The farmers expressed preference for farming techniques that pertained to the attainment of those productivist goals. Parallel ploughing or neat fields with an absence of weeds, the farmers maintained, are things respected by the agricultural community because they acted as symbols of the farmer's success in operating an economically solvent farm and achieving high levels of food production. Neat, weedfree and well ploughed fields, that is, were instances of embodied cultural capital objects that confirmed the skills and understandings of the relevant farmer, and demonstrated their observance of the good farmer's commitment to productivist ideals. By contrast, the AES options on offer that mandated a perceived hands-off approach to farming (wild flower meadows, low input fields) did not offer the chance for the farmers to demonstrate their skills and understandings as a farmer - and deviated from the productivist ideals of the good farmer. Pursuing those options represents, as a result, an undesirable loss in cultural capital.

To explain this phenomenon, the researchers developed the idea of 'roadside farming' (Seabrook and Higgins, 1988, Burton 2004). 'Roadside farming' is a concept used to capture the agricultural community's tendency to assess the farming credentials of nearby farmers according to the farm practices that are publicly visible from nearby roads or fields, and also the sense that their behaviour, discernible from the look of the land and the management practices they communicate, is open for judgement from other farmers. Farmers, that is, recognise the ongoing evaluation their land is under, and so carefully consider the techniques they employ. For this reason, farmers have a preference not just for land management techniques that lead to high levels of production (i.e. the productivist goals), but also the techniques that can effectively (visibly) communicate their commitment to those productivist objectives. AES options that mandate the establishment of wild-flower meadows or non-productive buffer strips, therefore, represented not just behaviours that would not help them achieve the productivist goals of the 'good farmer' but would be a highly visible evidence (i.e. through the notion of 'roadside farming') of their 
deviation from those ideals and identities (Burton et al. 2008). Because of the rules and preferences in the agricultural field, those managers risk losses in cultural capital, and so participation in an AES is perceived to be culturally unattractive. Other papers have employed similar methodologies and theories, and have found similar cultural resistances towards the adoption of agri-environmental behaviours and AES participation (Burton 2012, Yarwood and Evans 2006).

\subsubsection{Changing attitudes and values}

Central to the above research is the incompatibility between productivist farming activities of the 'good farmer' and AES schemes that mandate 'non-productivist' behaviours. More recent research has shown how farming self-identities, and the social codes that determine which behaviours reproduce different capitals, are in flux. Sutherland and Darnhofer (2012) used Bourdieu's concept of habitus to look into the changing construct of the 'good farmer' in the context of organic farming. Habitus is the accumulation of an individual's habits, experiences, knowledges and is an important feature in how Bourdieu accounts for an individual's behaviour. The social code that determines which behaviours reproduce what sort of capital are impressed upon an agent's habitus, and so the habitus functions as a lens through which the social is digested and made sense of, and through which an individual's behaviour is shaped (Bourdieu 1998). The habitus, importantly, has the ability to integrate new features of the agent's social world, and constantly regenerates itself to ensure the goodness of fit between the agent and the social world within which they operate.

They used the cohort of conventional farmers who had converted to organic farming for practical and economic reasons, as opposed to idealistic or environmental-moral reasons. Those farmers were responding to government incentives to pursue organic techniques, and the increasing market demand for organic products that made the relative economic returns for organic farming over conventional farming more favourable. These 'converted' farmers, they argued, would have historically subscribed to the symbols of the good farmer described above - high yields, weedfree fields and intensification. From this starting point, the researchers were able to 
gauge the development of their values and identities by inquiring into what farming styles and techniques the farmers now associated with the generation of cultural capital.

They found that through the habitus' capacity for iterative restructuring, the farmers were able to integrate their new circumstances (i.e. being an organic farm, receiving subsidies for being organic, and operating in a market in which organics offered promising and reliable returns) into their conception of the good farmer. Over time, and as a result of this integration, the behaviours linked with organic farming were becoming capable of reproducing cultural capital. Successful management of meadowland, or the existence of non-productive border strips, although not able to fulfil the productivist notion of the good farmer, were nevertheless able to earn the converted organic farmers cultural capital, due to their changing perception of what constituted good farming. The good farmer, they found, needs to be able to demonstrate their ability to operate in a system characterised by pro-environmental incentives and new economic opportunities - and organic farmers availing of the high food prices for organic produce fell under this rubric.

In a similar vein, Saunders' (2016) research into Swedish farmers' attitudes show how reductive productivist expressions of the good farmer concept need to be updated to include a more varied set of priorities. Whist there may still be significant and entrenched attachments held by the farming community towards the goals of high yields and high economic attainment, those goals are being qualified and tempered by other social and environmental objectives.

Such research stands in contrast to the prediction made by Burton and Paragahawewa (2011), who claimed that AESs would be unable to engender culturally sustained changes in the farmer's attitudes, because the scheme options did not offer any opportunity for the farmers to demonstrate their land management skills and understandings. The management of borders, meadowland and other AES options, the researchers argued, became arenas in which farmers could demonstrate their farming competencies, and so became a place in which they could earn cultural capital from other members of the community. 
In Bourdieusian terms, Sutherland and Darnhofer (2012) argued that the farmers were able to earn cultural capital whilst pursuing farming techniques not traditionally associated with productivist ideals, as they were able to demonstrate their creative abilities to respond to the changing economic and policy landscape of the agricultural sector. They founded this line of argumentation on the Bourdieusian idea of how the 'rules of the game' that determine which behaviours and artefacts are perceived as valued and legitimate are subject to change (Bourdieu 2000). The organic farmers they interviewed were, that is, able to earn themselves cultural capital through their meadowland management or buffer strips in part because they had become symbols of their ability to operate a financially buoyant farm in a political/legislative system characterised by pro-environmental incentives such as AESs. Sutherland (2013) added to these conclusions with the introduction of Bourdieu's concept of the 'taste of necessity' in which individuals have latent respect and regard for the decisions that help secure economic viability and survival (Bourdieu 1984). In this context, the decision to pursue an organic model represents a savvy, economic decision that helps ensure the farm's ongoing success - and so the high regard in which those farmers are held is grounded in an underlying 'taste of necessity'. Speaking in relation to

This research is echoed in Riley's (2016) longitudinal study. Here, the researcher conducted interviews with a group of farmers and follow-up interviews with the same farmers ten years later. The methodology was designed to provide an insight into the way in which the values of the farming community have changed, and circumvent the problems associated with the literature, above, that sought to frame agricultural values as an immutable feature of the agricultural community. The findings demonstrate that the accumulation of policy changes, an increased awareness of environmental problems associated with intensive agriculture, and strengthening bonds between farmers and AES officers have resulted in a realignment of the 'good farmer' concept to place a stronger emphasis on the environmental behaviours of farmers, and on the capacity for AES engagement and other pro-environmental farming behaviour to earn the farmers cultural capital. As with Sutherland and Darnhofer (2012), Riley (2016) also couches his findings in the Bourdieusian concept of capital, habitus and the changing rules of the game. 
As with the findings in Sutherland and Darnhofer (2012), Riley's findings were also put forward as a counter-point to Burton et al.'s (2008) claims. Specifically, that AESs are unable to provide an arena in which farmers can demonstrate their farming skills and understandings, and so are arenas from which they are unable to earn cultural capital. "Rather than a complete break from the past" Riley reports, "these 'environmentally good farmers' combine pre-existing symbols of good farming with the knowledge and skill to now operate within scheme prescriptions." (Riley 2016 p.73).

The above papers - Burton (2004, Burton et al. 2008, Sutherland and Darnhofer 2012 and Riley 2016 - are amongst the most important for this this research project. They represent a progression of ideas, all part of the same conceptual and empirical lineage, about the relationship between farming identities, the reproduction of Bourdieu's capitals, and the adoption of environmental management practices. These papers will be referred to throughout the thesis and this project's own contributions can be seen as part of a continuation of this lineage in particular. This thesis' uniqueness is, in part, located in its capacity to update and further understand the relationship between the rules of the game of the agricultural field, and the adoption or non-adoption of agri-environmental behaviours and scheme participation.

Although not drawing explicitly on the Bourdieusian theory, other researchers have also sought to understand how, and to what extent, farming values have changed in the face of ongoing agri-environmental policy exposure and how this affects their behavioural responses to AESs.

Wheeler et al. (2014) built used the good-farmer concept to show the intrinsic care and custodianship farmers feel towards the land, and how this translates into their own conceptualisations and enactments of environmentally responsible management. Although not written in direct response to papers such as Burton et al. (2008), their research helps develop a more nuanced understanding of the relationship between agricultural attitudes and environmental practice. Specifically, about the important 
position custodianship, environmental care, and farm-business longevity occupy in the psychologies of English and Welsh farmers.

McGuire et al. (2013), for example, sought to understand the development of environmental attitudes in the farming community in terms of the identity hierarchies of different farmers. The research is couched primarily in an identity salience analysis, in which individuals are argued to have a number of different identities, each of which are represented in varying degrees of importance and frequency depending on where the identity comes in the hierarchy. They found that the increasing public awareness around the water quality problems caused by intensive agriculture, and the existence of more environmentally conscious farmers in their area prompted a repositioning of conservationist attitudes in productivist farmers higher up their identity hierarchy. The research helps further reveal how farming identities are socially dynamic and how their behaviours are informed by the social norms and actions they perceive in their neighbouring managers.

\subsubsection{Post-scheme behaviour}

An important part of the research is looking into the long-term management impacts of ELS participation. The following represents the very limited body of research looking into the way farmers manage their AES options after their contracts have come to a close.

One directly relevant study has looked into the post-contract management of scheme options. Darragh and Emery (2018) use ELS to inspect the willingness of managers to maintain scheme options after their contracts finish, and the remuneration ends. They found that a complex suite of motivational factors determined whether participants would maintain an ELS option. In many cases, if doing so maps onto other economic and management needs, participants are willing to keep up with a scheme practice even after their financial reimbursement ends.

A series of criticisms have been levelled at AESs about their vulnerability to the crowding-out theory. The problem has been identified specifically in relation to ELS 
because of the minor changes the scheme required of its participants, and the superficial involvement the scheme design allowed for (Hodge and Reader 2010). The crowding-out theory asserts that once some behaviour has been subsidised, the recipients develop the sense that their ongoing commitment to the behaviour is contingent on ongoing financial reward. An important part of Darragh and Emery's (2018) research objective was to verify the accuracy of these predictions. In this regard, they conclude that the reductive economic thinking implied in crowding out theory is inadequate to fully account for an individual's post-subsidy behaviour. Their study has, however, an important methodological shortcoming. They interviewed a small cohort of ELS participants whilst their contracts are still in effect and ask them about how they intend to manage their land, once their involvement in the scheme ends. Such an approach is vulnerable to the intentions-behaviour gap, and is based on a problematically small research sample. It is unclear, in other words, how reliable their findings are, given the very real possibility that the stated intentions given by the farmers about how they plan to manage their ELS options are not accurate predictors of how they actually will manage their land, once their involvement with the scheme ends. Insofar as the study of post-ELS behaviour is a primary objective of this project, there is still considerable scope for novel research.

Kuhfuss et al. (2016) conducted research into the behaviour of French farmers at the end of their AES contracts. Specifically, they were interested in understanding what factors influenced the likelihood of participants maintaining land management practices mandated by an AES after their contracts had come to end. They employed a game-theory style analysis of questionnaires and interviews, and show how farmers are more likely to maintain an AES management practice after the scheme payments end if they are aware of nearby farmers also committing to do so. They argue that pro-environmental activity is an instance of conditional co-operation, in which the visibility of other actor's pro-environmental behaviour positively affects the likelihood of other actors making pro-environmental decisions.

Hiedenpaa and Bromley (2014) offer a theoretical perspective on the extent to which subsidised environmental behavior can dislodge pre-existing management habits and beliefs. Can participation in a payment for ecosystem service (PES) scheme, such as 
an AES, dislodge the productivist values embedded by "a lifetime - perhaps of several generations of predecessors - of habituated behaviors." (Hiedenpaa and Bromley 2014 p.182). Their research is not an empirical study, but builds on a theory of habit-making and habit-breaking activities. They assert that there is a strong possibility for monetary payments (such as those received through ELS) to be able to dislodge the farmer's productivist habits and replace them with new environmentally friendly practices that extend beyond a given PES or AES contract's duration.

Given the large potential for AESs to effect widespread, long-lasting management changes (namely with the adoption of a scheme practice beyond a contract's duration) there is a very limited amount of research empirically examining whether managers do or don't maintain their scheme options after their contract's end. Although Darragh and Emery (2018) have looked into the topic of post-scheme behaviour, their focus on the applicability of the crowding out theory, and their use of a methodology predicated on the predictions the interviewees gave about how they plan to act (i.e. not how they have, or how they are acting), means that there is still considerable scope for future research. This project, in aiming to understand the social and managerial impacts of ELS participation is well-placed to fill this knowledge gap.

\subsection{Chapter conclusion}

The review has uncovered valuable research that is able to hint at the possible answers to the project's research questions, described in the previous chapter. Importantly, the review has also identified areas where gaps in the literature remain. How does ELS fit in with the development of agri-environmental attitudes and practices, as depicted by the researchers availing of Bourdieu's theory and the good farmer concept? Just at research such as Sutherland and Darnhofer (2012) and Riley (2016) have updated the initial conceptualisations of cultural capital reproduction and the good farmer of Burton (2004), how can this project further add to this lineage? With regards to the long-term management impacts of ELS, the project is well placed to investigate into the largely unattended research question of postscheme behaviour. Darragh and Emery's (2018) paper represents the most relevant 
pre-existing research, but even that has its own detractions. Namely, that is focusses on an assessment of the economic theory of crowding out and, more importantly still, that it avails of a flawed methodology.

The above review will help ensure the project is able to attend to its main research objectives, whilst benefitting from a robust methodology that attends to the most pressing gaps in the literature. The following chapters will be concerned with the selection of a research theory and the development of the project's methodology. 


\section{Research theory}

\subsection{Chapter introduction}

Chapter 3 will be dedicated to providing a theoretical framework to underpin the research project. Without a research theory, social science research projects lack the conceptual tools to effectively design a methodology, and make sense of the collected data (be it large amounts of quantitative numerical data or a smaller number of in-depth research transcripts) in a thorough and academic way (Reeves et al. 2008, Bryman 2015). An ontology is needed to provide a framework within which the world can be made sense of, and with which the data can be systemically processed; an epistemological stance is required so as to mitigate against issues such as researcher bias, and to have an account of what constitutes knowledge in the research project; and robust conceptual definitions are needed to develop research materials (interview plans, questionnaires, surveys) and then to relay the findings in a meaningful way.

To this end, the chapter will begin with an introduction to the theory that will be used for the project, along with an explanation as to why the theory has been selected. The chapter will then move to a thick account of the theory with demonstrations of the theory's aptitude for the themes and objectives of this project.

\subsection{Choosing a research theory}

For reasons that will be detailed below, Bourdieu's interlocking theories of habitus, capital and field will be used for the project's theoretical framework.

As with many sociological theories, Bourdieu's attempt to understand human behaviour and psychology situates them as partly emergent from the individual's socialised upbringing (Jenkins 1992). The way that humans behave and think, that is, is informed by the values and behaviours of their parents, of their schooling, of their surrounding society and of other members perceived as being in their same social grouping (class, location, race). In the sociologist's vocabulary, these features of an 
individual's life amount to their structure, and generally speaking are the stable societal features that determine the way an individual lives, and the choices they are able to make (Schneider 2006). In this sense, the concept of structure is diametrically opposed to that of 'agency'. Where structure structures an individual's life (behaviour, values, choices), agency relates to the individual's capacity to make free agential decisions, unbound by exogenous determining factors (Sewell 1992).

One of Bourdieu's primary objectives for his social theory was to avoid the reductionist thinking that frames an individual's behaviour as a determined product of their social structures, whilst still nevertheless attempting to account for their determining influence (Jenkins 1992). In Hollis' phraseology, Bourdieu was attempting to provide a theory of practice that could account for individual's resemblance to both a 'Plastic Man' and an 'Autonomous Man'. "Where Plastic Man has his causes, Autonomous Man has his reasons' (Hollis 1977 p.12). To do this, Bourdieu provides the research tools fit for use in empirical research projects to account for agential motivations, as well as the impact that an individual's structure has on their values, desires and decision-making processes.

This desire places a number of taxing design briefs on the research toolkit that can be used to account for both an individual's agential plasticity, as well as their structuring influences. If the tools are only designed to analyse the self-declarations that a research subject makes qua accurate and complete accounts of their reasons for acting, the research theory will fall at the first hurdle. Individuals do not have complete access to the structures that influence their lives (insofar as they are the underlying impacts that an individual's upbringing and socialised education has on their behaviour, and do not necessarily form part of the known motivations behind their decision-making considerations), and so the research tools cannot use the accounts an individual may give about the way they act as a reliable and complete version of their motivations. Instead, the tools need to have the theoretical firepower to 'see through' the accounts an individual may give of the reasons why they acted in a certain way, to access the full suite of 'structured' reasons unknown to the research subject, as well as the agential motivations (partly) known to the subject (Robbins 2008). 
Before fully relaying what this toolkit is, however, it is already clear that his objective has direct relevance to the research at hand. This project is attempting to understand the development of environmental attitudes of ELS participants and the adoption of agri-environmental practices on the management of their land. To fully understand this developing environmental attitudes, we need to map out the values they have arrived at through agential consideration as well as the powerfully determining impacts that their upbringing (qua an individual in the farming community) has had. A theory such as Bourdieu's, that takes a nuanced perspective on the variety of motivations that lead an individual to act - both spoken and unspoken, known and unknown, agential and structural - is the precise breed of sociological tool that will help this research project meet its goals.

This objective - of understanding human behaviour and agency in the context of the determining impacts of an individual's structure - also lends itself to a more modern approach to understanding cognition and behaviour. Social cognition research, for example, has helped reveal how an agent's prejudices, beliefs and subjective perceptions of experiences, blur the access an individual has to their reasons for acting. This creates a corresponding unreliability of the self-declarations the individual is liable to give a research setting. The theories used in a social science research project must, as a result, be able to account for the unspoken and unknown factors that determine the individual's behaviour (Gawronski and Payne 2010). Similarly, there is a growing recognition of the absence of a neat causal link between the values and motivations an individual declares themselves to have, or the behaviours they claim to take/expect to take, and the attitudes they really have or the behaviours they actually adopt (Rhodes and de Bruijn et al. 2013). Insofar as the project needs to select a sociological theory that marries up to the most modern and empirically sound understanding of actions and values from other academic fields, Bourdieu's attempt to understand behaviour as the product of both agential and structuring causes represents a sound choice.

One of the primary tools Bourdieu used to achieve this textured and complex account of behaviour, attitudes, beliefs is his concept of capital. As was shown in 2.4.1, 
Bourdieu splits capital up into three separate strands - economic, social and cultural. Economic capital tends to dominate the dialogue surrounding wealth and capital accumulation, but as Bourdieu shows us (and as we will see in greater depth, below), agents are also motivation by the accumulation of social capital (the network of social contacts an agent is part of, and the sum of the capital those in-group members have access to), and cultural capital (either embodied - durable dispositions that relay the accumulation of the agent's work and expertise, objectivised - in the form of objects that relay the skill/cultural expertise of the agent in spheres highly regarded by his group members, or institutionalised - qualifications etc that communicate the owner's understanding and skill as sanctioned by the qualification giver) (Bourdieu 1986). Crucially for us, these tools help explain how and why agents make decisions that are not reducible to the pursuit of maximising their economic capital.

In the context of this research project - of understanding attitudes towards agrienvironmental behaviour/AES participation - the theory has evident application. AESs are predicated on the notion that they provide farmers with financial reimbursement for the adoption of non-economically optimised land management techniques, and so are designed to be economically 'neutral' acts (Gunningham and Sinclair 2005). If we reduce the scope of our research down to an economic analysis of the farmer's behaviour, relatively little may be uncovered. Instead, we need to employ to a theory whose conceptual tools can facilitate a more socially nuanced understanding of human behaviour that does not employ a homo economicus account of motivation. In unlocking the motivational factors that arise from the farmers' desires to be respected members of their community with farms that earn the respect from other farmers, the notions of social capital and cultural capital will help the project achieve a suitably textured account of the adoption agri-environmental behaviours (Burton 2004).

In offering an account of behaviour that does not lean on the principle economic maximisation as a sufficient and compete story of human motivation, Bourdieu is also offering a theory that chimes with research coming from a variety of other academic fields. These fields, including decision-making strategy theory (e.g. Simon 1959), economics (Sippel 1997) and even philosophy (Hollis and Nell 1975), have 
shown in a variety of empirical and a priori ways how humans are moved to act by a number of powerful motivational determinants besides the pursuit of economic maximisation. Insofar as the accuracy of economic rational-choice theories have been repeatedly called into question, utilising Bourdieu's social theory as a means of distancing the project from a simplistic analysis of the farmer's economic rationality will be of great use.

In order to fully understand Bourdieu's nuanced and dynamic account of agency, structures, and capital, one must engage in his concept of the habitus. Habitus, introduced in section 2.4.2, is arguably the most central and most difficult to fully apprehend aspect of his social theory (Maton 2008). The idea will be offered a more thorough treatment below.

The habitus is a "complex social process in which individual and collective everstructuring dispositions develop in practice to justify individuals' perspectives, values, actions and social positions." (Costa and Murphy 2015 p.4). An individual's habitus, as such, covers the agent's social upbringing, the values inculcated through childhood, the expectations they perceive to be placed on him by other group members etc. (the habitus' lasting structure), whilst simultaneously restructuring itself through iterative adaption to new situations, beliefs, values and social pressures (the habitus' permeable [re]structuring characteristic) (Reay 2015). As well as operating as the overarching "structuring structures" (Bourdieu 1990 p.53) in an agent's life, habitus is also central to understanding how the different types of capital are reproduced. As we will see below, habitus provides the research "anchor [and] compass" (Wacquant 2011 p.81) when attempting to develop a complete understanding of why agents act in certain ways, and how agents in specific fields, reproduce the different forms of capital (Bourdieu 1984)

Insofar as the habitus is a "durable, but not eternal" (Bourdieu and Wacquant, 1992 p.133) feature of an individual's life, the concept is directly relevant to the emphasis of the research project on the changing/changed nature of the agricultural community's attitude to environmental management. Along with the concept of hysteresis (the portion of Bourdieu's theory that explains how habituses responds to 
shifts in the agent's 'field'), Bourdieu's theory has inbuilt mechanisms to explain the process through which individuals come to subscribe to new values and adopt new behaviours, and how different behaviours become capable of reproducing altered levels of capital. When seeking to understand and document the changes in the agricultural community's attitudes to agri-environmental behaviours and the repositioned importance of environmental responsibility, the concepts of habitus, hysteresis and capital can therefore be mobilised to great effect.

The final benefit of adopting Bourdieu's theory in the context of this research project relates to the pre-existing literature on the topic of agri-environmental attitudes and sociological research into the respect farmers have for agri-environmental activity. As discussed in sections 2.4.1 and 2.4.2, some of the most revealing research into the agricultural community's changing environmental attitudes (e.g. Sutherland and Darnhofer 2012, Riley 2016) has been built on the Bourdieusian concept of field, habitus, capital, and to a lesser extent, hysteresis. Buying into the same conceptual tools as those papers will facilitate an unmodified integration of this project's findings into the pre-existing literature.

Although Bourdieu's theory may appear to be a neat fit with the demands and requirements of this project in particular, his theory is in fact, one of the most utilised across disparate field of social science research. The capacity for the central concepts of habitus, field and capital to be moulded to any number of different research groups has meant that the theory has been used by social scientists working in a variety of fields. The theory has, for example, been used in topics as diverse as career research (Lellatchitch et al. 2003), young offenders rural and urban migration (He and Wang 2015), as well as the topic of understanding how class mediates the scholastic attainment of children from different back grounds for which the theory was originally developed (Naidoo 2004).

\subsection{The theory, in-depth}

Having selected Bourdieu's theory of capital, habitus and field for the project's theoretical backbone, a sufficiently detailed account of the theory, from which the 
rest of the project can be launched, is needed. The following subsections will attend to this task. The specific components of Bourdieu's theory will each be the subject of their own subsection, and will be introduced in a way that makes their function and position in the wider theory most comprehensible.

\subsubsection{Field}

One of the most commonly cited definitions, taken from Bourdieu and Wacquant's (1992) Invitation to Reflexive Sociology, describes a field as:

A network, or a configuration, of objective relations between positions. These positions are objectively defined, in their existence and in the determinations they impose upon their occupants, agents or institutions, by their present and potential situation (situs) in the structure of the distribution of a species of power (or capital) whose possession commands access to the specific profits that are at stake in the field, as well as by their objective relations to other positions.

The above passage depicts how individuals assume a position in a field's hierarchy (the position of dominance/domination that any one individual has relative to other field members), where the individual's relative position is determined by the accumulation of the different incarnations of capital (i.e. cultural, social and economic) that they can lay claim to. The field is, therefore, the arena in which individual members vie for social position - whereby 'vying for social position' is achieved through the struggle to reproduce capital (Rey 2007). This combative and competitive element of an individual's life in a field is underlined in Bourdieu's depiction of a field as a "site of struggles" (Bourdieu and Wacquant 1992 p.104).

The boundaries of any one field are roughly demarcated by the point at which the relative hierarchical positions of the different members of a field no longer have any relevance. When an agent, well endowed with the different forms of capital, high up in one field's hierarchy, finds that they can no-longer mobilise their capital to assert their dominance over other individuals, they will know that they have crossed a field 
boundary. Put another way, one field begins and another ends roughly where the 'rules of the game' that determine social positioning and the reproduction of capital changes, and where new individuals can be witnessed as assuming dominant social roles (Mayrhofer et al. 2004).

The rules that determine the social rankings of the field are only tacit in nature (Wacquant 2011), and so must be intuited and internalised by the individuals in the field (Bourdieu 1983). Once those rules have been appropriated into an individual's cognition, they can be transposed into effective strategies that can be deployed within the field to ensure the individual's success (i.e. to ensure their ability to reproduce capital and acquire social standing). Individuals, in this way, have a disposition to want to improve (or maintain) their social standing, and have a propensity to digest and internalise the lessons that explain how field positions are established and how capital can be reproduced (Maton 2008,).

To bring the nature of this socialised activity of individuals within fields into clearer focus, Bourdieu returns to the notion of the 'rules of the game', and frequently offers an analogy that likens his 'field' to a football field and the game of football of which it is the site (Thomson 2008). A game of football has rules (i.e. specific rules that only apply within the football field) which the players follow. After some exposure to the game, the rules are internalised and the referee does not need to go over each rule at every moment of the game. People occupy different positions within the (football) field, and struggle for power and recognition (in football through performing respected/highly valued acts such as scoring goals or intercepting passes). The metaphor of the 'rules of the game' is thus used to capture the similarity of the rules that govern a Bourdieusian 'field' and the inculcation of rules and objectives at play in other fields (such as a football field).

Bourdieu's theory also accounts for the interplay between field members, and the changing (or inert) character of the field. Dominant members - i.e. those with large accumulations of capital, high up in a field's hierarchy - are better able to reshape the field that they find themselves in, usually to ensure their ongoing domination and success within the field. Newcomers to the field, or those lower down the field's 
rankings of capital accumulation will tend towards subversive or disruptive acts to attempt to reposition themselves in the field's hierarchy - or else be complicit in symbolic violence committed against them, whereby they are obliged to "recognise the legitimacy of a symbolic order that is unfavourable to them" (Hilgers and Mangez 2015).

That is what I mean when I describe the global social space as a field, that is, both as a field of forces, whose necessity is imposed on agents who are engaged in it, and as field of struggles within which agents confront each other, with differentiated means and ends according to their position in the structure of the field of forces, thus contributing to conserving or transforming its structure (Bourdieu 1998, p.32).

We can imagine, by way of example, the field of high-art. There will exist a number of individuals within that field (critics, successful artists etc) who can exert influence over the symbolic order - i.e. the order that legitimises and determines how much capital is reproduced by what acts/artefacts/behaviours. "The struggle in a field" Hilgers and Mangez surmise, "is a struggle to impose a definition of legitimate recognition, in which victory leads to more a less monopolistic control of the definition of the forms of legitimacy prevailing the field" (Hilgers and Mangez 2015 p.16).

\subsubsection{Habitus}

Habitus is arguably the central concept to Bourdieu's social theory (Maton 2008). It is the key to understanding why individuals are moved to act in certain ways, and "allows researchers to explain how and why social agents conceive and (re)construct the social world in which they are inserted." (Costa and Murphy 2015). It is, as such, not only a powerful conceptual tool, but an invaluable empirical one too.

Although already provided, the following definition is the most transparent one available from Bourdieu's own writing. Habitus is to be understood as: 
A system of lasting, transposable dispositions which, integrating all past experiences, functions at every moment as a matrix of perceptions, appreciations and actions. (Bourdieu 1977 p.95)

In this way, an individual's habits can be understood as a necessary but not complete component of their habitus. An individual's habits include the linguistic tropes they makes use of, or their behavioural patterns or taste preferences, but is not usually considered to encompass the way in which they constructs their social reality and does not, in typical definitions, cover the way that one's perceptions interact with the accumulation of one's experiences and beliefs. Habitus, on the other hand, performs exactly that function - and is the accumulation of an individual's upbringing and ongoing experiences that shape the lasting dispositions that emerge in the individual, and iteratively determines the way he experiences the world and the dominant patterns of thought and belief held by the individual (Bourdieu 1977).

Where the field is the social arena in which individuals struggle for social standing (through the attempt to reproduce capital), the habitus picks out the life-view of an individual, formed by the accumulation of their upbringing, life experiences, attitudes and beliefs and the resulting bodily/mental dispositions that shapes the way they operate in their field. As with the concept of the field, Bourdieu leans on the metaphor of 'the game' to bring the idea into clearer relief. Where the fields are run according to 'the rules of the game', which demarcate the power and capital each member has in the field, the habitus is construed as 'the feel for the game' - the process through which an individual comes to absorb the characteristics of the field to ensure they behave appropriately whilst playing. Importantly, the 'feel for the game' is not just meant to play into Bourdieu's ongoing metaphor, but is also designed to elicit the pre-rational process through which the 'socialising' process of the habitus occurs. The habitus is:

A source of cognition without consciousness, intentionality without intention, and a practical mastery of the world's regularities which allows one to anticipate the future without even needing to posit it as such. (Bourdieu 1990a pp.11-12). 
Habitus, thus explains how individuals in a field adopt similar practices and share a culture in common - not through a process of coercion in which agents are forced to adopt certain practices or taught to behave a particular way, but as a pre-rational reflex in which agents mirror acts in accordance with the rules of their field. A crucial component of an individual's habitus is their aspirations. An individual's habitus helps internalise the aspirations the individual recognises as appropriate and realisable.

In reality, the dispositions durably inculcated by the possibilities and impossibilities, freedoms and necessities, opportunities and prohibitions inscribed in the objective conditions generate dispositions objectively compatible with these conditions and in a sense pre-adapted to their demands. (Bourdieu 1990 p.111)

The interface between upbringing, habitus and aspiration setting is a major theme of Bourdieu's empirical work. His theories have been used to show how disadvantaged members of a field intuitively calibrate their aspirations towards the lower end of the field, and thus eliminate themselves from behaviours and acts (higher education, extracurricular activities) that would otherwise pertain to them achieving success in the field. This phenomenon arises due to their internalised vision, established through the habitus, of how successful they can expect to be, and what behaviours are (in)appropriate for them to adopt (Throop and Murphy 2002). The body and its dispositions are, in other words, "the device upon which, and in which, the very basics of culture, the practical taxonomies of the habitus and imprinted and encoded" (Jenkins 1992 pp.75-76).

The habitus, therefore, encompasses an individual's physical and mental dispositions, the accumulation of their life-experience (socialised education conveying the appropriate values and desires the individual should adopt) and the lens through which the individual perceives and processes their new world experiences. Through this pre-rational socialising construction of the habitus, an individual's life experiences shape and reshapes the way they operate in the world. 
Or, to invoke the sociologist language detailed in section 3.2, is the process through which an individual's structures impacts the way they operate in the world. Crucially, however, the habitus is not just limited to the accumulation of their lifeexperiences and surroundings (it does not, that is, limited itself to understanding human behaviour exclusively as the results of the individual's upbringing, education etc), it is also an iterative and adaptive life-view formed and reformed by the individual's new experiences, new field characteristics, and the newly reshaped dispositions those experiences give rise to (Murphy and Costa 2015). The habitus, is thus also defined as:

Structured structures predisposed to function as structuring structures (Bourdieu 1990 p.53).

As the nature of habitus becomes clear, we can also see how it helps pertain to one of the primary objectives Bourdieu had for his wider sociological theory. Namely, the attempt to distance himself from the reductionist thinking that frames human action as either a mechanistic and emergent property of an individual's social structure or the result of an individual's free agency (i.e. unbound by the motivational impacts of structure). Habitus, in this way, is "a bridge building exercise across the explanatory gap between these two extremes... between subjectivism [human agency] and objectivism [structural determinism]" (Jenkins 1992 p.74).

The mystifying definition that defines habitus as "structured structures predisposed to function as structuring structures" (Bourdieu 1990 p.53) is, in fact, the key to Bourdieu's attempt to perform the conceptual tight-rope act between the above two ways of understanding human practice, and deserves a closer inspection. The habitus is a structured structure insofar as it is the force that forms one's dispositions and beliefs (the structure in an agent's life) that was itself shaped by the social lessons experienced by an individual, the values of their parents, the way members of the same class operate etc (in that it was itself structured), which, crucially, is predisposed to act as a structuring structure, or, in other words, it is the force that forms one's dispositions and beliefs (the structure in an agent's life) that is itself continually (re)shaped by the features of the social world in which the individual is 
located (in that its process is subject to ongoing structuring). Or, in the latter definition, habitus is the "dispositions, reflexes, and forms of behaviour that people acquire through acting in society" (Bourdieu 2000a p.19). Society, that is, does not just happen to them, and humans are not neat carbon copies of societal structures but it is through their active (and agential) participation within the social world that their habitus is formed.

This particular characteristic of the habitus - it's evolving, reshaping, nature, combined with its capacity to reproduce societal values and behavioural tropes picks out a feature of Bourdieu's theory that is not only central to his epistemological objective, but one that will also be central to this research project. The habitus is not a rigid or static feature developed over a certain formative period in the individual's life, but is "an acquired system of generative schemes objectively adjusted to the particular conditions in which it is constituted" (Bourdieu 1977 p.95). It is, in simpler terms "durable, but not eternal" (Bourdieu and Wacquant, 1992, p.133). The habitus, that is, is iteratively (re)shaped by the field characteristics that form the individual's ongoing life-experiences, and so not only shapes the ongoing dispositions of the individual but it itself is reshaped accordingly.

Insofar as the research project is interested in the development of agri-environmental attitudes, and the shifts in land management plans catalysed through ELS participation, the concept of habitus that allows for an individual's changing attitudes, habits and beliefs, is of direct research value. To understand how farmers' ELS contracts are influencing their attitudes and practices, along with the constantly changing economic, political and social landscape in which they operate (i.e. the agricultural field), the habitus maps perfectly onto the research project's objectives.

In light of the specific demands of this research project, the interface between field and habitus assumes a central theoretical role. Bourdieu depicts this relationship in the following way:

The relation between habitus and field operates in two ways. On the one side, it is a relation of conditioning: the field structures the habitus, which is the 
product of the embodiment of immanent necessity of a field (or of a hierarchically interesting set of fields). On the other side, it is a relation of knowledge or cognitive construction: habitus contributes to constituting the field as a meaningful world, a world endowed with sense and with value, in which it is worth investing one's practice (Bourdieu 1989 p.44).

In simpler terms, habitus and field are "mutually constituting, in that each helps shape the other." (Thomson 2008). This relationship, however, is not static. Both sides are mutable, and given their interdependent construction, a shift in one is liable to effect a shift in the other. Habitus and field are "evolving, so relations between habitus and field are ongoing, dynamic and partial: they do not match perfectly for each has its own internal logic and history. This allows for the relationship between the structure of a field and the habituses of its members to be one of varying degrees of fit or mismatch.” (Maton 2008 p.55).

In the case of subtle or steady shifts in the field, the habitus is sufficiently elastic to accommodate the changes without any great effort or cognitive turmoil. Through an individual's practical sense (i.e. his dispositions to mimic social conditions in order to be a successful social operator in a field), their habitus is able to mirror both the rules of the field and also the minor changes that are liable to occur in the field's rules (through policy changes, societal changes, interpersonal relationship changes) (Maton 2008, Wright 2015).

For the most part, therefore, there is a match between the field in which individuals find themselves situated, and their habituses. This harmony is, however, not a necessary condition of the two phenomena, and Bourdieu accounts for the occurrence of major rifts between the two (Bourdieu 1977). If, for example, field characteristics change too quickly, or too dramatically, the habitus' capacity to adapt itself can be insufficient. Dispositions, that is, are deeply founded, slow to change, and their capacity to change is limited. If the change in field characteristics outstrips an individual's habitus to adapt to those changes, then the hysteresis effect occurs (Hardy 2008). 
Bourdieu asserts that hysteresis is a necessary by-product of the concepts of field and habitus:

Hysteresis of the habitus, which is inherent in the social conditions of the reproduction of the structures in habitus, is doubtless one of the foundations of the structural lag between opportunities and the dispositions to grasp them which is the cause of missed opportunities and, in particular, of the frequently observed incapacity to think historical crises in categories of perception and thought other than those of the past. (Bourdieu 1977 p.83)

It is a concept that he uses to describe the effects of change in the structures of any particular field where there is, at least for a time, a breakdown in an individual's selfregulation (habitus) which was established to fit a particular construction of society and particular field characteristics. In Bourdieu's words:

As a result of the hysteresis effect necessarily implied in the logic of the constitution of habitus, practices are always liable to incur negative sanctions when the environment with which they are actually confronted is too distant from that in which they are objectively fitted (Bourdieu 1977 p.78)

The classical example of the hysteresis effect occurs in Don Quixote (Bourdieu 1984). Don Quixote subscribes to a notion of knight-like chivalry that he believed was appropriate irrespective of his location in time and space. His knightly dispositions (habitus) do not, in fact, match the field characteristics, and he repeatedly fails to achieve the goals he sets for himself (and as a result looses cultural capital and field standing). Although he is, for swathes of the story, unaware of why this was, the comedy of the book turns on the audience's awareness of the mismatch between his dispositions and the field characteristics in which he was shaped (hysteresis)

Bourdieu also demonstrates the phenomenon through his empirical work. In the Bearn peasantry, for example, the hysteresis effect is manifest when the ancient inheritance and marriage traditions were rendered inoperable by national legislation 
changes to inheritance tax (Bourdieu 2002). The youngest sons of wealthy farmers, it transpired, were 'victims' of the legislation changes, and the established habitus of the youngest sons (i.e. relating to their desires to marry at a certain age, where they could expect a certain portion of the inheritance) were out of synch with the legislation that changed overnight. An image, selected for the front cover of the book, depicts a collection of these younger sons at a ball, as they are being left out of the romantic proceedings - seemingly left to lament their 'out of date' habitus in the face of the changed rules of the field: a visual demonstration of the hysteresis effect.

In empirical research presented in his 'The Weight of the World", Bourdieu (1993a) also identifies the Hysteresis effect in Algerian immigrants living in France. Their habituses cannot keep up with the vastly different field characteristics of their adopted country. The hysteresis effect ensured that they did not know how to carry themselves in a way conducive to establishing desirable field positions in their new field, and experienced the pain of exclusion accordingly. In this way, the hysteresis effect can be witnessed when an individual's field changes (as with the Bearn peasants), as well as when an individual changes field (as with the Algerian immigrants).

Along with his account of when the hysteresis effect occurs, Bourdieu also details what the expected social fallout of the effect will be. In times of dramatic field change, the field's social hierarchy and the behaviours that are capable of earning individuals capital (power) are in flux. These changes, however, are rarely capable of 'reshuffling' the social order - dominated members do not tend to capitalise on the disruption in the field, and dominant members do not tend to let their pre-existing capital slip from them amid the field chaos (Hardy 2008). "In a general manner, it is the people who are richest in economic capital, cultural capital and social capital who are the first to head for new positions" (Bourdieu 1996 p.262). By contrast members with lower capital and lower field position attempt to adopt the behaviours of the "dominant positions at a time when the profits they provide tend to be diminishing" (Bourdieu 1996 p.262), thus adopting the practices and behaviours that although previously may have been productive strategies, are becoming out-of-date and ineffective. 


\subsubsection{Capital}

From the above sections, and the introduction offered in the literature review, it has already become clear that Bourdieu's concept of capital functions as the currency through which individuals in a field vie for social position; and it is through an individual's habitus that the rules of a field are internalised that explain how they can reproduce capital, along with the lessons that explain why anyone should want to reproduce capital in the first place (i.e. to secure social standing in a group's hierarchy).

The act of mapping out how habitus and field function has, therefore, already provided a working conception of capital. The task of the following section will be to fill in the gaps of this definition, and explain exactly how capital functions in Bourdieu's theory.

With respect to capital, Bourdieu's primary conceptual objective is to widen out the concept's utilisation and definition to include the non-economic currencies that motivate human behaviour (Moore 2008). There is, in other words, a tendency to reduce our discussion of 'capital' to a discussion of financial and mercantile exchange that only serves to limit our capacity to engage in the complete suite of currencies that are needed to fully explain human practice. Along with 'economic capital' (i.e. those things with direct financial value such as stocks, money, or a salary), agents are moved to reproduce 'social capital' and 'cultural capital' as a means securing social standing in a given field's hierarchy.

As detailed above, 'cultural capital' itself comes in three separate incarnations embodied cultural capital, institutionalised cultural capital, and objectified cultural capital. Embodied cultural capital refers to the bodily and mental dispositions, understandings and abilities that a person has access to, that are recognised as valuable by the field members, and according to the field's 'rules' (Jenkins 1992 p.85). Within the field of art, for example, individuals can reproduce embodied cultural capital if they are talented painters with good brush technique; whilst footballers would be able to reproduce embodied cultural capital through consistent 
passing and accurate shooting. Insofar as embodied cultural capital is incorporated into the dispositions and abilities of an individual through hard work, labour and time, it is not possible for the possessor to transfer the capital onto another individual.

The behavioural habits or personal attributes that reproduce embodied cultural capital is entirely defined by the rules (preferences, objectives, values) of their respective field. They demonstrate the cultural competence of the individual in question, and mark them out as someone who understands the rules of the game, what products are held in high esteem within the field, and is adept at securing those products (Bourdieu 1986).

Institutionalised cultural capital is the capital reproduced by agents through the qualifications and awards (academic, vocational) of which they are in possession. The qualifications mark the owner out as experts in the discipline that is valued by the rules of the field in question, typically a discipline that pertains to the attainment of goals held in high esteem by their field's rules. Such qualifications, bestowed by respected institutions ensure that the abilities and skills of the owner cannot be called into question, and allow the agent to enjoy ongoing respect for their skills, even when they are not being applied. Again, the way in which institutionalised cultural capital is reproduced is dependent on the specific rules of the field (Moore 2008). A sociology degree, for example, may be unable to reproduce cultural capital for the owner in an amateur sports environment, given that the academic rigour and knowledge associated with the qualification do not pertain to the objectives and values at play in that field, just as a 'player of the season' award, or league title may not be able to mobilise any institutionalised cultural capital in an academic setting.

Cultural capital, in its objectified form, is the capital reproduced by the objects and artefacts that communicate the owner's cultural competence and knowledge. To return to the sporting analogy, an expensive pair of football boots will be able to reproduce objectified cultural capital for the owner, insofar as they communicate the owner's footballing competence (a set of skills that pertain to the objectives and values of the field such as goal scoring ability). The football boots are capable of 
generating objectified cultural capital, only if the owner is known to have access to the embodied cultural capital required to effectively use them. Relevant embodied cultural capital is, in this way, sometimes a pre-requisite of objectified cultural capital, and an individual must have the required embodied cultural capital before he is able to 'unlock' the additional objectified cultural capital on offer.

Along with economic capital and the three forms of cultural capital, social capital is the other currency that determines an agent's field position. Social capital, as outlined in the literature review, relates to the social network an individual has access to, and the sum of the capital associated with the entire membership of the network. Membership of the relevant group functions as a credential that the members can use to reproduce social capital. Within the football field, for example, members of successful, economically buoyant teams will be able to mobilise more social capital than their counterparts in worse off, and poorly performing teams. Individuals within such a network must maintain their membership through exchanges and interactions with other group members. The group is itself, equally dependent on the ongoing interactions of the respective members - and without such exchanges, social events or acknowledgements, the group is liable to dissolve and deprive the erstwhile members of the social capital they previously had access to. All sorts of different groupings can function as a network capable of reproducing social capital (businesses, families, clubs), so long as the group is cohesive enough that the individuals can demonstrate their membership, and so long as the group is maintained by the ongoing interactions and mutual affirmations of the membership of the constituent members (Bourdieu 1986).

We have already learnt how agents, within fields, vie for favourable positions in a field's hierarchy through the reproduction of capital, but we have not, as yet, covered the mechanism through which capital - economic, cultural, social - affects an individual's field position. Crucially, is not those types of capital, in and of themselves, that contribute to an individual's field position but rather the relationship those incarnations of capital have with the fourth and final version of capital symbolic capital. Symbolic capital operates on a different plane as the other three 
capitals, and in effect functions as the overarching category within which the other three fit. Figure 3.1, below, represents this relationship:

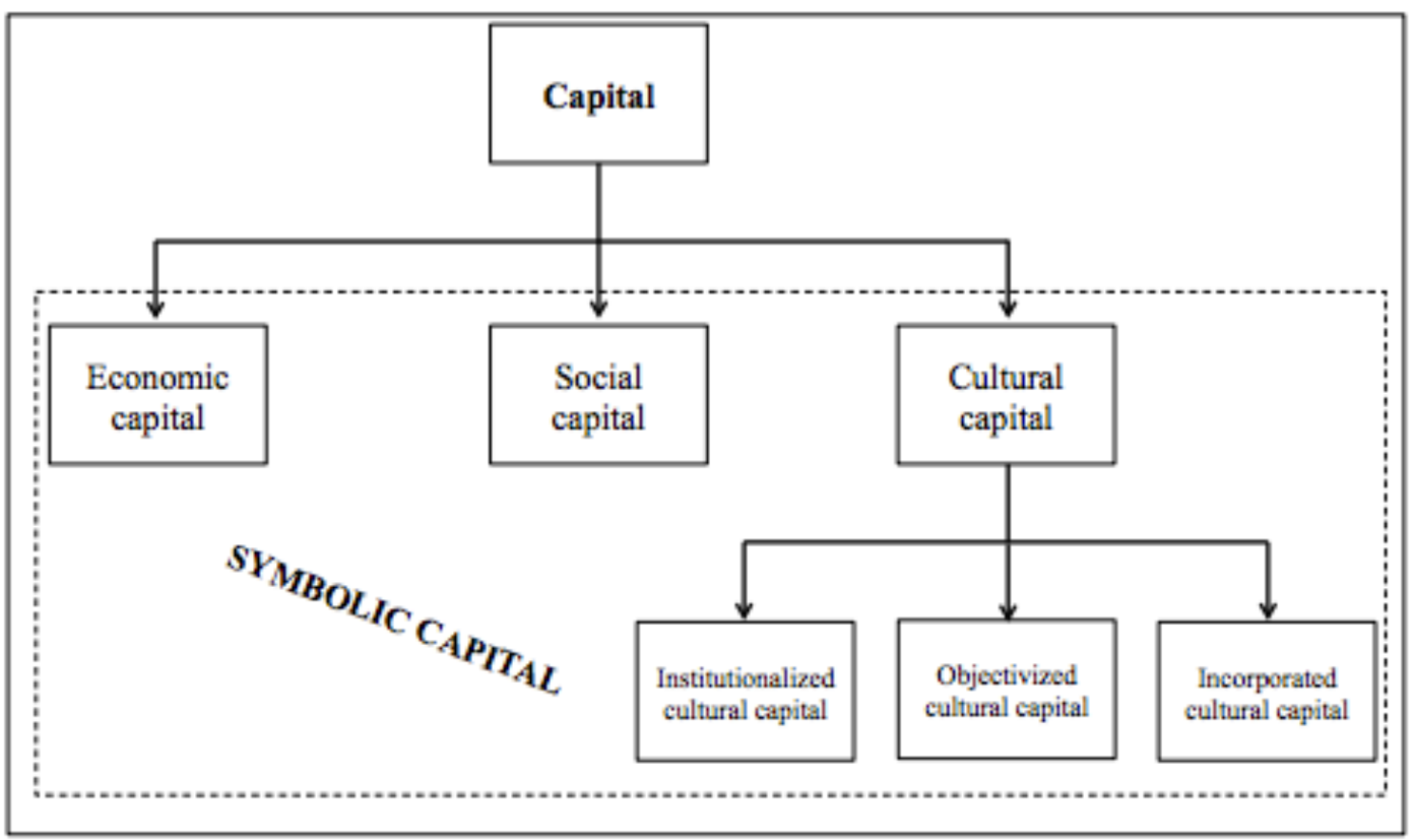

Figure 3.1 Schematic of capital, taken from Walther 2014, p.11

The behaviours/objects/characteristics that earn an individual either cultural, economic or social capital are, in fact, only valuable (in terms of what impact they have on position taking) in so far as they are recognised as legitimate within a field, and in so far as they have symbolic value. In the case of economic capital, for example, it is not money vis-à-vis money that helps the individuals in possession in their bid to secure a favourable field position, but it is because money is recognised as a legitimate resource that it reproduces symbolic capital for the owner that it helps them secure a favourable field position. It is, in this way, money (economic capital) $v i s-\grave{a}$-vis symbolic capital helps individuals in their position taking efforts.

This process also characterises the relationship between cultural and social capital and position-taking activities. The football boots (objectified cultural capital), the footballing ability (embodied cultural capital), football league titles (institutionalised 
cultural capital) or membership in a successful football team (social capital) do not, in themselves, translate to improved field positions - but only in so far as they are recognised as legitimate and desirable currencies in a particular field are they are able to reproduce symbolic capital, and thus contribute to an individual's field position.

Symbolic capital, therefore, needs to be understood as the overarching currency, into which the other forms capital are 'equated' - most normally through the subconscious and instantaneous recognition on the part of the field members. Symbolic capital is the "form that the various species of capital assume when they are perceived and recognised as legitimate" (Bourdieu 1989a p.17). This phenomenon can be witnessed in an area that Bourdieu returned to on many occasions - the artistic and cultural preferences of different classes, and the mechanism through which the individuals seek to differentiate themselves through their tastes. 'High culture' (fine art, opera, ballet) is perceived, across the socioeconomic spectrum as being of higher value, and is capable of generating more symbolic capital for those involved in that world artefacts from 'low culture' (daytime tv, broadsheet newspapers) would be. According to Bourdieu, however, this is not due to any intrinsic value of 'high culture' over 'low culture' but rather that those who occupy dominant field positions dictate that opera, or fine art are to be perceived as more legitimate, valuable cultural resources, and thus are capable of generating higher volumes of symbolic capital.

It is through this symbolic order (in which different acts, behaviours, artefacts are associated with higher levels of symbolic capital) that a breed of symbolic violence is effected on dominated members of the field, by the dominant members. The system through which field position is determined (i.e. through the reproduction of capital) is rigged to ensure the ongoing domination of certain members, and where the dominated members are forced to accept the symbolic order of things (the diminished legitimacy of the behaviours, tastes, and artefacts they engage in, and the augmented legitimacy of the behaviours, tastes artefacts that the dominant members engage in and from which they are [self] excluded) that places them far down a field's hierarchy (Bourdieu 1984). 
In developing the concept of symbolic capital and symbolic violence, Bourdieu is attempting to highlight the 'arbitrariness' of the acts that do and don't pertain to cultural dominance (Moore 2008). Arbitrary, in this sense, does not mean 'random' or 'ephemeral', but rather 'non-intrinsic'. The acts, dispositions or objects that are perceived as legitimate, that is, are not valued because of any intrinsic characteristics they may have, but rather because of silent 'decision' taken within a field to value those acts dispositions or objects, usually propelled by the dominant members of the field who have a vested interest in maintaining a certain symbolic order.

\subsubsection{Practice}

In a sense, practice is the culmination of Bourdieu's theory. The other components, outlined above, are tools that pertain to understanding the wider phenomena of an individual's practice: describing why a given agent in a given field does what they do. With those now in place, Bourdieu's theory of practice is ready to fall into place, with the help of the following formula:

$$
[(\text { habitus })(\text { capital })]+\text { field }=\text { practice }(\text { Bourdieu } 1984 \text { p.101) }
$$

The pseudo-mathematical formula simply aims to reduce his theory into a sociological epigram. Habitus (the accumulation of an individual's life-experiences, their dispositions, beliefs, desires) that dictates how an individual operates in a world, combined with the capital (economic, social, cultural) they has access to, all taking place within the context of a particular field (along with the field's hierarchy, and the logics that determine the symbolic value of different acts, behaviours and artefacts), determine the individual's behaviour (Maton, 2008, p.51).

\subsection{Deploying the theory in this research project}

As explained above, Bourdieu developed the theory with the express desire that it be used in research settings, and the 'thinking tools' outlined above are designed to be both powerful sociological concepts to understand human practice as well as wieldy 
empirical tools (Costa and Murphy, 2015). It is perhaps unsurprising therefore that the theory has enjoyed wide ranging applications in a vast number of different research projects (Sullivan, 2002).

As detailed above, theory is needed to ensure that a given research project is designed and conducted in an academically robust way, and to ensure that the data collected in the project's empirical phase can be computed and subsequently presented in thoroughly and meaningfully (Bryman 2015). To ensure the bond between Bourdieu's theory and the following empirical project is properly established, the following sections will be dedicated to the transposition of the above theory into the context of the research project at hand.

\subsubsection{Epistemological considerations in adopting Bourdieu's theory}

In integrating Bourdieu's theory into this research project, his epistemology first needs to be considered.

Bourdieu's theory represents a departure from a positivistic epistemology (Robbins 2003). Positivism is the position that holds that there exists a material universe independent of our subjective experience of it, and that through our phenomenological experiences of it, we (the researcher) have direct access to its reality, and that we can come to understand objective truths about the nature of the universe through diligent empirical observation (Halfpenny 2014). Empirical research, in this understanding, does not chart just our own experiences of the world, but maps out its objective characteristics. Bourdieu eschews this position on the grounds that our own subjective experiences are themselves so heavily structured and muddied by cognitive filters and biases, that when we attempt to do empirical research, we are prevented from having a clean, objective experience of the world and of the research subject (Webb et al., 2002).

The problems associated with having research laden with the subjectivities of the researchers can be seen from another angle. If researchers are not equipped with the 
tools to break from their epistemic ideas about the make-up of the world (or their research subject in particular), they will be unable to say anything new about it:

The construction of a scientific object requires first and foremost a break with common sense, that is, with representations shared by all... The preconstructed is everywhere. The sociologist is literally beleaguered by it... [and] is thus saddled with the task of knowing an object - the social world of which it is the product, in a way such that the problems that he raises about it and the concepts he uses have every chance of being the product of the object itself (Bourdieu and Wacquant 1992 p.235)

If, as Bourdieu's theory contends, we cannot rely on the researcher's pedestal to provide an objective vantage point on the world and the research subjects within (hence Bourdieu's express anti-positivism), how can empirical work be conducted? To this, Bourdieu offers the notion of reflexivity. Here, reflexivity relates to the need for social scientists to recognise their own research biases, their own beliefs, and their own research objectives when conducting their social empirical research; that they occupy a space in the same research setting as the research target; and that they are subject to the same breed of societal and personal influences as their subjects. Bourdieu's reflexivity demands that researchers should:

Explicitly position themselves in relation to their objects of study so that one may assess researchers' knowledge claims in terms of situated aspects of their social selves and reveal their (often hidden) ... values and assumptions. (Maton 2003, p.53)

One must, that is, not envisage the social researcher and their empirical project as having direct access to the characteristics and truths of his research subjects, but as one of the many features that exist in the scope of the research project. Despite it being a niche theoretical admission at the time of writing, social science reflexivity now represents the norm in social science settings - whereby the absence rather than the acceptance of the need for reflexivity is considered the graver research sin (Maton 2003). 
Additionally, a number of theorists contributed arguments that appear to bolster the researcher's capacity to engage in meaningful empirical research about the social world, in spite of their biases and subjective positions with respect to the research subject. Maton (2003), for example, argues that even though researchers necessarily operate from an 'interested' position (i.e. that they have their own research objectives), the process of empirical study, combined with the researcher's genuine desires to be objective, provides a sufficiently sized 'break from common sense' that facilities meaningful empirical research. Bourdieu was right to highlight the dangers of the subjective experience of researchers attempting to engage in objective empirical study, and was right to call for a research reflexivity but "While acknowledging the will to power [i.e. the desires of the researchers to produce good and interesting research], one need not deny the will to truth [i.e. the desires of the researchers to attempt to be objective in their research]" (Maton (2003 p.60)

To ensure commitment to Bourdieu's theory, we too must subscribe to the antipositivism of his epistemology and employ strategies to effect the break from common sense, bias-laden, analysis. Doing so will facilitate the creation of new and meaningful research - as far from the researcher's biases, subjectivities, objectives as possible. The ways in which this reflexivity will be achieved will be described in the following methodology chapter. It will, in short, be rooted in the methodological steps taken to create a distance between the researcher and the research subject in the way the data is both collected and analysis.

\subsubsection{Field, in the context of this project}

For this research project, the field in question is the 'agricultural field'. The 'agricultural field', not to be confused with a field in which crops are grown or animals grazed, signifies the grouping within which farmers vie for capital, and are interested in securing positions of high social standing. As previously discussed, the boundaries of fields are not neatly demarcated, but roughly trace the frontiers at which powerful field members can no longer exercise their power. In this way, the farmers across the whole country can be meaningfully said to be in the same field, 
along with members of Defra or NE, farm advisors, scheme officials and farming family members. They all possess varying degrees of capital within the field, occupy different positions in the field's hierarchy, and have all internalised the 'rules of the game' and their position in the field.

As we have seen, the farmers in the agricultural field have historically subscribed to a notion of identity that frames themselves as productivist farmers, seeking to a maintain an economically buoyant farm, producing high agricultural yield (McGuire et al. 2013). This 'identity' makes up part of the 'rules of the game' of the agricultural field and helps determine which behaviours and artefacts are held in high esteem by other members of the field, and the capital associated with those behaviours and artefacts. In Bourdieusian terms, the 'productivist activities' also function as a shorthand for the 'strategy' historically adopted by the farmers: they understand the symbolic order of the agricultural field and act in ways to reproduce the legitimised behaviours to ensure they adopt desirable positions within the field. As demonstrated by work such as Burton (2004) and Burton et al. (2008), for instance, the existence of well-ploughed fields demonstrates the farmer's farming skill, and well-kept machinery that communicate the farmer's diligence and technical understanding, pertain to the financial success of the farm, and reproduce capital for the respective farmers.

Importantly for us, the 'rules of the game' that dictate how the agricultural field operates is also determined by the politicians and policy officers who designed and implement various agricultural initiatives, along with the wider cultural shifts that place new social pressures on the individuals within the agricultural sector. Those rules, externally placed on the agricultural field, have a bearing on what strategies the farmers (and other field members) can and can't employ to ensure they can reproduce the desired levels of capital to become successful (powerful) agents in the field.

As described in 2.4.2, Sutherland and Darnhofer (2012) and Riley (2016) demonstrated how, in response to the changing rules of the agricultural field (societal pressures to be environmentally friendly, changing market preferences for different 
agricultural products, new government initiatives to promote agri-environmental practices), farmers are increasingly able to reproduce cultural capital through the adoption of organic or other environmental practices. The farmers who were capable of creatively responding to new funding opportunities and external pressures (changing rules and field characteristics) were respected by others, namely other farmers who occupy similar positions within the field's hierarchy, within the agricultural field.

The two papers also provide a valuable precedent for the mobilisation of the concept of a field in an agricultural context. They both include the farmers, along with their advisors, the governmental officials responsible for the regulations they are affected by, their families and members of the local community in the agricultural field and show how all those actors are implicated in the same interplay of position-taking and capital reproduction.

Insofar as the project is concerned with the way that the ELS has impacted the environmental attitudes of the farmers, and their land management plans for the land coming out of ELS contracts, the research project will be concerned with the farmers of the agricultural field specifically. Whilst there may be a variety of different actors within the field, that is, we are primarily concerned the farmers' attitudes and behaviours, and the strategies they adopt to play the game in a way that pertains to the reproduction of capital - specifically in relation to agri-environmental behaviour. It is, therefore, not of urgent important to precisely detail which actors are in the agricultural field, and which are not, so long as we can be sure that the farmers involved in the ELS contracts (i.e. the research sample) are.

\subsubsection{Habitus, in the context of this project}

The concept of habitus provides a framework within which we can understand how a farmer's upbringing, education, and social codes have been historically moulded around the rules of the game that favour the attainment of productivist goals and the adoption of practices that pertain to meeting those goals. Importantly, the concept is able to simultaneously look at how the shifting political, social, and economic 
landscape that the farmers are operating in is inviting them to creatively adapt to those changes - and how symbolic capital can be increasingly reproduced through the adoption of environmental practices. The concept is, in other words, equipped to understand how behaviour is the product of both the structuring factors in an individual's life, and their agential capacity to develop new strategies in response to the changing field conditions and rules of the game (Garth 2015). Especially in the context of a study of attitudes and behaviours in the farming community, this is of significant research value. Farmers are known to be a highly traditionalist community who place great stock in the attitudes and practices of previous generations (Haan 1993); as well as being a group who are continually expected to adapt to changing market demands, environmental regulations, technological advances, societal pressures (Huttunen and Peltomaa, 2016).

As the habitus is required to accommodate both of these features of an individual's motivations - their newly adaptive attitudes and the impact of his upbringing and life experience - the net must be cast relatively widely when researching into it. Amongst other things, the habitus will be marked out by the farmer's stated desires, beliefs, and attitudes, the values adopted through his socialised upbringing, his linguistic dispositions, the artefacts, behaviours and individuals he holds in high esteem, the way in which he responds to changing field characteristics (David 2015).

Those papers that have used Bourdieu's theory to inspect the development of agrienvironmental attitudes have also paid due attention to the importance of habitus in their research projects. Sutherland and Darnhofer (2012) stress that because the habitus is "developed in dialogue with the context," and that "structural adjustments at the farm-level and cultural norms are interrelated" (Sutherland and Darnhofer 2012 p.233). In their case, the changing economic viability of organic farming, through the iterative adaptive capacity of the habits, is shifting the agricultural attitudes towards organics, and the extent to which organic farming techniques reproduce capital for the participating farmers.

When mobilising the concept of habitus, it will also be necessary to include the related concept of hysteresis. As above, the concept of hysteresis relates to instances 
in which an individual's habitus becomes out of synch with the field in which they find themselves. If, for example, an individual changes field, or if changes in the field occur so quickly or to such an extent, that the habitus' capacity to adapt to new field characteristics cannot keep up. Riley (2016) argued that the concept of hysteresis can be brought to bear on the topic of agricultural attitudes towards environmental responsibility, because of the shifting field characteristics in the agricultural field effected by policy-shifts (such as cross-compliance) and changes in social or economic fabric of the field (such as alternative food strategies, and the rise of organics). In analysing his interviews, he employs the concept to pick out moments in which farmers were struggling to deal with the changed rules of the field, and the (slow) progress made by the habitus (dispositions, beliefs, attitudes, habits) in 'catching up'.

Beyond the specific confines of Bourdieusian research looking into agrienvironmental participation there a number of other, more recent studies relevant to this thesis. Thomas et al. (2020) focus on Bourdieu's concept of the habitus to look into knowledge-flows and behaviour change in the context of catchment sensitive farming and agricultural pollution. This malleable, adaptive makeup of the habitus forms a key part of the thesis, and is part of the reason why the above papers are so central to thesis as a whole. Whilst many papers have used Bourdieu's social theory, it is, however, the direct relevant of papers such as Sutherland and Darnhofer (2012) and Riley (2016) that make them of such central importance to the development and execution of this research project.

\subsubsection{Capital, in the context of this project}

A number of previous papers have employed Bourdieu's conception of capital to great effect in the context of understanding the agri-environmental attitudes in the farming community. Burton (2004), Burton and Paragahawewa (2011), Burton et al. (2008), Yarwood and Evans (2006), for example, have all deployed the concept to show how farmers, instead of pursuing activities purely because of their economic value, are moved to act in ways that help reproduce cultural capital. The desire to 
have well ploughed neat field, for example, holds a draw for the farmers beyond the financial efficiencies they represent: they reflect the managerial and technical prowess of the farmers, and so reproduce objectified cultural capital for the farmers, and the associated embodied cultural capital (Burton 2004, Burton et al. 2008). Similarly, Yarwood and Evans (2006) have shown how the choice of livestock breeds and the techniques used in their husbandry reflect the beliefs and competencies of the respective farmers and so are arenas in which farmers can reproduce cultural capital.

Those authors have also shown how the reproduction of cultural capital is associated with the productivist goals of high yields and the financial success of the farm. The well ploughed fields, for example, that reproduce cultural capital, do so because they reflect the farming competencies and skills of the farmer in the management of a financially successful farm. In his work, Burton has argued that despite the economic viability of AESs, the perceived loss of cultural capital associated with participation and the management techniques they mandate, arises from the deviation from the productivist behaviours. This, in turn, results in a deflated motivation for farmers to engage in AESs. For as long as the productivist objectives reign supreme in the farming community, and for as long as AESs mandate behaviours that deviate from those productivist objectives, there is a perceived loss of cultural capital associated with AESs such that even if they carry sizeable subsidies the farming community will remain resistant to participation (Burton et al. 2008).

To shed light on the reproduction of capital in the agricultural field, the concept of 'roadside farming' has been developed (Burton 2012, Seabrook and Higgins 1988). Given that the reproduction of capital (especially cultural and social capital) relies on the approbation of field members, the behaviours that are highly visible are more amenable to reproduction of capital than other, more discrete practices. Those visible behaviours, in turn, become the arenas in which the farmers are especially keen to distinguish themselves and communicate their farming competence. Fields ploughed in straight, parallel lines, for example, is a feature easily witnessed by other nearby members of the agricultural community (hence 'roadside farming'), and so is an arena in which the farmers sense an augmented capacity to earn (and lose) cultural 
capital (Burton 2004). The concept does not mean that it is only the practices that are literally visible from the road near the farm that are capable of reproducing capital. Farmers, as with members of any field, internalise the rules of the field and the judgment of other field members, even where, strictly speaking no external judgement takes place. Rather, the concept is deployed to show how the farmers have an especially keen desire to communicate their competence to the other farmers (field members) through highly visible practices, such as those visible from the roads near their farm holdings.

As we have seen, of all Bourdieu's tools used in the context of agri-environmental behavioural and attitudinal research, his notion of capital has been of greatest importance. Capital, that is, has been most useful in previous efforts to understand how environmentally sensitive farming techniques are regarded by members of the agricultural community, and how that regard interacts with the individual's likelihood of adopting such behaviours. It is expected that in this research project, too, capital will play a similarly central role. In inquiring into its research questions, the project is particularly interested in the capital (in all its three Bourdieusian varieties) the farmers believe is associated with agri-environmental behaviours, what symbolic dividends they expect to reap in engaging in environmentally sensitive management, and how they perceive other farmers when they engage in such activities.

There are also hints about how Bourdieu's concept can be brought to bear on rural sociological research from papers beyond the strict confines of agri-environmental attitudes and behaviour. Wynne Jones (2017), for example, looked into the importance of social and cultural capital in the maintenance of social relations in Welsh farming communities, and the knock-on effects of knowledge sharing and cooperation. Whilst such papers help demonstrate the wieldy and adaptive power of Bourdieu's social theory, the topic of the paper has only passing relevance to the focus of this research. The value of such papers, in the context of this thesis, lies in its ability to demonstrate how Bourdieusian research can be mobilised in social empirical research. 


\subsubsection{Conceptualising the good farmer}

The concept of the good farmer is one that reoccurs in the relevant literature, and although not part of Bourdieu's own writing, is heavily influenced by his theory. The concept relates to the behaviours and characteristics that are capable of reproducing capital for the respective farmers. It communicates characteristics of the 'rules of the game', the habitus of the individuals, and the capacity that different behaviours and artefacts have to reproduce capital. It functions, therefore, as a shorthand for a strategy to be employed, the symbolic order of the field resulting from the adoption of that strategy, and the perceived legitimacy associated with adopting the strategy.

The precise contours of the concept are, however, slightly ambiguous in the literature. Some papers (Burton 2004), for example, have used the idea as a sort of idealised 'identity' towards which the farmers strive to imitate. In such a conceptualisation, the good farmer has platonic form that pertain to the wider productivist goal of managing a financially successful farm with high levels of production. In others (Sutherland and Darnhofer 2012 for example), the good farmer is less an identity construct, and more a short hand for the behaviours that are associated with the promotion of the relevant farmers in the symbolic hierarchy of the field. As has already been noted, the different papers also tend to frame the construct as being either capable of change or as inert. Burton (2004), for example, explains how there is a resistance among the farming community to participate in agri-environment schemes because of a perceived loss of cultural capital associated with the adoption of the prescribed agri-environmental management techniques due to the deviation from the good farmer ideal, and the associated productivist goals of high yield. The implication thereof is that the good farmer is not just momentarily incompatible with the land management techniques promoted by AESs but will be incompatible in perpetuity because of the immutable characteristics of the good farmer. Riley (2016) and Sutherland and Darnhofer (2012), on the other hand, use the concepts of hysteresis and habitus change to explore how the good farmer ideal is constantly adapting to changing societal and policy landscapes.

This project needs, therefore, to articulate which of the conceptual variants will be used. Due to the selection of Bourdieu's concept, it will be preferably to leave behind 
the associations the concept has with an 'identity' with immutable characteristics. Bourdieu's theory aims to frame human behaviour as being shaped and reshaped by the societal conditions the individual finds themselves in, and so it is conceptually problematic to implicate a concept of an 'idealised identity' that is unresponsive to changing field conditions. Further, the concept of 'identity' is itself heavily laden with its own conceptual heritage (self-identity theory, identity salience theory), and to implicate the concept of the good farmer vis-à-vis the good farmer identity may frustrate the project's efforts, as opposed to further them.

The research project must, instead, be equipped to understand how the good farmer concept has changed and is in the process of ongoing change. When Bourdieu talks of the reproduction of capital, it is always in relation to the rules of the game (field characteristics). Those rules, which are shaped and reshaped by the external world and the changing pressures and opportunities faced by those within it, are similarly flux. As a result of these changes, the strategies that field members can employ to reproduce capital shifts changes, too. The research project needs, that is, to build into the good farmer concept a diachronic capacity to include new strategies and beliefs.

In the context of this research project, the good farmer concept will also only be inspected in relation to agri-environmental practices and environmental ideas. Whilst there will inevitably be a wide range of different features of the good farmer construct that pertain to the reproduction of different capitals, they aren't necessarily germane to the project's research questions. Yarwood and Evans (2006), for example, mobilised Bourdieu's social theory and the good farmer construct to look at how different livestock management practices reproduced cultural capital, and the motivational impact that those rules of the game had on Welsh livestock farmers. Insofar as this research project is looking at the attitudinal and behavioural impacts of participation in ELS and the development of environmental attitudes in the agricultural field, the position that different stock management practices occupy in the good farmer concept are not important (except where they have a bearing on the manager's environmental attitudes). The project is not, in other words, attempting to produce an exhaustive account of what behaviours fall under the rubric of the good farmer - but is instead just using the good farmer concept and Bourdieu's social 
theory to illuminate the development of environmental attitudes, and the adoption of environmental management practices.

Being a good farmer will be unpacked, therefore, as a set of behaviours and strategies, that are being constantly recalibrated to fit the changing field conditions. Or, understood in Bourdieusian terms, the rules of the game (that determines which artefacts and behaviours reproduce capital, and which do not) is able to change in accordance with the changed/changing field characteristics. The strategies developed through the (re)generative habituses of the field members (farmers) change in accordance with these new characteristics and rules.

\subsection{Conceptualising environmental management practices}

Over the previous chapters, and over the course of the rest of the research project, the concepts of environmental management practices, environmentally sensitive management practices or pro-environmental management practices will be frequently employed. What these terms mean is, however, contested. The way in which 'nature', and the understanding of the link between different agricultural management practices and the wellbeing of the rural environment differs between farmers, academics and scheme officials (Morris 2006). The literature around the topic seeks to map out what these differences are, what this means for the success of different agri-environmental interventions, and how to bridge between the different knowledge systems (Burgess et al. 2000, Juntti and Potter 2002). Whilst the aim of this research project is not to contribute to this particular body of work, it nevertheless needs to be mindful about the different ways in which the above terms can be understood by different actors, all of whom occupy different positions in the wider agricultural industry (farmers, policy makers, scheme officials, researchers).

The project, in particular, needs to be explicit in what it means by those terms given above, and justify why those definitions are being adopted. For future reference, the terms given above (environmental management practices, environmentally sensitive management practices and pro-environmental management practices) will be used synonymously and they will largely pick out the set of practices as promoted by the 
ELS scheme. The project is, in part, seeking to gauge the long-term behavioural impacts of ELS, and it stands to reason that the ELS's particular version of 'environmental management practices' (i.e. the practices promoted by the scheme, set out in the menu of options form which a scheme contract is formed) should be used as the metric by which the scheme's impacts are judged. Through the scheme, participants are obliged to adopt scheme-promoted management practices, they are provided information about the practice's expected environmental benefits, and details on how to properly implement them on the farm. These components of scheme participation are expected to be important factors in the scheme's potential to effect lasting behavioural changes. As a result, it is those behaviours that need to be covered when the discussion centres around the adoption of environmental management practices.

Where practices are introduced by research subjects that they self-identify as falling under the rubric of environmental management practices, they too may be considered in the research project's analysis. If some manager is, for example, commenting on some practice that is being constructed as having an environmental purpose, or if they pass comment on the adoption of such a practice on a nearby farm - even if the practice is not included in the ELS scheme - such insights can help pick out the position that environmental practices occupy in the rules of the game, and the capacity for such practices to reproduce different capitals. The primary focus will, nevertheless, be on ELS practices and, as above, the use of environmental management practices (or synonymous terms, above) will capture the sorts of practices contained in the ELS scheme.

There is, of course, considerable debate about the effectiveness of AES management practices in terms of their direct environmental impacts (Lastra-Bravo et al. 2015, Kleijn and Sutherland 2003), and of ELS's impacts in particular (Hodge and Reader 2010). In using ELS practices (potentially along with other management practices, too) as a proxy for environmental management practices, the project is adopting a value-neutral position on the extent to which those practices are delivering environmental value. This is not perceived as problematic, however, given the particular focus of the project's research questions. As described in Chapters 1 and 2, 
the research is not about gauging the environmental impacts of the scheme, but rather the long-term social, attitudinal and behavioural impacts. Using the ELS practices (including their long-term adoption, or the perceived legitimacy they have in the wider field as an indicator of the position they occupy in the rules of the game) as metrics in this regard is, therefore, appropriate. Insofar as considerable research went into the development of the scheme options, and the environmental improvements they are capable of effecting when being adopted, the project is not seeking to verify or disprove whether these improvements are being realised or not.

For reference, the following three tables detail which management practices fall under the rubric of environmental management. All the options and descriptions are lifted from NE's ELS handbook (Natural England 2013). The first (table 3.1) describes those relevant to arable land, the second (table 3.2) those relevant to livestock and grazing land, and the third (table 3.3) management practices that pertain to all different types of agricultural land. The tables are not exhaustive but present the management practices most relevant to this research project.

\begin{tabular}{|c|c|c|}
\hline Shorthand & Details of practice & Expected environmental improvement \\
\hline Buffer strip & $\begin{array}{l}\text { Leaving an uncultivated strip along a } \\
\text { watercourse. The ELS scheme has provisions } \\
2,4 \text { and } 6 \text { metre strips, all of which secure a } \\
\text { different number of scheme points. }\end{array}$ & $\begin{array}{l}\text { Protect the watercourse from run off } \\
\text { of excess agricultural chemicals; reduce } \\
\text { erosion of river banks; provide habitat } \\
\text { for small mammals and ground nesting } \\
\text { birds }\end{array}$ \\
\hline $\begin{array}{l}\text { Grass strips, } \\
\text { grass } \\
\text { corners }\end{array}$ & $\begin{array}{l}\text { Areas around the side of a cultivated field that } \\
\text { are left uncultivated, allowing grass to grow. } \\
\text { ELS has provisions for strips of different sizes. } \\
\text { The same management technique can be } \\
\text { located in corners of fields, specifically } \\
\text { targeted for areas in which it is difficult to } \\
\text { move agricultural machinery. }\end{array}$ & $\begin{array}{l}\text { Provision of habitat for ground nesting } \\
\text { birds, small mammals, reptiles. }\end{array}$ \\
\hline $\begin{array}{l}\text { Wild flower } \\
\text { strips }\end{array}$ & $\begin{array}{l}\text { Similar to the above option but includes the } \\
\text { cultivation of a pre-determined set of flowers. }\end{array}$ & $\begin{array}{l}\text { Provision of habitat for ground nesting } \\
\text { birds, small mammals, reptiles. } \\
\text { Additional availability of nectar to } \\
\text { encourage insect life, especially bees. }\end{array}$ \\
\hline $\begin{array}{l}\text { Bird cover } \\
\text { strips }\end{array}$ & $\begin{array}{l}\text { Similar to the above option but includes the } \\
\text { cultivation of a pre-determined set of } \\
\text { vegetation to encourage bird life. }\end{array}$ & $\begin{array}{l}\text { Provision of habitat for ground nesting } \\
\text { birds, small mammals, reptiles. }\end{array}$ \\
\hline Beetle banks & $\begin{array}{l}\text { The establishment of a grassy ridge through } \\
\text { the middle of a field, running from one end to } \\
\text { another. }\end{array}$ & $\begin{array}{l}\text { Provision of wildlife corridors to } \\
\text { encourage birds, small mammals and } \\
\text { insects }\end{array}$ \\
\hline $\begin{array}{l}\text { Over-winter } \\
\text { stubble }\end{array}$ & $\begin{array}{l}\text { Leaving the short stubbly remains of a crop } \\
\text { uncultivated after the crop has been } \\
\text { harvested. }\end{array}$ & $\begin{array}{l}\text { Provide a food source for seed-eating } \\
\text { birds over the winter. }\end{array}$ \\
\hline
\end{tabular}


Table 3.1 Table depicting environmental practices, relevant to arable land, as per the ELS scheme

\begin{tabular}{|l|l|l|}
\hline Shorthand & Details of practice & Expected environmental improvement \\
\hline Buffer strip & $\begin{array}{l}\text { Leave an area alongside a watercourse } \\
\text { ungrazed, allowing for longer grasses to grow. } \\
\text { This is typically achieved by fencing off the } \\
\text { target area, preventing the stock from } \\
\text { entering. }\end{array}$ & $\begin{array}{l}\text { Protect the watercourse from } \\
\text { agricultural pollution; provide a habitat } \\
\text { for mammals, birds, insects; stop } \\
\text { livestock from entering the } \\
\text { watercourse. }\end{array}$ \\
\hline $\begin{array}{l}\text { Low-input, } \\
\text { permanent } \\
\text { grassland }\end{array}$ & $\begin{array}{l}\text { Area that is considered permanent grass is } \\
\text { managed with low or very low input of } \\
\text { agricultural chemicals (slightly different } \\
\text { options are available which return different } \\
\text { points in return for different levels of } \\
\text { permitted application). }\end{array}$ & $\begin{array}{l}\text { Improved soil quality, reduced risk of } \\
\text { run-off into watercourses, reduced risk } \\
\text { of soil erosion }\end{array}$ \\
\hline $\begin{array}{l}\text { Management } \\
\text { of rush } \\
\text { pastures }\end{array}$ & $\begin{array}{l}\text { In fields with a sufficiently high density of } \\
\text { rushes, the fields are grazed and the rushes } \\
\text { cut only at certain times of the year }\end{array}$ & Provision of habitats for birdlife. \\
\hline
\end{tabular}

Table 3.2 Table depicting environmental practices, relevant to grazing land, as per the ELS scheme

\begin{tabular}{|l|l|l|}
\hline Shorthand & Details of practice & $\begin{array}{l}\text { Expected environmental } \\
\text { improvement }\end{array}$ \\
\hline $\begin{array}{l}\text { Hedgerow } \\
\text { management }\end{array}$ & Cut hedgerows every other year & $\begin{array}{l}\text { Encourage a particular growth } \\
\text { pattern in the hedge to ensure it } \\
\text { provides appropriate habitat for } \\
\text { smaller birds and mammals. }\end{array}$ \\
\hline
\end{tabular}

Table 3.3 Table depicting environmental practices, relevant to agricultural land, as per the ELS scheme

\subsection{Conceptualising post-scheme behaviour}

An important strand of the research project is an analysis of the long-term management impacts of scheme participation. To help conceptualise and navigate this research theme, other concepts and terms will here be introduced.

The decisions farmers make on how they manage the land falling out of an AES is termed 'the end of contract problem' (Whitby 2000). Critics of the AESs claim that the reliance on monetary incentives in the promotion of agri-environment management techniques ensures that when the schemes come to an end, so too do the farmer's commitment to the scheme's environmental objectives (Hodge and Reader 2010, Burton and Paragahawewa 2011). The criticism maps onto a wider problem 
associated with any PES instrument in which actors are paid to adopt certain proenvironmental behaviours (Engel et al. 2008).

The criticism is couched in a behavioural analysis of motivations that holds that extrinsic incentives (usually monetary) can harbour powerful motivational impacts, but often fail to effect long-term shifts in the behaviours of the recipients (Deci et al. 1999). The farmer's commitment to the prescribed behaviour of an AES, so the argument goes, is so heavily dependent on the financial incentives, that once the payments come to an end, the ongoing commitment to the behaviour cannot be expected from the scheme participants. The issue is typically unpacked in terms of the 'crowding out' theory (Darragh and Emery, 2018), which maintains that financial rewards suffocate or 'crowd out' intrinsic environmental motivations.

The crowding out hypothesis falls under the rubric of economic theory and has been deployed to inspect the motivational impacts of subsidisation in the context of blood donation (Titmuss 1970), private investment and state debt (Freidman 1978), charitable contributions (Abrams and Schitz 1978). The theory has clear aptitude in the context of our project. Does the adoption of environmentally sensitive practices, once the dynamic of being paid in return for their adoption is established, becomes contingent on continued monetary incentives? Once payments end (i.e. at the end of a scheme contract) do the farmer's commitment to the scheme-prescribed end, too?

In the context of AESs, the theory is not universally accepted. Some maintain that agri-environmental initiatives are frequently accompanied by the long-term commitment to the activities and attitudes promoted by the particular scheme. Hiedenpaa and Bromley (2014), for example, argue that the financial incentives provided in PES-style schemes help effect a break in the participant's land management habits, helps raise awareness of managerial alternatives and can help generate new 'extra-scheme' habits. Others have added empirical weight to this idea and have demonstrated a commitment to a land management mandated by a scheme, even once the scheme payments cease (Roberts and Lubowski 2007). To ensure this research project is able to directly contribute to this subset of the literature, the 
crowding-out theory will be used when discussing the post-scheme management of options.

The concept of 'additionality' will also be deployed. Additionality refers to the policy-value of an instrument (in our case ELS), beyond that which is technically paid for (Bennett 2010) In AES terms, the concept of additionality has been applied to a number of different phenomenon: the biodiversity improvements in fields with AES options not specifically targeting biodiversity objectives (Ulber et al. 2011); the capacity for schemes to catalyse long term commitment to the objectives of the initiative in question (Huttunen and Peltomaa 2016); and the diffused economic impact that scheme payments can have on regional and local communities (Courtney et al. 2013). In the context of this research project, the additionality refers to the long-term upkeep of a scheme option, beyond the scheme payments. Where ELS has been successful in catalysing long-term behavioural changes, it can be said to have good additionality.

In contrast to a scheme's potential additionality, there are also instances where an AES effectively pays a participant to adopt some practice that they were, in fact, already availing of. The idea of 'deadweight' is used to help conceptualise the problem. In such instances, the cost-effectiveness of the scheme is low, because of money is being paid to managers to adopt behaviours that they were already adopting, and would have adopted, irrespective of the scheme's intervention (Crabtree et al. 2001). Significant research has been done into an assessment of deadweight in ES's, inclusive of its ELS strand (Defra 2012).

With these conceptual features in place, we also need to know how they fit in with the project's wider theoretical framework.

\subsection{Conceptualising multifunctional agriculture}

The idea of multifunctionality, especially during the analysis of the phase 2 data, also plays an important role in the conceptual landscape of the thesis. The concept will briefly be explained here in the theoretical chapter of the thesis to ensure that when 
the concept emerges later on in the thesis, the details of the idea have already been made clear. The idea is related to the transition from productivist to post-productivist agriculture (Wilson 2007), and relates to the multiple functions that agriculture is capable of delivering (Boody 2005). Instead, that is, of just producing one good (i.e. food and fibre), agriculture is capable of delivering on a range of other public benefits - a healthy environment, biodiversity, access to green spaces, a stable rural economy (Renting et al. 2009). Agriculture's multifunctional potential is manifest in the policy landscape. Subsidies - Pillar 2 payments, and the Cross Compliance mechanism, for example, are all designed to create the economic and social conditions in which agriculture is just able to provide food, but also a whole range of other goods (Meyer et al. 2014). As we will see later on in the thesis (Section 7.3.1.5.2), these ideas are beginning to be encoded into the psychologies of the farmers who are being asked to deliver on these multifunctional objectives.

\subsection{Problems with Bourdieu's Theory}

The aim of this research project is not to offer an exhaustive account of the different criticisms levelled at Bourdieu's theory, or to respond to each of those respective issues. As with all theories that have gained as much traction as Bourdieu's, however, his theory has been the subject of considerable criticism. Before constructing a methodology around the theory, and before setting out on the data collection component of the research, it will be wise to note briefly what those criticisms are. This section will not aim to provide a conclusive retort to all those issues, but rather present them and offer a brief discussion on the responses that have been given.

One particular theoretical criticism claims that Bourdieu's habitus is unable to sufficiently distance his theory from a deterministic depiction of human behaviour (Yang 2014). The habitus, in explaining how the life-experiences of an individual are imprinted on his bodily/mental dispositions, cannot sufficiently account for the role of human agency, and thus cannot help the theory perform the conceptual tight-rope act between a subjectivist and structuralist account of human practice. Jenkins (1982), for example, claims that "his scheme remains essentially deterministic and 
circular" because "objective structures produce culture, which determines practice which reproduces those objective structures" (Jenkins 1982 p.270).

There is also an ongoing problem with the impact that a researcher's subjectivity has on the objectivity of the results when conducting the research. In forcing the researcher to consider a subject's structuring effects and their individual agency, habitus encourages a break from a common-sense analysis of the individual's practice. It represents, as a result, a valuable tool in bridging the gap between theory and empirical research (Burke 2015). For some detractors, this Bourdieusian argument remains unconvincing. They claim that even the most diligent application of the Bourdieusian habitus in an empirical project cannot sufficiently distance the researcher from the researcher subject; that total reflexivity, even with habitus in the researcher's arsenal, is not achieved (Maton 2003). The mobilisation of the habitus (and the other associated components of the theory), will necessarily be done by the researcher(s), and will be characterised by their biases and subjective filters (habitus) and so the research will never have access to the objective nature of the subject.

In this way, many of the strategies Bourdieu recommends to ensure a sufficient objectifying distance between the researcher's subjectivity and his research subjects fall foul of a breed of the regressive fallacy. The inclusion of multiple researchers, or the act of recognising one's 'interested' role in the research, for example, do not address the problem, but just move the problem 'one step back'. Including multiple researchers cannot get around the fact that each has their own interested and subjectively loaded role within the project, and the public recognition of the fact that the researchers occupy the same research space as the research subject cannot get around the fact that he or she is still engaging in the research process through his/her subjective experience. Put in a more abstract way, whatever technique Bourdieu recommends a researcher employ to circumvent his biases or subjective interpretation will themselves also be characterised by the same biases and subjectivities as the research techniques are trying to evade (Maton 2003).

Criticisms are also levelled at Bourdieu's theory that relate to the scale and type of theory he presents. Sociological theories are often categorised as being either grand 
theories or mid-range theories (Bryman 2015). Grand theories are those that offer a more abstract and theoretical account of society and aim to provide a universal or overarching schema within which human behaviour can be understood (Blute and Armstrong 2011). The concept was initially developed by Mills in his The Sociological Imagination (Mills 1959) as a pejorative term to pick out the social theory presented by Parsons's The Social System (Parsons 1951). Mills called for a more focussed, empirically practicable sociological theory, and argued against the axiomatic assumption in grand theories that holds that there exists a single sociological uniformity that has the explanatory power to implicate any social behaviour arising in any social grouping (Mills 1959). Mid-range theories, by contrast, are those that can be used to generate sociological hypotheses, which can be empirically mobilised to falsify or prove the hypothesis (Merton 1968).

Bourdieu's theory, insofar as it attempts to capture a universal truth that governs behaviour in all socialised settings is constitutes a grand theory, and so is heir to those criticisms. Namely, that they represent an overly abstract, cumbersome and reductive formula for social behaviour. The theory is, however, specifically designed to arm the social researcher with a toolkit with which can be mounted for use in an empirical social research project, and so is potentially equipped to circumvent the worst of the criticisms targeted at purebred grand theories. Indeed, Bourdieu returns on numerous occasions to his theory's practicability for empirical work, claiming that his work is not the "conceptual gobbledygook... that is good for textbooks", but is instead "a set of thinking tools visible through the results they yield" (Wacquant 1989 p.50). As with his attempts to resist the need to subscribe to a strictly structuralist or agential account of behaviour, his theory aims to tread a fine line between the mid-range versus grand theory taxonomies used to categories sociological theories. The extent to which Bourdieu's theory simultaneously resembles both a grand theory and a mid-range theory is evidently of great interest (Walther 2014), but as with a number of other theoretical tangents touched upon on this chapter, is not of primary concern for this project. Further reading is recommended (see Jenkins 1992) to fully engage in the discussion. 
What is important for the thesis, however, is the stress Bourdieu places on the research practicability of his theory, and its constituent elements (habitus, capital etc.). To emphasise the wieldy, fieldwork-ready nature of his theory, Bourdieu constantly referred to it as a toolkit, or as his thinking tools. This linguistic preference will be echoed throughout the thesis, and continual reference will be made to such terms.

\subsection{Chapter conclusion}

The chapter has provided a fine-grained account of Bourdieu's social theory, and an explanation as to how his theory will be mobilised in the context of this research project. Further conceptual clarifications were then made: a precise explanation of how the good farmer concept will be used in the research project; and an account of how environmental management practices will be defined and why that definition was chosen. A brief introduction was also offered to some of the criticisms levelled at Bourdieu's theory. The following chapter will explain the methodology employed by the research project. 


\subsection{Chapter introduction}

Along with the adoption of a research theory, a number of other features of the project need to be described before the data analysis is presented. These include the creation of a research design (a qualitative or quantitative project, for example), the development of research materials (interview questions, surveys, questionnaires), the selection of a temporal and spatial location within which the research will be conducted, and the selection of a research sample on which the research will focus.

Each of these extant issues will form the focus of a subsection, below.

\subsection{Research design}

Before presenting the project's research design, it will be of great value to pause and recapitulate the research questions of the project. As presented in the introduction, the project is aiming to answer the following research questions:

1) What are the recent developments of land managers' agri-environmental attitudes, and how can Bourdieu's theory of capital, field and habitus inform our understanding of this development?

2) How effective, as a policy tool for securing environmental action from the farming community has ELS been (including the environmental activity beyond the individual contracts' duration)?

3) What are the minimum environmental standards managers are expecting of each other, how can Bourdieu's thinking tools help understand this process, and how can the concept of the bad farmer be developed to account for this process? 
4) What impacts will the Brexit process have on managers' willingness to engage in agri-environmental management?

As will be discussed below, the first two questions were those originally developed to attend to the project's research aim, and the latter two were created in response to the analysis of the data secured through the first round of interviews.

\subsubsection{Selecting a qualitative methodology}

Given that Bourdieu's work relies on the dissection and (re)interpretation of a given subject's attitudes, ideas, accounts and beliefs to develop an account of their habitus, their field, and their understanding of how capital can be reproduced, the project adopted an in-depth, qualitative interview approach. A cornerstone of any empirical project employing Bourdieu's research tools is that it builds on a 'thick' account of an individual's life, and not on large quantities of 'shallow' data as secured through a quantitative methodology (Nowicka 2015). A cursory review of the projects mentioned at the end of section 3.2 - He and Wang 2015, for example - reveals the non-negotiable need for a qualitative methodology when mobilising Bourdieu's theory in a social science project. The same is true of research papers in the field of rural sociology, generally - Rye 2006, Baker and Brown 2008; and those interested in the development of environmental attitudes in the agricultural community, specifically - Burton et al. 2008, Riley 2016, Huttunen and Peltomaa 2016, Sutherland and Darnhofer 2012.

Without exception, the above papers use qualitative methodologies, along with different interview approaches to generate a detailed account of the farmer's (changing) environmental attitudes. Burton et al. 2008 asked his farmer interviewees to arrange a set of flash cards (depicting different agricultural objectives such as profit, sustainability, biodiversity protection) according to their priorities, as a means of provoking a discussion of their values and behaviour. Riley (2016) used the ethnographic technique of 'walking interviews' with the farmers on their farmland, as a means of coaxing more detailed and intimate responses to the semi-structured questions of his interviews. Huttunen and Peltomaa (2016) used qualitative content 
analysis on in-depth interviews to depict the changes in farm practices and their changing concept of the good farmer. Sutherland and Darnhofer (2012) also used semi-structured in-depth interviews across two case-studies to mobilise Bourdieu's social theory to generate an analysis of the agricultural community's relationship with organic farming, and the re-alignment of organic farm techniques with respect to the 'good farmer' ideal.

In researching the shifting values of the agricultural community, the above research projects are concerned with the subjective construction of the farmer's values and beliefs, and the way that they, as members of the farming community ought to act. The projects are not, that is, concerned with a reductive analysis of the material make-up of the world (what practices are in place, the farm's agricultural output), but on the subjective and socially constructed world the interviewees inhabit. Insofar as the qualitative approach seeks to "interpret social phenomena, producing a rich understanding of the complex meaning social actors construct in their specific social environments" (MacPherson et al. 2000 p.50), their selection is apposite.

Their usage of semi-structured interviews, guided by interview prompts to help keep the interview on topic, is also revealing. Whilst the research projects are concerned with the farmers' subjective accounts of their beliefs and practices, the projects are nevertheless interested in one portion of that lived experience: their perception of the rural environment and their willingness to engage in pro-environmental management practices. The researchers have used the semi-structured interviews to focus in on that topic, specifically. The use of such a technique has significant academic precedent, and theoretical backing (see Opdenakker 2006 for discussion).

The technique can also help the project from becoming a fully unstructured, participant-observation, ethnographic study (LeCompte and Goetz 1982). Whilst such methodologies have been the centrepiece of many valuable research projects, it is typically employed by researchers aiming to develop a full and textured account of a small number of research subject's lives (Kawulich 2005). When mobilising a research project to inspect the environmental attitudes of a larger number of subjects, 
and the long-term impacts of some policy instrument, participant observation techniques are not as expedient as a semi-structured interview approach.

To acquire data that is amenable to the usage of Bourdieu's thinking tools, and to ensure the subsequent analysis was able to attend to the project's research objectives, therefore, semi-structured in-depth interviews were used. The interviews were guided by questions and prompts (described below) to ensure the interviews focused on the target research topics.

\subsubsection{Considerations for researching post-scheme behaviour}

The research project is interested in the development of agri-environmental attitudes with respect to a farmer's participation in ELS, and the impact that participation has had on their land management plans - especially in relation to the post-contract management of scheme options. This latter feature of the research project carries with it acute research obstacles. In particular, obstacles that could prevent the project from having direct access to the management techniques that end up being realised once the interviewee's ELS contracts come to a close.

These obstacles arise, in part, because of the legal and privacy features of ELS contracts. Contract holders are only able to be contacted by researchers for the extent of the contract, and so farmers cannot be contacted years after their contracts have come to an end to see what managerial plans have been realised for the land previously under scheme management. Whilst this was not an issue for the portion of the study concerned with the deployment of Bourdieu's tools in an analysis of the agri-environmental attitudes represented in the caucus of ELS participants, it could have been problematic for the portion concerned with the long-term management impacts of the scheme.

Simply put, questions could only be asked about how the interviewees expected to manage their land once their scheme contracts had ended, whilst their contracts were still in effect. Such a line of inquiry is, however, highly susceptible to a number of different vulnerabilities. The social acceptability (or desirability) bias, for instance, 
in which respondents report what they believe you (the researcher) want to hear from them, or provide responses that they believe are more socially desired or expected, may be problematic (Nederhof 1985). Such an issue results in the under-reporting of socially unfavourable acts, and the over-reporting of acts that are perceived to be socially desirable. This phenomenon stands to manipulate the statements made by the farmers and may have caused them to over-report the pro-environmental intentions they have for the land or practices falling out of scheme coverage.

A research design based on interviewing subjects about the expectations they have about their land management plans may also be undermined by the interviewer bias problem. That particular bias relates to instances in which an interviewee's perception of the interview process (location, research objectives, research techniques employed) or the interviewer (as being a figure of authority, or as someone with a vested interest in the interview responses) impacts the answers they are wont to give. The problem can prevent interviewees from communicating their 'real' motivations or behavioural tendencies, and instead can cause them to provide responses they perceive as being appropriate (West and Blom 2017). Despite the fact that the interviewer was a $\mathrm{PhD}$ student, with no particular vested interest in the farmers' environmental attitudes and behaviours, it is easy to imagine how they could have been regarded as an official of some description. If this was the case, then the farmers may have been motivated to provide answers in line with what they believe such an official would have wanted to hear, and may, again, have resulted in the over-reporting of their pro-environmental management plans for the land coming out of their AES contracts.

Researching farmers' land management plans is also vulnerable to a psychological phenomenon relating to the unreliability of statements made by an individual about how they plan to behave in the future (Epley and Dunning 2000). The 'selfprediction' problem, in the case of this research, highlights the dangers of using the farmer's declarations on how they plan to manage the land coming out of schememanagement as accurate predictors of how they will in fact manage their land. The above problems all map onto the wider issue of the intentions-behaviour gap. The intentions-behaviour gap refers to those instances in which someone (typically the 
subject of a research project) does not do what they intend to do, or what they claimed to intend to do (Sheeran 2002, Sheeran and Webb 2016). In the context of our research, the intention-behaviour gap may open between the predictions the interviewees give for how they will manage their land falling out of scheme coverage, and how they actually manage that land once they are free from their scheme obligations. For this reason, methodological manoeuvres need to be taken to ensure the reliability of the research findings about the interviewee's post-scheme management decisions.

\subsubsection{Selecting a follow-up methodology}

To navigate this issue, whilst remaining compliant with the privacy provisions contained in ELS contracts, the research project adopted a follow-up methodology. Interviewees were contacted and interviewed whilst their ELS contracts were ongoing for the first interviews - and at the end of each interview permission was sought from the interviewees to contact them at a later date, after their respective ELS contracts had finished. In this way, the first round of interviews was able to focus on an assessment of the social and psychological impacts of ELS (i.e. the theme that could be meaningfully researched whilst the interviewees involvement in the scheme was ongoing); leaving the second round of interviews (arranged after the conclusion of contracts had ended) to inspect the long-term management impacts of the scheme. In terms of the project's research questions, the first round of interviews largely focussed on research question 1, and the second phase, research question 2 .

The above methodological decision also afforded an additional benefit to the project. Namely, the opportunity to identify important research themes that were not targeted by the project's initial research questions. The project originally identified two research questions ( 1 and 2, above) central to answering the project's main research objective. Over the course of the first round of interviews, and during the analysis of the phase 1 data, important themes emerged that were also relevant to the project's research objective. These themes were then developed into distinct research questions, (3 and 4) and subsequently integrated into the interview schedule for the second round of interviews. 
These methodological features are best expressed in terms of deductive and inductive research approaches. The deductive approach sees researchers apply a predetermined theory to the data for analysis purposes, whilst the inductive approach has the researcher iteratively generate theory and structure as the research and analysis process unfolds (Burnard et al. 2008). Having selected target research themes and having decided to use Bourdieu's theory as the project's theoretical framework, the project falls in part under the rubric of a deductive methodology. In employing a semi-structured interview schedule that allows for the organic introduction of research themes, the project does however, have an important inductive component.

In this way, the research adopted a hybrid approach - accommodating both a deductive element that targets certain research themes as well as an inductive element that will facilitate an iterative renewal of research themes for the follow up interviews. In the context of our project, the deductive themes are those expressed in research questions 1 and 2 - relating to the long-term management impacts of ELS, and the use of Bourdieu's thinking tools to inspect the development of agrienvironmental attitudes; and the inductive themes are those expressed by research questions 3 and 4 -relating to the development of the bad farmer concept, and the impact that Brexit is having on the adoption of agri-environmental practices. Such a methodology has significant academic precedent. By way of example, Fereday et al. (2006) and Brixey et al. (2007) both discuss their adoption of a similar methodology in different areas of healthcare provision.

The following schema captures the division of the project's research themes across the two rounds of interviews. It also indicates how the analysis of the two data sets will be written-up and presented. Each will form the subject of its own chapter, before a final chapter brings together the project's findings. 


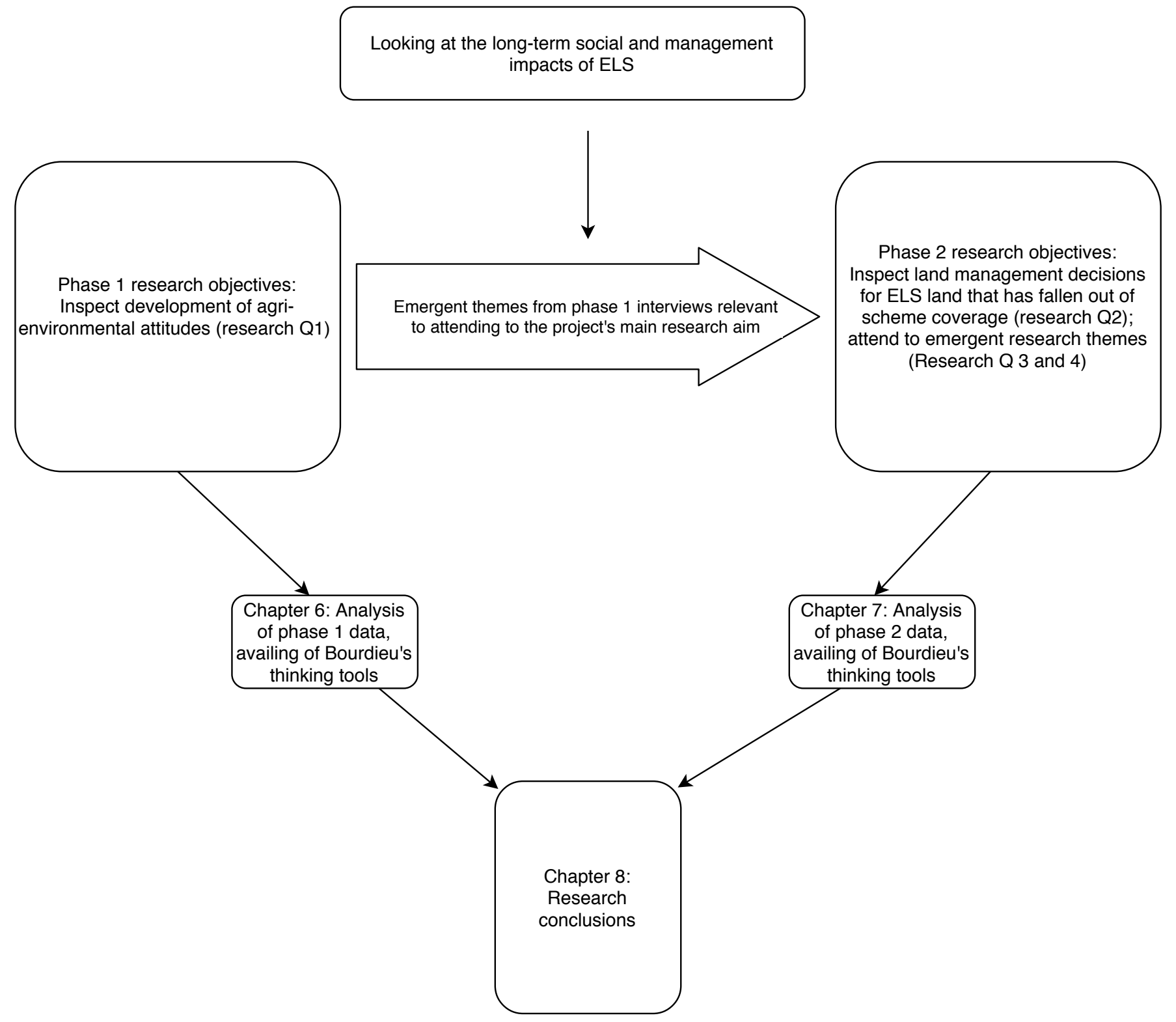

Figure 4.1 Methodological schema

Due to the time restrictions of the $\mathrm{PhD}$, decisions about when follow-up interviews could be arranged were highly restricted. The project was not, for example, afforded the luxury Riley (2016) who was able to conduct his interviews with farmers 10 years after the first round of interviews. Instead, follow-ups were arranged roughly one year after the initial interview. This allowed for the respective ELS contracts to come to a close, and for the participants to have made meaningful decisions about 
the ongoing management of the relevant land - all without placing too great a time constraint on the analysis of the interviews with respect to the end of the PhD's 3year funding structure.

The need to arrange follow-up interviews also informed the process through which the project's research sample was identified. As farmers needed to be contacted whilst their contracts were still ongoing; as the follow-up interviews needed to take place after a significant time has passed after their contracts' conclusion (to allow them to have taken meaningful decisions about how they plan to manage the land in their erstwhile ELS contracts); and as both rounds of interviews needed to be completed well within the $\mathrm{PhD}$ funding structure, the initial interviews were conducted with farmers in spring-summer 2017, during which time their contracts were very shortly due to end. In this way, the follow-up interviews were able to be conducted a year later (after which the respective managers had made decisions about the ongoing management of their land) in spring-summer 2018, allowing for the remaining time of the studentship (September 2018-April 2019) to be committed to the transcription, analysis and write-up processes. Fuller details about how these research details were realised in the project's methodology will be given, below.

\subsubsection{The comparative case-study approach}

The project also employed a comparative case-study methodology. Comparative research projects select research populations from different areas, demographics or lifestyle choices and subject the different groups to the same research procedure. The resulting data are then compared as a way of establishing whether the chosen research variable has an impact on the research topic of the project, and if so, what sort of mediating effect the variable has.

Case-study projects select smaller research population groups and inspect their chosen research topic in situ to develop a detailed, ground-level account of the phenomenon in question. A case-study methodology is an "an empirical inquiry that investigates a contemporary phenomenon within its real-life context; when the boundaries between phenomenon and context are not clearly evident" (Yin 1984 
p.23). The case-study approach, especially in the context of social science research, is recognised as a rigorous research strategy (Hartley 2004, p.323). The approach is capable of generating highly textured, ground-level perspectives on a given area of study and is well equipped to study the factors at play in assessing why certain agents act in the way they do (Bryman 2015). In our case, this amounts to an analysis of the different attitudes and behaviours represented in participants of the ELS scheme, especially in relation to the adoption of agri-environmental practices. For the case-study methodology, the importance lies in assessing the existence of different behaviours, artefacts, and the reasons for their existence, and is not concerned with the distribution of those artefacts or practices in the wider research population (Hartley 2004).

The combination of the comparative and case-study methodologies amounts, therefore, to the selection of two (or more) groups, subjected to a detailed research investigation, and where the resulting data are analysed and compared to get a fuller understanding of the target research topic. The technique has clear aptitude for our research project. In seeking to understand the impact that scheme participation has on the participant's environmental behaviour and attitudes, the project must recognise how the farming culture within which a given farmer operates is liable to play an important role in influencing the development of their environmental attitudes and practices. As is shown in the Swanwick et al. (2007) map, below, the different areas of the country are associated with different farming systems. Because ELS has different options relevant to different farm systems (described in Chapter 3), the way that the scheme influences an area's appearance will differ accordingly. Hodge and Reader (2010) conducted a thorough analysis of the distribution of different ELS options across the country relating to the first 5 years of the ELS scheme and charted the different scheme options represented in contracts and the location of those contracts. Hedge options are most highly represented in the midlands (associated with the smaller fields used in livestock farming); boundary options and other options relating to the removal of arable land from production were concentrated in the east; and grass management options in North and in the West all as per the farm systems most heavily represented in those respective regions. 


\section{Character Types}

Upland agricultural landscapes

Upland fringe dairy and stock rearing

Western dairy and mixed agriculture

Coastal areas

Chalk and limestone mixed arable landscapes

South eastern wooded and mixed agricultural landscapes

Eastem arable aricultural landscapes

Other

Urban

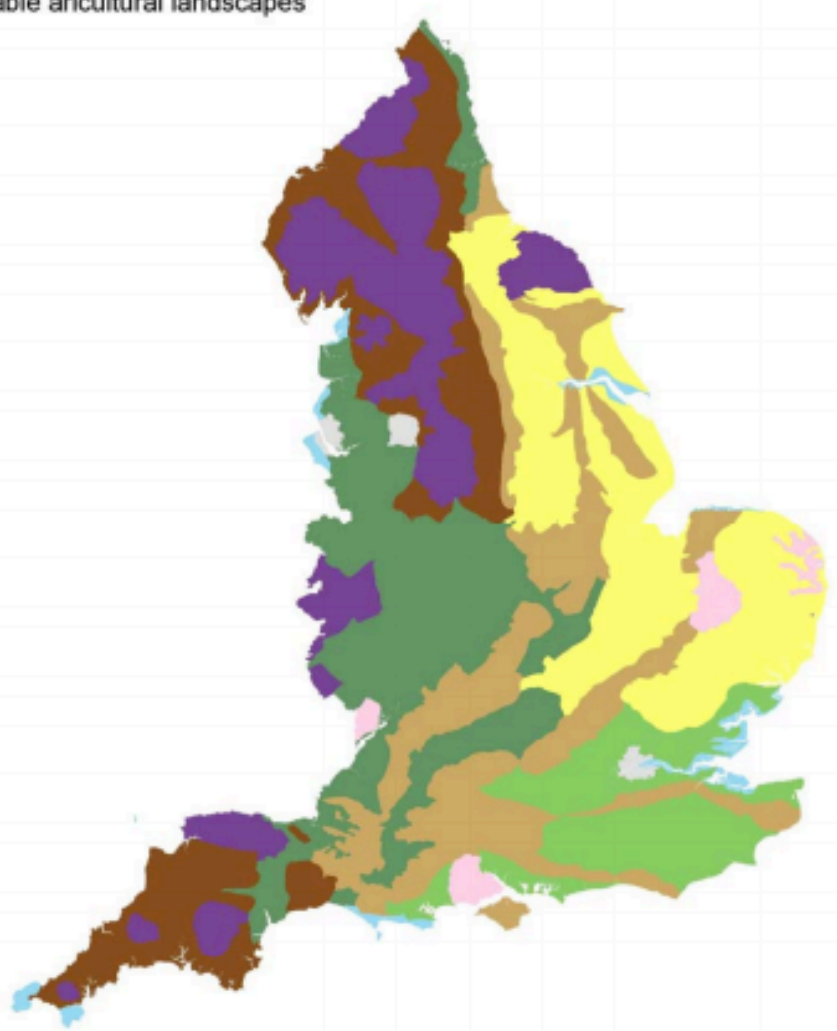

Figure 4.2 Swanwick's typology map, taken from Swanwick et al. 2007

Given the relationship between the different geographical areas of England, the farm systems with which those areas are associated, and the different ELS options targeted towards those different farm systems, it is of potential research interest to contrast the development of environmental attitudes within the agricultural community from two different areas of England. As discussed by previous authors (Seabrook and Higgins 1988, Burton 2004), the appearance of a given management practice is an important feature in its ability to reproduce different levels of capital and, as a result, its relationship with the good farmer concept. This idea is referred to as the symbols of the good farmer - the physical and visible manifestations of an individual's 'good farmerness', or cues which mark a given farmer out as one successfully navigating the rules of the game. 
The project's comparative element was developed to gauge whether the different farm systems represented in an area, and the differences this implies for the appearance of the ELS scheme, has had an influence in the development of the rules of the game in the field, and management practices and features that constitute symbols of good farming - in particular, relating to the adoption of environmental management practices. This feature of the project's methodology was included to add nuance and texture to its response to research question 1. What commonalities are there in the rules of the game in distinct areas of the country, what differences are there, and what role has ELS played (with respect to the different appearance it takes on different farm systems) in this development.

\subsubsection{Realising the comparative, follow-up case-study methodology}

Upon the recommendation of methods literature relating to qualitative comparative projects (Sandelowski 1995) and in accordance with other projects invested in similar themes availing of similar methodologies such as Riley 2016, Sutherland and Darnhofer 2012), each case-study targeted 25 interviewees. 25 interviews were expected to provide enough depth required for a meaningful analysis of the agricultural community, without saddling the project with an untenable target. For practical reasons the comparative element of the project was limited to two separate areas. As each case-study needs to be comprised of the determined 25 interviews, any more than two would have represented an undertaking too large for a $\mathrm{PhD}$ project, and any fewer would have deprived the project of its comparative component. Setting a target of 25 interviews for each of the two case-study areas was also intended to be high enough to mean that should the target not be met, enough data would still have been collected to carry out a meaningful analysis. 20 interviews for each of two case-study areas was identified as the minimum acceptable figure for the research project to function properly.

The size and location of the two case-studies was also carefully considered. The comparative element was developed to contrast areas of differing farm systems, and the different visual representations of the ELS scheme. If the case-study areas were too large, then the project would have lost its ability to meaningfully compare the 
respective symbols of good farming and rules of the game. The project needed, in other words, to compare two sufficiently compact areas with distinct characteristics, populated largely by a certain farm system. If, for example, the two case-study areas were vast geographical areas slurring across numerous regions characterised by different farm system, then the comparative tools used to compare the areas, the rules of the game and the symbols of good farming would lose their relevance. For this reason, the two case-study areas were developed to be confined largely within the Agricultural Landscape Type boundaries as defined by Swanwick et al. 's 2007 map, above. The first case study area, developed to capture an area of mixed and livestock farming is located in Swanwick et al.'s West Dairy and Mixed landscape typology, and the second, developed to capture an area of predominantly arable farming in the Eastern Arable and Chalk and Limestone Mixed Arable landscape typologies (Swanwick et al. 2007). Note, the eastern case-study area spreads across two of the typology areas. This was permitted because both typology areas were of arable designation. Their being split into two typologies is predicated on the different soil compositions they contain, and not on their contrasting make-up of the different farm systems. Details of both of these will be provided in full detail in Chapter 5 .

As described above, a number of temporal restrictions were also placed on the development of the methodology. These amount to the following considerations:

- Initial interviews needed to be done in the closing stages of the farmer's ELS contracts to ensure they could talk most meaningfully about their scheme experiences, and for them to be actively engaged in the internal conversations about the management of their land after the scheme's conclusion;

- Farmers could not be contacted or interviewed after their contracts had finished unless they have given their prior consent;

- Follow-up interviews must be conducted around a year after the completion of the farmer's ELS contracts, for them to have made and actioned decisions about the management of the land previously under scheme management; 
- The PhD is timetabled to finish in April 2019, and so the first round of interviews must take place in spring-summer 2017, and the follow-up interviews for spring-summer 2018.

To accommodate the above requirements, the project initially selected farmers whose contracts ended in April-August 2017 - meaning the contracts signed in AprilAugust 2012 (with ELS contracts lasting 5 years). The five-month period for ELS contract start/end dates was selected to ensure that sufficiently compact case-studies could be generated. If, for example, the case-study limited itself to the ELS contracts ending in just May 2017, then, for the case-studies to ensure they met the target 25 interviews, the case-study areas would have had to have been too large to attend to the demands of the comparative element of the project, and would likely have extended beyond the landscape and farm system typology boundaries described by Swanwick et al. (2007). There are only a finite number of contracts signed each month and, for the case-studies to be sufficiently compact, the acceptable range of contract start-dates needed to be broad enough to allow for the requisite 25 interviews

Each case-study was comprised of a cluster of National Character Areas (NCAs). (2007). NCAs are the administrative unit around which Swanwick et al.'s typologies was designed, and within which AES organised. In the name of continuity, the project will be organised around these designations.

A final note on the case-study design. Different terms are frequently used in empirical projects to capture subtly different features of the methodology.

Target population - the total group of people or things with a shared characteristic, about which the research is attempting to draw some generalised features. In this case of this project, this is the total number of all ELS participants, across the entirety of the scheme's duration and geographical extent.

Accessible population - the portion of the target population, limited by research practicalities, timings, finances etc. to which the researcher has access. In the case of 
this project, this represents the ELS contract holders, with contract start/end dates falling in the prescribed period (April-October 2012/2017), operating in the casestudy areas (described below).

Research sample - the group within the accessible population actually included in the data collection process. In our case, the farmers and land managers, from the case-study areas, with whom an interview is completed.

\subsubsection{A note on ELS, and ES}

Before presenting the case-studies, it is necessary to pause for a moment to clarify some details about ES, where the ELS tier sits within it, and what this research project is concerned with.

As previously described, alongside the ELS tier there was the OELS and UELS schemes - offering the same sort of broad and shallow scheme design, but with options targeted towards organic and uplands farmers, respectively. Alongside those, there was HLS. HLS was a targeted, competitive scheme only available to managers who had land of particular environmental value. They chose from a set of more demanding options for their HLS-applicable land and were reimbursed with higher payments. HLS contracts worked in conjunction with either ELS, OELS, or ULS contracts. Farmers, that is, signed an O/U/ELS contract for the whole farm, and then just chose particular areas of the farm for their HLS contract, and chose the relevant options from the HLS menu for those areas. The HLS contract 'sat on top' of the lower level ELS contract. Such contracts were described as an OELS+HLS, UELS+HLS or ELS+HLS contract. Contracts with an HLS component lasted 10 years, compared to the 5 years of a purely O/U/ELS contract.

This research project is interested in the ELS tier of the scheme, and the effects it has on the participating farmers in terms of their ongoing management plans and their environmental attitudes. There is, therefore, a potential ambiguity in knowing whether this means farmers with exclusively ELS contracts, or if it includes farmers with ELS contracts including an OELS, UELS or HLS component. For the sake of 
clarity, it is here reiterated that the project is concerned with the farmers holding only ELS contracts.

The scheme experiences associated with the different parts of ES (i.e. the different management obligations, rewards associated with HLS ELS, UELS or OELS), along with the different motivations there are for choosing one type of contract over another are divergent enough to mean that each scheme's impacts (in terms of the management changes and attitude changes they are likely to effect in the participating farmers) need to be the focus of a separate study. The motivations for becoming an organic farmer, for instance, implicates a separate body of literature relating to the alterity of organic farming, and the diffusion of organic techniques in tightly-knit communities (Padel 2001). Understanding how OELS affects the participating farmer's attitudes and management plans would need, therefore, to be situated in this organic-specific literature. The same is also likely to be true of uplands farmers, and the particulars of their particular identities and attitudes. Whilst these variables may be of evident interest, it represents an extra layer of analysis too great for the scope of the $\mathrm{PhD}$. Different questions would need to be generated for the interview schedule, and the respective farmer's beliefs and behaviours would need to be understood in the context of their organic farm system.

Similarly, the farmers who pursued HLS contracts will have been obliged to carry out much more demanding management obligations than their ELS counterparts, will have been rewarded with greater financial reimbursement, and will have had more attention from scheme officials throughout their ES experience. When their contracts come to an end, HLS contract holders are then also subjected to a more targeted effort to get them to re-sign with the ES's successor, CS. These factors will, in turn, determine the impact that their ES participation will have on their ongoing environmental attitudes and their future management plans. Again, particular efforts would need to be taken to unpick the HLS-specific impacts from the more general ES ones. Whilst it would be interesting to contrast the development of agrienvironmental beliefs and behavioural expectations caused by UELS, OELS HLS, and ELS contracts, the extra theoretical and data collection work would place an undesirable strain on the PhD's time limitations. The following case-studies are, as a 
result, made up of individual's whose ELS contracts had no HLS, organic or uplands element.

\subsubsection{The case-studies}

According to the above criteria, two case-studies were developed. These are shown in the Figure 4.3, below. The colours were chosen to highlight the different casestudy areas, and do not communicate or represent any further information. The first case-study, the eastern arable case-study, contains 109 ELS contracts signed in the April and August 2012 period, and covers an area 1.134m hectares. The second, the mixed midlands case-study, contains 81 ELS contracts signed in the April-August 2012 period, and covers an area covering $0.863 \mathrm{~m}$ hectares. Both of these case-study areas are described more fully in the following chapter.

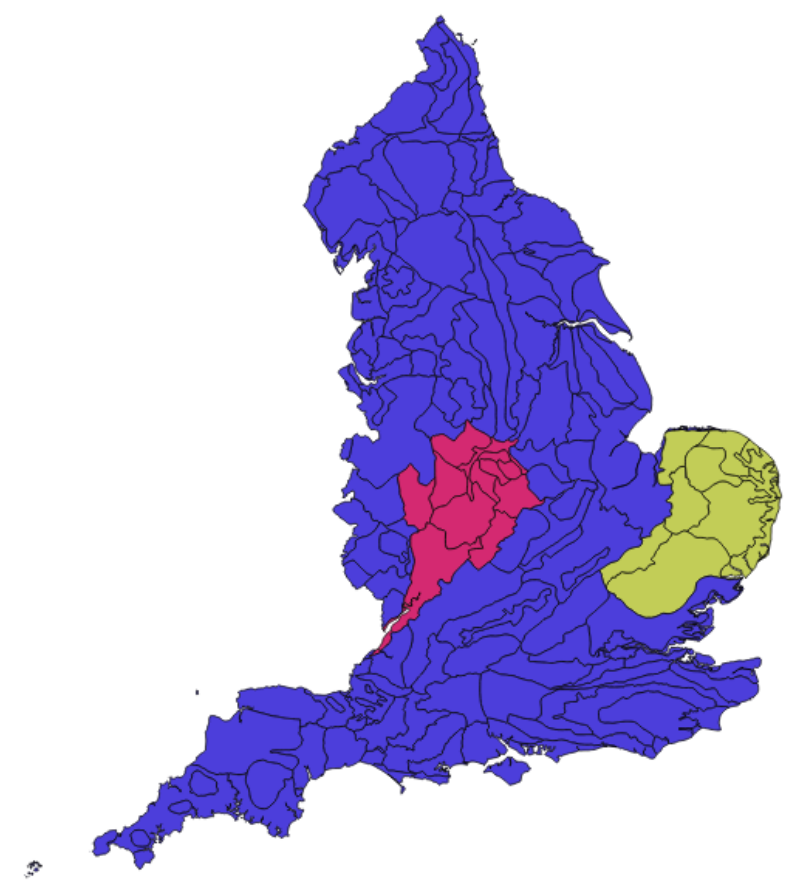

Figure 4.3 Map of case-studies

Over the course of the phase the phase 1 data interview process, a minor methodological adjustment was made. As described above, the initial time period of 
allotted ELS contract start dates was from April-August 2012. Although these dates appeared to yield enough contract holders to meet the methodology's sample size demands (i.e. to secure between 20 and 25 interviews from each case-study), in reality more were needed. This was due to a higher-than-expected interview request denial rate, and difficulty in making contact with the contact holders through the details provided (with many details leading to dead email addresses or mobile phones or contact details that lead to agricultural agents who were unwilling to speak on behalf of their clients or provide contact details for them). Additional contract holder information was sourced from NE for the relevant NCAs, with start dates in September-October 2012. The two additional months' worth of contract holders was sufficient to ensure the sample size requirements were met. After these changes were made, the eastern case-study contained 132 ELS contracts, and the midlands casestudy 117.

Due to the project's particular research objectives, certain potential research avenues were not being considered. In arranging the interviews, no distinction was made, for example, according to the location of the individual farm holdings within the casestudy areas. The comparative element of the research has already been met by the decision to compare the arable east case-study to the mixed farming midlands casestudy, and so there was no additional motivation to get a geographical spread of interviews within the case-study areas themselves.

Similarly, no attempt was made to assess the bearing that farm size has on the willingness or capacity to engage in environmental management, or the potential correlation between farm size and environmental attitudes. Previous efforts have failed to produce a consensus on the issue. Ruto and Garrod (2009), for example, showed how larger farms with greater economic capacity were better able to commit land to the non-productivity of AESs. Conversely, there is research to suggest that larger farms are more firmly attached to productivist, and so were less amenable to AES participation (Defrancesco et al. 2008). The meta-analysis of Lastra-Bravo (2015) about farm characteristics and AES participation found no conclusive correlation either way connecting farm size and AES participation or attitudes 
towards the environment. The project is not equipped to offer any further insight into this already well researched area.

\subsubsection{Bourdieu's theory and interview questions}

The methodology will now consider the task of rendering Bourdieu's theory into the questions used in the interviews. The questions needed be designed to ensure the responses they receive were amenable to an analysis availing of Bourdieu's thinking tools.

A portion of this requirement has already been completed. We have, for example, over the course of the previous chapter detailed what a Bourdieusian 'field' will be in the context of this research (farmers, their families, agri-environmental scheme officers, farm advisors etc.); what the different types of Bourdieusian capital are (symbolic, cultural, embodied, institutional) and the manifestations they have historically taken in the farming community (neatly ploughed fields, well-kept machinery, utilisation of government schemes); and we have seen what Bourdieu's concept of habitus and hysteresis are, and what they are likely to mean in the context of this research project. Attention must, however, also paid in understanding how to mobilise these concepts in an interview-based research project.

Before advancing, it is important to note that Bourdieu resists giving overly prescriptive accounts of how his thinking tools should be used in empirical research. He instead maintains that the most apt methodologies be selected to produce the most relevant data set (Grenfell and James 1998). In the context of interview schedule design, the ambiguity represents both a problem and an opportunity. There is no formula for designing interview questions that will be guaranteed to yield the appropriate sort of data. But, on the other hand, it affords a degree of freedom in the creation of questions so long as due attention is paid to the sorts of themes and the level of depth the questions are likely to elicit from of the interviewees. 
As detailed in the previous chapter, it is Bourdieu's concept of capital that plays the lead role in the research project. For Bourdieu, symbolic capital functions as the currency that field members strive to generate to achieve favourable positions in their field - and the three types (social, cultural and economic) are themselves converted into symbolic capital. Those capitals are, that is, the central element in the formula that explains why individuals are motivated to act in the way they do. Whilst a fieldanalysis of the agricultural field (inspecting what positions different actors occupy in the field's hierarchy) may be of interest, in the context of this research project such an attempt would be misplaced. The research project is attempting to understand the behaviours and attitudes of individual farmers, and the motivational factors that help determine those eventualities. In this way, the agricultural field is primarily interesting only insofar as it is the socialised context within which those individuals are acting, and within the rules that determine the reproduction of capitals hold sway. A thorough analysis of who occupies what position and why is not, therefore, necessary to understand the motivations behind an individual's (non)adoption of environmental practices. Indeed, it is highly likely that the interviewees will not be in direct social contact with each other, and so attempting to map out their relative positions in the field's hierarchy would not be an overly rewarding process. Instead, as above, the field's relevance is primarily as the arena in which the individuals are operating, and in which particular rules are in effect that determine which behaviours reproduce what sort of capital.

After capital, the concepts of habitus and hysteresis also played an important role. Those concepts articulate how individuals internalise the social rules that dictate the reproduction of capital, and how individuals respond to change in the field conditions. Insofar as they are central features to understanding how individuals respond to the changing rules of the game, and strategise to best succeed in the field's hierarchy, they are central to the project's ability to answer the research questions.

Allowing certain features of Bourdieu's theory to assume primacy in a research project, and others to play more minor roles has academic precedent. Part of Bourdieu's theory's value resides in its adaptability and that adaptability comes, in 
part, from this ability to focus on certain features of the theory for empirical purposes (Rey 2007). By way of example, Naidoo (2004) focusses on a field analysis of the power structures in the teaching profession; Thomas (2002) uses Bourdieu's habitus to look into student retention in higher education; and DiMaggio and Mukhtar (2004) use Bourdieu's taxonomy of capital to look into participation in the arts. It is not perceived as problematic, therefore, to focus on an analysis of the reproduction of capital in the agricultural community, in the context of agri-environmental attitudes and practices.

With these caveats in mind, the conversation, through the guiding effects of the interview questions, will lead to a discussion about the interviewee's attitudes towards environmental management practices, the regard they have for other managers who avail of them, what influence this has on their own agrienvironmental practices, and what this means for the long-term management of their ELS options. The common-sense concepts of 'regard' or 'respect' will be used as a sort of proxy for the more heavyweight and abstract terms employed by Bourdieu, such that their responses will be easily understood in terms of Bourdieu's theory, without having to engage with his arcane, academic and abstract linguistics in the interview setting. The substitution of the abstract concepts used in a research project's theoretical framework for appropriate 'folk' language alternatives when conducting interviews is recognised as an important way of facilitating natural, candid and honest research responses (Krosnick and Presser 2010).

\subsubsection{Interview schedules}

As explained above, semi-structured interviews were used to ensure appropriate focus was placed on the topics relevant to the research project. Room was also left in the design of the interview schedule to encourage interviewees to pursue relevant themes as they saw fit. Two of these themes (those that became research questions 3 and 4), as per the schema (Figure 4.1), were then integrated into the project's main research questions and phase 2 interview schedule. Many social science research guides provide similar recommendations - that questions be open-ended, and that 
interviewees are encouraged through the use of prompts to delve into the topics and themes that arise throughout the interview (Bryman 2015).

The interview schedule for the phase 1 interviews can be found in Appendix C, and the schedule used for the phase 2 interviews in Appendix D. These both include the questions and their prompts used in the interviews. Each question is also accompanied by a detailed description of the rationale behind their design, and an explanation of why they have been included. In the main, the phase 1 interview schedule was designed to attend to research question 1, and to introduce the topic of post-contract management. The phase 2 schedule was designed to inspect the management decisions taken, relating to the ELS options, after the interviewee's contracts had finished (research question 2), as well as to attend to the emergent research questions identified during the analysis of the phase 1 data (3 and 4).

The interview schedules were developed in consultation with Jim Egan, then acting as the Head of Training and Development at the Game and Wildlife Conservation Trust. Jim Egan is an expert advisor expert advisor on agricultural behaviour and agri-environmental practices, and is someone with a vast amount of experience in bridging the gap between scientific research, policy-orientated research and on-farm decision making. He was able to offer insights into how the questions would be perceived by the interviewees, and how to make adjustments to the question design to ensure the project was able to collect data that could underpin a penetrating analysis of the adoption agri-environmental decision-making amongst ELS participants. This iterative process took the form of a mock-interview, and so the natural flow of the questions was on show, as well as the specific wording of the constituent questions.

As a direct result of this exchange questions were, for example, changed from ones framed around conceptually-laden phrases (capital, field etc.) to ones around common-sense, discursive topics (respect, prestige, liking, disliking, friends, neighbours etc.). Taking such steps ensured the interview schedule would be able to provoke conversational and revealing reflections on behalf of the interviewees, without needing to weigh the interviews down with overly-academic terms. The 
expert was also able to explain how the interviewer could potentially risk being interacted with as if he were a NE employee with a vested interest, or someone who could leverage punishments if certain scheme obligations were not being fully met. As a result of these particular observations, the author's impartiality and universityaffiliation was stressed at the beginning of the interview to help ensure the candidness and honesty of the interviewee's, and to minimise the 'interviewer bias' problem (described more fully in Section 4.2.2)

Especially given the thoroughness of this process, the expertise of Jim Egan, and his ability to speak both as an agricultural-insider as well as an 'outside' research expert, the omission of a true interview pilot (i.e. with members of the actual research population) is not considered problematic.

\subsubsection{Privacy and ethics provisions}

The project's methodology and design created a number of ethical considerations. Although this is a standard feature of most research (Bryman 2015), steps needed to be taken to ensure the safety of both the interviewer and the interviewees throughout the research process, and to ensure the project was able to build on data for which the interviewees gave proper consent.

These ethical and privacy considerations were, in part, fulfilled by the completion of Defra's Survey Control Unit (SCU) research vetting process. The SCU evaluate all surveys, interview schedules and research request materials associated with Defra and NE projects to ensure they do not pursue personally or politically sensitive lines of inquiry, and to ensure the research population are fully informed about the nature of the research and are not unnecessarily impacted by the research (e.g. needing to commit excessive time or resources to contribute to the research).

In the context of this project, the SCU considered both the interview schedules and the initial research request letters. The letter, which can be seen in Appendix E, explained the nature of the research, and what their role in the process would be, should they agree to participate. As described elsewhere in the thesis, the contact 
details of the ELS contract holders who met the research requirements (operating in the correct area, with ELS contracts starting and ending in the right time period) were supplied by NE - who are permitted to contact scheme holders during the extent of their respective contracts for scheme-relevant research, or to share those details with affiliated researchers. After minor revisions, both the schedules and interview request letters were cleared by the SCU.

Alongside the provisions to ensure the research population were able to give their informed consent to participate in the research, other important steps were taken to ensure the interviewees' privacy, both during and after the research. Before the start of each interview, active consent was sought to record the conversation and at the end of each of the phase 1 interviews, consent was also sought to contact them a year later to conduct the phase 2 interviews (after which their respective ELS contracts had ended). During the transcription process, attributable details were omitted. The contact details supplied by NE have been deleted from the author's computer, as well as the interviewee's email addresses from the author's email account.

Despite the fact that neither the research design process nor the data collection process were conducted after the EU's new General Data Protection Regulations (GDPR) rules had been introduced, the steps described above mean that the project is nevertheless compliant with its stipulations except in one very minor way. The new rules now demand that solicitations for involvement in research operate on an informed consent, opt-in basis. The wording of the initial research request letter, however, imply an opt-out rather than an opt-in design - although it is still stressed that participation in the research was voluntary. Given how minor the deviation is from the GDPR rules, how high a standard those rules set for researchers, and especially considering how those rules were not in effect during the creation and execution of the research, this is not perceived as problematic.

\subsubsection{Data analysis}


A number of methodological features of the project also need to be described. How were the interviews recorded, how as the data processed, and how was it analysed? Each of these methodological components will be described, below.

Interviews were recorded and transcribed. This precluded the need to produce accurate notes from the interview and facilitated a more honest and revealing connection between the interviewee and interviewer. Recording the interviews also meant that complete responses could be returned to, long after the fact, without relying too heavily on personal memories or impressions. The practice of recording interviews, especially for use in qualitative research is standard practice (DiCiccoBloom and Crabtree 2006).

The process of transcription is recognised as an area with different available methodologies (Lapadat and Lindsay 1999). The need for a consistent transcription methodology makes itself apparent when the finer details of the transcription process are considered. There are, for example, many speech utterances that are not typically represented in writing. These non-verbal utterances (NVUs), such as 'umms' and 'errs' may not, in isolation carry semantic content, but can, in context, convey any number of subtle meanings. The researcher must therefore take a consistent line on whether or not such NVUs are included in a transcription. If, out of a desire to ensure the transcription offers a full account of an interview, the researcher decides to include NVUs, are they then similarly obliged to include pauses or stutters, or even hand gestures and facial expressions? Or is there a point at which the researcher/transcriber concedes they cannot create a full version of an interview?

Oliver et al. (2005) offer a spectrum of transcription methodologies to capture the different approaches that can be taken. On one end of the spectrum is a 'naturalism' approach, in which the transcribers attempt to capture as much information as possible to fully reflect the interview for future analysis (NVUs, hand gestures, facial expressions). On the other end of the spectrum are the 'denaturalism' approaches, which seek to remove all the elements of speech excepting for those traditionally recognised as having semantic meaning. Both styles have their respective merits, and the selection of an approach needs to be done in accordance with the characteristics 
of the research project (scale of the data collection, the objectives of the research and the theoretical framework that is being employed) (Davidson 2009).

Primarily because of the scale of the project, the transcription adopted a largely denaturalist approach, in which only the words and sentences used by the interviewees were honoured in the transcription. Whilst naturalism approaches may be slightly better equipped to record the totality of an interview, the technique is better suited to a highly ethnographic participant study with a small number of research subjects. As this project was based around semi-structured interviews with a relatively large number of subjects, recording that level of detail represented too great an undertaking. Where there were instances in which clear meaning is being conveyed through non-verbal utterances (groans, sighs) then they were, however, included. This approach permitted a degree of discretion on the researcher's part when transcribing interviews that allowed for the inclusion of patently significant speech idiosyncrasies. On Oliver et al. 's (2005) spectrum, this approach falls somewhere in the - focussing predominantly on the actual speech contained in an interview, whilst allowing for the inclusion of some NVUs, where they are clearly meaning-laden.

The steps taken in the analysis of the data need to also be described. Ritchie and Spencer's (1994) qualitative data analysis is designed for use with qualitative research projects in the arena of policy research and, because of the aptitude for this project, their analysis methodology was adopted.

Their framework describes an approach to data analysis that follows 5 predetermined steps: familiarisation, identifying a thematic framework, indexing, charting, and mapping and interpretation. The process of familiarisation amounts to the immersion of the researcher in their research data. This includes the reading and listening back to interview recordings and transcripts, and also continual reference back to the pre-existing literature relevant to the area of study.

The process of identifying a thematic framework involves the identification of the themes and topics according to which the data will be sifted and sorted. Ritchie and 
Spencer (1994) stress the importance of being malleable and adaptive enough to recognise emergent and themes within the transcripts even if they were not expected to be of significance, and to implicate those themes in the indexing process. This strand of Ritchie and Spencer's (1994) meshes with the methodological design described earlier on in this chapter. Namely, the selection of an inductive/deductive hybrid which accommodates a pre-determined set of research themes and also a constantly iterative look at emergent research themes (in our case ones that were revisited in the follow-up interviews).

Once a thematic framework has been developed, the chosen themes and topics are then applied to the indexing step of the analysis process. Indexing is the process in which transcripts are annotated to highlight where the pre-determined themes present themselves, and also the identification of emergent themes. For the last few decades, the process of indexing transcripts in qualitative research projects has increasingly been completed with the assistance of with research software packages (Bazeley and Jackson 2013). Although Ritchie and Spencer's original 1994 paper is silent on the issue, Srivastava and Thomson (2009) note that the indexing step in their framework approach lends itself to such software. For these reasons, and due to the large volume of data the project was expected to generate, this project followed the growing trend in qualitative research in employing NVivo as a data analysis tool. NVivo, along with ATLAS.ti are the two most popular qualitative research programmes in common usage, but due to the ubiquity of NVivo in the CCRI office, and therefore the quantity of easy-access expertise and advice, NVivo was chosen over the alternatives.

In the context of NVivo, Ritchie and Spencer's (1994) indexing process is better captured by the concept of coding. In line with the project's inductive component, described in section 4.2.2, the project began with a set of pre-determined codes that covered the themes targeted by the interview schedule. To accommodate the project's deductive element, topics that were raised independently by the interviewees were given new codes. When those topics re-emerged in other interviews, the codes were there to help systematically capture and collate the relevant responses. 
The charting step of Ritchie and Spencer's 1994 framework requires the researcher to compile and collate the different declarations made in an interview, according to the research theme they fall under. This can either be done across the whole data (i.e. anything said by any research subject about research theme $\mathrm{X}$ ) or broken down for each research subject individually (anything said by research subject Y about topic $\mathrm{X})$. They recommend the use of charts or tables as a means of compiling the frequency with which topics are raised, and also the adoption of a numbering system in the index stage of the analysis to facilitate a quick and easy reference system to avoid the chart becoming overloaded with blocks of verbatim interview text. This manual tabling system was replaced in favour of NVivo's inbuilt ability to compile excerpts that have been given a shared code. This allowed for the researcher to quickly and easily consider all responses, relevant to a particular theme, given by each of the different interviewees. Appendix A contains a number of screen shots that capture NVivo's coding process, and how it presents the data for subsequent analysis.

The fifth step of the framework relates to the mapping and interpretation of data. The researcher "searches for patterns and connections and seeks explanations for these internally within the data...[It] is not simply a question of aggregating patterns, but of weighing up the salience and dynamics of issues and searching for a structure rather than a multiplicity of evidence." (Ritchie and Spencer 1994 p.186) The mapping and interpretation step relates, therefore, to the distillation of the data into its fundamental research findings, and the representation of those findings in an intuitive and comprehensible way. This process is covered in Chapters 6 and 7, in which the analysis of the interview data is presented, and in which the project's findings are communicated. Bourdieu's research theory was brought to bear on the data collected during the two interviewing phases and his research tools were used to explain the interviewee's behaviours and attitudes.

4.2.12 Reflexivity and Bourdieu's epistemic break 
As described in section 3.4.1, the researcher must make specific efforts to imbue their project with an appropriate element of reflexivity. The researcher must, that is, recognise the influence that they are liable to have on the research subject, the role the occupy in the research space they share with the subject(s) of the research and recognise the extent to which they are likely to bring their own biases, objectives and subjectivities to the process. To attend to this, strategies need to be put in place to ensure the project's ability to generate new, meaningful research is not undermined. Bourdieu terms this process the epistemic break. The break, in this context, refers to the distance that needs to be made between an individual's influence on the research process and the final product of the research (the knowledge, hypothesis, findings) (Robbins 2003). The need for an element of reflexivity, although novel at the time Bourdieu was writing, is now an established part of conducting social science research (Berger 2013, Finlay 2002).

Bourdieu was sceptical about the researcher's ability to fully achieve the epistemic break. The researcher cannot, whatever measures are put in place, be free from their own desires and beliefs (habitus) - and any steps taken will be enacted through this filter (Maton 2003). The need for reflexivity, in this sense, simply demands that the researcher acknowledge the role they occupy in the research process and put in place strategies to mitigate against the ways that these subjectivities stand to undermine the process's objectivity (Wacquant 1992). To this end, three specific strategies - the details of which have already been outlined - are identified as those that will help effect the epistemic break. The first relates to the adoption of a follow-up research methodology, the second to the use of NVivo software, and the third to the use of a pre-determined interview schedule.

As described above, the follow-up research methodology was selected to mitigate against the intentions-behaviour gap. The gap is made more likely by the potential influence that the researcher is liable to have on the responses given by the interviewees. For social acceptability bias and researcher bias reasons they may have, in other words, over-reported their good environmental intentions. Having adopted a follow-up methodology in which the intentions offered in the phase 1 interviews could be verified in the second 2 interviews represents the precise sort of 
strategy Bourdieu's recommends as a means of recognising the position the researcher occupies relative to the research subject, and how this may influence the data that the project collects. The use of follow-up interviews as a means of verification, and the contribution that process adds to a research project's reflexivity is not something, to the author's knowledge, that has been discussed in the relevant methods literature. In this regard, this research project's originality is also present in its methodology.

The use of the software package, NVivo, is also a tool through which an element of reflexivity can be achieved. Computer-assisted qualitative data analysis software (CAQDAS), of which NVivo is an example, is identified as being able to help a researcher be reflexive in their research (Woods et al. 2015). The speed and efficiency of using CAQDAS software to inspect coded items simultaneously (as opposed to considering each excerpt in the context of the wider interview transcript) can help the researcher achieve an extra degree of reflexivity by adding to the researcher's sense of closeness to the data (Gilbert 2002). The use of CAQDAS software can also help effect an emotional distance between the researcher and the research subject (Tummons 2014). This can help ensure the researcher's personal investment in the narratives and characters involved do not colour the analysis process - again adding to the project's reflexivity.

The third strategy relates to the use of a pre-determined interview schedule, described above. Setting out what questions will be asked in each interview, before those interviews are conducted, is expected to minimise the impacts of the researcher's own bias in the interview setting (Pannucci and Wilkins 2010). By asking a pre-determined set of questions, the opportunity for the interviewer's habitus (inclusive of their biases, desires, objectives) to exert its influence on the interview and shape its results, is compromised. Here, the reflexivity is about recognising the researcher's own vested interest in the research process, and the results they either knowingly or unknowingly want to produce and putting in place strategies to limit the extent to which those features of the researcher's psychology can shape the research process. 
Mason (1996) introduces a three-part taxonomy of qualitative data analysis. $\mathrm{He}$ prescribes that the researcher must select one (or more) of the following three approaches - literal (in which interviewee's are taken to mean what they say); interpretivist (in which the researcher attempts to unpick the deeper truths or meanings behind the interviewee's account); and reflexivist (in which the researcher scrutinises their own impact on the interviewee's responses) (Mason 1996). The methodological decisions, explained above, dictate which of these brackets the project will fall into. In mobilising Bourdieu's social theory, the project is looking to go beyond a literal understanding of the interviewees' accounts as accurate representations of their full suite of motivations and beliefs. Instead, it is attempting to interpret the interviewee's stated beliefs and behaviours as an expression of their desire to reproduce the different types of capital and secure favourable position in their field's hierarchy. In this way, the analysis adopted a largely interpretivist approach. His theory, however, also requires the researcher to recognise what role they have in the research arena and what biases they are bringing to the research process. These recognitions, along with the steps taken to mitigate against the impact they are liable to have on the project's findings also mean that project will have an important reflexivist element.

\subsubsection{Data presentation}

The decision about how the data is presented also need to be considered. In smaller ethnographic participant observation studies, full accounts of the interviews are laid out, allowing for an immersive impression of the participants' lives and behaviours. The value of such studies derives from their ability to paint textured and rich stories about the participants, their beliefs and their behaviours, and so is dependent on a 'thick' account of each interview (Murchison 2010). In larger survey studies, it is not possible to record and communicate that level of detail, and so the findings are typically presented research theme by research theme, in which the important trends uncovered by the interviews are distilled into and represented by choice quotations (Anderson 2010). This study, in conducting 50 semi-structured interviews, falls closer to the large survey end of the spectrum. It would, as a result, be untenable to present 
and analyse extended accounts of each of the interviews and, once done, the analysis would be too sprawling for it to be either interesting or comprehensible.

Accordingly, a theme by theme analysis was be conducted, applying the 'thinking tools' presented in the Chapter 3. This analysis covered both the research themes initially targeted by the project (the pre-determined, deductive themes, coded in NVivo before the analysis process), and the themes that presented themselves throughout the interviews as important (the emergent, inductive, codes, added over the course of the analysis process).

Finally, regarding the presentation of interview quotes, the interviewer's words are always presented in italics, the main interviewee in normal type-face, the secondary interviewee in bold, and tertiary interviewees in bold, underlined type-face. Details of who these secondary or tertiary interviewees are, relative to the farm and the main interviewee, are given when their words are included. Where hyphens are used at the end of one person's speech, it indicates that the person speaking afterwards has interrupted them. Where ellipses are included at the end of someone's speech, it indicates they have trailed off, potentially inviting another speaker to contribute. Each interview is given a unique code. The letter relates to the case-study area the interviewee is located in, and the numbers were randomly assigned. The interview codes go from E01, E02, up to E18, and from M01, M02 up to M22.

4.2.14 A note on the case-study method and the generalisability of the project's findings

The design of the project's methodology has implications for the generalisability of its findings. The following paragraphs will detail what the project is equipped to say about the project's target population, beyond the confines of the individuals directly contacted.

Bourdieu's theory describes how social actions occur in a given field. Those fields have specific rules, and the boundaries of a field roughly trace the social groupings within which the same social rules and codes apply. Whilst there may be minor differences in the livestock portion of the agricultural field compared to the arable 
portion in terms of which artefacts and practices reproduce what capital, they are all contained within the same wider agricultural field because of their shared histories, economics, beliefs and codes. The project is attempting, amongst other objectives, to trace what the rules of the game are with respect to the adoption of agrienvironmental behaviour, and what role ELS has played in this development. In interviewing constituent members of the field using research tools explicitly designed to map out what the rules of the game are (which practices and artefacts reproduce different capitals), the project will be able to make claims about the agricultural field of which the interviewees are part. Importantly, because the field extends beyond (i.e. includes members of the agricultural field from across the country), the rules that are unearthed through the data collection and analysis process will largely pertain to the rules and codes experienced and adhered to by those other field members, across the country.

The ability to generalise the findings is, in this way, couched in an understanding of Bourdieu's social theory. The same approach is implied in the pre-existing research projects availing of Bourdieu's thinking tools in the context of agricultural decisionmaking and attitudes, detailed in the literature review chapter. Burton (2012), Burton et al. 2008, Sutherland and Darnhofer (2012) and Riley (2016), for example, all employ qualitative methodologies, typically in small case-study areas or involving relatively small numbers of participants, to map out the specifics of the rules of the game. Those rules are then expressed in terms that imply their relevance to the wider-agricultural field. Those researchers have, as this project also does, recognised the membership their interviewees have to the agricultural field, and use their accounts, stories and responses to map what the field's rules are. The implication thereof is that those rules, by and large, will hold for members of the field operating different farm systems or in different areas of the country.

The capacity to generalise the findings about the long-term management impacts of the scheme is, however, more modest. Research projects with case-study methodologies need to be cautious about the scale and strength of the generalisations they make, beyond the extent of their specific case-study areas or research samples (Wainwright 1997). The findings that pertain to a given case-study are potentially so 
context dependent that it is difficult to abductively draw conclusions relevant to the wider target population (Creswell 1998). In our case, the fact that certain interviewees may or may not be maintaining ELS options after their contracts' conclusion cannot be used as a general rule about the upkeep or removal of ELS features, post-contract.

The project, as can be seen above, is not making any methodological manoeuvres to get a representative sample of certain types of farm or attempting to gather the scale of data that can underpin a statistical analysis of different options and their long-term upkeep. Instead, in-line with the project's qualitative nature, the project is attempting to generate a textured, farm-level account of the motivations that exist for different behaviours. The potential existence of, say, managers maintaining features of their ELS contracts is interesting insofar as it demonstrates the possibility of managers making such decisions, and the existence of economic and social conditions that can (and are) leading managers to pursue such a behavioural pattern. The project is not, by contrast, attempting to make any claims about the distribution of managers making similar decisions, or the wider (i.e. beyond the case-study) long-term management impacts of the scheme.

Within these limitations there are, however, arguments that detail when and why tentative generalisations can be drawn from a qualitative case-study project. By providing a rich enough account of a given research sample, and of the factors germane to understanding the research subject's behaviours, practices and attitudes, the researcher and reader can be equipped to gauge the extent to which a project's findings can be generalised to other relevant actors (Mays and Pope 2000, Schofield 1992). Patton (2002) stresses the importance of extrapolating from a project's research findings, rather than generalising from them. Extrapolations, in this understanding, can be made about the "likely applicability of findings to other situations" (Patton 2002 p.584). In the context of our project therefore, qualified generalisations (or extrapolations) can be made, so long as careful consideration is given to the shared and divergent realities of the project's research sample and the population about whom the findings are being applied to - and the bearing this has on the findings' applicability. The projects findings, discussed in Chapter 7 and 
reviewed in Chapter 8, will return to the above discussion around the generalisability of the project's findings.

\subsection{Chapter conclusion}

This chapter has developed the project's research methodology. A research sample has been chosen, case-studies have been developed, and an interview schedule has been created. The chapter has also articulated the measures put in place to ensure the project attains an appropriate level of reflexivity, and offered an explanation about the limited capacity the project has to generalise its findings. Over the following chapters, the case-study areas will be more fully described, and an analysis of the data secured through the above methodology will be presented. 


\section{Contextualising the research}

\subsection{Chapter introduction}

Research projects availing of qualitative, case-study, methodologies need to thoroughly contextualise the setting within which the interviewees are operating. The value of such methodologies turns on their ability to generate thick, detailed accounts of the interviewees' lives, and the factors that lead them to think and behave in the way they do (Bryman 2015). To this end, this chapter will provide a description of the project's case-studies in terms of their agricultural make-up (representation of livestock farming, arable farming), in terms of the uptake and representation of the ELS scheme (which scheme options are concentrated, and where), and in terms of the key features of the policy landscape the interviewees are operating. This contextualisation process will facilitate and improve the analysis of the data, set out over the following chapters.

\subsection{Description of case-studies}

The two case-studies were chosen to contrast the development of the rules of the game and the symbols of good farming in two areas characterised by a high representation of different farm systems (and, as a result, different manifestations of the ELS scheme). To understand what this means on the ground, the following maps have been generated to represent the different farm system make-up of the two cases studies areas. The case-study areas (the two blocs of NCAs with purple borders) have been placed on top of graduated maps representing the density of different farm systems. Figure 5.1 shows the representation of arable farms in the UK, Figure 5.2 the representation of livestock, and Figure 5.3 the representation of mixed farms. The darkness of the shading reflects the number of the farms of a given type, as a percentage of all the holdings in the different NCAs. What the different shades represent is described in legends on the respective maps, with each map breaking down the figures into 6 Jenks breaks. The maps were generated with Defra's 2016 survey of farm holdings, where the number of each farm type was divided by the total number of holdings in the area. 
The maps (Figures 5.1, 5.2, and 5.3 below show how the landscape typology described in Swanwick et al. (2007) are reflected in the way the different farm systems are distributed across the country. The area covered by the eastern casestudy, as a result, has amongst the highest representation of arable holdings in the country, and amongst the lowest representation of livestock holdings. By contrast, the area picked out by the midlands case-study has a relatively high representation of livestock and mixed farms and, relative to the eastern case-study area, a low showing of arable holdings. These realities also map onto their desired purpose: capturing areas of different farm systems as a means of inquiring into the potentially varied way that the symbols of good farming have developed.

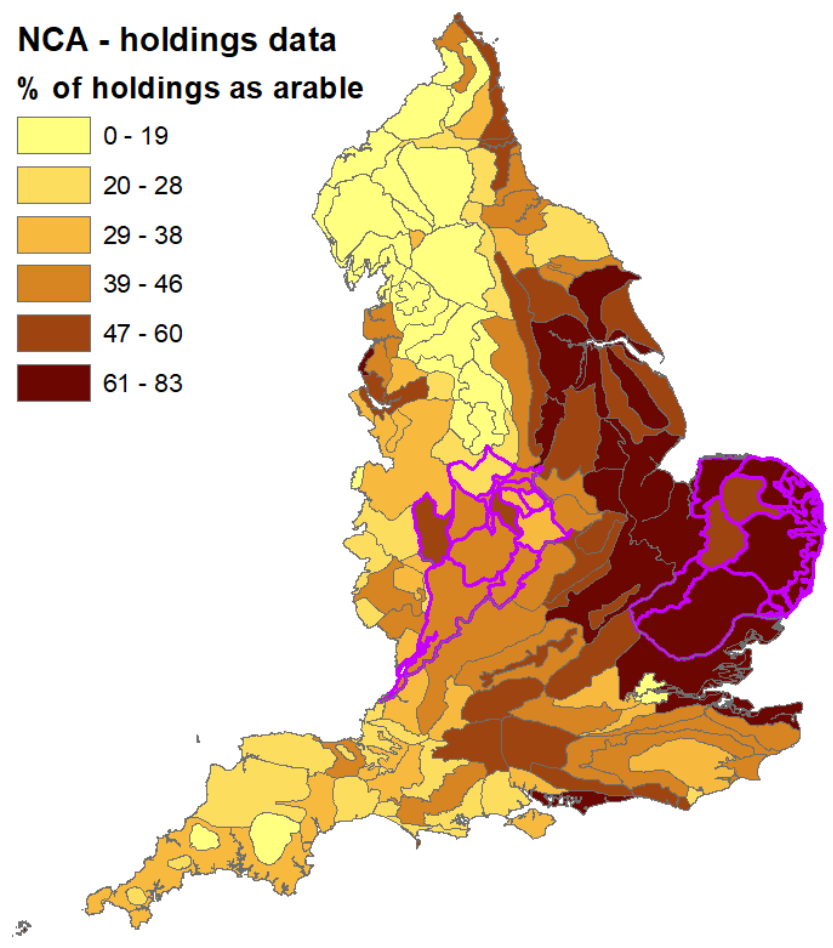

Figure 5.1 - Representation of arable farms 


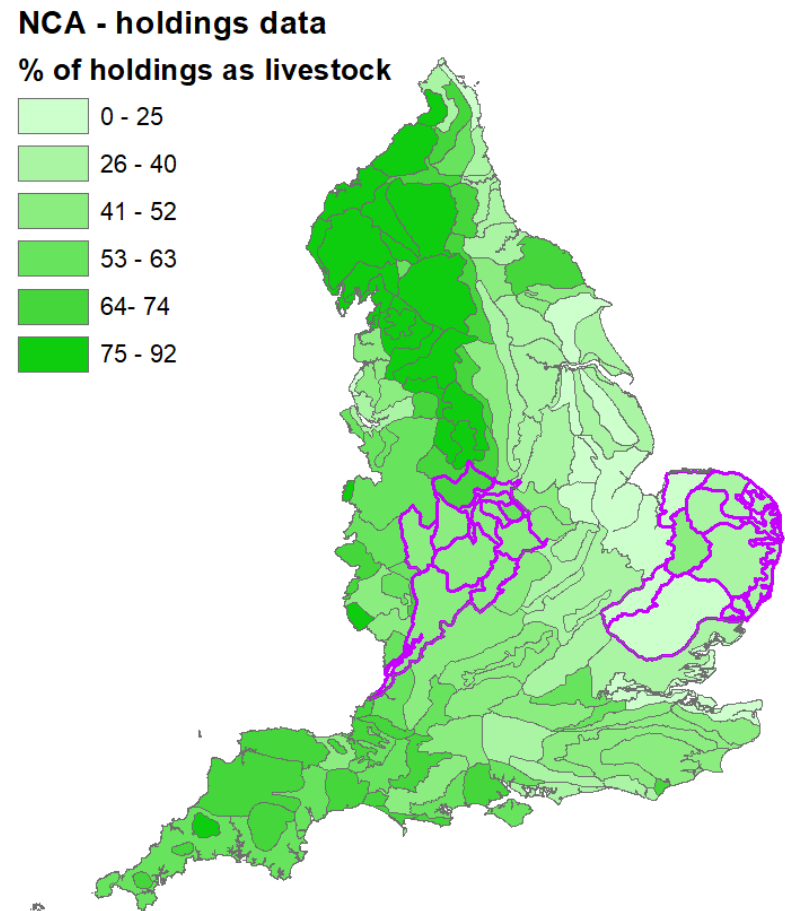

Figure 5.2 - Representation of livestock farms 


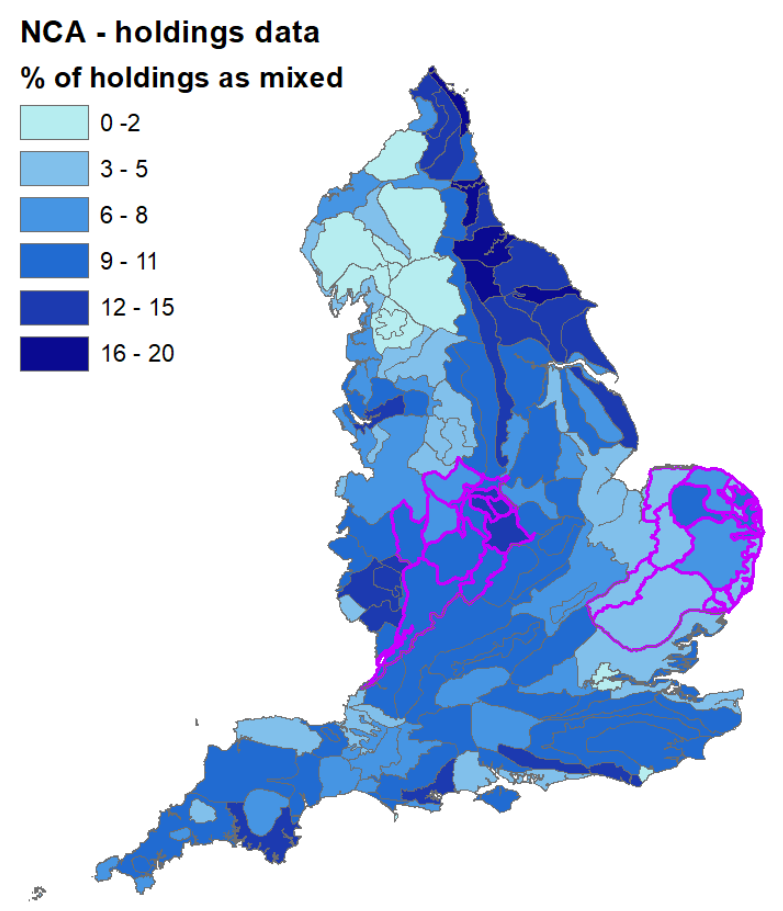

Figure 5.3 - Representation of mixed farms

As discussed in the previous chapter, the distribution of different farm systems also has a bearing on the way ELS manifests itself across the country. The following maps are taken from Hodge and Reader (2010) who conducted a thorough analysis of the distribution of different ELS options. For convenience, the maps have been overlaid with the map of our own case-study areas. As can be seen, the maps they produce, are based on a breakdown of the scheme on a Unitary Authority and Local Authority District breakdown, and not on the NCAs used above. In spite of the slight mismatching areas of designation used in the maps they produce, and this project's case-study maps that have been projected onto them, they still successfully communicate the distribution of different scheme options. 
The eastern case-study area is associated with a higher representation of land taken out of cereals production and set-aside options. Due to their nature, these are expected to be the most visible incarnation of the ELS scheme - areas that have intentionally been left out of production, typically alongside fields that are used for arable production. By contrast, the western case-study area has a smaller representation of boundary options and a considerably higher uptake of grassland options. The scheme will, as a result, have a less obvious appearance, with a higher number of scheme points being made up by grassland options which will not have the same dramatic and obvious appearance. The grassland options involve a reduced amount of agricultural chemicals being used on the given parcel of land, and so the change in appearance the option will catalyse will be minor.

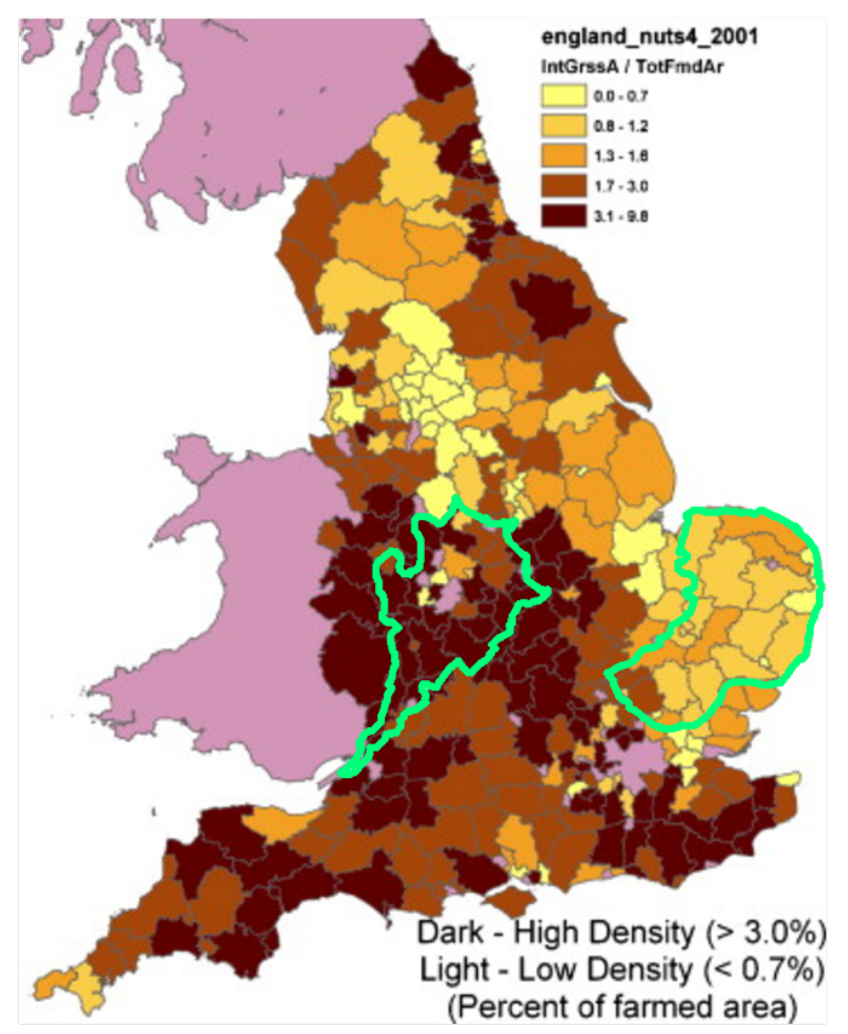

Figure 5.4 - Uptake of grassland ELS options (Hodge and Reeder 2010), with casestudy maps 


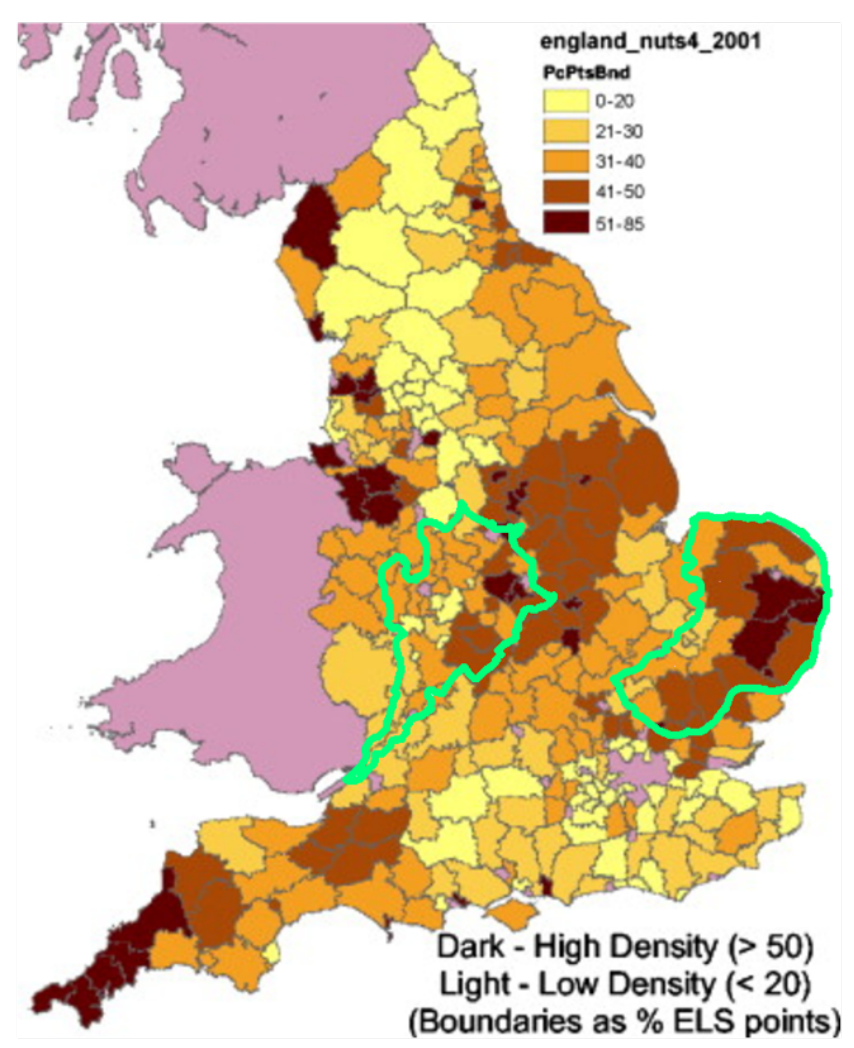

Figure 5.5 - Uptake of boundary ELS options (Hodge and Reeder 2010), with casestudy maps

The scheme's appearance, as a result of the varying degrees of visibility of the different sorts of options, is also amplified by the differing levels of uptake of the scheme more generally. The following map, also taken from the Hodge and Reader (2010) paper, shows the uptake of the scheme in the same heat-map style. The data is the result of a calculation of the area in the scheme as a percentage of the total farmed area. The midland case-study area, as can be seen, has a lower uptake of scheme compared to the eastern case-study area - although is itself relatively well accounted for, compared to the rest of the country. 


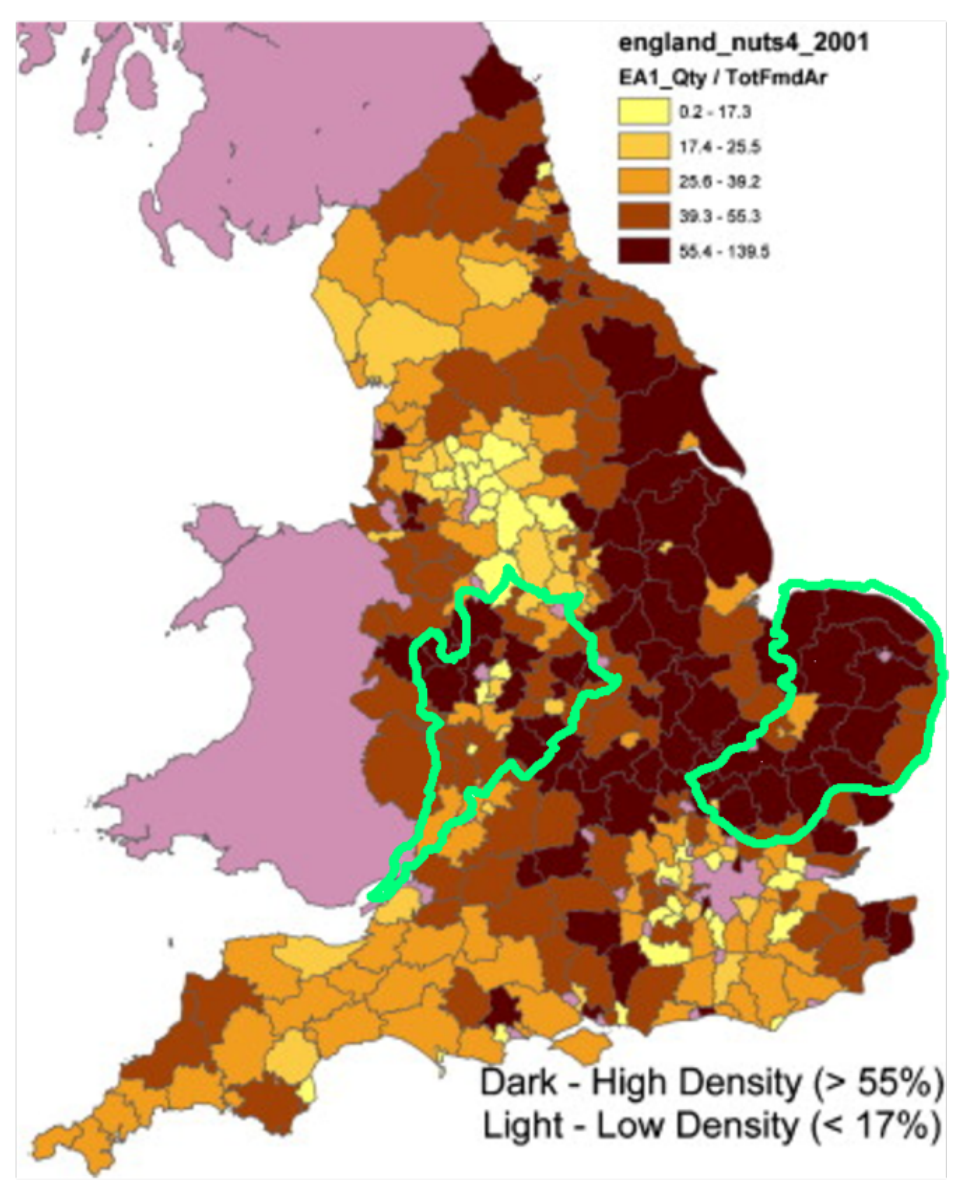

Figure 5.6 - Uptake of ELS scheme (Hodge and Reeder 2010), with case-study maps

The visibility of an individual's management decisions is frequently cited as an important fulcrum point when charting the rules of the game and the capacity for different practices to reproduce different sorts of capital (Burton 2012, Oreszczyn and Land 2000). Farmers, that is, inspect and evaluate the performance of their neighbours. How their performance appears is an important part of this process (Burton 2004). As described in the methodology chapter, the inclusion of the comparative element is an attempt to assess how the different farm systems represented in the two areas, and the resulting differences in the way ELS manifests itself mediates the development of the symbols of the good farmer. With this descriptive work in place, the interviews presented in the following analysis chapters will be more properly contextualised. This will, in turn, provide a clearer understanding of the differing appearances of the two areas, the appearances of the ELS scheme, and how this informs the project's response to its research objectives. 


\subsection{Description of the policy landscape}

Much that could feasibly fall under the rubric of 'policy landscape' has already been described elsewhere in the thesis. Most importantly, a thorough description was given of the ELS scheme and its different options, and an account of the agricultural, economic and social history that lead to the development of AESs in England and Europe. The following will provide a description of the policies that are playing potentially important roles in the decision-making processes of the interviewees.

Over the course of the following analysis chapters, reference is made to CAP's Greening measures, the post-Brexit AES, and the successor to ES, CS. Before the analysis of the phase 1 and phase 2 interviews can be presented, descriptions of what these are required to fully contextualise the interviews.

\subsubsection{Greening measures}

The Greening measures refer to the minimum environmental threshold, introduced in 2015, farmers are expected to meet to secure their full Pillar 1 payments. As was explained in Chapter 2, agricultural payments, administered through the EU's CAP are split into 2 pillars. The first is a direct, income-support payment in which payments are calibrated to the farm size. The second is the funding targeted towards more social or environmental targets (combatting climate change, improving the rural environment, fostering rural economies), and is the pillar into which AESs fall. The receipt of Pillar 1 payments is now contingent on meeting Greening requirements. Where farmers fall foul of those standards their direct payments are reduced or withheld through the cross-compliance mechanism. In full, the regulations are too extensive to detail here, but the following represents a sufficiently thorough breakdown of the Greening requirements for the purposes this project.

Farmers who manage 10 hectares or more are required to follow Greening provisions, or risk losing 30\% of their BPS subsidy - the Pillar 1 payments farmers receive in England. Holdings with 10-30 hectares of arable land must grow at least 2 
crops, holdings with 30 or more hectares must grow 3 crops. In both cases the main crop cannot take up any more than $75 \%$ of the land, and for the larger holdings the two main crops cannot take up more than $95 \%$ of the land (i.e. the smallest crop must cover at least $5 \%$ of the land). This is referred to as the crop diversification rule. For this purpose, temporary grass and fallow can both be used as one of the crops. Farmers are exempt from those rulings under a handful of circumstances - if $75 \%$ of the land is used for temporary or permanent grass, if the cultivation of crops is grown underwater (as with watercress), or if over $75 \%$ of the total holding is grassland.

Farmers with 15 hectares of arable land or more must include EFAs on their farm. This can include buffer strips, catch crops, cover crops, nitrogen fixing crops, fallow land, hedges and trees planted in a line. EFA land must cover $5 \%$ of the total arable land. The same above exemptions apply.

Management options used to meet Greening and EFA provisions cannot also be used in either ES contracts or CS contracts (either mid-tier or higher-tier). In instances where they are, funding will be reduced to stop that land being 'double-funded'.

\subsubsection{Post-Brexit agricultural policy}

The topic of the post-Brexit agricultural policy landscape was also cited as an important feature in the decision-making processes of the interviewees. The theme emerged over the course of the phase 1 data collection and analysis process and was added to the interview schedule and research agenda for the phase 2 process. To contextualise how these topics interact with the following analysis chapters, a fuller picture of the (known) details is also necessary. The most reliable indication so far offered by the government comes from the Defra Health and Harmony 2018 Consultation paper and the subsequent agriculture bill, which outline the future design of English agricultural policies and subsidies (as the environment is a devolved matter, the departments from the respective governments of the UK are running their own consultation and policy design processes). Pillar 1 payments are to be tapered off in a transition period immediately following the UK's departure from the EU, with funding being redirected to a more ambitious AES. The scheme, termed 
the new Environmental Land Management (ELM) system is expected to be the central feature of agricultural policy in England, post-Brexit.

The scheme will offer, as its predecessors have, remuneration for the adoption of environmentally sensitive management practices. The plan will also introduce a new payment by results component, whereby the managers delivering the most environmental improvements will earn higher rewards, as well as financial incentives motivating the collaboration of nearby farmers in developing a shared scheme contract (Defra 2018). Perhaps most importantly, the area-based payments, in which farmers are paid in accordance with the size of their holding, will be reduced from 2021 until they are phased out entirely by 2027 . In describing these plans, the government have availed of terms that make clear the principles at the heart of these changes. The scheme is designed to "free up" funds currently used for the direct area-based model that is "ineffective and pays farmers based on the total amount of land farmed. These payments" Defra explains "are skewed towards the largest landowners and are not linked to any specific public benefits". This money will be redirected to fund the ambitious ELM scheme described above, as a means of paying for "public goods" (all quotations from Defra 2018).

The reduced funding made available through CAP's pillar 1, the relative value of participation of an ELM contract will be discussed, and the intersection of these new realities with the rules of the game will be most relevant in the phase 2 analysis.

\subsubsection{Countryside Stewardship Scheme}

The final point to cover before the contextualisation process is completed is ES successor AES, CS. Especially when attempting to understand the management decisions taken by farmers at the end of their ELS contracts, an understanding of what schemes are available to the participants is needed.

From 2015 onwards, AES applications were made to CS, and not to ES. Farmers coming out of their ELS contracts in mid-late 2017 (as is the case with the project's interviewees), if they wanted to participate in an AES, would have to do so through 
CS. As opposed to ES, with its non-competitive, whole farm component (ELS) and its more ambitious, competitive component (HLS), contracts for both of CS's midtier and higher-tier components are awarded on a competitive basis. Farmers have to put together more ambitious projects with no clear minimum points threshold after which they would be guaranteed a contract. There were also targeted areas of significant environmental value - and contract bids located in those target areas were preferred over areas of lower environmental potential.

Concerns arose around the barriers to participation represented by certain elements of CS's design. Its competitive nature, which required farmers to invest time and money into compiling a scheme bid with no guarantee of being awarded a contract, was identified as a design feature that undermined managers' willingness to participate (Franks et al. 2016). From January 2018, because of concerns over the scheme's low-uptake, arising from, amongst other issues, the complexity of the application process, the scheme's overly onerous evidence provision, and competitive nature, four 'New Offers' were added. Those offers - arable, lowland grazing, upland, and mixed farming - provide a much simpler and reduced menu of options, allowing for quicker and easier application and streamlined ways for evidence to be provided. Farmers could, for example, opt for a largely predetermined scheme contract and detail how the management practices would be integrated onto the farm. Due to its relatively recent addition, no analysis of its uptake has been made public, but suffice to say for the purpose of contextualising the subsequent data analysis chapters, that by the time the second interviews were conducted, these New Offers had been made available.

\subsection{Chapter conclusion}

Chapter 5 has helped contextualise the setting within which the research was conducted. This will assist in the communication of the analysis of the following two chapters and will facilitate a more complete immersion into the research setting. The chapter has detailed, in this way, the make-up (in terms of farm systems, and ELS options) of the two case-study areas, relative to each other and the rest of the country; and the policy landscape within which the interviewees are operating. 
6. Analysis of data and discussion - phase 1 interviews

\subsection{Chapter introduction}

This chapter is dedicated to the analysis and discussion of the phase 1 interviews. Bourdieu's thinking tools - the tools Bourdieu developed to unpick and understand the social world - which were described in Chapter 3 will here be brought to bear on the data acquired over the first round of data collection. Before this can take place, however, a small number of outstanding issues need to be considered, along with a brief overview of the research sample.

\subsection{Research Sample}

The accessible population comprised of 249 ELS contract holders, with start dates from April-October 2012. 132 of these fell in the eastern case-study and 117 in the midlands case-study. The research sample consisted of 40 interviews -19 from the eastern case-study and 21 from the midlands case-study. Interviews were conducted between April and July 2017. Full details of the research sample (covering the interviewee's rough location, size of the farm, farm system) can be found in Appendix B. Due to the slight difficulties experienced in arranging interviews (primarily because of the quality of the contact details contained in the contract information provided by NE) a slightly smaller than desired research sample was achieved. More interviews could have been secured if the allocated interview period had been extended, but as that would have strayed into the very busy harvest period (during which refusal rates could be expected to be even higher), and as the $\mathrm{PhD}$ time limitations were pressing (needing to transcribe interviews, analyse the data and prepare for the phase 2 interviews), the decision was taken to stop at 40 interviews. Although the initial methodology targeted 50 interviews (25 from each), 40 interviews was identified as the minimum acceptable figure, and so the slight short-fall is not perceived as problematic.

Details of two interviews, both from the eastern case-study, should also be noted. One of them, E14, was an agricultural agent. Another, E12, was not an ELS contract holder, 
and so was not reached through the contact details provided by NE. In the case of the former, the agent was speaking on behalf of one of his clients, for whom he had set up an ELS contract that fell into the research population. The contact details supplied for this contract linked to the agricultural agent, and so an interview was made with him and not the owner or manager of the farmland in question. As we will see, however, he was able to speak both about the specific details of that ELS contract, and also about more generalised observations of the agricultural community and the impacts of the ELS scheme. In the latter case, through a mutual friend, contact was made with a farm operating in the eastern case-study area. Although the farm did not have an ELS contract (and never had), the responses given to the questions were of clear relevance. The decision to conduct the interview was made on the basis of an opportunistic chance to capture valuable data; and the subsequent decision to include it in the analysis process was based on the clear aptitude of the interviewees' reflections and experiences.

\subsection{Theme by theme analysis}

\subsubsection{Good farmers, bad farmers, and the reproduction of cultural capital}

A mainstay of the project's research relates to the cultural preference for a specific farm management approach and the impact it has on how land is being managed across the UK. To invoke and reintroduce the Bourdieusian thinking toolkit, the project will attempt to map out the rules of the game at play in the agricultural field that determine which behaviours reproduce cultural capital for the farmers. Those rules in turn shape (and reshape) the habitus of the members of the field, and so determine which behaviours are 'culturally' attractive, as well as those that are economically rewarding. The need to understand farmer behaviour in such a way is particularly acute due to the documented shortcomings of analyses that limit themselves to a consideration of the cost-benefit ratio of the different choices farmers make. Managers make decisions according to more than just economic motivations, and so other, more socially subtle accounts of behaviour and motivation need to be deployed. As previously articulated, the project will focus on the capacity for agri-environmental behaviour to reproduce cultural capital for the farmers in a community historically characterised as having a 
set of 'productivist' goals and behaviours that pertain to those goals' attainment that come with a perceived incompatibility with environmentally sensitive management techniques. The 'good farmer' ideal has been developed to help understand which behaviours attract respect and prestige from members of the farming community and, in turn, which characteristics and actions are those that the farmers are wont to adopt.

\subsubsection{The productivist identity and good farming}

There were instances in which the historical preference for a highly productive management approach emerged. This resulted in a distaste for ELS options that came with an associated dip in productivity. E05 offered the simple equation that:

Set aside is a $\sin$

and that it is:

Morally wrong [when farmers take land back out of production] to grow wildflower strips.

Even for E05, in spite of the unequivocal moral need to produce food, there was nevertheless a conciliatory tone of hysteresis with regards to his environmental attitudes. He recognised that his beliefs were most likely out of date, and that he was just the product of the structuring effects of his education:

What I was taught at college would probably be frowned upon now. It was basically grow more, grow more grow more... It was a bad time back in the $50 \mathrm{~s}$.

The subtle indication that it was a 'bad time' appears to function as a dual recognition that it was a bad time on account of there being potential food shortages in the country, but also that the practices the farmers were forced to adopt were a necessary evil, given what we now know about the environmental problems associated with a systems of intensive agriculture. Whilst agri-schemes and their set aside provisions are unable to 
attract his respect, there is an admission that within the wider agricultural field, an environmentally sensitive management approach may well be capable of attracting reproducing cultural capital.

In other cases, a preference for land in agricultural production was given as a function of the existential role farmers occupy as food producers. When asked about whether he likes to see environmental management, E06 replied:

I think nice crops give me more pleasure!

Even in this iteration of the food-producer identity, however, the capacity for environmental features to generate cultural capital is clear: environmental features are respected, albeit less than the presence of a tidy crop. At the very least, proenvironmental management is not incompatible with generating cultural capital, as earlier studies seem to demonstrate. E18 offered another expression of the good farmer/food producer overlap. Compared to his self-identification as a food producer:

Being termed a land manager is derogatory,

The productivist identity, in which yields are king appears to emerge, and with it a resistance to putting too much land out of production in the name of environmental management. Again, however, a look at the wider context of the response reveals a more subtle vision of how the productivist identity intersects with environmental management and contemporary agro-economics. The interviewee complained about the economic problems associated with CS participation:

By taking 5\% out, you have a farm, you have a set of employees, you have a set of equipment, straight away, you're 5\% less efficient. I'll be honest, margins are not great.

On first inspection, it may appear to be a cut and dry case of the productivist identity manifest - disliking environmental management on the grounds that it represents a 
deviation from the production the land would otherwise be in. The environmental feature, however, is not problematic qua land out of production: it's on the grounds that it represents an unfeasible economic outlay (hence referencing the 'set of employees' and 'set of equipment' that will not be able to be financed, as opposed to yield losses). In Bourdieusian terms, the loss that participation incurs is in economic capital - and is not about the perceived loss of cultural capital that has historically been at the core of issues around the cultural incompatibility between farming identities and environmental behaviour.

In a similar way, M10 claimed that the ELS's successor scheme - CS - required too much land out of production and over-restrictive regulations:

If you went into them, they really would stop you farming - it'd effectively be hobby farming.

The demanding stipulations contained in a CS contract (which was explicitly designed to contain more onerous environmental options and take a step away from ELS' 'broad and shallow' profile) appear to represent too great a deviation from the desired productivist behaviour. The 'hobby farmer' term is used pejoratively and is clearly not a version of the 'good farmer'. As a result, it represents an unpalatable loss of cultural capital. Later in the interview, however, he qualifies his resistance towards CS, and claims that "They are making it so constrictive with their rules that the costs are outweighing the benefits". Crucially, those costs are paid in economical capital and not in cultural capital: the outlay is in the time and resources needed to service the contract and is not about the perceived loss of face that comes with deviation from the productivist objectives of a high yielding farm. Indeed, M10 was otherwise a highly environmentally proactive farmer, critical of intensive operations that, in his eyes, left no room for wildlife, and was causing major damage to longterm soil viability.

6.3.1.2 The good farmer and the middle ground 
M10's position and his reaction to the prospect of the demanding CS scheme reveals a common attitude: that there can (and must be) a healthy middle ground for the farmer that balances the responsibility to manage the land in an environmentally friendly way, but where those environmental considerations do not interrupt the capacity to run a financially viable unit. Consider the following:

M01

No, I think you can leave a little bit of room, some people go a bit too close [to the ditch or hedge]

M16, responding positively to the question of whether he likes to see less intensive operations:

Few weeds don't hurt anybody!

E07

His reputation was that he used to farm part way down the ditch! Absolutely nothing got missed! Certainly no room for any environmental or wildlife facilities

And E06

Well I would have said a long time ago to produce as much as possible, but... slapping on that extra bit of nitrogen to get that, to squeeze that bit extra is not good... Makes more sense to hit a happy medium than to beat the yield records.

E06's statement is particularly instructive. Whilst there very well may have been a time in which yields were the goal to be pursued at all costs, we are passed it, and now other considerations - concern for the long-term soil health (as we will see below) and leaving room for wildlife - must be reconciled with the need for 
production. The good farmer, and thus the farmer best placed to reproduce cultural capital to secure desirable field position, must be able to navigate these less unilateral farming preferences.

Amongst the interviewees, this 'middle ground' represents a common expression of a new-look good farmer identity that doesn't come with a de facto incompatibility with scheme participation or environmental management. Talking about farmers with too tight a rotation, E09 reports that:

It's getting the balance. You can't go too far [with a low intensity system, long rotation], as you'll be out of business, but soil structure is a big issue.

The good farmer, in this version, is the one who can strike the balance between running a farm operation that doesn't deplete the soil (or, better still, help rebuild soil health), whilst avoiding such a low-intensive, pro-environmental operation that the farm business is rendered unviable. This preference helped shape the sorts of farm management he (dis)respected, and thus the behaviours capable of reproducing or losing cultural capital:

You know farms that have gone rape wheat rape wheat, and now have club root and soil born problems because it's not a big enough break. Whatever you do intensively, you're going to build up the natural predators or diseases.

The exchange between interviewees of E12 echo the above attitude:

I think looking over the hedge and seeing buffer strips and wildflowers, we all like that - don't we?

\section{I certainly notice it. [secondary farmer]}

But if we feel that the growing of that is actually going to affect the margin of profit, to such a degree that actually things are going to make any money that compromises our thinking. 
The qualification "to such degree" in the above statement is interesting: that environmental features may lose the participating farmer some money is both acceptable and inevitable. When that loss falls outside the tolerance level - the limit of which is when the viability of the operation in toto is undermined because of the environmental activity - then the capacity for the environmental work to reproduce cultural capital stops

The intersection between environmental management and income loss is also discussed by E10:

There are people who, and I would count us amongst them, can see a slightly wider picture... if we allowed a woodland edge to creep out that would be fine. It might look untidy. However, we would make sure we wouldn't put it somewhere there was a vital water carrying ditch which was maintaining our drainage system.

That a woodland edge is untidy isn't, in and of itself, problematic. The issue arises when the woodland edge has an adverse impact on the productivity of the land still in production through lost drainage capacity. Participants can prevent this from happening, however, through proper management and careful consideration of where options are located. As we will see below, scheme contracts and their delivery/implementation are becoming important arenas in which skill and knowledge is put to the test, and where cultural capital can be earnt or lost accordingly. In any case, the middle ground between the need to integrate environmental management with a business viable operation reveals itself as an important feature of the good farmer's management approach.

The balancing act between sensitive management and economic viability and is repeatedly cited as an important fulcrum point, determining the interviewee's reaction to the environmental behaviour of other land managers. Speaking about a nearby organic farmer, E09 reported that conventional farming has a lot to learn about how to work with nature, be less dependent on agro-chemicals, and rebuild soil 
structures. Asked if he was tempted to follow suit, he claimed that he could never go fully organic because he:

Couldn't stomach the disasters he has.

Integrating the above statements into an updated version of the 'good farmer', we can see that environmental behaviour, in instances where it causes an unacceptable dent in the farm's balance books can attract criticism and an associated loss of cultural capital. Where it can be integrated it into the management of an economically successful farm it is, however, capable of reproducing cultural capital for the participating farmer. Directly asked if he respected the organic farming approach, E09 was unambiguous:

Oh yes!

To further understand this formulation, we need to scratch beneath the surface of the respect associated with environmental behaviour. Under what conditions can environmental behaviour reproduce cultural capital, and why?

\subsubsection{Business-orientated environmental behaviour}

A large portion of the respect for environmental behaviour is grounded in its capacity to be part of a viable business model. As the relationship between high yields and economic success is remoulded by policy changes (in which subsidies play an increasingly important role in farm business, and in which subsidies are increasingly predicated on meeting environmental standards, or delivery extra environmental services), the agri-economics of modern farming, and concerns over long-term soil health and its business implications, the agricultural field is experiencing a period of hysteresis. The hysteresis is repositioning the perceived value of management decisions that aren't geared towards the short-term maximisation of yields, such that they are no longer necessarily a sign of lax financial management. Instead, they can be a reflection of the farmer's navigation of the farm subsidy system and produce 
margins, and their long-sightedness in tackling long-term soil health issues, and so are fully capable of reproducing cultural capital.

This idea is in evidence in the statements of the young farmer-cum-agricultural college lecturer in interview M09. Talking about the generational shift in environmental behaviour patterns, gleaned from interaction with her students, she reports that:

I think it's the younger generation coming through. More like 'no dad, you can't just burn it [plastics or tyres]' ... and all of that is linked in with all the different farm assurances. You can hardly sell now without being Farm Assured, and to comply with Farm Assurance, you're almost already doing half of the environmental stewardship stuff anyway - it will be difficult to be a dirty farmer, now.

The interviewee further develops her understanding of how farmers perceive the environmental activity of other farmers:

If you're talking about looking over hedgerows, it's a case of 'guess which stewardship they're in!' 'If they haven't cut that hedge this year, they must be in that scheme' or 'they've got that strip they must be in this scheme'. So, there is an awareness... rather than 'they're a dirty farmer' it's more 'they must be in that scheme'.

The need to be environmentally considerate - in this case about waste disposal, meeting Farm Assurance environmental standards, or participating in an AES - is so ingrained in maintaining a viable business in the modern farming world, that younger farmers unthinkingly integrate it their management of their land, and how they read the management decisions of their neighbours. Participation in an AES or meeting the standards of a Farm Assurance scheme, from this position, are treated as a noncontentious, standard part of managing a farm business, and so is capable of reproducing cultural capital in much the same way that any other farm practice could. At this level of familiarity ("guess which stewardship they're in") scheme 
participation or other environmental behaviour arouses a sort of ambivalence. It's only when farmers dip below this expected level of environmental sensitivity that it attracts the critical attention. The idea of falling short of a perceived minimum environmental standard and the criticism it can attract, as opposed to the respect proenvironmental behaviour can earn, will be further developed, below.

That environmentally sensitive management is respected qua reputable business practice - as with M09's account - can be seen throughout the interview data. Talking about a farm visit, and her reaction to a neighbouring farmer's operation, M20 said:

They have no end of it [environmental features] down there and gone for loads of grants. And the place looks brilliant! And I can't stand [name of farm manager removed] down there personally, but I sent him an email and said the place looks really smart and you should be very proud. To drive through it was a pleasure... He's put trees in, he's put a pond in a boggy bit and it's all under schemes.

Here, the respect seems to gravitate simultaneously towards the environmental benefits delivered by the different features established on the farm, and the savviness it betrays of the farmer who has managed to unlock the funding to get the work done. Without the existence of the scheme money, the environmental work would still have reproduced cultural capital for the farmer (the email would likely still have been sent, and the environmental features would still have "looked brilliant"), but there is an added component of cultural capital in having navigated the available schemes to help finance the work.

Unpacking environmental behaviour as a business decision is also evident in the language used by members of one of the larger, more agri-business style enterprises interviewed. For M13, adopting management approaches that place a less intense pressure on the soil, and managing features for biodiversity improvement fell under the rubric of "best practice" and so was a largely value-neutral attempt to run the farm business as best as possible. For others, the commercial value of environmental 
management was grounded in its marketing capabilities and was similarly tied up with the farm's business considerations. M03, one of the managers at another of the agri-businesses, discussed the wildflower strips on the farm driveway, and their being able to show supermarket buyers that they were achieving the desired level of environmental proactivity:

Our customers are Tesco's, Sainsbury's, Asda's. When we have a customer visit, we always show them we've a strip down there, we've got game strips down there, cover strips.

The ecological value of soil conservation practices or wildlife strips, in the above accounts, was firstly about their value as a business or marketing exercise, and secondly about living out their private beliefs on how to manage the land in a sensitive way.

E18, similarly, offered a direct link between scheme management and marketing one's produce:

[Scheme participation] is a business decision... if it helps our financial situation, then great...we have to promote a certain amount of responsibility to the environment. If the public can see that, then that must help. You have to promote public relations as a business exercise.

The business value of responding to market demand and public pressure for farm operations to meet certain environmental standards was another theme repeatedly cited as a motivational factor in adopting certain management approaches. When asked if there was an increasing motivation and understanding of environmental issues, for example, E16 replied affirmatively, adding that:

People who are pressurising them to take interest in the farm and the environment - all this sort of thing. 
M01 regales his experience of a long since passed local arable reversion scheme he was a part of:

I was laughed at... What I said to them was NE brought out a thing that said, 'we are spending $£ 1.5$ million down on the backs of the estuary over the next 10 years' and I could say 'well I got $£ 160 \mathrm{k}$ of that!' so you didn’t look quite so stupid. We got that on fences, planted a lot of hedges, we fenced both sides, on a capital basis.

Clearly a main portion of the pride comes from having been able to draw so much from the government pot, but as the money was claimed on a capital basis, he will have made little or no profit from the scheme, and so the satisfaction is also at least partly derived from the fact that he was able to lay so many hedges (which he elsewhere explicitly lauded for their habitat value) and install so many fences (which were elsewhere valued for helping the ponds and hedges to flourish by keeping out the cattle). Availing of the funding was framed as a direct rebuttal to the cultural capital he risked losing from other members of the community who laughed at him for putting so much land out of production. Indeed, elsewhere he described his motivation for going into the arable reversion scheme, his current ELS contract, and a failed HLS application as

partly financial. And some [environmental] interest.

If navigated correctly, scheme participation is the happy intersection of best business practice, and a welcome opportunity to deliver environmental services that would otherwise be financially untenable.

Soil quality is another important point at which environmental activity gets unpacked and valued as good business practice as well as environmentally sustainable behaviour. The attempt to secure yields, quick, comes at the sharp end of E02's criticism: 
That's what good farming is - passing on a viable business, and not ruining the ground... Problem is, a lot of the short farming agreements have been driven by the bottom line... You can make a profit in the short-term... but they seem to be on the shorter rotations. Because our rotation is longer because the various crops we grow... we're not getting those underlined diseases that were locked in the soil that people don't really understand yet.

Here, intensive farm practice is criticised for the financially and environmentally unsustainable use of the soil, and the farms that have too tight a crop rotation are the ones that are liable to lose cultural capital. Recall, also, E09's criticism:

[Some farms] have gone rape wheat rape wheat, and now have club root and soil born problems because it's not a big enough break. Whatever you do intensively, you're going to build up the natural predators or diseases.

His formulation of cultural capital is the same: the farms with intensive rotations are heir to cultural capital losses because those practices amount to bad business and environmental management.

M02, who has become heavily involved in minimum-till farming, reported that good farming is:

Trying to farm sustainably, trying to make a profit, whilst hopefully improving the soil.

In all of the above cases, at the top of the 'good farmer' check-list was long-term management of the soil as an essential measure for ensuring long-term business viability.

Understood simplistically, the above formulations do not represent too great a deviation from the traditional productivist identity. The top priority is (and has always been) to run an economically successful farm. Historically this has been directly tied up with high yields, and in lieu of today's current understandings around 
soil depletion and the loss of pollinators, the behaviours that pertained to consistently high yields (straight plough lines, high proportion of land in production, usage of agro-chemicals, well-kept machinery), by extension, also pertained to a financially buoyant farm. Now, due to the precarious price margins that farmers are reliant on, the relative value of subsidy payments to the farm business, an increased awareness over the long-term dangers of degrading soil quality, and the marketing value of environmental proactivity, a financially buoyant farm is increasingly tied up with the delivery of environmental features and the preservation of soil health, and so respect is conferred where those environmental steps are being taken. This attitude is neatly communicated by E03 when he explained his way of thinking about the farm's ELS contract:

It's the mentality that we've taken on - to think of it as a crop.

The contract's environmental features are just one amongst many in the farm's produce portfolio, part of the business make-up of the operation. In such a reading of the situation, the cultural capital is not necessarily associated with environmental management qua its environmental or ecological value, but qua business decision.

Those who were optimistic about the capacity for AESs, and the exposure of land managers to environmental regulations, information and practices, to catalyse longterm attitude shifts may be accordingly frustrated. Whilst the schemes may have been capable of delivering the environmental services contained within the participants' contracts, the land managers' long-term behaviour will be unlikely to change as their environmental pro-activity is still, in lieu of any substantial attitude change, largely contingent on scheme rewards. In terms of Bourdieusian thinking tools, the rules of the game that dictate which behaviours and artefacts reproduce cultural capital remain unchanged, and the respect farmers can attract through environmental management is predicated on the economic and policy landscape that offers financial rewards for the adoption of pro-environmental land-use practices. The only comfort is that the negative stigma associated with set aside and scheme participation appears to have abated, such that so long as the schemes are well designed and participation is well remunerated, the 'cultural resistance' described by 
Burton et al. (2008) towards them will not be an important determining factor in participation levels; and that many farmers have digesting and integrated information around soil health and soil depleting practices into their farm management and their analysis of the good farmer-ness of their neighbours. The process of change in the agricultural field, as such, seems to have occurred only to the extent that no cultural loss of capital will be incurred by through scheme participation, and that extra cultural capital is available for observing environmental practices where the intersection of environmental and business management is most clear (e.g. soil health).

\subsubsection{Environmental behaviour and cultural capital}

Look closer, however, and there are signs that the good farmer ideal has been subject to real and substantive changes, such that environmental behaviour is increasingly able to reproduce cultural capital for the respective farmer, beyond the economic contribution it makes to a farm's business model (i.e. where environmental management is respected even outside those topics with clear-cut businessenvironmental intersections). The best indication of this comes from the number of respondents who expressed a preference for contract options that were environmentally successful and well-managed over poorly delivered and environmentally valueless scheme option. Consider the response of the young shepherd respondent in interview E12:

I think you can tell the difference with different farms on the effort they go to doing it. You'll see some where you think there's clearly some effort gone in... You then go to some others where they drill it and forget about it token gesture. The money's in the bank.

And when asked about his preference for the two:

Well you can understand why the big boys are giving a token gesture - or say a big family farm, where, you know, they are a bit stretched for staff but they're of that acreage where they can manage, you can understand how and 
why it's a token gesture. But I've also got a lot of respect for people who are putting in the extra effort.

On a similar note, E15 recalled a visit to a nearby farm:

We went on a farm walk somewhere and they do the whole farm - a big farm - so they put down the borders, you know, either pollen mix or something else. Well I've never seen so much rubbish! I don't think they could have done it, I never seen a bloody plant.

Asked directly which she would have respected it more if the pollen mix had been properly delivered, she replied affirmatively.

In such instances, a well-managed and flourishing feature will provide the same level of economic contribution to the farm as a poorly delivered, failing option. There is, of course, a chance that the farmers with the poorly managed options, identified in the above statements, will be penalised through the scheme's mechanisms, but the tone of the responses indicate that the criticism are not about the likelihood of them being caught and financially reprimanded for their poor scheme performance, but about the shortfall of time, skill and effort, and ultimately the absence of the environmental benefit that a well-managed option would otherwise represent. Asked about the "enormous respect" E04 has for local land managers heavily involved in environmental management, he reported that:

I'm talking beyond scheme money. If one can increase butterfly, hoverfly, all such species as that, and at the same time make environments for the plover and the grey partridge... But it's a great art, and a great deal of time and money to do it properly.

Here, the motivations for his respect are laid bare. Those land managers who are doing a good job with their environmental stewardship and other voluntary efforts are attracting his respect for more than just 'scheme money' but for the range of biodiversity improvements they bring and the skill and effort it takes to do it. 
Cultural capital, in this equation, is not just rooted to the economics of modern farming and environmental subsidies, but is about the farmer's genuine desire to see environmental improvements and the associated respect for the motivation, skill and effort required to realise those improvements.

Indeed, statements of this sort - in which respondents demonstrate their respect for a successfully delivered option, the skill and effort it communicates of the respective farmer, and the environmental improvements it represents - were common. M02, when asked about his reaction to seeing other famers engaged in environmental management replied:

As long as they've done the options well enough! Some stuff you see around here that's supposed to be whatever it's supposed to be... like with anything, there's good and bad versions of stuff. Whether it's a wildflower bird seed mix that's actually grown and done its job and provided anything for the birds.

Asked why, his response was:

Well, it's just good to see other people doing their bit, really.

Clearly, the "doing their bit" is not about doing "their bit" for their balance books, but rather, doing their bit for the rural environment. E10, explaining how options require constant attention and explains that delivering an AES option:

Isn't something that you just allow to happen and manage as a second thought - you have to put a lot of time and effort and money in to make it work properly, and that's what the taxpayer is paying us for.

The stress put on good work, and the scorn implied for those who think that options can be managed without "a second thought" indicate the conditions that need to be met to unlock the potential cultural capital that stands to be generated through scheme participation. As we will see in the following subsection, the damage done by intensive agricultural systems, the value of integrating pro-environmental 
management into one's business model, and the need for some ecological management or soil promoting practices have become a normal, non-contentious considerations made by farm managers. This standardization, has, in turn, influenced the depiction of the good farmer ideal, and the rules that determine how and when cultural capital can be reproduced through environmentally sensitive management. That such a process of standardization has occurred was brought into clearest relief by those interviewees evoking a generational division of attitudes. E15, remembering her deceased father's approach to farming:

Yeah, they wouldn't have given nothing up for anybody [taking land out of production], would they? But I think that's a different generation now - my father was a bit like that. He's died now, but he was all 'oh we don't want to do that' for that little bit extra money.

6.1.3.5 Policy influence and attitude change

M04 draws the direct link between government influence and attitude change amongst the farming community:

I remember when I first did it [helped on the farm] we used to put a nozzle at the end of the spray boom right into the bottom of the hedges! It was all tidy farmland. But now you have to accept the farm isn't as easy on the eye when you're doing these things... Well what would influence that? Well the government I suppose, isn't it? They're pushing schemes. Before we were on ELS, we were on Countryside Stewardship... In the 80s it was still sort of push push push! And there was a bit of a shift in thinking wasn't there?

M19 goes one step further still and traces the relationship between subsidies, attitude change and respected/non-respected behaviours:

There is a mind change, sort of thing

From what to what? 
Firstly, it was subsidised a bit, obviously. And then it's just got folks into that mind set, hasn't it? You know, thinking about it. Years ago, you would be shunned upon, anything like that.

AESs - and ELS in particular - along with all the environmental messages and information they come with, have helped foster a widespread confidence amongst farmers to include the environmental performance of nearby land managers in their 'over the hedgerow' assessment of other farmers. Where environmental management was previously a fringe activity that was 'shunned' by nearby farmers, it is now so a common feature in farm management, that it is increasingly appearing in farmers' check-lists of how they assess the skill and knowledge of their neighbouring managers.

Along with the perception farmers have of other farmers' behaviour, a number of interviewees also explain the pride they have for certain features of their farm. Looking at pride, in Bourdieusian terms, can help lay bare the full equation of cultural capital reproduction - inspecting the behaviours that a given individual perceives as those that will be respected by others in the field, as well as the respect they have for other's behaviour. E10, showing pictures of wildflowers in a grass margin, that had been taken as part of an ecological survey to gauge the impact of ELS, said:

This is one of our grass field corners, and we just used a relatively small amount of wild flower mix in there... these are pretty good! Huge assets to the countryside.

And E13, discussing hedges that were put back in through ELS, talks about their biodiversity value:

It just gives a better environment, doesn't it? 
Recall, also E10's statements about the management of a woodland edge, and the need to position the edge so it doesn't interfere with the drainage capacity of a nearby ditch or river. For the interviewee, it was a badge of honour to be "able to see the wider picture" and accept the untidiness of a scheme contract in the name of delivering environmental improvements and accessing scheme rewards. If a participating farmer has the forward thinking-ness to "see the wider picture" of a scheme's economic and environmental value, and the skill to deliver it effectively, it can be the source of cultural capital. If, however, the feature is put in a bad place, is mismanaged, or is allowed to negatively impact the agricultural output the field, the opposite will be true. They will have marked themselves out as one who can't foresee the potential problems associated with putting a woodland edge near a water carrying ditch, and as someone unable to effectively deliver the contract. They will be heir to his criticism, accordingly.

For M02, the pride at his own environmental features had a competitive edge:

The thing what we notice most, quite soon after we started in 2000 with CS, with the strips, we seem to have more hares. My strips are always - dare I say it - better than most people's!

Here the pride at excelling is about both the skill required to establish the strips and the biodiversity improvements that features have helped bring about. Probably told with some embellishment, E19 regaled a story about the pride some nearby farmers take in their margins:

I think most farmers are actually, what I call, part conservationists, and it is quite amazing - the people who put $2 \mathrm{~m}$ strips around their fields, and I can name several farmers who have done this and keep it absolutely tidy, and when my wife goes out hunting, goes fox hunting, they're not allowed on the grass strips.

So, they're proud of them? 
Yes! Exactly that! We don't want you walking on the grass strips, we'd rather you walked on the wheat!

\section{For what reason?}

For conservation, and because, I suspect, it takes a lot of bloody effort.

Whilst the environmental value of an "absolutely tidy" $2 \mathrm{~m}$ strip may be called into question, for the participating farmers, their pride is rooted in the strip's conservation value, as well as the skill and effort that precedes the feature being established. These findings echo those of Riley (2016) who found how the delivery of AES options had become sites of embodied skill, and pride - and how the pride were about much more than the economic advantages conferred by scheme participation.

The above interactions further reveal that the schemes are being valued well beyond the economic contributions they make to the farm business. The pride, respect and associated cultural capital is not only tied to the successful navigation of the current subsidy and economic landscape to manage an economically successful farm, but about the skill and effort that delivering a scheme contract reveals of the participating farmer and the environmental goods they are providing.

\subsubsection{The bad farmer}

There remains one further insight the data has to offer about the relationship between the good farmer, cultural capital reproduction and environmental behaviour. The insight is one so far undocumented in the literature, and as such represents a conceptual contribution to the study of the agri-environmental attitudes and practices represented in the agricultural industry. The point that has already been hinted at in the above analysis and relates to the minimum environmental standards that farmers are increasingly expecting of each other, and the cultural capital losses for the 'bad farmers' that fall too far from this minimum threshold. 
We have already established the conditions under which farmers can access extra cultural capital through environmental management or scheme participation, for the business contribution they make to a farm (marketing material, financial value of subsidy, long-term soil/business health), and the skill and understanding they help communicate of the participating farmer. Running concurrently, there is also an increasing expectation that farmers meet a certain environmental level, or risk the criticism of nearby farmers. One of the most salient examples of this relates to the management of soil. We've already heard the value placed on long-term soil management, and the criticism that farmers may be heir to if they adopt too tight a rotation or try to get too much out of their soil, too quickly. For E07, the good farmer was someone who:

[farmed] for the long-term

and for E02, the same idea was expressed from the other extreme:

I think that's bad farming, short-termism.

The sentiment can be seen throughout the data. For E04, the good farmer had a balanced rotation to ensure long-term soil health - and by extension the bad farmer employed exploitative or intensive practices, in the name of securing short-term financial gains. When asked about the future of farming, he reported that:

You can't say it'll get infinitely worse as farming is pretty intense around here.

Clearly, there is a fulcrum point at which the intensity of production falls into the realm of 'bad farming'. This is further brought into relief, when he described his "shame" at having to plan to remove the environmental features once the scheme comes to an end. Shame in this instance is about having to adopt a more intensive management approach - perhaps one that errs the wrong side of the acceptableunacceptable divide described above - in order to sustain his farm business. 
Farmers attempting to produce too much food on too much of their land were also brought into the firing line of a number of different interviewees. E06 expressed his distaste for farmers who:

Take every last vestige of life out of it [the land].

Claiming that doing so was:

Unnecessary

When a nearby farmer was planning to take up a number of hedges and infield trees, he tried:

Phoning round to see what we could do to stop it

He set out his perception on the extent to which farmers are judged according to their environmental behaviour. When asked "do you think they judge each other by how environmentally friendly they are, or do you think not?" he replied:

No... well apart from if you get somebody who wipes out every tree in sight!

Clearly, whilst there may be a limited amount of cultural capital associated with overly proactive farmers, those negligent or damaging ones are falling short of some perceived level of care that farmers are obliged to deliver and attract his criticism accordingly.

M06 helped detail the good farmer/bad farmer, production/over-production tension as a reductio ad absurdum style argument:

Well if it [a wildflower strip] encourages the birds and that, fine! [older farmer, father] 
But it's not good farming, no! You're letting good land go to waste. So, it's not good farming, is it? That's not what farming's about... Ripping out the hedges I think was probably wrong, that's what everybody used to do years ago but then the fields were too small. [younger farmer, son]

You could not farm with all little fields, no.

Oh yeah, the machinery is too big.

But the reverse of that - if you'd have carried on with where they're going, there would be one big field from here and London and there wouldn't be a hedge! You go to the middle of America and it's ten times the size and you can't see nothing, it's just corn for miles and miles and miles and not a hedge in sight!

And is that bad farming would you say? How they do it.

Yes I would!

The same reductio criticism is offered by the interviewees of E12:

The farmers... we lightly and jokingly call them prairie farmers, but we do have areas in East Anglia where it's just 'woosh' [miming a flat expanse]. Very easy to be critical of them, because they're not doing a lot of favours to the environment. [main farmer]

Oh yeah [farm employee]

And for you is that good farming?

Not really. 


\section{They aren't top notch farmers...They literally plough up to 9 inches of the road!}

In pursuit of production and financial gain, those farmers are clearly falling short of some level of environmental behaviour that the interviewees expect of other land managers. For the interviewees of M06 and E12, telling such stories helps characterise an overly intensive approach - one that clearly comes with the sort of criticism that precedes a loss of cultural capital.

E08's vision of the bad farmer was vitriolic. Describing a nearby farmer who left no room for wildlife, took up hedgerows, shot birds, and ploughed right to the edge of the field as a "bastard", and "obsessed" with having a tidy farm, with his unthinking reliance on slug pellets particularly vexing because of the damage they did to bird populations. Similarly, E09 equated the overreliance on agro-chemicals with a disappointing loss of skill and pride in arable farming:

We don't need to use that glyphosate if we'd ploughed it properly in the first place and buried all the rubbish.

The comment was made in particular reference to the value of low-intensity farming when building up organic matter in soil, and the idea of the bad farmer farming, although not explicitly raised, is clearly at work: those farmers who have no pride or skill in ploughing, and who make up for the shortfall thereof with glyphosate, are doing unnecessary damage to the land and are heir to criticism accordingly. M01 expressed the distaste for overly intensive practices through a farming adage:

Live as though you'll die tomorrow and farm as though you'll live forever.

Before claiming that farmers should

Leave a little bit of room. Some people go a bit too close. 
For M15, it was the issue of over reliance on sprays that came into his negative judgement of nearby farmers:

We've just been saying that some want to plough everything up but-

\section{Fatal [older farmer, father]}

What do you mean by that?

\section{Well they destroy some of the things that are good for farming, aren't they? Insects and whatever.}

It's the bees, isn't it? [younger farmer, son]

The criticism here is not just grounded in the associated impact that such an approach has on farming, but in the ecological concern for the impacted wildlife:

And when you see the enormous sprayers, I mean I know you've got to have the food, and there are a lot of people to feed, but you can't help but think all of the little animals and bugs and things that are on there. And they're just being covered in this stuff!

The criticism for environmentally negligent behaviour was also expressed in relation to water quality, NVZ regulations, and the interventions made by the local water board to nitrogen pollution. E03 was clear both about the positive association of proactive farmers as well as the criticism for negligent farmers:

If some farmer was known to be really lax, or dragging their heels, or doing stuff that the farming community now knows to be damaging, do you think it would be badly received?

Yes, I think people would... we know each other well enough, that it would be flagged up and something would be said. It would be mentioned. 
For E03, in other words, he would criticise and disrespect those not paying enough attention to water quality issues, and whose practices are jeopardising the shared natural asset. The environmental profile of a farmer is, in other words, an arena in which cultural capital can be earnt or lost. In a Bourdieusian analysis, the statement is particularly instructive: that the positive or negative conference of cultural capital can function is dependent on them "know[ing] each other well enough", or that the field is sufficiently bound together.

Although a tangentially related, E17's perspective on the behaviours of the bad farmer is also interesting. A cattle and pig farmer, he took umbrage with stock farmers who were reluctant to sacrifice their own time and energy in the name of animal welfare. There are, he claimed:

People who look after stock, and there's a stockman and there's a bloody difference between the two!

The difference is most discernible when there are health issues with the stock:

If I was going somewhere and there was a problem, I'd cancel that straight away, deal with the livestock, deal with the problem. But you see a lot of people on these units... they just do their 7 in the morning, 5 at night.

Indeed, if we recall the 'middle ground' style statements, offered above, the idea of the bad farmer as an overly intensivist farmer reoccurs. Consider the following statements:

M01

No. I think you can leave a little bit of room. Some people go a bit too close [to the ditch or hedge]

Pushing to get the last bit out of the land... few weeds don't hurt anybody! 
And E06

Well I would have said a long time ago to produce as much as possible, but... slapping on that extra bit of nitrogen to get that, to squeeze that bit extra is not good... Makes more sense to hit a happy medium than to beat the yield records.

The role of the farmer is clearly to produce food, but where that objective tramples over other considerations - when they come at the cost of soil health, animal welfare, insect life, birdlife - then farmers risk the scorn of the field, and a loss of cultural capital.

Drawing together the different insights provided by the data, a clearer picture of the conditions that need to be met for cultural capital to be reproduced through the adoption of environmental management can be divined. The following list is an attempt to distil the above analysis into a succinct and discrete crib sheet for the reproduction and loss of cultural capital within the agricultural community of the two case-studies, with regards to environmental behaviour and scheme participation:

1. Little of the purely productivist identity remains that has previously caused a cultural aversion to AES contracts on the grounds that the scheme options represent a deviation from the high production goals. That cultural capital can be lost or earnt through scheme participation or other voluntary environmental management is determined by a number of factors detailed below, and not an ideological commitment to maximising yields/aversion to the reduced yields of an environmentally sensitive management approach.

2. Where scheme participation is integrated into a farm business cultural capital is reproduced as it represents the successful navigation of the current policy and agro-economics landscape (in which environmental management and subsidies are playing an increasingly important role, in which buyers are expecting certain environmental standards) 
3. Successfully delivering the environmental features of an AES contract can reproduce more cultural capital still, for the dual reasons that it demonstrates the skill and aptitude of the respective farmer (knowing where to place options, how to establish them, and the requisite attention needed to maintain them), and helps deliver environmental objectives that are valued in and of themselves (rural environmental health, biodiversity, water quality)

4. Through the adoption of other environmental management practices (including, but not limited to, sustainable management of soil, provision of wildlife habitat), extra cultural capital can be reproduced. In some instances, it is heavily rooted in the business value that such management practices represent (long term soil health needed for long term business health, unlocking the marketing potential of pro-environmental management, improving long-term yields through protection of pollinators, or natural pest predators). In others, where the business value of the environmental work is contested, or less clearly understood, the value of the management practice is valued for more 'pure' environmentalist reasons (provision of wildflower or hedges for the biodiversity value, for example).

5. The adoption of environmental management practices (scheme participation or otherwise) is only capable of reproducing cultural capital where it does not jeopardise the farm business as a whole. That the adoption of an environmental feature or management approach (low intensity production, too much land out of production, organic farming, no-till) may cost the respective farmer money is acceptable/inevitable, but where it costs so much that the farm's viability is risked, the farmer's business management capabilities are called into question, and a loss of cultural capital is incurred.

6. Where farmers overlook environmental or ecological considerations, normally through the pursuit of short-term maximised yields, negligence or miscomprehension, it represents a deviation from the desirable 'middle ground' (between production and environmental sensitivity), and farmers risk 
erring into the categorisation of a 'bad farmer', and cultural capital is jeopardised accordingly. Examples include soil health being risked through intense, short crop rotations; water health risked through improper agrochemical application; biodiversity issues related to committing too much land into production or the removal of features such as hedges or trees. These criticisms are typically grounded in the joint concern over the long-term business problems that such management approaches are liable to incur, and an intrinsic concern for the environmental damage with which they are associated.

The topic of the bad farmer is, notably, an important emergent theme of the research. As we have seen, the idea of the good farmer represents an important conceptual contribution that has helped shed light on the participation of AESs and the adoption (or non-adoption) of agri-environmental behaviours. The bad farmer concept, outlined above, could similarly represent an important conceptual contribution. Its emergence in the phase 1 interviews means, however, that whilst a number of the interviewees hinted at the bad farmer identity or gave accounts that reveal the losses of cultural capital incurred through environmental negligence, it was not discussed as a matter of course in all the interviews. There were, in other words, a number of interviewees who made no comment either way about the behaviours of the bad farmer, or the potential losses of cultural capital. Fortunately, the project's inductive/deductive hybrid design and follow-up methodology mean that it is well stationed to integrate dedicated questions into the phase 2 interview schedule. To this end, the following emergent question was added to the project's initial two:

What are the minimum environmental standards managers are expecting of each other, how can Bourdieu's thinking tools help understand this process, and how can the concept of the bad farmer be developed to account for this process?

\subsubsection{Hysteresis, habitus change and new attitudes}


Having laid out the revised rules of the game that determine when cultural capital is earnt or lost through one's enactment of environmental (mis)management, the analysis will now turn to the question of tracing how and why this development has taken place. As we will see, the proliferation of AES contracts (notably with the ELS scheme), the widening public pressure around the rural environmental, and a changing agro-economic subsidy landscape have all helped normalise environmental practices in the agricultural community. This has lent farm managers the confidence to evaluate the environmental profile of their farming neighbours, as part of their standard assessment. Such insights have already been hinted at over the course of the previous subsection, but given the importance of the interlinking processes of hysteresis, attitude change, and rules of the game in the taxonomy of Bourdieu's thinking tools, they will here be given their own subsection.

Due to the longstanding, often multi-generational, perspectives represented in the interview data, valuable insights emerged relating to the shifting field conditions within the agricultural field. When discussing the change in attitude towards environmental management, interviewees often evoked a sense of 'how dad used to do this', or 'they used to do that', or '20 or 30 years ago, we would...'. Such statements function as a short-hand for talking about changed attitudes or practices and provide useful queues when mapping out the processes of habitus change and hysteresis that connects the lived experience of previous field conditions to current ones.

M21 builds on the idea of a generational divide to demonstrate the changing attitudes within the agricultural community:

You probably get a generation - there were farmers, what I call the ICI [large British agro-chemical manufacturers] generation, and they tend be more older farmers now in the 70s 80 s and 90s who were brought up after the second world war saying that you must produce as much food as possible. ICI saying 'bang on this white stuff' fertilising it to death... it was difficult for that older generation other than my old man [who was previously described as a forward thinking environmental farmer, before his time] - some of the 
neighbouring farmers were a bit like that, and they would sneer and laugh at people who went into environmental.

And then, later:

I do think a lot around my generation are very open minded to it?

And they've gone away from that sort of sneering-

Yeah. My age and younger are definitely more open... I don't think you necessarily have to be organic, but you have to be careful what you do do.

In a similar way, consider M04, talking about the potential conflict between a preference for a tidy farm and environmental management:

well when my father was like that - well he's died now - but when it all sort of kicked off you know... I remember when I first did it, we used to put a nozzle at the end of the spray boom right into the bottom of the bottom of the hedges! You know it was all tidy farmland.

And when asked about whether the community is becoming more switched on to issues like agricultural pollution of waterways, E03 attributes the change to cohort replacement:

we [have] reached a tipping point. I think at the moment the age of farmers is still increasing, and dad always joked that for the last 10 years the average age of farmers has been his age [laughs] - it's gone up with him - but just, unfortunately natural selection-wise, we are reaching a tipping point where it will jump down. Yes, so that's obviously changing things, where each generation is a bit more [environmentally conscious].

The above three accounts all share things in common. All were given by younger farmers, and all put distance between themselves and their attitudes and practices and 
the less environmentally sensitive attitudes and practices represented in previous generations. All also, either in the excerpts given or elsewhere in their respective interviews, explain how the new rules of the agricultural field determine how cultural capital can be reproduced through environmental behaviour, in line with the rules detailed at the end of the previous subsection. M21's account, for example, includes a transparent explanation of the changed level of cultural capital associated with intensive agricultural practices and environmentally sensitive ones: his father was sneered and laughed at, whereas him and his peers are open minded to it and have moved away from that negative response pattern. Participating in a scheme was, in other words, previously associated with a loss of cultural capital, whereas now, being 'open to it', cultural capital can certainly be earnt through environmental management, most likely in accordance with the rules outlined at the end of the previous subsection. Similarly, when asked if he respects other farmers for providing wildlife habitats alongside their productive land, M04 replied:

Yeah definitely

And E03 explains what factors he considers when judging nearby farmers:

your first look is a clean crop. As a farmer, if it's covered in weeds, you're not going to care what their hedgerows look like, but if you've got a perfectly clean crop and then a really nice, full, beetle bank or hedge margin with loads of different flowering nectar plants into that, it looks nice.

The three accounts all also present the process of attitude change as complete: the attitudes of their father's and/or their father's generation remain locked in the past, and the restless pursuit for "tidy farmland", and the "sneering" that comes with environmental activity is gone. All of them, also, lack the sort of cognitive struggle that characterises the hysteresis process. Their habituses, in other words, have kept step with the changing agricultural field, its economic subsidy landscape, and its new knowledge systems, and all are at ease with the new field conditions that is more critical of highly intensive systems and an acceptance of the need to integrate some sensitive management into the farm. 
Contrast those positions with the more problematic hysteresis process, manifest in E05's reaction to set-aside style management options:

What I was taught at college would probably be frowned upon now. It was basically grow more, grow more grow more... It was a bad time back in the $50 \mathrm{~s}$.

Recall also one of Bourdieu's more succinct depictions of the hysteresis process:

As a result of the hysteresis effect, practices are always liable to incur negative sanctions when the environment with which they are actually confronted is too distant from that in which they are objectively fitted. (Bourdieu 1977 p.78)

The explanatory power of the concept is evident. "What I was taught at college" i.e. to "grow more grow more" equates to the practice that was "objectively fitted" to a now "too distant" environment. The gap is so great that the individual is "liable to incur negative sanctions" from members of the field. Or, in the interviewee's words, he would "be frowned upon". E05, an older farmer, whose habitus was formed to fit an agricultural mentality characterised by high levels of production is coming into friction with the new field conditions that places value on sensitive management and set-aside, and the reconciliation of the habitus to the field conditions is far from complete. Similarly, M11 recognised that there was a growing trend in farming, manifest in AESs, of having unproductive land, but that he was at odds with the approach:

That's what it's about, is about having to take land out of production, I don't like idea.

Although such reactions emerged during the process, much more common were the farmers (such as M21 M04 and E03, above) who were more reconciled to the new field rules, detailed at the end of the previous subsection, that expect the pursuit of 
yields to be tempered by certain environmental considerations. This subsection will be dedicated to finding out what factors have encouraged the rules of the agricultural field, to which M11's and E05's habituses were designed around, to change to those that M04, M21 and E03 recognise.

\subsubsection{ELS experience and attitude change}

Consider E10's account of his involvement in ELS, and the blow-by-blow account of attitude change it contains. Here, he explains how his sceptical attitude towards biennial hedge cutting has, over time, morphed into one of familiarity and assent.

When I first came here, and that was 28, 29 years ago, the policy was to cut all the hedges every year, and they were lovely hedges. Well they weren't, actually... It was very expensive, but they did look beautiful.... And when we went into the original Arable Stewardship, which involved leaving the hedges for two years before you cut them, he said 'terrible mess'. But he accepted it. There had been some good research, looking at the number of insects that lived in a hedge that was cut every year compared to a hedge cut every two years.... And so he was happy to give it a go. Initially I suppose we felt it did look a bit untidy, but actually we suddenly realised that in the second year, you got vastly more things like dog roses and gull roses growing in there... Frankly, we've got quite used to it.

Noteworthy linguistic turns are littered throughout the excerpt. The interviewee initially casts the hedges cut every year as "lovely hedges" before immediately correcting himself, adding the caveat that "they weren't, actually". Clearly, on some level his preference for a tidy hedge persists. That association is, nevertheless, some way down the path of being undermined by a distaste for the relative environmental drawbacks and expense of a yearly cutting regime, and an increasing respect for the wildlife value of slightly messier hedges cut every other year. The remodelling of the habitus, with a little of the struggle of hysteresis process, is in operation. His habitus, which has a habitual and longstanding attachment to his "beautiful" and "immaculate" hedges has come into contact with new field conditions which dictate 
that those hedges are inferior when considering the wildlife and business management benefits associated with a biennial trim. Fortunately for the interviewee, the worst of cognitive strife that comes with having one's habitus remoulded to better fit new field conditions is over, with the interviewee appearing to be largely reconciled to his new belief system and behaviours: "frankly, we've got quite used to it".

A few features emerge as crucial to the above process. The interviewee's initial willingness to trial the management approach was couched in the scheme's remuneration, and in the "good research" into the wildlife benefits of the new approach; and the long-term integration of the approach into the interviewee's management preferences was couched in his seeing the environmental benefits of the technique with his own eyes ("you got vastly more thing like dog roses and gull roses" for example).

Having been paid to adopt some management practice, and getting the risk-free chance to see the technique in action, a number of participants reported a sense of being won over by a scheme management technique, thus easing the strain that would otherwise come with the prospect of adopting the practice where its value would have remained unexperienced and abstract.

The exchange with M20, for example, revealed the favourable comparisons being made between the management approaches being financed through the scheme participation and the management approaches that she (and her father) had historically taken:

I went into it sceptically 10 years ago thinking 'this is a way for me to improve my farm

Improve your farm as in...?

As in new fences. Because, you know, dad had taken it on and all they'd done was bung a bit of new wire on top of the old wire. Whereas we ripped it all 
out and put new in [with ELS per-capital-item finances] But I couldn't believe the difference it made to the wildlife... I went into it as a sceptic on the environmental side. Now I am completely behind it, and I can see the benefits.

Consider also, E15's response when asked if she would keep the water course strips she had in her ELS contract:

Yes.

And were they things you did before the scheme?

No, they're bits we did when we went in... I think they've made a lot of difference. I understand the old water courses and that.

Or M02, speaking in a more generalised way about how experiencing an ELS management technique can convince land managers of their environmental and management value:

I think they see for their own eyes, if they do some of the options, you know, I'm sure they can see any improvements, or, you know, for themselves... As long as they've done the options well enough... Whether it's a wildflower bird seed mix that's actually grown and done its job and provided anything for the birds.

Seen in this light, the scheme's intervention emerges as an important feature in the process by which the new attitudes and habits are absorbed into the habituses of the participants. Adopting practices that required only modest modifications to the management of the farm, seeing the management practice in action and having the management practice financed through the scheme's remuneration (i.e. where the losses associated with the adoption of the practice are accounted for), allows the scheme experiences to be accommodated and integrated into the participants' habituses at a rate and scale amenable to its capacity for iterative self-renewal. If the 
management practices were drastic, or if they were forced to adopt them without a financial cushion, then the rate and scale of the changes could easily have outstripped the habitus' capacity for change, and the hysteresis process could have been triggered. In such an instance, the positive experiences associated with the adoption of the scheme practices may not have been so easily integrated into the long-term management of the farm.

The chance to personally experience a management technique through scheme participation may not, however, be able to secure long-term attitude and behaviour change in and of itself. Here, M19 explicitly identifies the scheme's influence in the diffusion of environmental attitudes and practices, and provides an account of the relationship between an individual's own habitus, and the perceived habitus change of other members of the field:

There is a mind change, sort of thing.

\section{From what to what?}

Well firstly it was subsidised a bit, obviously. And then it's just got folks into that mind set, hasn't it? You know, thinking about it. Years ago, we wouldn't have thought about anything like that. Even though they are, obviously, because they are subsidised, but it still puts you in that frame of mind - why are we doing it, like?... I mean everybody knows about it, don't they? It's very much in the news, everybody knows that you've got to leave fields for wild flowers and stuff, don't they? Years ago, you would be shunned, anything like that.

As before, being forced to deliver the options of his ELS contract has helped M19 reflect on the importance of environmental considerations when managing his farm ("years ago we wouldn't have thought about anything like that.... But it gets you thinking what you're doing"). That change is, however, at least partly dependent on a perceived community-scale shift and is not just founded on his own personal experience of the scheme's environmental information and management techniques. 
By making reference to the ubiquity of agri-environmental contracts and the media attention focusing in on agricultural environmental issues ("everybody knows about it... it's very much in the news"), the interviewee hints that his being "put in that frame of mind" is contingent on the fact that many other members of the field are similarly engaging in such reflections, and are altering their practices accordingly. This is perhaps most evident when he feels the need to justify his conversion to a more environmental outlook - seemingly to both himself and the interviewer - that it's not just him that's thinking that way, but that "everybody knows about it, don't they?" In exactly the same way, when asked how he feels about the environmental behaviour of others, M02's response appears to situate what respect he has for it in the scheme's high uptake:

How do you think that factors in [seeing other farmers adopt environmental management practices], when other farmers see-

Uhm, I don't know. A lot of people have obviously got, or have been on ELS. Most farmers have been on ELS haven't they? Majority I'd have thought...So yes, most people are doing it, I suppose". It is, in other words, the community-wide normalisation and adoption of environmental management practices that has made the above interviewees more amenable to integrating the scheme's environmental recommendations and information into their formulation of cultural capital reproduction.

The idea that "everybody knows about it" is a revealing statement - a sentiment present in many of the interviews. Farmers repeatedly demonstrated their awareness of the environmental behaviour of their neighbours, and the spread of environmental considerations throughout the agricultural industry. Consider the follow excerpts:

Well they've all got it [an ELS contract]! I'm sure everyone's got it. 
You were in the minority if you weren't [in ELS]

\section{And E10}

Quite a lot of them would have ELS, and some of them HLS.

In other interviews, instead of blanket comments about the spread of environmental practices, interviewees cite specific farmers, their scheme activity, or the steps they are taking to combat various ecological, soil or water quality issues:

E04

A big change, in this year, I know two or three big estates, where there's much more attention being paid to soil structure. Hence catch cropping. Absolutely no soil inversion, or anything like that.

E05

I know my neighbour, well he does my spraying and stuff - he's a contractor - and he's gone all over to rubber tracks, and thinks after 3 or 4 years he sees an improvement

E15

Next door have kept all theirs [grass buffer strips] beside ours. They came out last January.

The big farm at the top, they'd be into it, they've got $6 \mathrm{~m}$ margins so higherlevel stuff and that. 
The effect is the same. There is a recognition of the environmental issues associated with agriculture and an associated acceptance of the value of integrating environmentally sensitive techniques (remunerated or voluntary) into the management of the farm to tackle those issues or to unlock scheme money. As a result, and as can be seen in the tone of the reactions to the adoption of environmental techniques, those practices have become considered non-contentious, standard parts of farm management, that fail to attract the "suspicion" (M21) or "laughter" (M01) that they once did. In other words, environmental management whether that be meeting the standards of a farm assurance scheme or GAECs, or AES participation, or other sustainable land management practices - has become a normalised part of running a farm.

\subsubsection{Normalisation of AES participation}

The normalisation process is, it is argued, at the heart of the phenomenon that has seen the environmental profile of other farmers play an increasingly important part in the good farmer, bad farmer ideals. Because of the widespread, non-contentious recognition that there are environmental issues associated with agricultural practices and, by extension the long-term viability of the farm, and because of the widespread recognition that there are environmentally sensitive management techniques (remunerated or not) that can have a positive bearing on the farm business and on the rural environment, farmers have acquired a confidence in assessing the environmental activity of their fellow field members. Where there is a perceived community-wide acceptance of the threat of environmental issues and the value of sensitive management techniques (hence M19's couching his new-found respect and understanding for environmental management in "everybody knows about it"), field members find it easier to (dis)respect the environmental (bad)behaviour of other land managers. When those ideas were fringe, contested or new, however, there was none of the perceived consensus around the value of environmental management, and so the respect for positive environmental behaviour or disrespect for negligent behaviour was only expressed by farmers with personally held convictions in those issues. Interestingly, the perception that such practices and beliefs are widespread is 
just as powerful as their actual widespreadedness and acceptance would otherwise be. So long as land managers feel that such attitudes and behaviours are enjoying a consensus, then the powerful 'herd mentality' style effects can take hold: if everyone is agreeing about the threat of $\mathrm{X}$, or the management value of $\mathrm{Y}$, then so should $\mathrm{I}$. That other in-group members are seen as thinking and doing a certain thing, that is, acts as a powerful and convincing force to also think or do that thing. To this end, and as is the case with M19, interviewees frequently cited other manager's adoption and acceptance of the value of environmentally sensitive practices/beliefs when discussing their own behaviour and attitudes.

To tie this idea into our Bourdieusian framework, the perceived recognition of the threat of water, soil or ecological issues and the widespread adoption of sensitive management practices has helped perpetuate the momentum behind the changing field conditions that legitimises environmental proactivity and rejects intensive management styles. To put it in the words of the interviewees, the idea that “everybody knows about it" (M19), or "you were in the minority if you weren't in ELS" (E01), are the exact sorts of attitudes that mean that farmers like E05, who know that their pursuit of the productivist goals at the expensive of environmental considerations would "be frowned at". Even for farmers like E05, that is, who are not themselves convinced of environmental information or the accompanying management recommendations, it becomes a motivating factor in and of itself that other farmers buy into those ideas.

What factors, though, are at the heart of this normalisation process? The media attention - notably media directed at the farming community - emerged as an important factor in bringing environmental topics to the mainstream of farming. Talking about the spread of no-till practices, M02 (an early adopter of no-till and proactive member of the BASE farming group) recognises that its proliferation is helped by media attention giving the (potentially inaccurate) impression of it is as a common practice:

Well as I say there's more and more stuff in magazines, and you think blimey everyone's doing what I'm doing now, but actually when you drive about you 
realise it's still actually quite... there's a few people - quite a few people getting into it, but there's still a lot of ploughing and cultivating!

In a similar vein, M04 reports the spread of environmental practices with reference to its heightened media attention:

I mean I go over to Norfolk quite a lot...you can see things that they're doing there - they've got margins, and you see bits of cut corners out of production and they've got game covers in strips so they're doing the same thing. But yeah, I think the last few years, we've been encouraged to improve our lands you know - in the Farmers Weekly every week it's soil structure and organic matter and all that sort of thing.

Similarly influencing the normalisation process, is the more general impact of increasing public awareness around environmental issues. As we have already seen, consumer preferences for environmentally sustainable production practices are playing out in the management decisions taken on farms. E14, an agricultural agent explained that:

With the bigger farms it's more down to corporate responsibility, and if you're into the bigger farms, then you're actually looking at some people who are very close to their supply chain - their buyers. Then you're getting into the supermarkets and they want Leaf accreditation and they want this and that - they want to be able to tell those stories.

The story is corroborated by one of the interviewees speaking on behalf a large agribusiness. Explaining part of the motivation for participating in ELS, M03 explains that:

Our customers are Tesco's, Sainsbury's, Asda's. When we have a customer visit, we always show them, you know, we've a strip down there, we've got game strips down there, cover strips. 
The effects of public demand are also being felt by smaller farmers. M09, a small grazing farm, reported that:

The general public are beginning to be thinking 'well actually, buy English' or 'I want to know where our stuff has come from' so I think it makes you think, well actually, we can tap into that. [Mother, older farmer]

Later on, in the same interview, the younger lecturer-farmer makes reference to the near ubiquity of quality assurance schemes and the environmental standards that participating farmers must meet:

You can hardly sell now without being Farm Assured, and to comply with Farm Assurance, you're almost already doing half of the environmental stewardship stuff anyway.

And later,

If you're talking about looking over hedgerows, it's a case of 'guess which stewardship they're in! if they haven't cut that hedge this year, so they must be in that scheme' or 'they've got that strip they must be in this scheme'. So, there is an awareness. [Daughter, younger farmer/agricultural college lecturer]

Although the word normalisation isn't specifically raised, the casual familiarity of M09's account indicates that farmers are regarding the environmental activity of their neighbours as a standard, non-contentious feature of a farm management.

The effect of public awareness is also being felt beyond a direct 'consumer demandmanagement approach' formulation. Instead of public awareness exerting pressure on farmers qua suppliers, farmers are being exposed to an increased public conversation around environmental topics as members of the public themselves. An exchange with M02 drew the link between public awareness about environmental issues more generally, and the impact it has on farmers: 
My dad or whatever, taught at college that that was the way to do it...

So, generally speaking the younger-

Yes, there's more environmentally awareness generally, across farming sector as well as the broader public, so people are more aware of the benefits of a bit of untidy, unkempt bit of land, aren't they?

Similarly, E02 says that:

[The environment] is more headline. It is of concern, and quite rightly so and the general public view it as part of it [farming].

E16, asked why members of the farming community have become more switched on to environmental topics, replied that:

I think it's pressure from people - people who are pressurising them to take interest in the environment.

The increased societal pressure to be more environmentally conscious was also raised by M06, although with a slightly more cynical tone:

Do you think that environmental topics are becoming more... do you think there's a raised awareness in the farming community about it?

Well there's a raised awareness about it everywhere - because it's what everybody goes on about. They'll go on about it till we have a food shortage, and then they'll say oh bollocks to that, do whatever you like, plant wherever you like and do whatever you like!

In E09's account, the impact that public pressure is having on farming is raised in direct relation to the reproduction of cultural capital through environmental 
management. Asked about whether it's respected in the farming community to be doing one's bit for the environment, the husband and wife interviewees replied:

Yeah it is [husband/farmer).

\section{It is now. Because it's what the public want, and it's what you intuitively do. [Wife/farm administrator]}

As environmental topics are becoming a standard feature of the "national conversation', so too are they becoming standard features of the conversations had within the agricultural community. The following excerpts see farmers relaying their experiences of how environmental topics have crept into farmer's own exchanges. Such intimations reveal that environmental issues have become so heavily normalised in the agricultural community that they form part of their shared conversational vocabulary:

E02

I do meet up with my neighbours and we have a few meetings as such - not just about production - the environmental stuff comes in on the side - and with the farm walks that people do, it's always tagged on and included.

E07

Of all the farmers that I know and speak to, I think there's more recognition now that environmental matters are part of farming.

E03

A lot of the catchments in this area are NVZ... So, it was on the high-risk thing, but since they've started doing all their awareness stuff, virtually every farmer, certainly every major farmer, goes to all their seminars, it's very well attended. 
And later in the same interview:

We know each other well enough, that it would be flagged up and something would be said [if some farmer were being negligent with regards to water quality]. It would be mentioned

Consider the exchange of the young shepherd respondent of E12 and the follow-up comment from the main interviewee:

\section{I went to a farm in Lincolnshire on Friday, last Friday, went to grass and muck, and much talk about soil health.}

We haven't looked after it as well as we should have done

E15, explains the conversations she frequently has with her land managing neighbours:

We go to a local gun club - and the hot subject was mid-tier.

M04's reflections on the changing nature of exchange within the agricultural community are particularly interesting, not only for the insight into the prevalence of environmental topics in farming conversations, but for its demonstration of the very modern way that those exchanges are conducted:

But I think now, with the internet, and the way they get information to you... it is all there, and you've got your iPhone and they're sending you environmental matters and environmental things all the time and so information is spread a lot easier that way isn't it?

M13's exchanges with other farmers, as with E12's above exchange, show that soil quality issues and its possible impact on long-term business viability have particular traction in the farming community: 
More and more people are talking about putting organic matter back into the land - a lot of the people you talk to, talk about more of a friendly environment to farm.

M19's depiction of exchanges also is particularly useful for its depiction of the reaction of farmers to environmental management is changing is happening in tandem with the increased prevalence of environmental topics featuring in farmer exchanges:

It's [managing the farm with environmental considerations] not poo-pooed like it was. It's sort of... folks are talking, like 15, 20 years ago, talking about things like that, they'd be laughed at, you know. But not now. It's an in thing. You do actually talk about it.

The above accounts show that environmental behaviour has become normalised through the two related influences of consumer demand and public awareness. On the one hand, and often for marketing purposes, managers are directly responding to the consumer demands for food with a better environmental provenance, and on the other, farmers are themselves being swept up in the same public awareness campaigns and information exchange as the rest of the population which have helped create the above consumer preferences. Michel-Guillou and Moser (2006) and Karali et al. (2013) have similarly noted the feedback loops linking public opinion, consumer preferences and producer attitudes. Here, the impacts of the marketing value of environmental management, the raised awareness around certain topics, notably soil and water quality, and the generally raised profile of environmental issues are all acting in symphony to help bring environmental considerations into the mainstream, normalised management of the farm. As before, this sense of "everybody knowing about it" has helped remove any sense that environmental management (and its associated loss in production) represents a deviation from the good farmer ideal. 
Whilst there are certain management techniques that have enjoyed being normalised, there are still practices and attitudes that are more fringe, contested or new to agricultural world, and so lack that same consensus. Such techniques, in other words, do not enjoy the sense of "everybody know[ing] about it", and have not achieved proper integration into new field rule changes and cultural capital reproduction formulae. Inspecting such techniques can help understand how it is that practices spread, generate momentum and become normalised. Consider, for example, the following reactions to no-till farming. Consider the following excerpts:

E15

Well they no ain't done none of that [rebuilding soil structure]. No muck. Nothing. Terrible.

E17,

People drilling in from August to September. Minimum cultivations. I mean that bollocks there, I mean, I've never seen such black grass.

Those reactions clearly resemble the laughing and sneering reactions that were historically associated with AES participation or the adoption of other environmental practices. No-till, if it is becoming a normal, non-contentious and respected approach to managing a farm, is not as far along the normalisation process as AES participation or other, more recognised practices.

The above reactions are corroborated by the accounts from the other side of the equation - the no-till practitioners coming at the sharp end of the above criticisms. M10, who over the last few years has been rolling out a no-till approach across his farm, offered a number of valuable insights into the sorts of responses described above, and the way those responses have morphed over time:

We started no-tilling 3, 4 years ago. And you talk to the neighbours and they'd almost just... 'they're mad! Absolutely mad' 
Those same neighbours, however, after some time would be softened to the practice:

They see it, and they see it's perhaps not as bad as they think, and 'we'll give it a try'

And finally:

I was talking to him last week and funnily enough he's just started trying some!

A near carbon copy of the story emerged in M02's interview:

Obviously, lots of people look at you and think you're mad.

Before explaining that

[There is now one neighbour] who is going down that route... and he's getting on well with that.

Clearly, the chance to see no-till management techniques in action has helped dispel the local community's mocking, cynical reaction to it. M10's own analysis of the process is particularly insightful:

I think it's a very long-term process and no one wants to stick their head about the parapet and do it. They ain't going to change quickly. Funnily enough, this neighbour, who I was saying to you about, a few years ago, that bloody man, and I was talking to him at the weekend and 'we're going to do some direct drilling because this works and this that this' and you think 'yeah I had this conversation with you 3 or 4 years ago' but it's quite interesting because he's had to convince himself. 
Evidently, being moved to do something is not a straightforward process - but is something that responds to a complex suite of influences well beyond being told by one person of its benefits. Instead, the neighbour has presumably been swayed through a similar process to the one that has helped normalise other environmentally sensitive techniques as described above: media attention to soil health and no till topics, getting to see the practice in action, believing the practice is becoming more widespread. Although M10, and presumably M02 were, by themselves unable to motivate behaviour changes in their neighbours and friends, their providing a viewing platform to see no-till in action has undoubtedly helped the process.

The relevance these stories have in understanding how ideas and practices spread, and the insights that can gained to help understand ELS's impact is clear. ELS, with its widespread uptake has helped provide those same viewing platforms onto different environmental practices all around the country, and often right in farmer's own land. In doing so, it has played an important part in the normalisation of different techniques, seeing them change from the sorts of approach that no till practiced attract to standard, and respected approaches to managing a farm. When E02 accurately highlights that "you were in the minority if you weren't [in ELS]", he is stating a commonly subscribed to sentiment that very many farmers are engaged in one environmental practice or another, and that it no longer represents a niche, or fringe management approach. When E12's following account expresses the same sentiment:

As we drive along, we do see more and more $5 \mathrm{~m}$ margins on the headlands, around the field. I'm happy to see it. I think it's only come about because of the support system. I don't think it would have happened otherwise

Similarly, immediately after expressing his respect for those farmers trying to encourage bird life and sustainable soil usage M04 explains that:

I think every farmer I know around here was in ELS. 
Statements such as these appear to indicate that AESs - and ELS in particular, due to its high uptake - has played an important role in normalising the idea of environmental management and scheme participation. Whereas a number of respondents reported the negative reactions they faced when they went into earlier AESs, or for their adoption of no-till practices - recall M01's being laughed at for his involvement in a local Arable Reversion scheme, or M10 being called "absolutely mad" - the interviewees report no such reaction to their ELS participation now. Although a number of factors (media attention, consumer demands, public pressure, raised awareness etc.) have evidently contributed to this change, the impact ELS's enormous coverage has had is clear. The community has not been able to cling on to those negative associations in the face of such a large proportion of land being committed to the scheme, and such a high percentage of farmers being involved. It has, instead, moved certain types of environmental management to a very visible position within the agricultural community, providing very many managers with new information about environmental techniques, allowing them the 'risk-free- chance to put that information into practice, or at the very least, the chance to see those practice being enacted on a nearby farm. That so many participants report that 'most people were in ELS' or 'farmer X was doing it' or 'you were in the minority if you weren' $t$ ' is, at least in part, the result of the normalised role that ELS has helped environmental management occupy in the farming world, and an important part of the process that has stripped environmental management of its 'laugh-' or 'sneer-' worthy reputation. E02 neatly sums this phenomenon up:

ELS got a lot more acceptance for it [than the first-generation CS]. It seemed it was more mainstream. I think, yeah, it's acceptable, and yes, and it's recognised. As I say, it is now the norm.

This normalisation is tightly bound up with the changes experienced in the rules of the game in the agricultural field. Something becoming a standard or normalised part of an industry or community is a precursor to its being expected; and something being expected is a precursor to the loss of cultural capital when those expectations are not met. That it would be - according to E03 - "flagged up" if some member of the community were being environmentally negligent, or that a farmer would earn 
the reputation - according to M09 - as a dirty farmer if he engaged in improper waste disposal methods is building on the expectations placed on farmers to meet certain environmental standards. As with previous studies looking at the spread of information, and the spread of farming cultures, the importance of social networks is of central importance (Sutherland and Burton 2011, Fisher 2013). Farmers are acutely tuned-in to their social grouping, and the perceived acceptability of a given behaviour, and the potential losses or gains in cultural capital are prime movers in how behaviours and knowledges spread.

In Bourdieusian terms: The widespread uptake of ELS, the increased visibility of environmental management, the media attention and public awareness around environmental issues, the consumer demand for environmental standards, the increased understanding about the pressures exerted by intensive agricultural procedures, and the value of less intense practices have been integrated into the working knowledge-base and management approaches of many farmers. The widespread adoption of those new attitudes and behaviours, and their increased visibility within the agricultural field, has helped normalise and further perpetuate the sense that many farmers are making such environmental considerations when managing their farm and so, in circular fashion, the growing number of farmers embracing new information, and successfully navigating the political-social-subsidy landscape that responds positively to environmentally sensitive management and disrespects environmental negligence has helped further consolidate those changes to the rules of the game.

Those changes have culminated in the widespread recognition and subscription to the new field rules, outlined at the end of the previous subsection, that determine the reproduction/loss of cultural capital through environmental proactivity/negligence. For many, the changes in the field rules have happened concurrently with their own changing attitudes, and so their habituses have reformulated in time with the field rule shifts. Those field members now confidently communicate those preferences, and are well placed to strategise their way through the field to best secure field positioning (communicate dislike for intensive, negligent farmers, subscribe and claim scheme money, avoid short-term intensive rotations etc.). For those who have 
lagged behind and have not embraced integrated the preferences of the changing rules, their habituses may now find themselves in field conditions far from those that they were designed to fit, and are being critically restructured through the hysteresis effect.

\subsubsection{Scheme-inspired management changes, and post-scheme behaviour}

Alongside a sociological study of the impact that ELS has had on attitudes and beliefs of the farming community, the scheme also needs also to be assessed in terms of the direct impact it has had on the land management decisions participants have made as a result of participation. This analysis needs to cover two different metrics: the scale and quality of the land management changes enacted as a result of entry into the scheme; and the scale and quality of the land management decisions taken after the conclusion of the scheme's payments, as a result of scheme participation. If farmers implement land management changes to meet scheme requirements, then the scheme has delivered the environmental goods it paid for; if no changes were needed to meet the scheme requirements and farmers get paid for adopting no additional practise, then the scheme's value is less. Further, when leaving the scheme, if a farmer decides to voluntarily maintain the practices they were paid to adopt under ELS then the value of the scheme's intervention is higher than if the managers stop employing the practice once the scheme payments stop.

As described in Chapter 4, the project can avail of a handful of tools to help conceptualise the above phenomena. The idea of additionality captures such instances where the scheme's intervention delivers more than it technically pays for - namely by securing the long-term adoption of scheme practices, beyond the extent of the contract's payments. At the other end of the policy value-for-money spectrum is the idea of deadweight. If a scheme contract contains management options that the farmer was already fulfilling, and intends to fulfil after the contract's cessation, that respective contract can be described as carrying deadweight. (Defra 2012).

For the purposes of this project, the term 'post-scheme' will be used to capture the behaviour of farmers after the termination of their contract. It should also be noted that 
because of the project's methodological design, an analysis of the participant's postscheme behaviour will primarily be conducted over the course of the phase 2 interviews and discussion, and so the following represents only one part of the thesis' analysis of the impacts ELS has had on the long- and short-term management of participant's land. The idea of crowding-out will also be introduced, which predicts that where a behaviour is promoted through financial reward or reimbursement (as with AESs), that behaviour becomes contingent on the ongoing payment (Darragh and Emery 2018). The payments suffocate or 'crowd out' the capacity for the target actors to generate their own, indigenous and long-lasting commitment to the objectives or behaviour in question, and instead foster short-term, financially dependent attitudes about the role environmental conservation should play in the management of their land.

\subsubsection{1 deadweight or actual management change}

The topic of deadweight in ELS has already been subject to an extensive analysis, notably in the Defra Dynamic Deadweight in Environmental Stewardship report. The findings here - which cannot expect to achieve the same comprehensive scale of analysis - will be presented in comparison to those already-documented findings.

The Defra 'Dynamic Deadweight in Environmental Stewardship' report represents a comprehensive analysis on the levels of deadweight in the ES scheme (for both ELS and HLS), the different factors that affect deadweight, and the nuanced approach that needs to be taken when considering deadweight levels. They report a deadweight level of $52 \%$ in ELS (as a percentage of management options that would have been undertaken in a non-participation hypothetical); but that the quality and extent of the management techniques adopted through scheme participation may be better than the management would otherwise have been. A survey about management practices and participation may, for example, technically register some participant's involvement as 'deadweight', but the scheme may nevertheless still be responsible for an improved environmental profile of the management technique in question. In such instances, the farmer will have to adhere to the specific timings and stipulations of the scheme prescriptions in line with the research that informs the creation of those options, where 
their management would otherwise be self-taught, unregulated or uninformed, and where observing the management approach may waver in the face of other financial or management pressures. The report also found that deadweight levels vary between options: hedge management, historical landscape features and grassland options are more susceptible to claiming payments for pre-existing features or practices, whilst buffer strips and arable options were more likely to represent scheme-inspired management changes.

With regards to the varying deadweight levels associated with different options, the project's findings broadly line up with those of the Defra report. Hedgerow maintenance - an option on each of contracts of the different interviewees - was frequently cited as an easy option choice, in which the participating farmers were already maintaining the feature. In line with also with the Defra report, however, is the quality of that deadweight: in many instances, although farmers were already managing their hedges (and would continue to manage them), the biennial cutting regime was a new, scheme inspired feature of their management approach. Consider the exchange with E02:

If you don't go into it [CS], do you think any of those options, the hedgerows, or the strips

Well the hedgerows won't particularly change, but the cutting regime may change.

The implication thereof is that the biennial cutting schedule is something new to the management regime, and so not deadweight proper. E04 makes similar implications about the influence that scheme participation has had on the management of his hedges:

What do I think is good farming? I like to see them tidy, hedges tidied up and stuff like that. Some people say that's not right - they want these hedges great big 30-foot hedges. To me, that's wrong. Is that good for the wildlife? I think the thicker the hedge, the more chance the little birds have got. 
E16, similarly claims that:

You talk to NE, one of their biggest things they want you to do is 2-year hedges. Which is a disaster. Because all the hedge does is woosh, like that [motions a quickly growing hedge]. You never see a hedge nest in a hedge like that. You see a bird nest in a hedge like that over the road.

With regards to the idea of scheme inspired management changes, the tones in the above three excerpts indicate that the ELS cutting regime was not something they followed before the scheme, and so represents a substantive scheme inspired change to their management approach.

Similar to the above hedgerow deadweight (or, rather, partial deadweight), the extent to which scheme involvement mandated real changes in the management of grazing or grassland was mixed. The contracts of M01, M04, M09, for example, all had lowinput grazing options, which they were by and large already achieving, but were having to be conscious of the option rules to ensure they didn't fall foul of them. For others, scheme participation represented no change at all for their low input grazing regime. M17, for example, a dairy operation with hedge, woodland and low input options reports that:

We didn't have to change a lot to do it - we didn't actually have to do a lot of things to make the points up.

In a nearly identical way, M14, a dairy operation admits that:

Actually, didn't do much more than what I would do anyway.

Again, these findings map onto those of the Defra's Deadweight Report (Defra 2012), in which grazing options were frequently subscribed to by land managers already pursuing low-input management styles. 
Also, in line with the Defra Deadweight Report, the arable options represented the clearest cut instances of management changes being implemented through the scheme's intervention. E03 and E10, two larger arable operations, both report having to establish their nectar mixes and beetle banks to deliver their scheme. M03, E09, E15 and E17, E19 - cereal and/or vegetable operations, all with rivers or water courses in their property - also report having to establish (amongst other options) buffer strips for their scheme. As with the above accounts of hedgerow management, inferences can be made about the changes participants had to adopt to meet the scheme obligations from the statements they made about their intentions for the contract options once their involvement ends. E16, for example referring to the corn plot features on his contract, claimed that intended to:

\section{Plough them back up}

The implication is, however, that they did not exist before the scheme. In other instances, scheme participation also delivered an element of additionality. M02, for instance, explains how he went over and above the scheme requirements, and established a varied wildflower mix instead of the simple grass as per his contract:

I just selected the flowers that I thought would look nice and do a job.... they cost me more than they needed to do. I could have just got the grass mix, so I did spend more on them than I needed to - we wouldn't have put anything in there if it hadn't been for the scheme, because we wouldn't have thought of it!

There were, nevertheless, instances of partial deadweight even for the arable options. In such cases, as with the low-input grazing options, managers report having to make only minor changes to their management style (timings of decisions, using certain blocks of land for certain purposes, type/extent of agrochemicals used et) to satisfy their contractual obligations. M08, for example, has always had overwinter stubble on different bits of the farm, but due to including overwinter stubble options in her ELS contract, she was forced to make those decisions on certain blocks of land where she may otherwise have made slightly different decisions. In other instances, 
farmers were already meeting the contract obligations, but only through their involvement with previous schemes. Again, although such cases would be classed as 'deadweight', moving options from one AES to another (usually from the predecessor AES, Countryside Stewardship) has helped keep those options maintained on the farm where they may otherwise have been removed. M02, for example, moved his grass strips that he had in CS to his new ELS contract, where, without involvement in ELS they may have been put back into production.

There were also those who were able to develop an ELS contract that did not require them to make any land management changes whatsoever. E07, for example, was able to secure enough points through traditional building maintenance:

[Our scheme is] Very simple. We have the advantage of a series of old buildings. So, we got a reasonable number of points for the maintenance of old buildings. And then we've got hedgerow management and enhanced hedgerow management on the miles of hedgerow we've done.

E06 had a similar experience:

I was getting a bit of money without having to do things I wasn't already doing, really.

The existence of such cases hints at ELS's unfavourable policy cost-effectiveness. Due to the relatively low threshold ELS makes on its participants, in line with its 'broad and shallow' design the scheme has an amount of deadweight in it. Some managers, as a result, were able to draw scheme money, and comply with its demands without having to implement any changes whatsoever.

\subsubsection{Post-scheme behaviour}

As has been explained in the methodology chapter, the project is designed to include follow-up interviews to help understand what impact ELS participation is having on the long-term management of farmland, and to better know the fate of the vast number 
of ELS scheme options coming out of scheme coverage. The decision was taken to include follow-up interviews as a way of circumnavigating the potential interview biases that the project may otherwise fall foul of, and the intention-behaviour gap that can open up between an interviewee's stated intentions of how they plan to act and how they actually behave. During follow-ups, that is, farmers can be asked what happened to a given ELS option, as opposed to what are you planning on doing with that option, as a way of avoiding the discrepancies between the interviewee's reported behavioural intentions and their actual behaviour. Insofar as this subsection only covers the phase 1 interviews, the following section should only be considered as one part of the full analysis of the topic. The next chapter, written after the follow-up interviews have been conducted, will be able to provide the second part. There are, nevertheless, still valuable insights to be had from these interviews relating to the expectations different land managers have of their scheme features. Looking at the behavioural expectations offered by farmers with regards to the fast-approaching termination of their scheme will also help inform the development of the phase 2 follow-up interview schedule.

Broadly speaking, the land management expectations of the interviewees fell into one (or more) of these three categories:

The ELS practices or features would be reverted to its erstwhile productive use (discussed in 6.3.3.2.1);

The managers would seek remuneration for their ELS options under some other scheme - typically for ELS's AES successor, CS (discussed in 6.3.3.2.2);

The ELS management practices would be maintained without any remuneration (discussed in 6.3.3.2.3).

Those three choices represent significantly different things for an appraisal of the policy value of the scheme. Broadly speaking, where managers have been moved to maintain the environmental feature, compelled by its long-term management or environmental importance (except in instances where the management approach was 
already being pursued before the scheme), or where scheme participation has been a sufficiently positive experience to encourage future participation in the successor scheme, ES can be described as having a degree of additionality, and its policy valuefor-money is high; where the scheme options will be put back into production, and the environmental services undone, the scheme's policy value is cast in a less favourable light.

A final note. Since conducting the interviews in the summer of 2017 , the scheme has begun to offer simpler contract packages for different farm systems in response to the complaints about the complexity of the application process, the competitive nature of the application process, the scale of evidence that needs to be provided to prove one's observation of the scheme rules, the breadth of options available and the long list of stipulations attached to the different options. As the comments made during the phase 1 interviews are at least partly 'out of date' (the scheme having changed in response to the sorts of grievances aired during the interviews), using the responses to scrutinise the scheme would be misguided. Insofar as analysing the design of CS was not part of the original interview schedule or research brief, it would also be misplaced, too. ELS's successor scheme will, accordingly, be discussed only as a conduit to talk about the fate of ELS contract options, and the impact participation has had on the expected environmental practices of the participants. Suffice to say that at the time of interviewing, the prospect of the CS scheme was highly unpopular:

E14

[CS] is just too complicated. I think everyone is just completely fed up with the target lead approach.

E07

The publicity for the CS has been that the administration by the RPA or NE, has been abysmal 
Too much bureaucracy. Most of us hate going in the office.

With regards to the future management expectations, in many cases they need to be analysed with respect to the sorts of management changes they inspired to begin with. Where the scheme carried deadweight - i.e. where it inspired little or no substantial changes to the farm management - it should not be considered a positive reflection of the scheme's policy cost-effectiveness when those management practices are being maintained after the scheme's cessation. M15, for example, who had in-field trees, and hedge and ditch management on his ELS contract did not have to change his management to meet the scheme requirements. That he plans to "carry on as we are anyway" whether or not he goes into CS should not, that is, reflect positively on ELS's policy value, and is not a case of scheme additionality. The low intensity grazing options in the scheme contracts of E01, M01, M04, M09 and M14, described above, which were largely being followed before the scheme's intervention, are similarly not set to change after their respective contracts end. The laconic exchange with M14 puts it most clearly:

You were just saying that a lot of this stuff for these options you would have done anyway?

That's correct.

So presumably when the contract comes to an end, you'll carry on roughly with the same stuff.

That's right.

As with deadweight, the extent to which ELS options are liable to be maintained or put back to production at the end of the contract, appears to depend on the different options designed for different farm systems. We have seen how the above low-input grazing options, where a low-input management was already in effect, are liable to be pursued after the contracts' closure, even where participation in the successor 
scheme looks unlikely. The story with arable options and their post-scheme fates is more varied.

\subsection{Removal of ELS options}

Where participants report having had to remove arable land from production to meet scheme requirements, financial barriers were cited as reasons for being unable to maintain the feature outside of the ELS scheme. In some instances, this was about the inability to cede the land, voluntarily, to an environmental feature. In others it was about the perceived drop in remuneration offered by the CS scheme in comparison to the ES scheme, and the increased difficulty associated with meeting the scheme requirements. E04, a farmer who elsewhere expressed his "enormous respect" for the environmental proactivity of his neighbours, admitted was "ashamed" to be putting his $6 \mathrm{~m}$ field margins back into production, because he could not afford to maintain that practice if it was not being remunerated through an environmental scheme. Similarly, E11 reports that:

Of course it [maintaining the margins on his arable land] will stop!

Explaining that:

The commitment costs money.

E16 explains that once his ELS contract comes to an end:

We shall plough up the corn plots. We've got low-input grassland in an ESA, we'll plough that up - some of that up. We can't continue.

That he "can't continue" is later justified in economic terms: the remuneration offered by CS is too low, and the cost of keeping it out of production voluntarily is too costly. This phenomenon maps onto the good farmer formulation outlined in the above subsection: environmental management is respected and would be pursued, 
but in instances where it is perceived as a threat to the farm's financial viability, then the management approach is passed over.

For E10, the potential problem with maintaining the margin features on his arable land was rooted in classification and legacy issues threatened by having land out of production for too long. He explains that

I have got a few options, that we dropped out of CS in 2013, and didn't move into ELS, so I've got to be very careful that they maintain their status as arable land, you know I don't want them to become permanent pasture, which is what happens after five years. So if I don't get a new CS in 2018, to pick all those options up, I'm going to have to think very hard.

For a time, E10 was maintaining the grass margin feature outside of the scheme coverage - the sort of voluntary environmental management that AESs hope to be able to inspire - but the rigid classification rules may stand to undermine the interviewee's desire to continue to voluntarily maintain those out-of-production margins.

\subsection{Upkeep of ELS options through CS}

Perhaps unsurprisingly, one reliable chance that ELS practices have of being maintained is through a successor CS contract. In the rare instances where interviewees were hoping to participate in the new scheme, there was an expectation that this would include a re-appropriation of ELS contract options into the next CS one. E10, having moved many of the features from the first CS scheme, into the current ELS one, now hopes to move them into the new CS contract:

When the [first] Countryside Stewardship ended, we extended our ELS to include a lot of the margins and the grass field corners that had been in Countryside Stewardship... we've got all the application to apply for what I 
call it the agri-environment countryside stewardship mid-tier. We'll got for mid-tier CS.

Similarly, the interviewees of M21 expected to be able to transpose the wildflower nectar options into a new CS contract without too much change in management:

I haven't looked into it in great details - but I probably should, the bumble bee one. You know, planting lots of clovers and flowers and stuff in corners of fields and what have you [main farmer].

\section{Because we already grow flowers, don't we? [farmer, administrator]}

\subsection{Voluntary Upkeep of ELS options}

Other interviewees reported how they plan to maintain some ELS management practice that they weren't previously doing, even if no CS contract is secured. Such a scheme option trajectory (adopted through due to the scheme's intervention, maintained after the scheme's payment's finish) represents the best possible costbenefit ratio for an AES - in which it does not pay out for deadweight, and also manages to secure additionality in the form of post-scheme commitment to a given management practice. E15, as has been mentioned, plans to maintain the riparian buffer strips on her farm, irrespective of whether she goes into CS - a management practice implemented to meet ELS's obligations. Explaining why, she claimed that:

I understand the old watercourses and that

And when directly asked if she was keeping them because she' $d$ been convinced by the environmental value of them, she replied "yes". Clearly the environmental information that ELS participation has exposed the manager to (along with a number of other information sources) have convinced E15 of the severity of the issue of water pollution and the capacity water buffer strips have to tackle the problem. M13, a manager at a large vegetable operation also explains that a number of the options of his ELS contract will be maintained "irrespective of the payments" he may or may 
not receive depending on if he goes for a CS contract. Motivated by water quality issues and biodiversity, he wants his farm to make a serious contribution to the rural environment, where that commitment is not contingent on scheme rewards. In line with the above analysis into the concept of the good and the bad farmer, M13's motivation is situated simultaneously in having been convinced by the severity of certain environmental issues, in the long-term business management of the farm and in the marketing value environmental management can have: "It's a bit of both really [pursuing environmentally conscious farming practices for environmental reasons and long-term business and corporate social responsibility reasons] - but more focused on the personal side. We want a good habitat. And the benefits from that is going to be rewarded in the future. But we don't want to be putting something down just to receive the payments."

In a similar vein, E09 explains the situation on a block of land he manages where the ELS contract has already finished. "We kept just them [grass margins] because they're nice to have, basically. Don't think we ploughed anything up.” For E09, however, the decision to maintain the margins was dependent on his being able to manage them on his own terms, and not having to strictly observe the stipulations of the scheme. He intends, for example, to use the strips for turning and storing agricultural machinery (a practice forbidden within the rules of ELS). That they are 'nice to have' is, in this way, the combination of the ease of management it offers, as well as the environmental benefits of margins that ELS participation alerted him to.

E09's 'partial' maintenance of the scheme practice (i.e. keeping the grass margins but not strictly observing the stipulations about not moving machinery on them) represents a common phenomenon. Although the scheme options may not be upheld after the contract's cessation to the same level of strict observance of the rules as within, the environmental profile of the respective participants has still been improved. Through participation in the scheme, participants have been alerted to a management practice that will be maintained after their contract ends, albeit with some modifications to better fit their farm practice. E17, for example, talks about his plans for his buffer strips when his contract ends: 
What I'll do, if I don't go into the [CS] scheme, I'll spray it off and put it down to rye grass mix, probably make them a bit wider, then I'll cut them for silage for the cattle. That way I shan't have to worry about when I spray the fields, and being near the watercourse.

Clearly, the information about the risks of water pollution through fertiliser application has filtered into his management-knowledge base, and although the buffer strips aren't being maintained in the wholly un-productive way prescribed through ELS, they will nevertheless exist in some form, and will still deliver an environmental benefit relative to there being no riparian strip at all. Such examples echo the findings of Riley (2008) who found the importance of localised, contextspecific expertise of farmers in the delivery of agri-environment management practices. For the above managers, operating outside the confines of a scheme contract allowed them to preserve the environmental value of the scheme, whilst still being able to bring to bear their own localised knowledges and understandings.

The maintenance, or partial maintenance of a scheme option was particularly noticeable in instances where marginal land was used to locate scheme options. The motivations for selecting the least productive to accommodate ELS options are clear: claiming financial rewards for putting land to non-production/reduced production makes most financial sense if it can be done in the least productive areas of land. In such instances, the motivation to put the land back into production post-scheme is, however, also accordingly low. Consider the following:

E13

No it won't [go back into production] - I'll just keep it as rough grazing land.

Not worth it. It's all stony. It's not worth the trouble to do it.

M03

We probably would [maintain the ELS option after scheme's cessation]. We've put them, as has everyone else, we've put them in awkward field 
corners, in marginal land, you know... so yeah, we probably just keep them, we probably wouldn't change much.

The capacity for marginal land to be used for ELS options, combined with ELS's widespread coverage, in M03's estimation, means that through the scheme's intervention there may be a great deal of marginal land being left unmanaged or otherwise out of production, even after the respective ELS contracts stop obliging the farmers to manage their land in that way. ELS's additionality, seen form this position, stands to be very high. As described by Heidenpaa and Bromley (2014), Payment for Ecosystem Services (PES) schemes, such as ELS can secure long-term management changes from participants by acting as a habit-breaking intervention.

The fates of scheme options located in areas of land of differing quality is perfectly drawn out by M04. Asked if he would keep the margins in his arable land if he didn't pursue a CS contract, he replied:

Well the ones by the wood are pretty unproductive anyway, so it's a no brainer keeping those in really. Some of the more productive ones I might rip out.

Clearly, deciding to keep a margin installed, or to remove the strip and put it back into production is not a matter of ideological preference, and nor it is a foregone conclusion that as soon as the contracts end, so too will the maintenance of those features. The decision, in this case, comes down to the relative loss incurred by maintaining the strip once they have stopped being financially 'productive' courtesy of the scheme's remuneration. On some level, the environmental and management value of margins out of production in such marginal land has been absorbed by the farmer - an attitude presumably acquired over his exposure to the scheme option and the environmental information that comes with participation - and he is willing to leave some of the strips as they have been under ELS. The productivity lost through having the strips placed in good areas of land is, however, the threshold point at which maintaining the feature becomes too expensive, and the need to secure yields and financial income takes over. 


\subsubsection{Analysis of post-scheme behaviour}

The management expectations of the land after the contract comes to an end is determined by a suite of different factors. The most compelling determinant is the financial outlay associated with maintaining the option once they stop being financed through the scheme's remuneration. Where future CS contracts can be secured, the outlay is offset or replaced by the new contract's payments, and those features stand every chance of being transposed into a successor CS contract. Where CS is perceived as unattractive or untenable (usually on account of the options being too onerous, the application process too complicated, the remuneration levels too low, the provision of evidence too time consuming etc.) the likelihood of the option being upheld is accordingly compromised.

There are, nevertheless, still factors that can motivate the respective managers to maintain the feature in either complete or partial observation of the ELS stipulations, even after the contract stops obliging them to do so. Firstly, where an option was located in less productive, marginal land, the relative financial outlay of maintaining the feature may be acceptably low due of the land's poor quality (recall the good farmer formulation in which environmental management is respected where it does not interrupt the financial viability of the unit). Secondly, where the land manager has been convinced by the severity of the environmental problem that the feature is targeting, and also that the feature can help tackle the issue (water pollution and the value of buffer strips, for example), the relative economic loss associated with maintaining the feature may be considered a reasonable exchange for the environmental value the feature can deliver. Thirdly, where the manager has come to value some other incidental management benefit that maintaining the feature can offer (i.e. being able to move machinery on margins, helping to meet the environmental standards set by some other piece of legislation, promoting the farm's environmental credentials for marketing purposes), then the loss incurred by maintaining the feature is offset by the perceived benefit for the management of the farm. Especially in instances where the above factors act in chorus, a scheme option stands a strong chance 
of being maintained in one form or another after the managers stop being paid through the ELS scheme, and even when no replacement CS contract is secured.

It was, perhaps unsurprisingly, the farmers for whom scheme participation represented substantial management changes or exposure to new management practices that expressed the most changed management expectations for their land after their scheme's end in comparison to their pre-scheme behaviour. The above motivating factors (having established a new feature on the land, being convinced by the management value of the option, witnessing the feature in operation on one's own land etc.), are all rooted in having had to have implemented a different management approach and coming face to face with the value it can hold for the farm. The longterm integration of ELS options on M09, E15 and E17's land, for example is made possible by their having had to have implemented those options in order to meet the obligations set by their ELS contract. For M01, M04, M09 and M14, on the other hand, who were already meeting their ELS obligations before the advent of their contract, no long-term management changes in a post-scheme setting can be expected. They have not, that is, seen any new management techniques in action, have not had to think about the value of having a new and different management practice in effect on their farm, or think about the relative environmental value of their old management versus the new prescribed approach. As a result, they will not be not moved to implement any long-term management changes. In this way, the issue of deadweight cuts both ways. Where farmers did not have to make management changes to meet their scheme contract obligations, they will equally be unlikely to make any long-term behaviour changes through the scheme's intervention.

The project, at this point in its timeline, is not able to offer its full analysis of ELS's long-term management impacts, or its analysis of the scheme's additionality. A fuller picture of whether the above expectations are being realised after a scheme contract's termination will emerge over the phase 2 analysis.

\subsubsection{Regional comparisons}


Different farm systems are subject to different economic, societal and environmental pressures, and are targeted by a different suite of ELS scheme options. As per the research design, the project will inspect whether, and to what extent those factors play a part in the development of agri-environmental attitudes and practices in the farming community. Two case-studies were developed to help contrast the beliefs and behaviours of the land managers in two areas characterised by different farm systems - the highly arable make-up of the eastern case-study, and the varied makeup of the farms in the midlands case-study. Do the different pressures, opportunities and scheme contracts of, say, an arable farm have an impact on the sorts of management practices adopted as a result of the scheme, or the extent to which proenvironmental attitudes filter into their psychologies, relative to a mixed or a livestock farm? Further, does being surrounded by a particular make-up of farm systems play a part in the development of one's agri-environmental attitudes? Does it help determine which symbols of good (and bad) farming pertain in a given area?

A large portion of this comparative element has already been covered in the previous subsections. We have seen, that is, how arable farms, and their relevant options are more likely to be associated with the implementation of management changes to meet scheme contract obligations, and an associated increased chance of inspiring long-term management changes. For livestock options, on the other hand, there was a higher incidence of deadweight in scheme contracts, and an associated inability to motivate long-term management changes beyond the scheme's extent. This finding clearly has a regional bearing. In areas where there are more arable farms and thus arable options (see Hodge and Reader (2010) for a comprehensive breakdown of the distribution of different Environmental Stewardship options across the country), such as within our eastern case-study, the long-term impact of ELS will have a relatively higher impact than in areas with a higher representation of livestock farming. This is playing out on two counts. Firstly, in terms of the land management decisions adopted as a result of participation - both to meet the scheme's contractual obligations upon entry, and in terms of the post-scheme management of options relative to the farmers' pre-scheme behaviour. And secondly in terms of the raised awareness and knowledge of the farmers - where the schemes that required actual management changes (i.e. where deadweight was absent) are inspiring managers to 
inspect the long-term value of the practices promoted by the scheme relative to their pre-scheme behaviour.

As a result, the environmental and social impact of the scheme's intervention is likely to be greater in areas with a higher representation of arable holdings, and land in arable production - or, more accurately, with a higher representation of arable land being managed under some scheme option. In terms of our interviewees, the phenomenon cuts clearly along farm system lines, with livestock farmers (M01 and E01, for example) and arable farmers (M15, and E13, for example) from both casestudies conforming to this trend. Are there any impacts, however, on the attitudes and behaviours of a given farmer that arise from their operating in an area characterised by a specific farm system, beyond the determining factor of their own farm system and associated scheme options. Does the area within which one farms namely, the composition of the farms in the surrounding area - play a part in the development of agri-environmental attitudes? As we will see, below, there are insights to be had from the data relating to the visibility of the options targeted at different farm systems, and the normalisation of agri-environmental attitudes and management.

We have already seen how the perceived widespread adoption of agri-environmental practices has helped normalise participation in AESs, or the adoption of other environmentally sensitive management practices. That normalisation, in turn, is an important factor in the changes experienced in the rules of the game, and the ways in which one's environmental profile helps reproduce or lose cultural capital. It has helped normalise the integration of pro-environmental practices onto farm management approaches taken by a wide range of farmers; has helped agrienvironmental techniques become associated with savvy, forward-thinking farming; and has helped generate a culture whereby environmentally negligence attracts the criticism of their members of the agricultural world. Consequently, in areas where scheme participation is less visible the influence of the increasingly widespread adoption of agri-environmental measures stands to be reduced. 
In this vein, an important distinction emerged between the visibility of different options and the inferences farmers drew from their neighbours' environmental proactivity. When discussing the scheme participation (or other agri-environmental practices) of their neighbours, interviewees invariably cited management techniques on arable land such margins, wildflower strips, game plots, beetle banks; and not the low-input grazing options of livestock farmers. When E01 explains how he tells who is in a scheme, he reports that:

You can tell by the strips.

In the same vein, consider the following interview excerpts:

M11

I notice a lot of margins around fields. I guess that will be because of some scheme.

\section{And M14}

The big farm at the top, they've got $6 \mathrm{~m}$ margins so higher-level stuff and that.

The importance of visibility and the capacity for some environmental practices to be more or less visible was directly raised by M03:

It's got to be visual - they won't know if our organic matter has gone up $2 \%$, will they? They won't care!

Although raised in relation to the justification of public expenditure, the issue is the same: some agri-environmental practices - low-input grazing, or soil fertility conservation practices, green manure - have a low visibility, and so cannot make the same dent in the public conscience, or the consciences of their neighbouring farmers. 
Other options - margins, floristic strips- are highly visible and are capable of picking out the participating farmer as one engaged in environmental considerations.

As a result, areas in with higher representations of 'visible' options may come with an associated increase in the perception that agri-environmental behaviour is widespread, and the normalisation with which that is associated. In areas with a higher representation of 'invisible' options, on the other hand, farmers may be less aware of the steps their neighbours are taking to address agri-environmental issues, and the prospect of integrating environmental considerations into the management of the farm may still be perceived as a fringe activity, or something that may be at odds with the rules of the game in the area and that incurs a loss of cultural capital. To evoke the language of M12, physically seeing certain practices in action is an important part of the process that stops them being the sort of thing is 'sneered at' by members of the agricultural field.

That the above insights have a regional impact is, unfortunately, an issue of slight conjecture. The 'high visibility' of arable options and its associated impact on the normalisation of agri-environmental behaviour played out in both case-studies, with no discernible difference in the sorts of responses given in the two case-studies. This may not be surprising: both case-studies have a high representation of arable land (the Midlands case-study has an equal share of land in livestock and arable production, with each representing $47 \%$ of agricultural land, with the Eastern casestudy having a $73 \%$ representation), and so farmers from both case-studies have been exposed to a high showing of arable farmland and the visible scheme options and environmental management practices options with arable production is association. Even the case-study, that is, with a relatively lower level of arable farming will still have had a sufficiently large amount of arable land committed to the scheme and arable options, and so the normalisation that comes with visible agri-environmental practices neither confirms nor denies the above thesis. The rules of the game, that is, along with the corresponding symbols of the good and bad farmer did not emerge as having any significant differences. Livestock and arable farmers from both areas all identified similar features of the good and bad farmer, and all held in high esteem the managers mindful of the intersection of good environmental and business 
management - and because of the high representation of arable land in both casestudy areas, this was typically associated with the efforts being made on arable land.

For this reason, the comparative element may have been able to provide even more compelling results if the methodology had been designed slightly differently. Specifically, if the case-studies had been located in areas with more drastically differing representations the different farm systems, then the particular influencing factor of the environmental practices' visibility would have been made more apparent. Whilst the eastern case-study was successful at representing a sufficiently high level of arable farming, if the midlands case-study had been swapped for one located in the for North West or South West, then a more dramatic comparison could have been made with an area of almost exclusively livestock farming and the invisible agri-environmental practices and scheme options that would have been prevalent there. There the 'visibility' of scheme options would be even lower, and the relationship between the visibility of agri-environmental practices, the normalisation of those practices, and the changes experienced in the rules of the game could have been more reliably verified. As it is, the comparative element of this project can only indicate that there may be an additional (although in the case of our case-studies, negligibly small), impact on the development of agri-environmental practices and attitudes determined by the representation of different farm systems in the area within which a given manager operates.

The comparative element was supposed to shed light on the project's first research question:

What are the recent developments of land managers' agri-environmental attitudes, and how can Bourdieu's theory of capital, field and habitus inform our understanding of this development?

But, due to the limited scale of 'comparison' available when contrasting the experiences of the farmers from the two case-studies, especially in terms of the make-up of farms represented in their local areas and the visibility of different agrienvironmental practices, the comparative strand of the project cannot add anything to 
analysis. The issue will similarly undermine any potential comparative efforts of the phase 2 interviews. The make-up of the two case-study areas in terms of how many arable and livestock farms there are, and the impact this will have on the visibility of the corresponding agri-environmental and AES practices will persist. For this reason, this comparative element will here be dropped from the phase 2 analysis.

\subsubsection{Brexit}

Of the themes that were introduced, independent of the interview schedule, the topic of Brexit and the post-Brexit policy landscape, was the one that had the strongest bearing on the idea of agri-environmental management. The topic was most frequently introduced in relation to the predictions the interviewees made of the future management of their land, and the expectations they had for ongoing AES participation.

For E14, the agricultural agent, he reported a widespread conservativism amongst his farmer-clients resulting from the Brexit vote and its impact on environmental subsidies:

And I suspect that [Brexit] would probably put people off signing up to a scheme as well, because they say, 'we don't know where we're going to be in 5 years, and I don't want to tie myself up with something.'

That stance was echoed by M14

But no, I think this Brexit and everything else, people don't know whether they're coming or going... I think they're standing off.

M17, on the other hand, expressed concern that no replacement would be found for the environmental subsidy and the consequence that might have on the environmental management of farmland: 
I think unless there is some sort of funding, or something from central government, I think it'll get worse. As much as you like to think they'll carry on doing it without funding, then I don't know whether they would or not.

Given the above accounts, consider the second research question, asked at the very beginning of the thesis:

How effective, as a policy tool for securing environmental action from the farming community has ELS been (including the environmental activity beyond the individual contracts' duration)?

The questions were developed before the Brexit vote had taken place. Given the clear significance of Brexit on the topics of agri-environmental policy and farmer behaviour, asking the above questions no longer seems plausible without also considering Brexit's impacts. For this reason, the theme of Brexit and how it interacts with agri-environmental decision making will be integrated into the interview schedule for the phase 2 interviews. Consideration of the topic will, however, now be left. At the time the interviews were conducted (April through August 2017), the dust was only beginning to settle over the fallout of the 2016 referendum, and the impact it would have on British agriculture. Including it consistently in the phase 2 interviews will provide a more systematic analysis of responses - and will not just cover the beliefs of those interviewees who raised it of their own accord. Further, as the trajectory of the agricultural policies will (hopefully) have been developed by the time the follow-up interviews are conducted, targeting the topic in the follow-up interviews will allow for a more informed conversation with less of the conjecture and future-gazing that characterised the responses of the phase 1 interviews. The following emergent question will, as such, be added to the project's initial research questions:

What impacts will the Brexit process have on managers' willingness to engage in agri-environmental management? 


\subsection{Chapter conclusion}

The chapter has provided the first major analysis component of the research project. The interview data, collected in accordance with the methodology explained in Chapter 4, has been analysis using Bourdieu's thinking tools. Along with an analysis of the pre-determined questions, 2 other research questions have been considered. Relevant questions will be included in the phase 2 interview schedule, and the research questions will be given a more thorough consideration over the course of the subsequent analysis chapter. 
7. Analysis and discussion phase 2

\subsection{Chapter introduction}

Chapters 3 and 4 detailed the methodological and theoretical features of the project. Decisions were explained about the selection of Bourdieu's theory as the primary tools of interpretation; about the choice of a deductive and inductive methodological hybrid; about the stylistic presentation of the analysis (a theme-by-theme presentation, and not an ethnographic account for each interview); and about the formatting of interview quotations (italics for the interviewer's words, normal typeface for the main interviewee and bold, and bold-underlined for the secondary and tertiary interviewees). The above decisions will be mirrored for the analysis and discussion of the phase 2 interviews.

\subsection{Phase 2 interviews research sample}

Not all of those consulted in the phase 1 process were contacted for involvement in the phase 2 interviews. Some interviewees played increasingly minor roles in the management of the farm, and so had little involvement or understanding of how the farm was going to be run in the future (or even at the time of phase 1 interviewing). Although those interviewees and their responses may have been able to shine light on the state of the farming community and would have been valuable for, say, a study on farm succession, they were not particularly useful in the context of this research project. To streamline the project, and not overburden it with low-value research data, the project excluded those participants from the follow up interview process.

Alongside the self-imposed drop-off of interviewees from phase 1 to phase 2, there was also an expected level of interview attrition. The phenomenon was not particularly problematic for the project, with only interviewee being lost to its effects. In that case (M13), it was a large horticultural operation, and the employee who had given the phase 1 interview had left his job with none of the remaining staff willing to speak in his stead. Attrition is an inevitable feature in follow-up 
methodologies (Olsen 2005), and especially given the low influence it had on the project, it is not perceived as problematic. Otherwise, the cohort of interviewees carried over from phase 1 to phase 2 interviewing benefited from good continuity.

With these factors in mind, phase 2 of the project yielded 24 interviews, 12 from each case-study. One of the responses from the midlands case-study (M03) was given as an email response to an adapted version of the interview schedule described in Appendix D (omitting the rationale for each question, removing square bracketed notes) as he was unable to arrange a face to face interview. Further, as in phase 1, one of the interviewees from the eastern case-study (E14) was an agricultural agent speaking on behalf of one of his clients who had an ELS contract that fell within the initial search parameters of the methodology. Although in this case he was not able to answer specific questions about the management of that holding in particular (as he was no longer involved with the holding through which he was contacted for the first interview), he was well placed to offer reflections on the relevant themes based on his experiences with a range of other clients. It should also be noted that a technical fault, experienced during phase 1 interviews, lead to the loss of the audio file for one of the midlands interviews. That interviewee was nevertheless selected for phase 2 interviewing. Where other interviewees were asked questions such as "in the first interview you said...", this interviewee was asked more general questions: "what changes have taken place since the first interview?". The interview was given a new and unique code (M22).

The interview sample for the phase 2 interviews was, in short, the result of a conscious effort to capture the same number of responses from the 2 case-studies; to exclude the interviewees from phase 1 who were ill-placed or unable to offer meaningful reflections about the future management of the holding; to equally represent the different intentions offered in phase 1 interviewing with regards to the post-scheme management; and the unavoidable problem of follow-up interview attrition. 
7.3 Theme by theme analysis

\subsubsection{Post-scheme management}

The most significant part of the phase 2 interviews was the opportunity to discuss the management of ELS options in a post-scheme scenario. The methodologies of most other research concerned with the post-scheme management of options (e.g. Darragh and Emery 2018) involve interviews that take place before the termination of the contract, and the intentions the interviewees have to manage their land in a certain way. In such instances, the intentions-behaviour gap always threatens to undermine the reliability and robustness of the paper's findings (Armitage and Conner 2001). To sidestep this methodological pitfall, follow-up interviews were used, whereby interviewees could be quizzed about their actual behaviour (i.e. not intended). Although there exists research that avails of similarly robust methodologies that looks into the post-subsidised behaviour of actors involved in other environmental schemes (e.g. Rode et al. 2015 looking into the long-term impacts of economically incentivised biodiversity schemes), to the best of the author's knowledge, no research has been done into farmer's post-AES behaviour that includes post-scheme interviews. In this particular methodological respect, the PhD's contributions are new and unique.

Accordingly, it is the findings from this particular strand of the interviews most in need of a fine-grained analysis. This subsection will be broken down into 6 further subsections (7.3.1.1 - 7.3.1.6), below. The first three will describe the broad pathways into which farmer's post-scheme management approaches can be categorised: Entry of the ELS land into a new CS agreement (7.3.1.1); unremunerated upkeep of ELS options (7.3.1.2); and re-entry of the land into agricultural production (7.3.1.3). The fourth (7.3.1.4) will consider the extent to which the findings relating to the post-scheme management of ELS options can be generalised. The fifth subsection of these four will reintroduce Bourdieu's thinking tools, and inspect the lessons that can be learnt from deploying his theory in the 
context of post-scheme management 7.3.1.5). The final subsection (7.3.1.6) will consider the relevance the findings have to the crowding out theory

\subsubsection{Entry into CS, and use of ELS land for CS purposes}

Of the 24 interviewees (only 23 of whom were speaking on behalf a specific farm, as one of the interviewees was an agent), 6 had successfully entered into the new CS scheme, with a further 3 waiting for confirmation for their application. Although the project is not an assessment of ELS's AES successor - CS - within the context of the research questions, there is clear scope for some relevant analysis.

A number of participants, for instance, express how participation in one scheme can help promote participation in future schemes. The phenomenon is one already recorded in the literature (Lastra-Bravo et al. 2015, Defrancesco et al. 2008). Once farmers have gained experience of a scheme - how its administration functions, what sort of behaviours are expected of them, they are more amenable to participation in future schemes. The comments of E15 - who has made an application for a CS contract - sheds light on this relationship:

When we first went into the schemes, I thought oh bloody hell, so many hedges, got to put so many strips in, and you think Christ it's going to gobble up... but it's surprising but once you get around... it's surprising how you soon gobble it up [the options needed to meet point requirements].

M20, one of the farmers with a successful CS application, is unequivocal about the transition from an easy-to-fulfil scheme contract to more ambitious AES agreements:

Well ELS got me into HLS which got me into higher tier. ELS, I think is how you get people into it, but it's got to be simple.

As discussed in the phase 1 analysis, being involved in ELS is lending farmers a confidence in their ability to participate in a scheme, and a greater understanding of what practices are expected of them. The three accounts above all show how 
participation in a scheme has helped furnished them with an increased understanding of more environmentally sensitive management practices on the farm, a better understanding of what behaviours an AES will demand of them, and how the administration of the schemes function. The transition from ELS to CS is not, however, just made easier in terms of the respective manager's attitudes and experiences provided by participation in the scheme. Participation can also furnish a farm with the sorts of features a follow-up agreement is likely going to need to include.

M03 (the email respondent), for example explained the trajectory of land falling out of ELS coverage:

Are there options that have been put back into production?

No - grass strips remain and whole fields have been entered into mid-tier along with extra areas from other fields.

Are there options that have been put into a successor mid-tier or higher-tier agreement?

Yes - some grass strips and banks, some whole field options.

M04 similarly explains the transition from ELS to CS options:

And so, all of the bits from ELS have largely gone into the new CS?

They have, pretty much. It's a far bigger scheme than what we've done on the mid-tier than what we did on the ELS.

Although M22 was not perfectly clear on which features would be carried over from ELS, his response at least suggests that a mainstay of his ELS options will be used for CS purposes: 
So, the mid-tier you've gone into. Is that largely the same options that was in the ELS that has gone?

Yes, we've increased the margins, field corners or whatever you call it. Headlands by a brook.

So there's more in the new one than in the old one?

Yes

Although participation in ELS may act as a positive factor in the transition towards CS, with such a low uptake, it is clearly not a sufficient factor. As explained before, the project is not an assessment of the policy design of CS, and so a thorough analysis of the reasons for the scheme's low uptake will not be given. Largely, however, the scheme was perceived to be too onerous; the scheme required too much land to be taken out of production relative to the payments offered; the competitive application process deterred potential would-be applicants from developing a contract for fear that their time and efforts would be wasted; and farmers were concerned that they would get locked into a suboptimal scheme when a potentially more generous or suitable scheme would be available in the next few years as the post-Brexit agricultural transition process works itself out. Where these concerns are pertinent to the research questions they will be covered in greater detail, below.

Of potential interest to the project is the total absence of knowledge or recognition of the attempts made by the CS policy designers to make participation in the scheme easier. CS's four new offers (described in Chapter 5) were developed to simplify the application process and bridge the gap between ELS's broad and shallow design and CS's competitive design. No interviewee volunteered their recognition of the new component and when a follow-up prompt was offered raising the new scheme design, no interviewee said they had been made aware of the new scheme. Whilst an effort was made to attract a higher level of participation, and to respond to the criticisms around the scheme's design, the new offerings have, as far as this project 
can discern, not succeeded in raising CS's profile or remedying the problematic perception it had amongst the agricultural industry.

\subsubsection{Maintenance of options in no-CS settings}

Of the 17 remaining interviewees with no CS successor contract (as above, 6 had entered the successor scheme, and a further 1 of the remaining 18 was an agricultural agent who was not in a position to confidently speak about the fate of the land on behalf of which he was speaking for the phase 1 interviews), each, to a greater or lesser extent, described how some/all of their ELS options would be maintained in the wake of their respective contracts' termination. The nature of this maintenance varied greatly from farm to farm, however, and in many cases, the description of the motivations was not expressed in environmental terms at all. Of the other motivating factors, some were moved by the management ease of keeping an option, some by realisations about the actual low economic return of farming the land put into the scheme, and others were keeping up with a management practice for (potential) use in other subsidy programs at some point in the future.

\subsection{Economic motivations}

One of the primary motivations for unremunerated, post-scheme option upkeep relates to realisations the respective managers had about the income the land was capable of generating when in agricultural usage. Consider the justifications the following managers offered for why they had chosen to keep certain features of their ELS agreement.

E09, speaking about grass margins explains that:

They were taken out because they were not profitable anyway.

Or E15: 
We took out bits that weren't productive... and we've left, I suppose it's 3 or 4 of them, big corner chunks where there's shitty land we've just left it as grass and we just keep it cut.

Although E15, at the time of interviewing, had applied for a CS contract, her statements elsewhere made clear that the upkeep of her ELS options are not contingent on her application success. Here, E19 expresses the same sentiment about the agricultural quality of the land put into the scheme, and the resulting deflated motivation reclaiming the land for agricultural purposes at the end of the contract:

So in instances where you will leave those conservation bits in, without being in any scheme or getting money back for it, what are the motivations?

General motivations - ease of farming. Because as I say, there's no money either side of the fence so you might as well have ease of farming.

In all of the above cases, the managers had elsewhere asserted that the land in question was removed from production to meet their ELS contract requirements. Participation, in this sense, catalysed a streamlining of the way the farm is being managed by taking marginal land out of cultivation. In some cases, the managers appear to have always known that the land was marginal but were perhaps farming it out of habit or for some related path dependency reasoning (say E19) and in others, the low value of the land appears to have been something the managers have come to realise over the course of the agreement (say E15). In both cases, the motivations are largely financial - the time and resources spent farming the land do not compensate for the limited agricultural income the land was capable of producing - but the longterm environmental impact of the scheme is still of significant value. Management techniques that required initial financial remuneration, are now being maintained at no additional cost to the public purse. The catalysing power of ELS to short-circuit habitual management practices is neatly summed up, later on in the interview, by E15: 
We never put them in until we were pushed - you get the money, and that gives you an incentive, doesn't it?

Such a finding has clear relevance for the theoretical literature around the capacity for AESs or Payment for Ecosystem Service (PES schemes) to deliver long-term behavioural change from scheme participants. Hiedenpaa and Bromley (2014), for example, predict that such schemes as having 'habit breaking, habit taking' potentiality. At least in the context of ELS's long-term impacts in the project's casestudy areas their predictions have proved accurate.

\subsection{Ease of management motivations}

In a similar vein to the reasons given, above, interviewees also reported ease of management motivations for wanting to maintain ELS options in a post-contract setting. In such instances, the loss of income associated with maintaining an option is offset by corresponding benefits they offer in terms of how easy the farm is to manage. E03, although in the process of putting together his CS application, had set ideas on how the ELS options would be managed, even if the bid for a new contract was unsuccessful:

And then if you don't get into CS, what do you think the fate of them will be?

Field margins we would probably keep anyway. Because a lot of the ones it's useful. We might just cut them a fraction more often than we're allowed now... Beetle bank would probably just stay in there anyway because it's a natural divider between two of our fields - so we'd just be taking it out for no real benefit to us so that might as well stay in. And the field corners, might bring some of them back in but a lot of them we tried to do it where we could square off fields.

E18, who was in the process of putting most of the ELS land back into production, nevertheless plans on keeping the more awkward areas out of production: 
There are parts of fields strips, margins, whatever, that we took - some were awkward corners, some are in corners that are in fields that are just not practical to get in with a $36 \mathrm{~m}$ wide sprayer.

So those bits have stayed in?

They have in the main part.

And were they bits that were put in through ELS - or have you always not managed those?

No, they were done as part of the ELS.

And in a near identical situation, E02 explains that:

Our ELS finished in July last year, and as they're [grass margins] coming rotationally convenient to remove, we're removing them.

Before recognising that, when the amount of work required to get them back into the rotation outweighs the agricultural value of the land, the strips and corners will be left in:

Generally, there are awkward little corners to get them back in is not very easy to do without extra remedial work to get them back in to the field

In all of the above the cases (E03, E18 and E02), the lost income associated with having the land out of production is offset by the different managerial benefits the ELS options confer. Depending on the option at hand, fields can be squared off allowing for the easy use of larger pieces of machinery, access to fields can be made easier, and boundaries can be created between fields where none otherwise exist. As before, these motivations are not rooted in realisations about the environmental value of the options, or about changed personal motivations regarding the scale of 
environmental management they want to have on their land - but about benefits that can be secured for the running of the farm business.

\subsection{Environmental motivations}

Although such environmental motivations were in the minority, there were nevertheless instances of interviewees being moved by the environmental improvements conferred by a scheme option. When detailing why he thought so many managers were leaving ELS options in, E09 explains that:

In our case and in most people's case, they enjoy it, it's nice to have. Nice to walk down and see a bit of stuff about.

Here, involvement in the scheme, meeting scheme requirements and later deciding to maintain the option is helping give expression to the interviewee's (and, we assume, the people he knows who have helped him form the more generalised opinion his statement contains) preference for having environmental features on his land. For others, the scheme has helped spread information around environmental issues, and the sorts of management techniques that can mitigate against those problems. For E15, for example, part of the reason for keeping an ELS buffer strip in a post-scheme setting was because:

It stops anything going in the river. That's the biggest thing - that's why we said we'll keep them.

Whilst for M15, the scheme has helped spread knowledge around how to best optimise the environmental value of his hedgerows, and has helped secure his ongoing efforts:

I think we'll give more consideration to the hedges and the times we cut the hedges. And in general, that's the thing I've become more aware of, and maybe it is due to being part of ELS, I don't know, but I've laid another 
hedge, maybe I said last year - but about $100 \mathrm{~m}$, the year before last. And another $100 \mathrm{~m}$ this year.

And M17 was happy to see the changes in the quality of the grass effected by the ELS low input options he had:

You got grass varieties coming back in - they're actually coming back, because the-

Because of the low input?

Because of the low input, you know, I think you put so much fertiliser and slurry on and docks and thistles come. Whereas you take that out the equation and they don't do the same. There's lovely wispy grass, really good to see.

\subsection{Policy motivations}

In some instances, the policy landscape within which farmers are operating are also motivating the upkeep of ELS options. Even without a successor CS contract, that is, there are legislative instrument motivating the sorts of management practices typically contained in ELS contracts. The re-appropriation of ELS options for the purposes of meeting the EFA Greening measures represents the most significant factor in this category. E14, the agricultural agent, has a broad perspective on the different post-scheme management decisions farmers are taking, asserted that

Yes, there are definitely people who were using what was in ELS as their Greening or BPS

On the ground, E17's account corroborates E14's predictions:

I had strips. Strips against the water course. Field corners. Meadows were in it as well. Now I've got... I've left the headlands where they are but I'm not 
getting anything for it. But I have put them in, some of them I've done, actually no I haven't... the corners I've put in to set aside.

\section{For Greening?}

Yes.

Whilst for E16:

We kept the corner plots, kept the legume fallow plots. Kept all those. Haven't got rid of any of them at all

What's the reason for that?

Because they're on corner plots on a little bit land, they're established. We're waiting to see what comes out next under the EU rules, when we come out of the EU. We've got to do more Greening, to get money so we've left them where they are for a year.

Although E16's primary motivations are about the relatively easy way his Greening requirements can be met with his former ELS options, his account also hints at another motivation that will be explored in greater detail, below. As the Brexit negotiations continue, and as the new look Environmental Land Management Plans (the next generation of AESs) are being designed, farmers are cautious about seeking a new CS contract if they think they are going to be locked into the scheme that will earn them less money or be less suitable for their management approach than the future offering.

\subsection{Combined motivations}

Although the above examples have been used to draw out specific factors explaining why and when an option is being maintained, more often than not, the decisions taken were the result of a number of contributing factors. Examples emerged, for 
instance, where the ease of management gains that maintaining some ELS option offered were complimented by the relatively low loss of agricultural income represented by the land, or by the opportunity they represented for Greening measures. Consider the following exchange with M16, prompted by a question about his motivations for leaving his grass strips in after his contract's conclusion:

Well the wildflowers in some of them it was amazing, the amount of insects and butterflies, you get in them...

Were they there before ELS or did you put them in with ELS?

We put them in with ELS, where there were marginal bits of - unproductive bits - of land.

Here, getting to witness the environmental improvements on his land, and the sense of satisfaction at having helped effect those changes is an important part of his reason for wanting to maintain the feature. Taking the decision to maintain the feature was, crucially, made easier by the low agricultural value of the land. A different combination of motivations is explained by E10. Although E10 was one of the interviewees who had made a successful CS application, a portion of the ELS land was left out of the CS contract, and so had fallen out of any scheme coverage. When asked about the features in neither ELS nor CS he explained that:

Those [strips] that didn't [go into CS], I've kept in and I have now put them in under BPS fallow and claimed them as EFA. EFA fallow plots - so they're grass. So they didn't become arable, they didn't default back into arable land, so they're being claimed, but by and large just plain grass and not big areas.

And so keeping those was primarily a managerial thing, meeting the Greening-

Well it was meeting the Greening and it was also meaning we weren't then ploughing up plots or strips of grass - none of them particularly big - but 
strips of grass that were valuable. And also, they had been put in place where we probably couldn't turn a tractor over small corners, or where there are telegraph poles around

The opportunity to use certain ELS strips for Greening requirements, paired with the environmental value of the grass strips, and also the potential difficulty there would have been in taking them back into production all act in chorus to help motivate the decision to keep them out of production. In E17's estimation the most potent combination of factors motivating managers to maintain ELS is the prospect of being offered a better AES further down the line, and the managerial benefits they otherwise offer:

It's case by case, but I think in a lot of cases people actually carry on. A) they don't know what's going to come around the corner, whether there'll be a new deal which offer better returns, and B) in a lot of cases they're quite happy with the boundaries and the things with how they are because it's quite operational

One important caveat to add to the above findings is that a number of the interviewees, when explaining their intentions to keep up with an ELS option, recognised that they would not observe the same stipulations as they were bound to do under the scheme. E02, for example, has opted to maintain certain grass margins, but follow a more hands-on approach to their maintenance:

So, in your own way you're doing the mid-tier options, just not necessarily to the same standard-

No. We won't... the cutting dates and that are too restrictive.

Here, E03 explains that:

No, well a lot of the stuff hasn't been taken out and back into production, but we're... where the hedgerows have encroached, we're knocking them back 
this year, in areas where it's bramble and scrub that's coming up in the autumn winter time, we'll knock that back, so we've got a fresh start.

So it's not going properly back into agricultural production?

No.

But not managed under the same stipulations as under ELS?

No.

M02 explains his decision to maintain his ELS grass margins in terms of the management benefits of using the margins as a strip between the arable centre of a field and the hedgerow and Greening grass strip. The perceived value of having such a strip can only be unlocked, however, by using it as a sterile driveway - and so the future management of the feature will deviate from the ELS option that would otherwise proscribe such behaviours:

We're only just doing it now, but the winter crops are now too tall to go around over the crops with the quad bike sprayer, so it's really useful just to spray that little sterile strip between the buffer... It's just to easier to drive around with a bike or however you do it, having a bit of a strip.

This phenomenon is an upshot of the motivating factors typically compelling farmers to maintain an ELS option in a post-scheme scenario. If, that is, they are moved to keep some feature for its ease of management, or because of realisations about the low-income value of the land, then their motivations are not primarily environmental, and the 'short-cuts' taken when maintaining an option out of the scheme, compared to delivering the option within the scheme, will typically come at the expense of the feature's ability to deliver environmental benefits. It is precisely the components of the initial option design that were developed to optimise their environmental value of the feature that are being sacrificed to secure the managerial or financial benefits the farmers otherwise perceive in in the maintenance of a given 
option. In the case of the grass strips, for example, under the scheme rules, restrictions were placed on the movement of machinery, or on cutting and spraying times, so as to protect the ground nesting birds and other mammals hopefully using that space. Where managers are keeping those grass margins as a means of reserving space to turn machinery or spraying them to ensure a sterile strip between the centre of the field and the messier headlands, however, the capacity for the grass strip to deliver environmental benefits is being compromised.

This is not true for all options maintained in a post-scheme setting. As we have seen, there are some managers (say E15's buffer strip) who have been moved to maintain an ELS option precisely because of the environmental benefits of the feature, and so, within reason, they will maintain the option to the same environmental standards as promoted by the scheme itself. In other cases, there are those for whom the perceived management or economic benefits do not come at the expense of the environmental value of the feature. In such instances, no tensions arise between the features ability to deliver both managerial and environmental benefits, and so no sacrifices have to be made one way or the other. E03's beetle bank, for instance, is valued for its ability to act as a field margin, and so is being left exactly for its unfarmed, and uncultivated quality. In the number of cases where corners were put into the scheme to square off fields (say E18), the same is true. The areas are being left because they are awkward and hard to farm, and difficult to get machinery in, and so no tension arises between the option's ability to deliver environmentally (as uncultivated grass for ground nesting birds, pollinators, butterflies etc.) as well as managerially (as land left to rationalise the shape of the field).

\subsection{Additionality and deadweight}

The final reflection offered by the portion of the project relates to scale of the changes made to enter the scheme and the impact that has on a manager's postscheme behaviour. Perhaps unsurprisingly, where entry into ELS did not require the implementation of any management changes, falling out of the scheme did not catalyse any management changes. Where farmers already favoured a low-input grazing approach, for example, when their scheme (that included a low-input grazing 
option) ended, the management did not lurch towards an intensive program of application. The post-scheme upkeep of an option should not, in such instances, be mistaken for evidence of the scheme's long-term, positive environmental impact.

As described in the phase 1 interview analysis, and as has perhaps become clear over the course of the above analysis, this phenomenon has a bearing over the long-term impact of the scheme on different farm systems. It is primarily arable farmers and their set aside (grass strips, floristic margins, buffer strips) who had to effect managerial changes to get into the scheme, and so arable farmers who have been alerted the managerial, economic or environmental value of the practices that were not previously used on the farm.

M12, who had a low-input grazing option on ridge and furrow land explained that although he was not going into the CS scheme, falling out of scheme coverage would incur little to no managerial change - primarily because no management changes were needed to enter into the ELS initially:

They sent a letter saying it's coming to an end, hopefully you'll continue, but you know, I can't... I don't think I'll start splashing on fertiliser, but I'll spray the weeds down there.

So it's not like it'll go back to an intense management style?

No, well it never was actually.

In a near identical situation, M17 details the management plans for some of the land previously under a low-input option under ELS:

And that even without the CS, those are being managed in relatively the same way as through ELS?

Yes 
Before explaining that:

I mean, there was sort of 30 acres across the other side which was on a low input, and it suited, really, because it was grazing ground we never mowed it or anything, never put any slurry on or anything, and we'd not put any fertiliser on or anything like that - it's just beautiful grass.

M20, a mixed farmer, who had secured a follow-up CS contract, was not allowed to put her ELS low-input grazing options into her new contract because of new rules that didn't allow the co-location of archaeological feature options and low-input options. In her case, however, she was not historically in the practice of applying nitrogen to those areas, and so not being allowed to put a low-input option on that land with the archaeological feature was not reason enough to start doing so, even after the new scheme, in theory, permitted:

[In CS] you couldn't have low nitrogen on old pasture and some archaeological feature. Which was a bit daft, because my argument was, “I'm not going to put any nitrogen on there, so why don't you pay me for doing that?" and she [her advisor] just said "it's the rules"

Of the other phase 2 interviewees with a livestock element to their farm - E17, M15 and M06 - none had low-input grazing options on their ELS contract (all were able to make up ELS points through a mixture of hedgerow, historic building or arable options), and so it is difficult to draw any conclusions over ELS's capacity to catalyse changes in how they managed their grazing land. The point, however, remains. Where an ELS contract does not require managerial changes to a farm's management, it is unlikely to catalyse long-term changes; and given that the ELS grazing options were typically those that required little to no managerial change meet the ELS requirements (as demonstrated, primarily in the phase 1 analysis, but also shown, above), the ELS scheme is liable to have effected a smaller scale of managerial changes on ELS land with grazing options compared to arable options. 
To reintroduce the concepts used to dissect the phase 1 interview data, the scheme's additionality is highest with arable options, and its deadweight highest with livestock options. As described in the phase 1 analysis, the incidence rate of ELS options paying participants for practices that they were already using on their land was highest amongst the low-input, grassland options - and this has a corresponding impact on the scale of managerial change the scheme's intervention is capable of making upon exiting the scheme. Deadweight was high, that is, and the additionality of those scheme options, low. For farmers with arable options on their ELS contracts, on the other hand, they were invariably having to make substantive changes to how they managed their land (i.e. taking portions of land out of production, establishing flower strips or beetle banks etc.). These changes, as we have seen, have represented a circuit-breaker, forcing the managers to inspect the possible worth in maintaining those options, even after the scheme stops paying them to do so. The additionality of the scheme, where those reflections are motivating the long-term adoption of the practices, is correspondingly high, and the deadweight, low.

Although the quality and scale of the maintained ELS options can be expected to vary greatly across different farms, it is a significant research finding that all of the farmers for whom it was relevant, had maintained some or all of the ELS features on their land. As we have seen, the motivations for this can vary greatly from farm to farm. In the two case-studies, the scheme was effective at capturing some of the lowhanging fruit on offer: by motivating the removal of land that was of poor agricultural quality, and by catalysing the adoption of alternative management practices, many managers report their having maintained those practices even after their ELS contracts compel them to do so.

\subsubsection{Removal of ELS options, re-entry into agricultural production}

Despite all the interviewees detailing how they have maintained certain ELS features on their land, in many cases this was not true of all of their options. Some farmers, that is, were maintaining certain options, but returning others to agricultural production. This subsection will consider the scale of this phenomenon, and the factors motivating managers to take such decisions. 
The most clear and obvious motivation for returning ELS features to agricultural production was economic. Where good land had been taken out of production to meet ELS requirements, farmers cited economic reasons for reclaiming the land for agricultural purposes.

E02, as described above, is leaving some of his ELS features in place on the farm, co-opting others for Greening measures, and returning others back into agricultural production. His motivations for deciding which options will follow what trajectory are business pragmatic - where option can be easily reintegrated into production, they will be, and where they can't, they will be used for other purposes:

[It's] rotational requirements, and getting that field back in to its timescales, to get that bit back in without causing you - because generally there are awkward little corners to get them back in is not very easy to do without extra remedial work to get them back in to the field, so the ones that go back in easily into the field will go back in, and the other ones I might square other bits off more but for different reasons, different usages.

In this light, both the decision to leave the options in place or reclaim them for productive purposes are about managing the farm business as economically and efficiently as possible. This principle is neatly summed up when he explains why the above decisions were taken:

It's running a business

Similar motivations and practices are described by E18:

So subsequently, all of those strips are now out. They've gone. We're looking at, in the region of 40 acres

Put back into production? 
Yep... There are parts of fields that strips, margins, whatever, that we took some were awkward corners, some are in corners that are in fields that are just not practical to get in with a $36 \mathrm{~m}$ wide sprayer.

So those bits have stayed in?

They have in the main part.

And were they bits that were put in through ELS - or have you always not managed those?

No. They were done as part of the ELS.

Before later explaining that:

The top and bottom of the whole thing is that we're running a business, and we're trying to earn a living from that business.

The economics of running the farm, combined with a perspective on where the largest area of the field is, dictate that where appropriate, land should be removed from its previous ELS status and returned to production. Where the practicalities of it prescribe, however, features will be left in - and so the decision to return land to production are not ideologically orientated around productivity maximisation, but rather economic pragmatism.

E19's account further sets out this operating principle:

I'm conservationally minded and there are certain strips or places where it's convenient to have banks. Not banks, but rough grass, whatever you want to call it. They've all been pulled up recently, in the last 2 years, got that back into control.

Back into production? 
Yes. They needed to. Not all of them - but the bulk of them have. They needed to because they were beginning to grow trees. So that is one side of it. The other side of it is... yes, so I think the conservation minded bits, I haven't pulled them all up but everything that was commercial to pull up will be pulled up.

But there will be bits on unproductive land that will likely be left?

Yes. But whereas beforehand a $10-15 \%$ of the farm was put into the scheme because it was convenient and wasn't making or losing any money, was better for conservation. That's all gone. The strips now, doing conservation work, are areas that I cannot get a tractor in.

Here, the decisions are again founded in practical farm business motivations. Despite self-identifying as a conservationist, E19 was taking the ELS features back into production where it was 'commercial' to do so. In other words, the economic practicalities of running a farm dictated that in lieu of AES payments that helped the grass margins be cost-neutral, he could not afford to have them out of production. Further, there were long term managerial considerations at play. Cautious of losing the land to tree growth, he wanted to clear the whips from the grass margins before they were too big to be easily removed (or before he lost the right to lose them, having expressed elsewhere frustration at the rules prohibiting him from removing trees once they had attained a certain size).

Elsewhere in the interview data, reclassification concerns were also motivating farmers to remove land from its erstwhile ELS usage. In such instances, there were issues with land being reclassified as a different agricultural type against the will of the farmers, due to it being used in a particular way for an extended period of time. This problem was typically motivating farmers to return grass strips to cultivation to allay fears of it being reclassified as permanent grassland (which temporary grass does, after a period of time).This was even happening in cases where the managers 
would have otherwise wanted to leave the grass strips in place - but, to ensure their continued freedom of management, put them back into cultivation.

E09 explains a situation on some land he contract farms:

We've got one farm, a contract farm, got some grass margins and actually we're going to plough them up this year because of bloody Defra, because they've been down as temporary grass and they're going to go down to permanent.

So you wouldn't do that otherwise?

No, we would have left them as grass, but we've been forced to because they'd have stipulated it as permanent pasture.

Here, E03 explains how widespread he believes the issue to be:

I think people who aren't contracting will keep a lot of the options. I think the main reason people will not go into CS would be fear of it changing.

Changing classification, you mean?

Yes. And there's a lot of things already that, like fallow land, where if you put it in for fallow land, by the time you come out that's then permanent pasture. Little things like that put people off.

E14, the agricultural agent, has witnessed similar situations unfold. Here, he not only his experiences of the phenomenon what the situation is, but also potential policy remedies, too:

I think certainly RPA conversations about grass margins becoming permanent pasture. Rightly or wrongly, they're just paranoid - don't want it to be permanent pasture because "I want to be able to plough it" - "yes but 
you weren't going to plough it anyway because that's why you put it there" but that's the view - you can't actually change that. I think, you know, if they'd just said, "if it's in a stewardship scheme, it never becomes permanent grass". Everybody would have been quite happy and that would have got the right result.

The findings from the previous two subsections, along with the analysis from phase 1 all point to the same motivations. Where possible, within the constraints of managing a financially viable farm business, managers are willing and motivated to have environmental features on their land. In the context of post-scheme management, this is frequently expressing itself in terms of maintained ELS features. Where those options are, however, occupying valuable agricultural land, and where they can be simply and efficiently brought back into agricultural production, then they are liable to be brought back into production.

\subsubsection{Generalising the project's findings}

The above analysis, about the upkeep of scheme options in a post-contract setting represents one of the major research themes of the project. The extent to which the findings can be generalised beyond the extent of the case-study is, therefore, worthy of consideration. Section 4.2.14 explained which of the project's findings, because of the project's theoretical framework and methodological design, can be generalised about the project's wider target population and which cannot. Inferences can be drawn about the rules of the game in the agricultural field, for example, because of a close understanding of Bourdieu's explanation of how a field's membership interacts with the jurisdiction of its rules. Such analysis will be offered in section 7.3.1.5, below.

Regarding the long-term maintenance of ELS features, however, the project was not equipped to make such robust generalisations. The project was predicated around a qualitative case-study analysis of the features and factors in the decision-making processes that lead managers to maintain or remove their ELS features after their contract's closure. Whilst it was revealing how so many managers had decided to 
keep their ELS features, the findings cannot be used as independently sufficient to claim that the same motivations and experiences are true of ELS contract holders, more generally. Section 4.2.14 did, however, articulate how, a case-study's finding can be generated to a wider population, so long as careful consideration is given to the shared and divergent realities the case-study has with the group to whom the findings are being applied. The textured and rich account a qualitative case-study analysis can produce can be used to assess the relevance of the findings in terms of their potential wider applicability

It is argued, in this way, that some of the above findings about the long-term management impacts of scheme participation, especially in relation to the postcontract upkeep of ELS features or practices, can be extrapolated to shed light on ELS's country-wide impact. Many of the material facts that were identified as motivating factors in the long-term upkeep of scheme options can be expected to apply to other ELS-participants, beyond the extent of the research sample. When compiling a scheme contract, many interviewees with arable elements to their farm holding explained how they decided to commit marginal arable to the scheme. In doing so, they could effectively monetise a part of their farm they knew was delivering a lower economic return. The low quality of the land and the low economic return it was capable of producing whilst in productive use, and the positive impacts the feature has had in managing the farm were, in turn, identified as important factors in the long-term upkeep of those features. It is argued that this operating principle (putting marginal land into the ELS scheme) in the name of economic expedience, is liable to have been employed across the country by farmers compiling ELS contracts on farms with arable elements; and that farm holdings across the country all contain areas of low-agricultural quality that would have been the first to be used for ELS purposes.

Grounded in Patton's (2002) analysis about the extrapolation of a qualitative casestudy project's findings, it is argued that the findings detailed above - about the long-term upkeep of set-aside options, especially buffer strips, grass margins or awkward corners - have potential applicability to the wider population of ELS- 
contract holders across the country. Future research - about the wider upkeep of ELS options post-contract - would be well placed to verify these tentative generalisations.

\subsubsection{Reintroducing Bourdieu's thinking tools}

The previous subsections have given an overview of the different trajectories of ELS features being managed after the termination of the interviewee's contracts. This subsection will now reintroduce Bourdieu's thinking tools and set out what insights his theory can offer, in relation to the topics of the phase 2 interviews.

For the phase 2 interviews, the deployment of Bourdieu's thinking tools was slightly frustrated. For the first round of interviews, farmers were asked questions about the management decisions taken by nearby farmers that were easily identifiable - and so easy to form opinions about and discuss. For phase 2, however, when asking questions about nearby farmers' decisions about manging post-contract scheme options, interviewees found it more difficult to identify which features were being maintained under an existing ELS agreement, which were under CS, and which were being maintained outside of a scheme contract. Short of knowing precise details of another farm's ES or CS contract, that is, the appearance of an option being managed voluntarily, or under some scheme contract were indistinguishable, and so it was hard to stimulate discussion about their perspectives on managers following those different approaches.

To short-circuit this problem, hypothetical questions were asked - "what would you make of it if somebody was maintaining an option outside of the scheme" or "what would you think of someone who put their ELS options back into production" for example. Such questions were successful in eliciting appropriate responses about the respectability and regard the interviewees had for different management approaches. Furthermore, the problem was not ubiquitous. Some interviewees were able to identify and reflect on management decisions taken by nearby managers and, even where they were hypothetical, valuable insights were nevertheless still offered. The issue is not perceived as problematic for the thesis' ability to attend to its research objectives. 
7.3.1.5.1 The rules of the game

Consider the range of responses below, all given to identical questions about their assessment of farmers deciding to return ELS features to agricultural production:

M15,

I think it'd be a bit rough to think "I'm not being paid for it, I'll plough it up"

E15,

I think just keep them, really.

M04,

No, I don't think that's right - I wouldn't say that at all. Leave some bits in, if you can, definitely.

E04,

Understandable, but very disappointing for the environment

And E02

No totally respect it, it's whatever is economically correct.

There is a latent preference and respect for those farmers maintaining their ELS features without remuneration (M15, E15, M04), but a recognised primacy around the need to manage a financially viable farm, such that decisions taken to ensure that goal is met are understood and valued (M04, E02, E04). Although there is respect available for those managers able to run a financially viable unit whilst still making 
room for environmental measures, ultimately, the need to ensure the farm's business viability means that the decision to re-enter ELS features into productive use is understood (hence it being "understandable" or claiming that features should be left in only "if you can"). The rules of the game, as detailed over the course of the phase 1 analysis are, in other words, in evidence. Whilst there is cultural capital available for environmental pro-activity, it is only available after a farm's business is first secured.

During the phase 1 interviews, continual references were made to the competing pressures to be environmentally conscious and the need to be economically sustainable - and how the primacy of the need to ensure the farm's economic viable trumped the desire managers may otherwise feel to be more environmentally considerate. That analysis also revealed, however, how new information and experiences around the economic value of an AES contract, the marketing value of environmental features, or the long-term business value of implementing environmental and soil conservation practices on the farm were being integrated into the farmers' habituses, and were re-shaping their understanding of the intersection between good environmental and good business management. These new widespread knowledges and understandings were exerting themselves on the rules of the game, and had repositioned the perceived legitimacy of adopting environmentally sensitive practices. Participation in an AES, or the adoption of soil conservation practices, in this way, became evidence of a manager's savviness, and forward-thinking business acumen - and not of an overly lax approach that deviated from the productivist goals of high production and intensification. They were, as a result, well placed to reproduce cultural capital. Only where those environmental efforts were badly delivered or came with an unnecessary loss of agricultural yield (through the result of a lack of skill or knowledge), or frustrated the farm's ability to be economically viable, did they incur a loss of cultural capital.

The reflections farmers offered over the course of the phase 2 interviews revealed how these new features of the managers' habituses, and the corresponding shifts in the rules of the game were also in effect when assessing the different management choices available to other farmers in a post-contract setting. Consider the following 
responses, all given to questions about the perspectives different interviewees have on the management decisions being taken by other - sometimes hypothetical managers in the wake of their contracts' termination:

M06

I think possibly with sprays and that, people have learnt they can get away with using less.

Well I think this big neighbour, I was talking to him this spring, and he's gone into it [CS] and again he's massive scale, and he is taking corners out, because those corners are under performing and are bringing his average yields down... so he's better off.

Yes, I think once you've got them in there, you realise you weren't producing much from there anyway! Much easier to get around, walk around, or drive around and see what's going on a bit.

And M20

I think when people do the maths, they know it. Because the maths is good! I'm sure I get more for a buffer than I do for a crop.

Having been involved in ELS, having established different scheme options, and having all made decisions about how to manage those options in a post-scheme setting, all the above interviewees are clearly actively involved in reflections about the agricultural practices of the options contained within their contracts, and the value those practices represent for the running of a farm business. Those reflections are, in turn, rubbing off on how they are assessing the management decisions taken 
by their fellow field members. Bourdieu's habitus, and its capacity for iterative restructuring in the face of new information and experiences, is in action.

M06 (reflections initially catalysed by their observation of NVZ regulations, and not through their ELS contract), for example, had seen how excessive fertiliser application does not facilitate a corresponding increase in yields, and does not make up for the extra expense incurred in purchasing the chemicals. As a result, he had a new respect for the knowledge and expertise of other farmers availing of a lower level of agricultural chemical application. M10, in the same way, had elsewhere explained how he was planning on keeping his ELS corners out of production (which he had, prior to participation, cultivated) because of their low agricultural quality and the difficulty he had in efficiently farming them.

Those managers have, in other words, as a result of their participation in ELS, and as a result of their having considered the benefits of keeping or abandoning their ELS features, assessed the net business and environmental gains and losses of maintaining those options. In many cases, as we can see, they have come to recognise the managerial, environmental or economic benefits such features can represent, and so increasingly understand and respect the decisions of other managers preserving similar features or practices outside of their own AES contracts. Where the perceived intersection lies between environmentally conscious management and business savviness is, as a result, further shifting - and the perceived legitimacy of integrating such knowledges (in this case the long-term adoption of certain ELS practices) into how they manage their farm is changing accordingly. Here, Bourdieu's concept of the habitus is particularly illuminating. The habitus functions as both the thing upon which new experiences impress themselves, as well as the lens through which individuals process and assess other's behaviours. The participants' scheme experiences, and the new understandings and knowledges they have facilitated are reshaping their habituses. This is, in turn, reshaping the way in which they evaluate the behaviours of the other members of into the agricultural field. Specifically, reshaping it towards an increased regard for the long-term integration of environmental or ELS features onto their farms. 
That the reproduction of cultural capital is tied up with the demonstration of an individual's skill and experience has been discussed in previous chapters. In this context, the skills and experiences acquired through scheme participation express themselves in the savvy comprehension of which land can be used to secure environmental benefits with little or no loss of agricultural income or what the other managerial or economic benefits some environmental practice may offer the farm. The rules of the game, in prioritising the management of an economically sustainable farm, and maximising, within that limitation, the farm's environmental profile, will recognise the legitimacy the management decisions that avail of such practices. The good farmer, in this way, will be able to recognise which ELS practices can be preserved with an acceptable loss of agricultural yields, what the other managerial or environmental improvements those practices can deliver and, in doing so, demonstrate his skill and knowledge and reproduce cultural capital accordingly. And individual's own ELS experiences are catalysing the widespread acceptance of those knowledges.

7.3.1.5.2 Multifunctionality in the rules of the game

Consider the following exchange with the younger farm manager in the E10 interview:

Do you think it's respectable to be leaving them in even on those Fen farmlands, or-

Again, I think it depends on the agreement. As Ron has said, if it's a tenancy and it's a guy who has spent a lot of money kitting himself out, and he's on the breadline and needs to make every acre pay, then really, he probably will be farming it.

The inclusion of 'Fen farmlands' in the above question is a reference to an earlier description he gave about the sorts of farmland most likely to have options preserved in a post-scheme setting. Asked about his predictions for ELS land across the country, he explained that: 
I think if you pick a farm in the middle of the Fens who, for whatever reason had put some strips and things in, I think those guys will be taking their strips out, because I think they'll take a view that they can grow a high value crop on their because it's still pretty good land. But if you take a rural estate, perhaps one that has been an ex-livestock farm and has gone all arable, with some small fields, and shady corners by the sides of woods, I think those will be the guys who will be leaving what they put in. But on grade 1, quality arable land, you'll see less of leaving the margins in.

This statement indicates another important finding of the research. Namely, that there are management behaviours that are expected or acceptable on a certain part of the farm - or on certain farms - that are not respected or acceptable on others. This idea hints at a multifunctional vision of the good farmer, in which the perceived value of a given farm management practice is contingent on the quality of the land, the size of the farm, the tenancy situation of the farm, or some other characteristic that helps determine which management style is most appropriate.

As described in Section 3.7, multifunctionality in agriculture refers to the idea that the farming sector is capable of delivering a range of goods beyond strictly food production (biodiversity, healthy rural environmental, economic stability etc.). This idea has, as we will see, been encoded into the habituses of the farmers. This process is resulting in a willingness of the individual farmers to identify which parts of their farms - or which holdings - can be best dedicated to deliver which of agriculture's varied functions. There are, as a result, certain farms, or particular parts of a given farm, that are perceived as having one appropriate function (say, for environmental stewardship purposes) and other farms, or different parts of a given farm, another (say, agricultural production). In this way, the rules of the game are subtly tuned to the land or farm in question, such that the management decisions that are best placed to reproduce cultural capital on some farm, or on some part of a farm, are different to the management decisions best able to reproduce cultural capital on others. 
E16's response to a question about the respect he has for the maintenance of ELS options in a post-scheme setting, for example, maps onto this multifunctional vision of farming. His account also indicates the impact this has on the reproduction of cultural capital:

If they [grass margins] were around a large field, where he's growing them to get the ELS, and done the whole field, probably good management [to return them to production]. But if he's got a corner plot where he's growing them and it's difficult to manage, then I would leave it. But if it's part of a big field which he set aside, say this is the field, [motions a square field] and say he's left a nice big strip down that side, then you'll bring it all back into production. But where you use them as a management tool for awkward corners or that sort of thing, then I see no reason to bring them back in.

Here, the regard E16 has for the decision to leave ELS set aside areas out of production is calibrated to the quality and type of land put in in the first place. If the land is of high quality, and can be easily integrated into a field's cultivation, then its appropriate use is in agricultural production - and so there is a recognition of the steps taken to take ELS land of this nature back into production. For poor land, or land that is not easily farmed, there is a recognition that its appropriate use to be contributing to the environmental quality of the farm, and for it to potentially be generating 'income' by being committed to an environmental scheme or to meet Greening requirements.

Here, Bourdieu's conceptualisation of cultural capital is especially relevant. Cultural capital (in any of its three forms) is generated when an individual's skill, expertise and knowledge is in evidence. When managers have the skill and knowledge to identify which parts of their farm are amenable to certain business models, or certain agricultural practices, and to not blindly follow some approach irrespective of the land's quality, they are demonstrating the precise sort of knowledge and expertise associated with the reproduction of cultural capital. 
The following excerpts are all expressions of this process. The perceived legitimacy of adopting a given practice is determined by the land's characteristics and potentials, and cultural capital flows to those who have the skill and expertise to make those identifications and assessments. In these cases, the cultural capital is in its embodied form: the physical marks and artefacts that are the result of an individual's skilful management practices.

E10

I think it's quite right that the less productive areas, the areas that have got huge weed burdens, areas on the sides of woods and things, you know, it's right they're probably come out of production because they're not sustainable anyway - and if there's money to take them out of production all the better for it; but even if there isn't money, you're almost cropping areas that are not worth it, that are just dragging the average yields down anyway.

E17

What they're probably doing on the bigger farms is ploughing the ones up that are a nuisance, and then on the crappy bits they'll probably leave a little bit more.

And M17

And you only do that [maintaining a low-input programme for grassland] for a proportion of the farm - it's nice to see the flowers up there, and the wispy meadow up there, but you wouldn't want to see it all over the place.

The behaviours of the good farmer and the reproduction of cultural capital does not, in other words, imply a reductive 'one-size fits all' management approach. Instead, in-line with the characteristics of the good farmer outlined above, and in the previous analysis chapter, farmers should ensure the economic viability of their farm (cognisant of the intersection of good environmental and good business 
management), whilst ensuring, to the highest degree possible, the farm's environmental profile. And, as the above accounts demonstrate, this can be best serviced by recognising which parts of the farms can be used for environmental purposes and which areas should be used for agricultural production.

Again, Bourdieu's conceptualisation of the habitus is illuminating. Through its capacity for iterative restructuring and in responding to the new experiences acquired through scheme participation, along with the and the new widespread knowledges in the agricultural field, the habitus' functionality as 'lens through which the world is viewed' is shifting. Having experienced how certain parts of their own farms are best committed to environmental or non-productive use, they are integrating those management experiences and expertise onto the expectations they project onto other managers, and their assessments of a different areas of a farm's appropriate use. The multifunctional role of agriculture, and the policies designed to encourage it (AESs, Cross-Compliance etc.) are subtly moulding the psychologies of the farmers - who are now actively engaged in reflections about how to deliver on agriculture's different and varied roles on different parts of their farm.

Beyond an 'intra-farm' multifunctionality (whereby different areas within a farm are being identified as ones that can best be used to deliver different agricultural goods) there is also an inter-farm or regional multifunctionality component to the good farmer concept. Farm systems, or farms operating in certain landscape types should, in other words, be adopting a business models and targeting management objectives suited to their holding. The good farmer, that is, does not just recognise which parts of their farm are best put to environmental or agricultural usage, but should be able to recognise when their whole operational management can be geared towards environmental subsidies or when it needs to be predicated on a more traditional model of agricultural production. E04, for example, who manages two farms, employs a different management approach on his two holdings:

The Cambridge farm ...that's 550 acres. And in order to meet ELS requirements, we've got all their requirements on this farm [in Sudbury, some 40 miles from the Cambridge farm]. Because we've got so much bad land, 
and you can say "have that 20 acres, have..." and it makes up for not having any at all in Cambridge.

Where food can be efficiently produced, and where the farm's business can be run relying on its agricultural output, its appropriate use is as a productive farm. The limited amount of land dedicated to its environmental profile is acceptable so long as there are other farms, or other parts of other farms that do not have such 'productivist' capabilities - areas that are being managed to a higher environmental standard. In this way, so long as the net amount of land being put to environmental uses (in this case, across his two operations) is sufficiently high, the negligible environmental work done on the Cambridge farm is justified. The same sentiment is present in M04's assessment of the direction of travel he would like to see on his farm, versus more productive arable operations:

I'm quite happy on a farm like this to go down the environmental route, because it isn't a productive farm, and it isn't a viable arable farm in its own right. Not like some of the farms in East Anglia, huge farms and they probably stand up on their own right.

M04's account differs from E04's, above, in one very important aspect. That there should be a 'net' level of environmental concessions made is not playing out within the land he manages, but across the country as a whole. Whereas E04 is contented by the environmental features on one of his farms, and the legitimacy it lends the more intensive approach taken on the other, M04 recognises that this balancing act also needs to be made across the entire country. His farm (in the west midlands), with its high environmental potential acts as a counter balance to the East Anglian farms with higher agricultural potential, that can justifiably be farmed with more unilateral agricultural objectives in mind. The same attitude is represented in the following excerpts:

M12: 
Not every farm would suit that [a business model predicated on subsidisation and the provision of environmental good.]. My land suits it, because it's that type of farm, small fields, plenty of hedges, and the spinney... But if you've just got 130 acres of flat arable land, how are they going to get anything for environmental, with that production.

The reproduction of cultural capital, in this way, is calibrated to the potential of a farm - or part of a farm - and the need to balance the provision of environmental goods and agricultural production. For individuals participating in the scheme, ELS has helped shed light on what land is best used for agricultural purposes, and what land may be appropriate for a less intensive management style, given the other benefits their ELS practices have helped secure - namely managerial improvements (say, ease of access), financial (say, through another AES contract or Greening measures, or through not farming marginal land at a loss) or environmental (say, an improved level of biodiversity, increased soil fertility, or an increased interest in the environment). Seeing other managers leave marginal land or awkward corners, or adopt a lower-input program, especially on parts of the land suited to such measures, reflects the knowledge and skill of the respective farmer and their progressive understanding of the intersection of good environmental and good business management. As described above, the reproduction of cultural capital is intimately tied up with the demonstration of a given person's accumulation of skill and expertise. A manager who has the wherewithal to identify the appropriate use for different parts of the farm to maximise its environmental and economic output can, as a result, expect to reproduce cultural capital through their embodiment of the multifunctional component of the good farmer.

The phenomenon maps onto the land sharing or land sparing policies policy debate (see Green et al. 2005, Fischer et al. 2013 for discussion). The debate centres around the efficiency of agri-environmental interventions that encourage the removal of land from production (land sparing), versus those that encourage the integration of environmental management with food production (land sharing). Although it is beyond the theoretical scope of the thesis, the multifunctionality of the good farmer could be an interesting way of understanding when and where land sharing or land 
sparing interventions are targeted, and how the potential willingness of farmers to engage in a scheme will be mediated by the perceived agricultural and environmental potential of their holding.

The above phenomenon is also playing out on a regional level. Consider the following:

E07

And if you look at a Norfolk farmer farming on light sandy soils, compared to a Somerset farmer doing mainly dairy, and worried about not having too much rain - well the two are so totally different that you couldn't conceivably think the two would have the same thoughts on these things.

M18

It depends a bit where you are - if you're out on grade 1 fenland, I can imagine you're not so keen [on committing land to AESs] if you're on our grade 3 .

And E14

I suspect if you're around here [Suffolk-Norfolk border] and you're looking at some of the very commercial arable farms they will just say "we want to get on with it, and we're going to do exactly what we want, and production is key". I suspect if you're running a mixed farm up north somewhere, where you haven't got the soil conditions, you haven't got the climatic conditions, haven't got the field sizes... then the environmental side of it will be the only way to get any realistic income.

The above excerpts all imply how the business opportunities, agricultural potential and environmental potentials that exist on different farms is liable to be determined by their location. The Fenlands farms are identified as having high agricultural potential, and so there is a perceived legitimacy in managers in those areas 
predicating their business model on agricultural output. Upland farmers, in the North or in Somerset, on the other hand, are identified as having high environmental potentials, and so there is a perceived legitimacy in managers in those areas predicating their business model on the subsidised provision of environmental goods. What the good farmer does, the business model they adopt and the scale of environmental work they do is calibrated to the quality of their land and its appropriate usage. The quality of the land is, here, identified as having a regional element, and so the good farmer in one area may legitimately follow a different approach than the good farmer in another.

This tendency does not, of course, imply distinct sets of rules from region to region. Even within Norfolk for example, there will be farms of higher and lower environmental or agricultural potential - and those opportunities and assets will assume primacy in determining dictate the appropriateness of different management styles, and the cultural capital available for adopting some approach over another. This regional component, apparent in the above excerpts simply recognises the tendency for farms in certain areas to have shared landscape assets, shared farm systems and so a shared set of legitimatised management practices. The need to manage a financially viable farm, and the need to maximise the environmental profile of the farm within that constraint, still assumes centrality in the good farmer concept and the way in which cultural capital can be reproduced; and where a particular farm's capacity to realise those goals is achieved in a way that deviates from its region's typical approach, that approach will still be favoured.

Although the multifunctional feature of the good farmer is largely geographical or topological, it is worth noting that other characteristics of the farm/farmer were identified as having a bearing on the sorts of management practices perceived to be legitimate, and so capable of reproducing cultural capital. Of these, the most commonly described related to the tenancy situation of a given farm. Farmers who owned their holding were recognised as having a higher degree of economic liberty in how they managed their farm. Within the framework of the good farmer - the goal of achieving the farm's economic sustainability and delivering environmental benefits to the land - the legitimate level of environmental management employed on 
a farm was higher for those who owned their land than for those who were on farm business tenancy agreements, or for those contracting the land. This phenomenon was particularly pertinent in the discussion around the regard for the management of ELS options as they fell out of scheme coverage.

Consider the following:

E10

On an estate like this it's traditional, and we're very happy to manage land in as environmentally friendly way as we can - then yes, go for it. And that's why I was determined we would go down the route of CS.

And then later, in the same interview:

If you have a tenant farming 1000 acres who was paying a high FBT rent, probably borrowed quite a lot of his capital, in arable farming today, he is really up against it, to you know, to make a profit, and to pay off his borrowings and to maintain himself and his family. So he really has got to farm pretty hard to make his objectives.

E07

If you're a 10,000 acre farmer and you've got big assets and you've got probably a reasonably strong balance sheet giving you some room for manoeuvre, that's very different from a farmer doing 5, 6, 700acres where it's hard in any year to make enough money to be able to have a decent living and having a margin for error in the years where it's difficult.

And E03

Contract farmers, if they're not going in, it'll just be gone. Back to the wall to wall cropping. 
In the same way that a farm's business opportunities and perceived appropriate management style is determined by its landscape assets, agricultural potential etc., its farm tenancy situation has a similarly important role. The need to meet the prime goal of ensuring the farm's business viability can be secured through very different approaches, depending on whether the farm is rented, owned, or contract farmed. Where farms are under greater pressure to be economically productive (typically rented or contract farmed land), the decision to return ELS features to production, or to leave less room for environmental features is perceived as legitimate and is not criticised in the same way. Where farmers own their land, however, there is a perceived legitimacy in the decision to make more environmental concessions, because the need to run the land economically sustainably can (and should) be met whilst allowing for a greater scale of environmentally sensitive practices. By way of example, M10 recognised the pressures on having rented ground, and the need to make "every square metre count". Management decisions taken to ensure the farm's viability, in this situation, will have to be geared towards combating this pressure, and so there is an implied recognition and regard for renting farmers making fewer environmental concessions. If, however, the economic pressures are not so acute, then there is a recognition and perceived legitimacy in the steps taken to ensure the farm's environmental profile.

All of the above multifunctional characteristics of the good farmer are expressions of the same rules of the game that determine the reproduction of cultural capital. Cultural capital is available for the farmers maximising the environmental quality of the farm whilst ensuring its economic viability - typically by availing of up to date information and skills that allow them to expertly navigate the intersection between good environmental and good business management. As we have seen, however, what management practices pertain to the realisation of these goals, and what scale of environmentally sensitive management practices can be integrated onto the farm before the need to ensure the farm's economic viability is frustrated varies from farm to farm. The core rules of game are the same, but are expressed in different ways, as determined by important characteristics of a given farm - whether it be the farm's location, its landscape assets, business opportunities, or tenancy situation. The 
reproduction of cultural capital, as a result, is attained through different behaviours. This phenomenon has academic precedent - Saunders (2016) similarly recorded how new social and environmental objectives were being integrated into conceptualisations of the good farmer. That these new goals had been internalised into the farmers' psychologies stands in contrast to historical understandings of farmer attitudes, and their more unilateral productivist priorities (Saunders 2016).

It should be noted that the multifunctional component of the good farmer emerged independently of any specific questioning - and so was not subjected to systematic, per-interviewee, questioning. As a result, precise details of the interface between the good farmer concept, the reproduction of capital, and the farm's landscape, tenancy or regional characteristics cannot be fully described here. If a Norfolk farm pursues a model an intensive model of agricultural production with no concessions to environmental features, is it respected because of the legitimate realisation of its agricultural potential - or is it criticised for not including environmental features where its balance books would have in fact been able to accommodate them? Would a small uplands livestock farm with high environmental potential that nevertheless pursued a business model predicated on specialisation, maximised yields and intensification be criticised for deviating from its apparent legitimised use, or would it be well regarded for its attempts to ensure its economic viability? Such questions would clearly benefit from future, more dedicated research.

\subsubsection{Crowding out, crowding in}

As previously described, some of the debate around the post-scheme management of AES features is framed in the crowding out in debate (Darragh and Emery 2018). Does the presence of a financial reward suffocate and 'crowd out' the pre-existing motivations of the participants, and promote the idea that such behaviours should only be adopted in the presence of financial reward; or does the exposure to the scheme-promoted practices and accompanying information foster, or 'crowd in', their environmental motivations? 
Little research has been done into the crowding in/crowding out phenomenon in the context of AES participation, with much relevant research not actually using the crowding in/crowding out theory as its framework - but rather conducting research that has an overlap with the theory's main themes and topics, and citing the theory as something that could shed some light on the situation. Lowe (1999) and Bager and Proost (1997), for example, assert that participation in an AES would have a positive impact on participant's environmental attitudes. Hodge and Reader (2010) and Burton and Paragahawewa 2011, however, maintained that because of ELS's broad and shallow characteristics, and easy to deliver management practices, the extent to which participant's environmental attitudes would be fostered was minimal. Darragh and Emery (2018) are notable in that their empirical research, based on qualitative interviews with farmers coming to the end of their ELS contract, was predicated on the mobilisation of the crowding in/crowding out theory. They concluded that the pessimistic expectations offered by Hodge and Reeder (2010) have not been realised, and found that in many cases AES options were being maintained.

Darragh and Emery's (2018) discussion identified the applicability of the theory, as the subsidy system was set to move away from ELS's broad and shallow design, and towards the competitive, limited availability of subsidies made available through CS. "In environmental contexts, crowding-out postulates that land managers who had previously provided public goods for free, but that are subsequently remunerated for the provision of said public goods, will come to expect payment for their continued provision... The crowding-out question arises in the current situation because many farmers in England that had been eligible for the ELS will not be eligible for its replacement scheme" (Darragh and Emery 2018 pp.370-317).

The landscape has, however, changed. As a result, the rationale behind the deployment of the theory has been undermined. With the policy shifts catalysed by the Brexit process - namely the refocussing of subsidies away from direct area-based payments and towards an increased availability of AESs - farmers are not going to be exposed to a system in which the payments for adopting environmentally sensitive management practices are removed, but rather a system in which their availability is set to increase. Whilst the transition from ELS to CS may have well invited a 
discussion around the crowding out of motivations, the transition ELM muddies the issue. Those interviewees above, for example, who are maintaining their ELS features for use in a future CS agreement, or those who have avoided the CS scheme with the express intention of using them for future ELM usage are evidence of how the crowding out theory misfires. They are not, that is, moved one way or the other about whether to keep up with their subsidised behaviours in lieu of continued subsidisation or to return them to agricultural production, but are instead in a holding pattern, keeping up with the practice with the expectation that they will soon be able to resume its subsidised status. Their 'post-subsidised' behaviour is, in such instances, a matter of conjecture.

The theory, nevertheless, has some aptitude. As we have seen, not all participants welcome the impending changes to the subsidy system, and the way they manage their land falling out of scheme coverage represents, and many interviewees were not intending to move into CS and made no comment one way or the other about their future participation in a post-Brexit AES. Have these managers, the theory asks, found themselves with a greater willingness to adopt the practices, or have they been furnished with the sense that environmental behaviours can only be expected of them in the presence of remuneration.

We have heard about, over the course of the analysis in 7.3.1, the high volume of options being maintained after a given contract's termination. The motivations are typically grounded in managerial and economic concerns. Where poor land was taken out of production, or where options represented a more savvy business choice (for example where a low-input option incurs a minor loss of yield, relative to the cost the agricultural chemicals would otherwise have cost, resulting in a net profit gain, or where poor agricultural land was put into the scheme that they were previously farming at a loss). The scheme, in this sense, by stimulating initial adoption of such practices, prompted farmers to assess the actual economic or managerial value of their pre-scheme behaviours, and consider the long-term adoption of the ELS-promoted practices. E07 neatly sums this process up: 
Probably some ELS stuff encouraged farmers to do what was sensible anyway, and get paid a bit of money for it.

With E09 expressing the same sentiment

I think the majority of it [ELS features] is just being left.

What's the general reason - why do you think that it-

Because they were taken out because they were not profitable anyway.

Such instances do not, in fact, represent the fostering of environmental attitudes per se, but rather long-term commitment to the behaviours promoted by the scheme because of the intersection they represent with good business management. The influence that the scheme has had on management practices should not, as a result, be mistaken for the influence it has had on the attitudes of the participants. Nevertheless, the raised awareness about the value of permanently adopting their ELS practices certainly does not represent evidence for the crowding out theory. Exactly because of the prime objective of running a financially viable unit, interviewees who have seen and experienced the managerial or economic benefits of particular scheme options are unlikely to revert to their pre-scheme practices because of an acquired belief that such behaviours should only be done in the presence of state subsidisation. Indeed, the large proportion of interviewees who are maintaining their ELS features outside of an AES (irrespective of whether they are doing so because of the environmental or economic or managerial benefits the practices represent) are all evidence against the crowding out conjecture.

The situation is not, however, as simple as that. It could be the case that even those managers preserving their options in a post-scheme setting have developed a sense that such behaviours should only be done in the presence of a subsidy - but that that motivating factor does not outweigh the economic or managerial benefits the practices otherwise confer. Such situations did in fact arise, with a number of interviewees - all of whom were planning on preserving certain ELS features - 
expressing the exact sort of sentiments predicted by the crowding out theory. The following responses were given to questions about the willingness of managers to maintain environmental features after they stopped being subsidised:

M12

You don't do anything if you don't get paid for it!

M18

Well if you're not going to pay me to do them, I'm not going to do them.

Basically, to be brutally honest.

And E09

What can you can't expect me to do is take my land out production and give me nothing for it!

The above three interviewees appear, in other words, to follow the trajectory predicted by the crowding out theory. Having been subsidised to adopt some practice, all expressed the sentiment that in lieu of the continued provision of subsidisation, they could not be expected to continue with the practice. Although it is impossible to assess what their attitudes were before their participation in an AES, to see if they had pre-existing environmental motivations that have been suffocated by the presence of the subsidy, inferences can still be drawn. The provision of a state subsidy has precluded or 'crowded out' the motivation to perform the practice voluntarily and has instead fostered the sentiment that their continued adoption of some environmental practice is contingent on ongoing subsidisation. In reality, however, we know that to a greater or lesser extent all of those managers had maintained certain ELS features, for a range of other managerial or economic reasons. 
In such instances, the primacy around the need to manage a farm in an efficient and cost-effective way meant the crowding-out style sentiments about the upkeep of scheme options post-contract were obscured by the presence of the managerial, environmental or financial benefits the options conferred. Although there may be the reactions predicted by the crowding out theory - as represented in the above excerpts above interviewees - such concerns are of minor importance relative to the need to run a farm in an efficient and financial way. As Darragh and Emery (2018) describe, the complex motivations that lead any a manager to pursue a course of action deviates from the simplistic economic causal explanations integral to the crowding out theory. Whilst the provision of subsidies may crowd-out indigenous, pre-existing environmental motivations, in the context of agricultural decision making, this is unlikely to prove the deciding factor relative to other more pressing economic or managerial objectives.

This inadequacy of the crowding-out theory to explain post-scheme decision-making is also amplified by the changing subsidy landscape, described at the start of the subsection. Whilst the theory may have had a certain degree of aptitude when inspecting manager's behaviours as they moved from ELS to CS (i.e. in which the availability of the subsidy is reduced), looking into the behaviours of the managers as they now move from ELS to a post-Brexit policy, the theory has less value. The supply of subsidies designed to promote environmentally sensitive management practices is going to increase (as money is being redirected from direct payments to ELMs), and so the pertinence of questions around manager's 'post-subsidy' behaviour do not trigger to the same extent. Relative to the value of Bourdieu's thinking tools, the crowding out theory can, it is argued, shed less light on the lived realities of farm decision-making, especially in the changes to the policy landscape catalysed by Brexit.

\subsubsection{Provision of public goods and Brexit}

As described in Chapter 4, a decision was made in consultation with the project's NE supervisor to include a question about the willingness of managers to be paid to provide environmental or public services, and their attitude to a subsidy model that is 
moving away from direct area-based payments. The request was motivated by the changing policy landscape catalysed by Brexit and the government's plans, once they are free to generate their own agricultural subsidy system outside of European rules, to redirect money to AES style subsidies and away from the direct support money that has historically fallen under the CAP's Pillar 1 remit. Brexit's impact on mangers' environmental behaviours also emerged as an important research theme (research question 4 ) of the phase 1 interviews theme to be included in the phase 2 schedule. Because of the clear overlap of these two topics, especially in relation to the project's main research questions, they will be considered in one joint subsection, below. What are the impacts of Brexit on manager's agri-environmental decisionmaking, and are farmers happy with the resulting shift away from direct-support and towards a subsidy model more heavily predicated on supporting farmers for the provision of environmental or cultural goods?

The concept of public goods was defined in the methodology chapter (4.2.8.2) and was included in the interview schedule because of its relevance to the research project. How does the prospect of being paid to provide public goods mesh with the rules of the game; how have the expected reduction in pillar 1 payments catalysed by Brexit - on which, a large number of farms currently rely (Grant et al. 2016) - been integrated into the habituses of the ELS participants; will the changes effect an increased willingness to engage in AESs (insofar as they will be the only support available) or will it result in a reduced willingness because of the need to maximise profits elsewhere, to ensure the farm's economic viability?

7.3.2.1 Brexit, AES participation, and the adoption of agri-environmental practices

The following responses were all given to questions about the general willingness of farmers to engage in a subsidy model predicated on the provision of public goods, in which the money available through direct payments are set to be phased out: 
Yeah, I don't know, it's [the proposed shift in subsidy towards the provision of public goods model] definitely a step towards becoming environmental stewards rather than farmers which doesn't bother me.

But does bother some people?

Does bother a lot of people. Depends. I always think, I've been brought up that the farm is a business... and if they're going to pay you to crop it environmentally, then that's the niche to go into

E09

I don't give a damn so long as we're paid for it. What you can't expect me to do is take my land out production and give me nothing for it. This is my job, you can't expect to come along half my job away, whilst I still have to pay the mortgage on it.

So it's just a business question at that point?

Yeah, if I can make as much money growing flowers, I'm happy to grow flowers

E14

I think more and more it's a business decision. It's going to-

So there's no ideological opposition to the public services side of it?

No, provided the money's right. 
I don't mind. Yeah, I think some people will be mixed - I guess it depends what it involves really. But yeah if it's economic to do whatever they want doing, I guess you do it.

And M18

If you paid us more to have a wild meadow full of lovely flowers than grow wheat, I'd be terribly happy with that.

These excerpts map onto findings already described over the course of the previous analysis chapter and the subsections above. There is a primacy around the need to maintain a financially viable unit, and an associated value in being responsive to the business opportunities represented by availing of different schemes or management practices, if they can help realise this goal. In this case, there is no sense of ideological aversion to the prospect of having money redirected from direct areabased payments, so long as a suitably large amount of money is available elsewhere - namely in the form of subsidies offering remuneration for the provision of public goods. The good farmer does not, in other words, reject the expected shift in the delivery of agricultural subsidies, but avail of the money on offer where doing so is appropriate for the management of the farm in question. In the caricatured hypothetical situation described above, farmers would be happy if they were "paid more to have a wild meadow full of lovely flowers than grow wheat". In such a situation, the presence of a field full of wild flowers would attract embodied cultural capital because of the savviness it betrays of the manager in question, and not lose it because of the deviation it represents from the productivist goals of high yield and intensification.

Beyond the business pragmatism imbedded in the above responses, a number of interviewees also recognised the wider improvements represented by a move away from direct area-based payments. 
E10, for example, recognises the role that agriculture has played in the loss of rural wildlife, and the sound reasoning behind having a subsidy system designed to attend to those issues:

The Healthy and Harmony thing from Gove. I suspect that the policy will go very much along the lines that that is indicting. The money will go into what we used to call Pillar 2. And is that right? Yes I think it is. I don't think as an industry in anyway shape or form say that we haven't played a role in in producing the pressure the wildlife is under.

On a similar note, M03 was contented with the proposed shift because of the problems that direct area-based payments cause with the pricing of land:

I think a change away from area payments is a good thing, all area payments do is just drive land price up, and just drive large scale land buying and farming.

There were, however, a number of interviewees who expressed less favourable expectations about the shifting focus of the subsidies.

Consider, for example, the exchange with E02:

Do you think as BPS goes down will that make the relative attractiveness of these sorts of agri-environment schemes, do you think people will be more motivated to get involved with them?

No. Less

Reason being?

There's less reason to get the interaction with government agencies. Interaction with government agencies - the further arm's length it is the better. 
So if they stop giving you the BPS money, then you think that's a license to not get involved in any of it?

I wouldn't say a license not to, but less motivation to get involved... But to make an HLS [higher tier, not HLS] scheme viable, we think we need at least 30 hectares management to allow for the time it takes to do the surveying to get the return to break even with the surveying... For me it is a business decision.

The position is echoed by E18:

So are you happy to see the BPS and that sort of thing tapered off? What effect do you think that will have?

I think it's going to be fairly catastrophic to be honest. I have in my mind a broad figure that if BPS halved from where it was now, I'd seriously consider whether it was worth going into at all.

You mean with all the stipulations that come with it?

Yes, all of the policing... that nagging doubt in the back of your mind that the whole year around that something is going to be wrong and you're going to get hammered for it - irrespective of what good you may or may not have done in the process.

Even for these interviewees who felt negatively about the shift, their concerns were expressed in economic terms and not as an ideological or cultural aversion to a move towards the provision of public services. The concern is, in other words, that the scale of money made available through new AESs will potentially not match the money they cost to implement - and that they will certainly not make up for the money lost through the reduced BPS. Once this particular impact of the Brexit process comes to fruition, there is a reduced need to get involved with government 
agencies and their subsidy offerings entirely. Similar concerns were expressed by other interviewees. E03, for example, although he elsewhere in the interview was happy with the principle of a move towards the public services model, nevertheless identified some economic concerns implied in the changes:

I mean any time they're going to taking down money you're never going to get as much out the other end.

E16 was concerned about the loss of food security potentially implied in a move towards a public services model of subsidisation:

If you get paid to put a margin around each field, so you don't spray the hedgerow, you don't spray the edge of the crop, that's fine. But you've still got to grow a crop - we've still got to have food production. We can't go too much the other way. They'd rather import it!

Although not expressed in terms of the reduced finances per se, E18 resents the proposed provision of public services model, because of the implications it makes about the intentions and desires of farmers in general and more general worries about the provision of food security for the country:

The way the scheme is administered, the whole policy seems to be "we are giving you public money for public goods." Fine. "We will enforce that by penalising you if you get it wrong, we won't come and help you, we won't come and advise you." You might get one visit, one fleeting visit saying, "they love to see this, and love to see that" but beyond that there's no "you've made this a bit small, don't do it again”. It's a small carrot and a big stick.

And then, later

as soon as you concede to saying that the environment isn't good enough, you're basically saying that whatever you're doing now is wrong. So there's a moral balance there somewhere that yes you can still grow crops, still feed 
the country, but you've got to tone it down a bit. We don't blatantly go around spraying everything just for the sake of it

There are, in short, a number of real concerns around Brexit from the agricultural community. The concerns are, for most, largely financial. The reduction in BPS payments will not be made up for by the increased money available through ELM; and the difficulty associated with delivering an ELM scheme, and limited income possibilities that they predict a contract could secure may, in fact, motivate them to move away from the subsidies entirely, rather than towards whatever subsidies still remain. For others, the move towards a model of provision of public goods will incur an unwelcome increase in surveillance and inspections from government agencies further motivating those managers to remove themselves from the subsidy system. For other still, this increase surveillance is not just a practical issue of incurring potential penalties, but is a more principled worry about the guilt farmers are assumed to have about their environmental intentions, and the tacit acceptance implied by participation that they are to blame for the degradation of the rural environmental. Concerns also exist about the country's capacity to feed itself as agricultural subsidies increasingly promote the inclusion of environmental practices on the farm and are being drawn away from direct income support.

The equations around the good farmer, and the intersection between economic sustainability and environmental proactivity are set to be altered. The revenue lost through BPS could put an increasing pressure on many farms - especially rented or contracted - to make the farm as agriculturally productive as possible, and so, make fewer concessions to environmental practices. This is especially likely if the net money available to individual farmers is reduced in the re-routing of finances from BPS to ELM. In such a scenario, participation in the scheme may not represent savvy business decision making, but a decision only available to those in a financially stable situation. The pressure exerted by Brexit and the resulting shift in the agricultural subsidies could, as a result, see a move away from participation in AESs.

Importantly, however, the concerns above are all expressed in terms of the financial or managerial issues that will potentially accompany the new agricultural subsidy 
landscape. The issues are not tied up with a cultural resistance towards the concept of being paid to provide public services, but rather concerns around whether the finances available will be suitable, or whether participation will incur an unwelcome level of surveillance or paperwork. Presently, the rules of the game no longer dictate how participation in an AESs, or the adoption of environmental practices incurs a loss of cultural capital, because of the progressive thinking, skill and savviness it betrays of the participating farmer. So long as the money made available through the ELM is sufficiently high, then the rules of the game will recognise the legitimacy of participation, given the positive impact a contract could have on a farm's business.

One other impact emerged relating to the Brexit process - one that was raised earlier in section 7.3.1. The issue relates to the temporary resistance interviewees expressed towards entry into the CS in favour of waiting to see if an ELM contract may represent a more suitable or lucrative offering. Farmers, that is, are resisting the temptation to enter into a 5- or 10-year CS contract, believing that the ELM scheme which is due to come online in 2019 could be a better deal. This pause in participation could represent a vulnerable period of time for the features and techniques previously mandated by an ES contract - whereby managers are faced with the decision about whether to maintain the practice or revert to the pre-scheme usage whilst waiting for the ELM scheme to become available:

E09 reports this phenomenon

But we've got to be a little bit careful of getting committed into a 5-year agreement sort of thing, and you find 3 years down the road the rules have changed - because we've got X amount that's already in an agreement, we then can't match the requirements without taking more land out.

E14 has seen the situation unfold with some of his clients

People saying, "do I really want to tie myself up for 5 years when there's change on the horizon?" 
And so too E16:

We're waiting to see what comes out next under the EU rules, when we come out of the EU.

The two managers above (recall E14 was the agricultural agent) had in fact decided to preserve their ELS options whilst waiting for the new ELM scheme. The hesitation to enter the CS whilst waiting for more details of the post-Brexit subsidy system has not, in these cases, incurred a loss of land used for environmental purposes. It is easy, however, to imagine a manager similarly holding off from participating in the current AES offerings to see if the future ELM will be more appropriate - but instead re-appropriating the land used in a previous AES contract for agricultural purposes. Although the phase 2 process did not interview anyone who claimed to have made such managerial decisions, it nevertheless remains an interesting and real possibility, and could be an avenue for future research.

Brexit's impact is, in short, acting as a temporary deterrent from participation in AESs. Believing that substantial changes are on the horizon and believing the current CS scheme to be overly onerous and insufficiently remunerated, farmers are waiting to see what subsidy will be presented in the near-mid future. The issue was, in fact, predicted by a number of interviewees in the phase 1 analysis and discussed in section 6.2.5, and was one of the key factors motivating the inclusion of the theme in the phase 2 analysis. Those predictions have, for a number of the managers interviewed in the second round, come good. Fears about the 'limbo' like quality of the Brexit transition period, and the knock-on damage done to the willingness of those managers to engage in AESs are being felt in the management decisions taken by managers who may otherwise be more amenable to participation.

\subsubsection{Brexit, habitus change and hysteresis}

In bring Bourdieu's thinking tools to bare on the topic of Brexit, his thinking tools of the habitus and hysteresis were also pertinent. In analysing the interviewee's responses, reactions and expectations regarding the Brexit process, pre-echoes of the 
hysteresis phenomenon were identified. The above analysis has showed how the participant's habituses have absorbed their new field conditions and experiences; and how those changes are reshaping their assessment of other farmers adopting agrienvironmental practices (the long-term upkeep of an ELS option, for example). As described in Chapter 3, the hysteresis process occurs when an individual's habitus is exposed to field conditions and field rules that are so dramatically different from the conditions in which their habitus was formed, that the habitus' capacity for iterative restructuring is outpaced by the scale and speed of the changes. The result is a form of cognitive dissonance, whereby an individual's understanding of their social world does not map onto their lived experiences of it. The Brexit process, because of the dramatic changes it represents for the agricultural industry, and the changes it represents in the way agricultural subsidies are awarded (i.e. away from direct support, towards the provision of public services), threatens to inspire the hysteresis process amongst the individuals least able or willing to engage in the imminent changes.

Consider the following accounts:

E2

Yes it's running a business. And again, so much uncertainty with Brexit, the uncertainty, where we stand, where the capping stands, I don't know if it [the farm business] is even viable, I don't know if the capping impacts on environmental schemes.

When the BPS goes, and they increase the environmental schemes, do you think people are happy to be-

Farmers - a lot of farmers - do not like being told how to run their business... If a scheme is simple, that's the key. 
Financially, we won't be in business. You take that [BPS] away, with the pound where it is, against the Euro. What is it now, £80/acre? Something like that. Well that pays the rent. Damn near pays the rent on the whole block. I got a check for the two farms for $£ 120 \mathrm{k} . .$. Without that we would have made a loss this year and the last year. And last year it was a very good farming year. To answer your question, I don't think it [increased finances available through AESs] could ever compensate for that $£ 120 \mathrm{k}$.

E09

Which is the worry, because that [reduction in BPS] means we're going to have to do it [the new ELM] because we're not profitable without the payments. And if we're already tied up in some scheme we haven't got any land left - we'll have to take decent land out to then qualify for the new one [ELM].

The above concerns all centre around the expectation that major changes in agricultural economics are imminent, and that the respective interviewees are not properly equipped or informed to navigate those changes. That farmers don't want to intrusion of complex AES to replace BPS because they done like being told how to run their business, and that some managers do not know if or how their farm businesses will be viable after their pillar 1 payments stop is evidence of this illpreparedness. Once those changes are realised - depending on how quickly they come about and what the precise details of the changes are - it appears likely that their habituses (inclusive of their management habits, their understanding of farm economics, and their savviness in navigating the intersection between good business and good environmental management) will be out of step with the realities of the field conditions. In such an eventuality, the hysteresis phenomenon could take hold leaving with the discomfort of having the strategies they have previously employed to succeed in the agricultural field rendered unfit for the new rules of the game. 
The Brexit process has not (at the time of writing) yet occurred, and the changes to the agricultural subsidies have not yet taken place. Farmers are still in receipt of their pillar one payments, and applications are being directed through CS and not through the ELM program. The hysteresis phenomenon is not, as a result, yet in effect. The above accounts simply demonstrate the disarray that dramatic changes in agroeconomics and subsidisation stand to catalyse in the members of the agricultural industry, and how those impacts can be understood in terms of Bourdieu's notion of hysteresis. Whether or not these pre-echoes come to fruition will depend, therefore, on the scale of the changes, and of the speed in which they happen - and whether those changes happen at a pace and rate beyond the habitus's capacity for iterative restructuring. If the changes in the field conditions and rules of the game happen too quickly, the habitus (along with the strategies employed to navigate the erstwhile field rules and conditions) will not be able to keep step, and the painful and confusing experience predicted by the hysteresis process will take place.

Given the fluid nature of the Brexit process, and especially given its 'unfinished' nature, there is limited published research looking into way it is being experienced by land managers in the UK, or on its impacts on land management practices adopted by farmers in the UK. Journalistic pieces (e.g. Harvey 2018, writing in the Guardian), however, hint at the major overhaul the Brexit process is liable to have on the farming sector (especially regarding labour, and access to markets); whilst academic papers have focussed on the more technical and economic aspects of the Brexit process (Helm 2017). As a result, these findings are unique in the behavioural and cultural tools used to look at how the process is being experienced 'on the ground'.

\subsubsection{The bad farmer}

Over the course of the phase 1 analysis chapter, an important research theme emerged relating to the loss of cultural capital incurred by those causing unnecessary damage to the environment through their shortfall of skill and knowledge, and those adopting an unnecessarily intensive agricultural approach. To help better understand this phenomenon, the concept of the bad farmer was developed. Whilst the good 
farmer concept had been useful in understanding which behaviours are culturally attractive to farmers, the bad farmer concept was needed to understand the minimum expectations farmers are expecting of each other and the loss of cultural capital managers risk when falling short of those standards. It was decided that the phenomenon should be subjected to more robust scrutiny over the course of the phase 2 interviews. This subsection will detail the findings of the second-round interviews, regarding the bad farmer concept.

Deployment of the bad farmer concept corroborated the initial findings of the phase 1 interviews. The exchanges and comments made by the interviewees over the course of the phase 1 interviews that alerted the research to the minimum environmental standards farmers were expecting of each other, and the cultural capital risked by falling short of those standards were, in other words, reflective of a wider reality in the field.

The following are responses all made to the same request to describe bad farming. Recall, framing the question around 'bad farming' and not 'the bad farmer' was used as a means of ensuring the conversation was not distracted by potentially abstract concepts (i.e. to avoid awkward sounding questions such as "what is the bad farmer"):

Non-sustainability. As I say, live as though you'll die tomorrow and farm as though you'll live forever.

If you're bad environmentally, it normally means you're a bad farmer anyway. Because if your fertilisers, pesticides and everything go in the water courses, you're pouring money down the drain. 
Yes, the farmer who's out on a windy day who can see it drifting and all that sort of thing, yes, bad farming.

And is that concern for the environment, or for concern of wasted money?

Environment, public perception. And also, the fear that it's going to damage your crop sometimes.

I suppose from a no-tiller point of view, not looking after your soil, probably. People are thinking about it far more these last couple of years, definitely more on the agenda, looking after your primary asset. But a lot of people not doing it, I guess.

Is that because if you don't look after it it's a bad business decision?

It's bad full stop. Long term, food production, health of the environment. Yeah, the potential for the land to keep producing food?

M03 (email respondent)

No thought for environmental, not engaging with public, farming purely for profit without good land management or farm/integrated pest management. People who get suck in their ways and won't try new crops/machines/people/ideas!

Wrecking the ground - you see all these spud farmers hammering the ground. Agri-business farms. Because that's the way it's going, everyone is getting bigger, don't give a shit about the environment. 
Short-term gain, long-term loss. You keep pulling up the hedgerows, and spraying -you've got to have sprays at least for arable crops but I don't think these massive monoculture fields. I don't think they're great.

Throughout the responses, the principles of bad farmer concept, as outlined in the phase 1 analysis re-emerge. The bad farmer is one not mindful of the intersection between good business and good environmental management; where that leads them to adopt practices that are damaging to the land or to wildlife without carrying with it an increase in yield or profitability; where their technical or knowledge deficiencies end up causing unnecessary damage to the environment; and where their bad environmental management exacerbates the public relations reputation of the agricultural industry. Describing the characteristics of the bad farmer helps, in this way, to understand the rules of the game at play in the agricultural field and the behaviours and practices that are liable to lose farmers cultural capital. The reproduction of cultural capital, as has been discussed throughout the thesis is tied up with the demonstration of one's accumulated skill and expertise - and so when the above interviewees express their criticisms of the bad farmer in terms of their shortfall of skills and knowledge, they reveal the conditions under which farmers can lose cultural capital. Cultural capital is, in other words, lost when a farmer's behaviours reveal them to have a limited understanding of when and why intensive practices are damaging both economically and environmentally; when their technical deficiencies effect unnecessary damage to the environment where a more skilful farmer would not have caused the same problems; where farmers are opting for management practices (especially in relation to soil health) that secure short-term financial gains at the expense of the farm's long term viability.

Ideas around the interplay of social norms, social networks and behaviour change are well documented in the literature (Fisher 2013, Blackstock et al. 2010). Whilst such papers have described the social relatedness of farmers, and the way that information and behaviours travel along those social vectors, the idea that environmental 
messages are being integrated into the farmers' psychologies, and how they are exerting their influence on the standards by which they are judging each other is new. This subsection will build on the findings presented in the previous chapter and will explore the mechanisms through which these social pressures are being effected.

As hoped, the inclusion of the question has lent the project a more robust inspection of the phenomenon. Whereas the bad farmer concept was an emergent theme of the phase 1 interviews, we have here seen how the attitudes of the above respondents many of whom made no allusion whatsoever to the idea in the phase 1 interviews fall into line with the initial, phase 1, analysis. Beyond the features of the bad farmer concept that have already been described, the inclusion of the topic also provided interesting new details. In particular, and as had already been raised in this chapter, the bad farmer concept also has an overlap with the concept of multifunctionality.

Consider the following responses:

M12

So those people out there planting their big fields, that's not bad farming, for you?

No. It's bad for wildlife, maybe. Whether it's bad farming, that's debatable. I wouldn't like the whole country to be like that. But I wouldn't say it's bad farming.

If you're a 10,000 acre farmer and you've got big assets and you've got probably a reasonably strong balance sheet giving you some room for manoeuvre, that's very different from a farmer doing 5, 6, 700acres where it's hard in any year to make enough money to be able to have a decent living and having a margin for error in the years where it's difficult. So, it would be easy to badge farmers as one group, but the reality is, like the whole of the 
population, it's a whole mix of people with different issues, different challenges, different circumstances, different land qualities.

When discussing the reproduction of cultural capital, and the management of postcontract ELS features, the idea of multifunctionality emerged as an important determinant of whether some behaviour was deemed suitable, appropriate, and whether it was capable of reproducing cultural capital. There was, for example, a perceived appropriateness and good sense in reserving poor agricultural land for environmental purposes (subsidised or not); and a similar recognition of pursuing a business model more heavily predicated on the provision of environmental goods and participation in AESs where the farm's landscape assets lend itself to such an approach - and a corresponding respect for those with high quality agricultural land to have a business model more heavily predicated on agricultural production. The above concepts reveal the potential for the same multifunctionality to inform farmer's conception of the bad farmer, too.

Whilst M12 would not consider the presence of big, intensively managed fields typical of the bad farmer, in abstraction, he would nevertheless not like the whole country to be characterised by such an approach. By extension, there are certain areas that can and should be farmed in such a way, but others that should be reserved for practices that are not so "bad for the wildlife". Although just a passing comment, his comments reveal a wider desire for the makeup of the country's total farmed land. The goodness or badness of an approach is, as such, partly determined by how it sits in this vision. Although he is not explicit about when his willingness to identify someone as either a good or bad farmer triggers, it will be, in part, determined by how it maps onto this wider multifunctional desire for the country's agricultural industry.

E07's account demonstrates how the willingness to determine someone as a bad farmer is mediated by the situation of the person in question. Although the interviewee elsewhere explained how their own approach is characterised by committing a large amount of land to environmental measures, he was expressly critical of management styles that risk the degradation of the rural environment - and 
was reflexive about the freedom they are afforded by their own farm's economic and tenancy situation. His willingness to actively condemn the management styles they avoid (intensive, leaving no room for environmental measures) is, as such, modulated by an awareness of the economic pressures placed on farms in different situations. The bad farmer concept is, in other words, shown to have a multifunctional component, whereby the practices that lose cultural capital for the respective manager are in part determined by the landscape assets of the farm, by its tenancy arrangements or by its economic pressures.

As explained at the end of section 7.3.1.5.2, the multifunctionality of good and bad farmer emerged in spite of its not being included in a systematic way in the interview schedule. As result, the extent to which a farm's characteristics, location, pressures and opportunities can determine the extent to which certain practices either gain or lose cultural capital cannot be fully accounted for here. Is a highly intensive farm in the Fenlands that reserves no room for environmental concessions wholly exempt from the criticism of being a bad, overly intensive, farmer because of their location and because of the agricultural potential of the land? Can an uplands farmer with virtually no food production, and a business model entirely reliant on income gained from the provision of public services reproduce cultural capital in the agricultural field, and fall under the rubric of the good farmer? Would an uplands farmer who pursues with the productivist goals of high production and intensification, making no environmental concessions be considered a bad farmer for his deviation from the land's perceived appropriate usage? Such questions would clearly benefit from future research and could help further illuminate the interface between the multifunctional components of good and bad farmer concepts. The project has, nevertheless, made a valuable contribution to the field of rural sociology and farm behaviour, in making these initials conceptualisations. 
8. Conclusion: Research Findings, Research Reflections and Future Research Agendas

\subsection{Chapter introduction}

This chapter will offer concluding remarks about the project's research contributions and will reflect on the project's methodology, design and execution. The chapter will attend to the following questions. What are the project's key findings; to what extent have the project's research questions been answered; which areas for future research have been identified; and what lessons can be learnt from the project's methodology?

\subsection{Research findings}

The following is an executive summary of the project's findings. These findings also represent the contributions the project has made to the literature, in terms of the new knowledge it has produced:

- Because of the intelligent, forward-thinking management expertise it communicates of a given farmer, the adoption of agri-environmental practices or the participation in an AES reproduces cultural capital. Such practices fall under the rubric of the good farmer.

- Although there is a low-ceiling on the cultural capital that environmental proactivity can reproduce (namely the point at which a manager's environmental efforts frustrates their ability to run an economically viable unit), the widened understanding around the intersection of good environmental and good business management has motivated a new feature in the rules of the game, whereby environmental negligence is criticised and incurs losses in cultural capital. The bad farmer concept can help conceptualise the minimum environmental expectations farmers place on each other, and the loss of cultural capital associated with falling short of those expectations. Where such behaviours are attracting the critical attention of other field members, doing so also risks social capital. 
- ELS's widespread uptake has played an important part in changing the position that environmental proactivity occupies in the rules of the game, and the perceived legitimacy of participating in AESs or adopting some other agri-environmental practice. It has helped normalise such behaviours, facilitating it becoming a standard, non-contentious and legitimised feature of managing a farm business in the current socio-economic landscape.

- Many farmers in the case-study areas have maintained some/all of the practices contained in their ELS contacts. This is typically the result of an increased understanding of the good business sense the practice delivers, or the improvements it delivers in the management of the farm - and is not typically grounded in environmental motivations. ELS, not least because of its high-uptake, has acted as a large-scale circuit breaker, prompting many managers to consider the long-term adoption of the practices promoted in its constituent scheme contracts.

- Fears exist within the agricultural industry that the changes in the agricultural subsidy system catalysed by the Brexit process - the reduced finances available through BPS, and the redirection of that money to more ambitious AESs, such as ELM - will have unintended consequences. Namely that managers will remove themselves from the subsidy system altogether, especially if the finances made available through future AESs do not properly compensate for the finances lost through the reduced BPS. The scale and rate of the changes that the Brexit process will potentially imply, and the resulting confusion in manager's expectations of how to manage their farm businesses can be understood in terms of Bourdieu's concept of hysteresis.

- In the short-term, Brexit's impacts are also being felt. Managers are resisting the current CS scheme in the hope that the ELM scheme, which is due to come online in early 2019 , will represent a better or more lucrative arrangement.

8.3 Revisiting the project's research questions, and a future research agenda

As well as an executive summary of the project's findings, it will also be a valuable exercise to revisit the project's research questions. The following subsection will 
assess the extent to which they have been successfully answered, and will identify areas of future research. Where topics for future research are identified, they will be presented in bold type face.

To facilitate this process, the project's research questions are presented, below. As explained over the course of the previous chapters, the project's inductive component facilitated an iterative renewal of research questions. This process took place at the end of the phase 1 analysis, whereby new research questions ( 3 and 4 ) were added to the project's initial 2 research questions ( 1 and 2), because of the relevance they had to the project's wider research objective.

1) What are the recent developments of land managers' agri-environmental attitudes, and how can Bourdieu's theory of capital, field and habitus inform our understanding of this development?

2) How effective, as a policy tool for securing environmental action from the farming community has ELS been (including the environmental activity beyond the individual contracts' duration)?

3) What are the minimum environmental standards managers are expecting of each other, how can Bourdieu's thinking tools help understand this process, and how can the concept of the bad farmer be developed to account for this process?

4) What impacts will the Brexit process have on managers' willingness to engage in agri-environmental management?

Consider research question 2 (question 1 will be addressed, below). It can, itself, be broken down into a range of constituent questions. What land management decisions did participation in ELS require of its participants; what management decisions are farmers taking at the end of their contract's lifespans; and what does this mean for a policy evaluation of the scheme? The following will give an overview of the project's response to these constituent questions. 
Over the course of a scheme contract, farmers were forced to consider the managerial, economic and environmental benefits of the practices demanded by participants' scheme contracts. In many cases, these benefits outweighed the agricultural or economic value of the practices in place before scheme participation. The project has been able to show that ELS delivered a substantial amount of additionality - namely in the form of long-term, post-scheme management changes of the participants. By way of example, many managers who had taken marginal land out of production around the outside of a cultivated field had since adopted those features, beyond the scheme contract's extent. These findings chime with those of Darragh and Emery (2018). Namely that the economic and managerial benefits the ELS practice conferred to the farm, relative to the low agricultural output the land was otherwise producing have helped motivate the long-term upkeep of the practice. As described in section 4.2.14 and 7.3.1.4, tentative extrapolations, based on the likely shared realities of the research population and the wider population of ELS contract holders, were also made about the likelihood that similar decisions were being made by other managers once their contracts had come to a close. Future research would be well placed to verify these predictions, and could assess the extent to which different ELS options are being maintained, in a post-contract setting, across the country.

A key finding of the project is, therefore, that the ELS scheme has helped advance mangers' understanding of how the farm's business potential can be maximised through the adoption of certain environmentally sensitive management techniques, frequently achieved through continued upkeep of ELS options. Corroborating the findings of Sutherland (2013) - although here in the context of AES participation, not organic management - the research found how many of the managers explained and rationalised their decision to maintain some scheme feature or practice in business-orientated terms. ELS has, in this way, secured a certain amount of lowhanging environmental management fruit. Low-hanging, because it has not necessarily done the harder work of augmenting participant's long-term commitment to pro-environmental ideals, but has instead catalysed long-term behaviour changes 
for reasons amenable to managers' pre-existing priorities of running an economically viable farm business.

The factors motivating managers to maintain some ELS option do, however, represent potential qualifications for the scale of environmental improvements the newly adopted practices are capable of delivering. Where managers are primarily moved by financial or ease-of-management motivations - and not environmental ones - then their willingness to observe the fullness of the scheme option stipulations will be reduced. This, in turn, stands to undermine the capacity of the feature or practice to deliver environmental benefits. This issue is something that would clearly benefit from future research. Where farmers are maintaining ELS options (or, indeed, options from any other AES) beyond a scheme's duration, the motivations for doing so could be compared with an ecosystem services study of the feature's environmental value.

An important finding of the project relates to ELS having acted as a large-scale circuit breaker for the participating managers - prompting managers to take a step away from their managerial habits and styles, and consider the environmental, economic or managerial value of the ELS management practices. This was, in part, achieved by its broad and shallow design. By offering easy-to-deliver options and easy-to-meet contract point requirements, managers could enter into the scheme only having to make modest changes to their practices, or removing only their most marginal land from production. And it is frequently because the ELS options demanded such a limited scale of behavioural change from the participants, or required only the least productive land to be committed to the scheme, that the longterm adoption of those options is rendered economically tenable. The predictions (hopes) expressed in Hiedenpaa and Bromley (2014) about the 'habit-breaking' potential of AESs have been well documented in this thesis.

This aspect of the scheme design is, however, also partly responsible for the deadweight recorded by the research. Because of the ease of access into the scheme, many interviewees, especially those with livestock features in their contracts, were already achieving the requirements of their contracts. Due to the comprehensive 
analysis the topic of deadweight in ELS has been subjected to, notably in the Defra (2012) report, the project's capacity to add new knowledge to this strand of the research question is limited. In broad brush strokes, the research project's findings map onto those of that. Namely about the varying levels of deadweight recorded in options targeted towards livestock management options (high) and arable land (low).

ELS's impact was also being felt in attitudinal and social terms. Especially over the course of the phase 1 analysis, Bourdieu's thinking tools represented a powerful tool for an analysis of the development of the agri-environmental attitudes, and the role that ELS has played in changing the perceived legitimacy of managers implementing environmental practices on their land. With regards research question 1 , the analysis revealed how little of the cultural resistance towards the adoption agri-environmental practices or scheme participation, detailed in earlier research (e.g. Burton et al. 2008), remained. Instead of such decisions representing a problematic deviation from the productivist goals of high production that have historically been at the heart of the rules of the game and the good farmer concept, participation in an AES, or the implementation of some environmental measure is now able to reproduce cultural capital for the respective manager. This is primarily because of a prioritisation of the need to manage an economically viable unit, and the emerging recognition of the economic value that can be delivered by a scheme contract, the marketing value of having environmental features on the farm, or the long-term business benefits associated with the integration of soil conservation or other environmentally sensitive management techniques onto the farm.

In this climate, making such management decisions was not reflective of a lazy or unskilled approach to managing a farm, but the savvy and skilful navigation of current agricultural economics. Demonstrating one's skill, knowledge or expertise is an important feature in the ability to reproduce cultural capital and, as a result, the rules of the game in the agricultural field now recognise the legitimacy of integrating pro-environmental management practices onto the farm. Pursuing such practices is capable of reproducing embodied cultural capital, and the marks it leaves on the farm (buffer strips, grass margins etc.) objectified cultural capital. 
The participant's experiences of being involved in the scheme was an important part in the changing rules of the game, and the widespread recognition of the economic benefits of adopting such environmental practices. The practices they were exposed to, along with the economic, environmental or managerial value they conferred to the farm were absorbed into the habituses of the farmers. Insofar as the habitus is both the thing upon which new experiences, ideas and beliefs are impressed, as well as the lens through which the behaviours of other field members is processed and assessed, these experiences were an important part of the process that lead to the changing rules of the game and the increased capacity for environmental management to reproduce cultural capital. In response to question 1, Bourdieu's thinking tools have underpinned a revealing analysis of the development of environmental attitudes represented in the agricultural industry. As was hoped, the thesis has been able to add to the conceptual and empirical lineage of researchers availing of Bourdieu's tools (Burton et al. 2008, Sutherland and Darnhofer 2012, Riley 2016, Thomas et al 2020) to look into environmental attitudes in the agricultural sector. It has, in this sense updated to and added to our understanding of how farmers think about environmental issues and how they conceive of their appropriate relationship with the management practices able to attend to those issues.

As a result of these changes, the good farmer is mindful of the intersection of good environmental and good agricultural management - and has the requisite skill to maximise the farm's environmental profile within the constraints of securing its economic viability. This involves the skilful implementation of environmental practices (where it doesn't unnecessarily come at the expense of the farm's agricultural output), the navigation of agri-environmental subsidies, the use of environmental management techniques for marketing or PR purposes. Cultural capital, because of the integration of these new field conditions and rules into the field member's habitus, flows towards those adopting such agri-environmental practices. 
The project's response to research question 1 was further developed in the second round of interviews. The respect farmers offered for farmers adopting different management practices (regarding the post-scheme management of their scheme options) depended on the agricultural quality of the land put into the scheme, and the agricultural potential of the farm at large. The good farmer concept was, in this way, identified as having a multifunctional component. Farmers need to be responsive and alert enough to recognise which land can be best reserved for environmental purposes (within or without an AES) and which should be used for productive purposes. Cultural capital was reproduced by the farmers best able to identify which parts of their farm could be used for what purpose, as a means of maximising the farm's environmental profile without incurring an unnecessary loss of agricultural output. The phenomenon also scaled-up to an inter-farm, regional, level. The appropriateness of managing a farm does not just refer to a recognition of which parts of the farm are suitable for what purpose, but a wider recognition of the business approach most suitable for the holding as a whole, as determined by its landscape type, farm system and its agricultural or environmental potential. The good farmer on an uplands dairy farm in the north of the country may, for example, pursue a model heavily predicated on the provision of environmental services, whilst the good farmer on a horticultural farm in the fenlands may reasonably make a smaller level of environmental concessions, and look to maximise its agricultural potential.

There are details about the multifunctionality of the good farmer concept that remain unclear. If the good farmer is typically one who maximises the farm's environmental output, how and why is it regarded as appropriate for a fenland farmer to make fewer environmental concessions on the farm where the farm's business viability could otherwise be ensured by making more such concessions? The multifunctionality emerged over the course of the phase 2 interviews and so could not be integrated systematically into subsequent interview rounds. The topic would, therefore, benefit from future research. As noted in Chapter 7, the multifunctionality described here could also be brought to bear on the debate around land sparing and land sharing interventions. Research combining these two theoretical 


\section{tranches could deliver valuable insights into how agri-environmental policies can be designed according to the location and landscape type of the target area.}

The generalisability of the above findings also needs to be considered. Within the tradition of using Bourdieu's thinking tools to understand agri-environmental behaviour (Sutherland 2013, Burton 2004, Burton et al. 2008, Riley 2016), there is clear precedent for drawing conclusions about the rules of the game of the wider agricultural field from one or more case-studies. The generalisations are grounded in an argument, presented more fully in section 4.2.14, about the jurisdiction of the rules that govern a particular field. In brief, the rules identified through an analysis of the responses given by the interviewees in the two case-studies are taken as representative of the rules that govern the reproduction of capital in the country's wider agricultural field.

This is not, however, to say that the rules are uniform across the agricultural field: there may be regional or farm system variations. Bourdieu's theory recognises the porous nature of field boundaries, the indistinct, blurred, edges that lay between the dominion of different rules in different fields, and the possibility for sub-fields to exist within a wider field (Bathmaker 2015, Bourdieu 1985). There may, for example, be variations in the rules of the game from one region to another, or a number of sub-fields within the agricultural field, for different farm systems. Especially given the thesis' findings relating to the multifunctional component of the good farmer concept, and the different levels of legitimacy associated with adopting a given farm practice in different parts of the country, or on different parts of the farm, this seems possible. Future research could help provide texture to our understanding of the rules of the agricultural field, and the differences that may exist from region to region, or from farm system to farm system.

Over the course of the phase 1 analysis, whilst attending to research question 1, an emergent research theme presented itself. In applying Bourdieu's thinking tools to the interview responses of the participants, it was made clear how managers could attract criticism for the adoption of overly intense management styles, or the use of practices that were perceived as having an unnecessarily negative impact on the rural 
environment, where a less intensive approach could have been pursued without risking the farm's financial viability. The good farmer concept was perceived as being ill-equipped to account for this phenomenon, and so the bad farmer concept was developed. Research question 3 was added, accordingly.

The bad farmer concept captures the losses of capital risked by farmers adopting an overly intensive management practice. The phenomenon is a result of the combined effects of the integration of environmental knowledges into the habituses of the field members, and the centrality associated with the need to run an economically viable unit. As farmers are unwilling to offer their respect for a manager whose excessive environmental proactivity is jeopardising their farm-business, the integration of the new knowledges and understandings about long-term business importance of making environmental concessions on the farm into the habituses of the farmers are being expressed at the other end of the spectrum. Namely, as a dislike and distaste for environmentally negligent behaviour. Although there may be a limited capacity for environmental proactivity to reproduce cultural capital (i.e. when it frustrates the farm's economic sustainability), the perceived legitimacy associated with environmental pro-activity has crystallised itself in new rules of the game that dictate how overly intense, environmentally inconsiderate behaviour is criticised because of the in-expertise and ignorance it reveals of the managers in question. The rules of the game, in other words, prescribe both how the good farmer's environmental management practices (because of their business value, intrinsic environmental value, and the skill, understanding and effort it communicates of the participating farmer) can reproduce cultural capital, as well as how the bad farmer's environmental negligence (because of the negative business implications, environmental implications, and lack of skill, understanding and effort is communicates of the participating farmer) can lose cultural capital. Social capital, because of the potential exclusion and criticism the adoption of such negligent practices attracts, is also risked.

The concept is a new contribution to the literature, and future research could mobilise it to better understand the influence it is exerting on the decisionmaking processes of farm managers. It could, by way of example, be 
particularly relevant to an assessment of collaborative AESs, whose effectiveness turns on the willingness of farmers to collectively work to ensure the contract's targets are met - and the social pressure and expectations the constituent contract holders project onto each other.

The emergent research question 4 was also developed in response to the phase 1 interviews. Interviewees hinted at how the changes to agricultural subsidies prompted by the Brexit process emerged as a potentially important determinant on the future participation in AESs and the adoption of agri-environmental behaviours more generally. Accordingly, the project integrated interview questions into the phase 2 schedule about the willingness to engage in a subsidy model predicated on a provision for public services model, and away from the direct support currently delivered by BPS.

The phase 2 analysis found that there was no de facto, ideological aversion to the shift towards a subsidy system predicated on the delivery of public services and away from the direct-support for agricultural production - but a concern that the scale of money made available to farmers would suffer a net reduction. In such an event, if farmers do not believe the finances made available through the new ELM sufficiently make up for the money lost through the reduced BPS, there may be a temptation to disengage totally from government subsidies. Committing increasing levels of prime agricultural land, and the increase in surveillance and paperwork that comes with interaction with government agencies were identified as the most potential deterrents. This was perceived to be a particularly acute issue in the context of a post-BPS subsidy system, whereby farmers expressed their intentions of having to make sure the agricultural output of the farm is as high as possible to ensure the farm's economic viability.

The changes the Brexit process is likely to catalyse can also be understood in terms of Bourdieu's thinking tools. Pre-echoes of the hysteresis phenomenon were identified, with farmers predicting disarray and confusion at how to manage their farms in an agricultural economic system (the reduction of BPS money, for example) dramatically different from its current profile. The hysteresis phenomenon is made 
possible because of the speed at which the changes are liable to happen. In such an event, the changes to agricultural subsidies and agricultural market conditions stand to happen at a rate that outstrips the habituses' capacity to iteratively regenerate itself in line with the new field conditions and rules. Due to the situation's fluidity, little academic research has looked into the impacts of Brexit on the individuals within agricultural sector. This research is able to add, therefore, the tentative first building blocks to our cultural and social understanding of the research body that has, up to this point (Helm 2017), focussed on Brexit's economic and legislative components. Depending on how the Brexit process unfolds, and the speed at which the agricultural economic realities change, Bourdieu's conceptualisations of the habitus, habitus change and hysteresis could underpin valuable research into the way in which the members of the agricultural field are navigating Brexit's economic and subsidy changes.

The Brexit process is also playing an immediate role in AES participation terms. Mindful that the changes in AES design are imminent, managers are resisting the CS scheme for fear of being locked into a contract that, compared to the new-look ELM, would not be suitable for their farm, or would not be as well remunerated. In answer to question 4, the Brexit process and the changes it is catalysing in agrienvironmental policy is acting a demotivating factor for participation in CS; as well as a more long-term deterrent for future participation in ELM, depending on the scale of the subsidies made available through the new scheme. Short of there being substantial economic incentives to participation, the finances lost through the reduced BPS may prompt a reversion back to a business model entirely predicated on agricultural production. These findings are, of course, the matter of some speculation, with many details of the ELM scheme, and the time-scales of the reduced BPS, as yet unknown. Future research could gauge whether the predictions offered by the interviewees are proving accurate. Will the reduction in BPS money result in a reduced willingness to engage public subsidies; will it result in an increased level economic precariousness on farmland in England, and what impact will that have on farmer's willingness to adopt subsidised or unsubsidised agri-environmental practices? 
8.4 Methodological and theoretical reflections

\subsubsection{Evaluation: follow-up methodology}

The selection of the follow-up methodology was motivated by two factors. Firstly, it represented an important opportunity to revisit the emergent research themes of the phase 1 analysis in the phase 2 interviews. And secondly, a welcome level of robustness when assessing the management predictions given by the interviewees in the first round of interviews regarding the land falling out of scheme coverage.

As described in Chapter 4, an important part of the project was its inductive/deductive hybrid design. Making such a methodological choice ensured the project was capable of assessing both a pre-determined list of research themes, as well as being responsive and agile enough to accommodate emergent research themes that were not identified at an earlier stage in the project design. Where themes emerged in the phase 1 interviews, they could be integrated into the interview schedule for the phase 2 interviews. This ensured that the emergent themes could be considered and assessed with a welcome level of systematic thoroughness. Instead of taking the opinions given by a handful of interviewees about a particular emergent topic as the full range of opinions represented in the complete research sample, the project was able to register the importance of the topic, and then introduce those themes into the phase 2 interview schedule and systematically canvas the opinions from each of the interviewees. Whilst very many projects include an inductive component, whereby research themes and topics are iteratively renewed, the combination of the inductive component with the follow-up methodology proved particularly powerful.

The design delivered the benefits it was hoped it would, with some of the project's most interesting findings coming as a result of the follow-up, inductive/deductive hybrid methodology. The topic of Brexit and the concept of the bad farmer were not, for example, included in the initial phase 1 interviews questions, nor were they selected ahead of the indexing process for use as an NVivo code. Because they both emerged as important avenues for the research, with each being cited or raised in the 
phase 1 interviews by a number of interviewees, however, they were included in the phase 2 interview schedule. The phenomenon is well documented in the methodological literature. Using an inductive methodology helps ensure the researcher is agile enough to identify where potential research avenues may lay hidden and can help generate valuable research findings (Cutcliffe 2001). The combination of a follow-up interview methodology and an inductive research design can help further secure these research benefits (Vincent 2013, Snelgrove 2014).

The methodology chapter also explained the other motivating factor in the decision to adopt a follow-up methodology. Namely, the strength of such a methodology in overcoming the problem of there being potential differences between a manager's predictions for how they planned to manage their land post-contract (as described in the phase 1 interviews) and how they actually managed their land post-contract (as described in the phase 2 interviews). As described in the Chapter 4, and again in Chapter 6, the intentions-behaviour gap (Armitage and Conner 2001, Kollmuss and Agyeman 2002) was expected to arise in part because of the interviewer bias problem (whereby an interviewee expresses an opinion or idea they believe the interviewer wants to hear - most likely more environmentally proactive behaviour, or participation in the CS successor scheme), and because of unforeseen material factors (for example where an interviewee expresses their intention to enter into the CS scheme, but then does not because of a problem with the application process, or because of economic constraints that arise after the phase 1 interviews). The followup methodology was capable of short-circuiting the problem by not taking the intentions offered in the phase 1 interviews as given, but instead asking interviewing the participants a year-after their contract had come to an end. By the time these interviews had taken place, substantive agricultural decisions had been made, and the fate of the ELS options had been largely determined.

The decision to take such a precautionary measure was well founded, with a number of the interviewees' behavioural predictions given in the phase 1 interviews deviating from their actual, post-scheme, behaviour. E16, for example, was bombastic in the first interview, expecting to "plough it all back up" after the contract's end; but in the second interview, after he had properly considered the 
agricultural and managerial benefits of effecting such a decision on that farm, he did the exact opposite - "We kept the corner plots, kept the legume fallow plots. Kept all those. Haven't got rid of any of them at all".

It should be noted, however, that for the vast majority or interviewees, the management expectations given in the phase 1 process were good predictors of the management decisions they actually took. A number of different explanations may lay at the root of this phenomenon. The intentions-behaviour gap is typically smaller where the research subjects have a greater degree of conviction in their predicted behaviour, and where their predicted behaviours are couched in a wider belief or value system (Godin et al. 2010). In our case, the farmers may have been set in the reasoning behind their behavioural intentions, or situated their intentions as part of a wider value-based vision for the management of the farm, and so ended up observing the predictions they made in the phase 1 interviews. The alignment of the farmer's predictions could also be due to the smaller-than-expected impact of the different researcher biases described in Chapter 4 . Where it was expected that the interviewees would have felt some social pressure to provide responses to research questions that mapped onto the perceived desires of the interviewer, the researchers may have felt no such pressure, and were transparent in their behavioural predictions.

Despite the intentions-behaviour gap not fully manifesting between in the project's two interview data sets, the rationale behind the methodological decision was sound in principle. And, because of the range of other benefits conferred by the follow-up interview process, the design was a good one.

\subsubsection{Evaluation: regional comparison}

The decision to conduct the research in two different case-studies was motivated by an attempt to gauge whether different symbols of the good farmer pertain to the respective areas, potentially as a result of the different manifestations of the ELS scheme. The two areas were characterised by a different make-up of farm systems (mainly arable in the eastern case-study, mixed farming, in the midlands case-study), and so it was hypothesised that the different sorts of options targeted to the different 
farm systems, and the different aesthetic appearances of the scheme options prevalent in the respective areas, would have facilitated a divergent vision of the good farmer concept and its relationship with environmental management. This component of the project represents, unfortunately, its most significant shortcoming. As explained over the phase 1 analysis, the regions selected for comparison were not sufficiently different in their make-up to properly compare how the composition of an area's farmland and resulting appearance of ELS (i.e. heavily livestock, mixed, horticultural etc.) mediates the development of agri-environmental attitudes, and the symbols that pertain to the good farmer.

Whilst there may have been less arable farming and more livestock farming represented in the midlands case-study area, there was still a sufficiently high level of arable farming for there to have developed symbols of good (and bad) farming relevant to the management of arable land. And, because of the high visibility of those arable features, when farmers discussed their conceptualisations of the good and bad farmer, it was typically the management decisions taken on arable land that filtered to the top of the conversational agenda. Even, that is, in the case-study developed to capture an area of high representation of livestock and mixed farming. No significant differences in the rules of the game, as a result, were recorded when comparing the accounts given by the interviewees regarding questions about the good farmer concept, or the respect they had for farmers managing their land in different ways. As previously discussed, the selection of two case-studies with a more dramatically different make-up of farm systems (say one in the south-west to capture a primarily livestock area, with one in the fenlands capturing an almost exclusively arable and horticultural area) would have been able to facilitate a more illuminating comparison on the development of agri-environmental attitudes. In particular, the way in which the development of those attitudes is mediated by one's surrounding area and the sorts of agri-environmental management techniques that are most visible as a result.

This is not to say that the project is not able to make any regional comparisons. We have seen how the level of deadweight (i.e. where scheme contracts remunerate participants for the 'adoption' of some practice that they were already doing) was 
higher for livestock options, and how the scale of additionality (i.e. where the contract secures a greater level of environmental activity than it technically pays for. In our case, this typically refers to the post-contract preservation of scheme practices) was higher for arable options. This reality is liable to have a regional bearing. The high representation of arable farming in the east, and the high representation of livestock farming in the north and southwest, as communicated in the maps presented in Chapter 5, mean that there will be a correspondingly high level of additionality and deadweight in those regions, respectively. This conclusion is, however, a matter of slight conjecture. The deadweight and additionality reported in the contracts of the interviewees (from both case-study areas) need to be extrapolated to make conclusions about the deadweight or additionality likely to be contained in similar contracts located in other areas.

Whilst the project may be able to make tentative assertions about the scale of environmental activity caused by the scheme, and the varying levels of deadweight and additionality contained the scheme contracts across the country, it is largely unable to comment on whether the symbols of the good and bad farmer are different in different regions, or if the agri-environmental attitudes and rules of the game have a regional bearing. Both of these topics - the differing levels of deadweight, additionality and scheme influence across the country; and the potential differences in the symbols of the good and bad farmer across the country - would be fruitful areas for future research. Further comment will be made below about the capacity for a qualitative research project such as this one to make generalised comments about the wider research population.

\subsubsection{Evaluation: Bourdieu's thinking tools}

The project employed Bourdieu's social theory as a way of unpicking the agrienvironmental attitudes represented in the participants of the ELS scheme. The decision was motivated by its proven ability to form the theoretical centre-piece of qualitative research into environmental attitudes and behaviour, and a desire to have some continuity with pre-existing research in the same field of agri-environmental decision-making and beliefs Its selection was well founded, and over the project's 
two analysis chapters, its tools have helped understand when environmental management can reproduce cultural capital, why environmental negligence can lose cultural capital for the respective farmers, and what the characteristics are of the good and bad farmer. With some of the most interesting research being done into the adoption agri-environmental practices using Bourdieu's thinking tools (e.g. Burton and Paragahawewa 2011, Sutherland 2013), the findings of this project can, that is, be easily mapped onto this wider research lineage.

The one very minor setback experienced in deploying Bourdieu's tools came when discussing the post-scheme management decisions with interviewees in the second phase interviews. As mentioned previously, it was hard for interviewees to identify whether some feature or practice was being maintained within an ongoing ELS contract, in a CS contract, or was being managed for Greening purposes, or being done voluntarily. Interrogating the respect they had for managers pursuing those different approaches was, therefore, frequently done in hypothetical terms: "what would you think if someone were to maintaining an ELS feature for free, after their contract ended?" or "what would you make of it if some manager removed the ELS feature and put it back to production once their contract had ended?". This was not perceived as problematic, however, and valuable insights about the interface between the rules of the game, the reproduction of cultural capital and the post-scheme management of ELS options were still possible.

\subsection{Final reflections}

There is, at this juncture, a valuable opportunity to reflect on the lessons I have learnt throughout the $\mathrm{PhD}$ process - a comparison between the research knowledge and skills to which I could lay claim at the beginning of the $\mathrm{PhD}$ process and then at the end.

Some of the skills are easily identifiable. In the development of the case study maps, for example, I have had to become proficient with the ArcGIS software package; and whilst completing the transcription, coding and data analysis part of the research, I have acquired news skills with NVivo software. Over the course of the two data 
collection phases, I was also able to develop my interview skills - and there is, occasionally, a notable difference in the quality of responses achieved in the early stages of the phase 1 interviews compared with the phase 2 interviews. Knowing when to pursue certain lines of inquiry, when to allow a moment's pause in the knowledge that the interviewee will pick up and go further into some reflection or being able to subtly steer the conversations away from irrelevant topics are a couple of examples of the 'soft' interview skills that can, occasionally, be the difference between securing good and great data. Especially over the final months of the thesis write-up, I have also had to think about how an extended piece such as a $\mathrm{PhD}$ can be structured and organised so as to ensure an engaging and 'enjoyable' reading experience.

Some of the research skills acquired over the course of the $\mathrm{PhD}$ are best expressed in terms of the methodological choices I would make, were I to start the studentship over again. I would, for example, have paid more attention to the selection of the two case study areas - to ensure a more meaningful comparison could be made between the two areas and the attitudes and behaviours represented in their constituent farming populations. I would also have complimented the interview schedule development process at the GWCT with an interview pilot. Whilst Jim Egan was able to offer valuable insights into the research project's design and interview schedule questions, it would have helped to further refine the interview schedule and interview style over the course of a brief interview pilot. Indeed, availing of interview pilots to see how the research population responds to potential research questions is a standard feature in most qualitative research design.

\subsection{Chapter conclusion}

The chapter has evaluated the contributions the project has made to the understandings of the effectiveness of AES schemes in effect long-term management changes in the participations, and of the influence exerted by the Brexit process in the future adoption of agri-environmental practices or AES participation. It has also added to the lineage of research using Bourdieu's thinking tools and the good farmer concept when looking into agri-environmental attitudes and behaviours and has 
developed the concept of the bad farmer to capture the minimum environmental standards farmers are expecting of each other.

In summary, the project has attended to its overall research objective, and has offered a valuable look at the long-term social and management impacts of the ELS scheme. To do this, the four constituent research questions, outlined above, have been deployed in a qualitative, cases study project. The data collected over a total of 64 interviews (with 16 participants being interviews once, and 24 interviewed twice) was analysed with Bourdieu's thinking tools, and the findings described in full over the previous two chapters. The project's findings, the contributions to the literature, as well as avenues for future research have been described over the course of this final chapter. 


\section{References}

Abrams, B., Schitz, M., 1970, The 'crowding-out' effect of governmental transfers on private charitable contributions, Public Choice 33:1 29-39

Anderson, C., 2010, Presenting and Evaluating Qualitative Research, American Journal of Pharmaceutical Education, 74:8 141

Bager, T., Proost, J., 1997, Voluntary regulation and farmers' environmental regulation behaviour in Denmark and the Netherlands. Socilogia Ruralis 37:1, 79-96

Baker, S., Brown, B., 2008, Habitus and homeland: educational aspirations, family life and culture in autobiographical narratives of educational experience in rural Wales, Sociologica Ruralis, 48:1 57-72

Barreiro-Hurle, J., Espinosa-Goded, M. and Dupraz, P., 2010, Does intensity of change matter? Factors affecting adoption of agri-environmental schemes in Spain, Journal of Environmental Planning and Management 53:7 891-905

Batary, P., Baldo, A., Klein, D., Tscharntke, T., 2010, Landscape-moderated biodiversity effects of agri-environmental management: a meta-analysis, Proceedings of the Royal Society B 278:1713

Batary, P., Dicks, L., Kleijn, D., Sutherland, W., 2015, The role of agri-environment schemes in conservation and environmental management, Conservation Biology, 29:4 1006-1016

Batary, P., Holzschuh, A., Orci, K., Samu, F., Tscharntke, T., 2012 Responses of plant, insect and spider biodiversity to local and landscape scale management intensity in cereal crops and grasslands, Agriculture, Ecosystems and Environment, 146:1 130-136

Bathmaker A.-M., 2015, Thinking with Bourdieu: thinking after Bourdieu.Using 'field' to consider in/equalities in the changing field of English higher education, Cambridge Journal of Education 45:1 61-80

Bazeley, P., Jackson, K., 2013, Qualitative Data Analysis with NVivo, $2^{\text {nd }}$ edition, SAGE publications

Bennett, K., 2010, Additionality: The Next Steps for Ecosystem Service Markets, Duke Environmental Law and Policy Forum 20:1 417-438

Berger, R., 2015 Now I see it, now I don't: researcher's position and reflexivity in qualitative research. Qualitative Research, 15:2 219-234

Blackstock, K.L., J. Ingram, R. Burton, K.M. Brown, B. Slee., 2010, Understanding and influencing behaviour change by farmers to improve water quality. Science of the Total Environ 408:1 5631-5638 
Blute, M., Armstrong, P., 2011, The Reinvention of Grand Theories of the Scientific/Scholarly Process, Perspectives on Science 19:4, 391-425

Boody, G., Vondracek, B., Andow, D., Krinke, M., Zimmerman, J., Welle, P., 2005, Multifunctional agriculture in the US, BioScience 55:1, 27-38

Bourdieu, P., 1977 Outline of a Theory of Practice Translated by Richard Nice. New York: Cambridge University Press

Bourdieu, P., 1983, The field of cultural production, or: The economic world reversed, Poetics 12:4-5

Bourdieu, P., 1984, Distinction: A Social Critique of the Judgement of Taste, Oxon: Routledge.

Bourdieu, P., 1985, The Social Space and the Genesis of Groups, Theory and Society 14:6 723-744

Bourdieu, P.,1986 The Forms of Capital In J. Richardson (ed.), Handbook of Theory and Research for the Sociology of Education, pp. 241-258, New York: Greenwood Press

Bourdieu, P., 1989. In Wacquant, L. (1989) Towards a reflexive sociology: a workshop with Pierre Bourdieu. Sociological Theory 7:1 26 -63.

Bourdieu, P., 1989a, Social Space and Symbolic Power, Sociological Theory 7:1 1425

Bourdieu, P., 1990, The Logic of Practice, Polity Press

Bourdieu, P., 1990a, In Other Words: Essays Towards a Reflexive Sociology, Cambridge Polity Press

Bourdieu, P., 1993, The field of cultural production: Essays on art and literature, Cambridge Polity Press

Bourdieu, P., 1993a, The weight of the world: social suffering in contemporary society, Stanford University Press

Bourdieu, P., 1996, The rules of Art: Genesis and Structure of the Literary Field, Polity Press

Bourdieu, P., 1998, Practical Reason: On the Theory of Action. Stanford University Press

Bourdieu, P., 2000, Propos sur le champ politique, Lyon: Presse Universitaire de Lyon

Bourdieu, P., 2000a, The politics of protest: an interview by Kevin Ovenden, Socialist Review, No.242 
Bourdieu, P., 2002, Le Bal des célibataires: Crise de la société paysanne en Béarn, Translated by Richard Nice (2011), The Bachelors Ball: The Crisis of Peasant Society in Bearn, University of Chicago Press

Bourdieu and Wacquant, 1992, An Invitation to Reflexive Sociology, University of Chicago Press

Bowler, I., 1985, Some consequences of the industrialization of agriculture in the European Community In Healey, M., Ilbery, B. (eds) The Industrialization of the Countryside. GeoBooks, Norwich, pp.75-98

Brixey, J., Robinson, D., Johnson, C., Johnson, T., Turley, J., Patel, V., Zhang, J., Towards a Hybrid Method to Categorize Interruptions and Activities in Healthcare, International Journal of Medical Informatics 76:11-12 812-820

Bryman, A1., 2015, Social Research Methods, $5^{\text {th }}$ Edition, Oxford University Press

Buckley, C., Hynes, S., Mechan, S., 2012, Supply of an ecosystem serviceFarmers' willingness to adopt riparian buffer zones in agricultural catchments, Environment Science and Policy 24:1 101-109

Burgess, J., Clark, J., Harrison, C., 2000, Knowledges in action: an actor network analysis of a wetland agri-environment scheme, Ecological Economics 35:1 119-132

Burnard, P., Gill, P., Stewart, K., Treasure, E., Chadwick, B., 2008, Analysing and presenting qualitative data, British Dental Journal 204:1 429-432

Burke, C., 2015, Habitus and Graduate Employment: A Re/Structured Structure and the Role of Biographical Research, Appearing in Chapter 4, Costa and Murphy (eds.) Bourdieu, Habitus and Social Research: The Art of Application, Palgrave MacMillan

Burton, R., 2004, Seeing through the 'good farmer's' eyes: Towards developing an under-standing of the social symbolic value of 'productivist' behaviour, Sociologia Ruralis 44:2 198-215

Burton, R., 2004a, Reconceptualising the 'behavioural approach' in agriculture studies: a socio-psychological perspective, Journal of Rural Studies 20:3 359-371

Burton, R., 2012, Understanding Farmers' Aesthetic Preference for Tidy Agricultural Landscapes: A Bourdieusian Perspective, Landscape Research, 37:1 5171

Burton, R., 2014, The influence of farmer demographic characteristics on environmental behaviour: A review, Journal of Environmental Management, 135:15 $19-26$

Burton, R., Kuczera, C., Schwarz, G., 2008, Exploring Farmers' Cultural Resistance to Voluntary Agri-environmental Schemes, Sociologica Ruralis 48:1 16-37 
Burton, R., Paragahawewa, U., 2011, Creating culturally sustainable agrienvironment schemes, Journal of Rural Studies, 27:1 95-104

Burton, R., Wilson G., 2006 Injecting social psychology theory into conceptualisations of agricultural agency: toward a post-productivist farmer selfidentity? Journal of Rural Studies 22:1 95-115

Capitanio, F., Adinolfi, F., Malorgio, G., 2011, What explains farmers' participation in Rural Development Policy in Italian southern region? An empirical analysis. New Medit 10:4 19-24

Carey, P., Short, C., Morris, C., Hunt, J., 2003, The multi-disciplinary evaluation of a national agri-environment scheme, Journal of Environmental Management 69:1 7191

Costa, C., Murphy, M., 2015, Bourdieu and the Application of Habitus across the Social Sciences, Appearing in Chapter 1, Costa and Murphy (eds.) Bourdieu, Habitus and Social Research: The Art of Application, Palgrave MacMillan

Courtney, P., Mills, J., Gaskell, P., Chaplin, S., 2013, Investigating the incidental benefits of Environmental Stewardship schemes in England, Land Use Policy 31:1 26-37

Crabtree, B., Chalmers, N., Eiser, D., 2001, Voluntary incentive schemes for farm forestry: uptake, policy effectiveness and employment impacts, Forestry: An International Journal of Forest Research 74:5 455-465

Creswell, J., 1998, Qualitative inquiry and research design: Choosing among five approaches, Sage, Thousand Oaks, CA

Darragh, H., Emery, S., 2018, What can and can't crowding theories tell us about farmer's 'environmental' intentions in post-agri-environment scheme contexts? Sociologica Ruralis 58:2 370-391

Davey, C., Vickery, J, Boatman, N., Chamberlain, D., Parry, H., Siriwardena G., 2010, Assessing the impact of Entry Level Stewardship on lowland farmland birds in England, International Journal of Avian Science 152:1 459-474

David, C., 2015, Learning to Fly: Entering the Youth Mobility Field and Habitus in Ireland and Portugal, Appearing in Chapter 7, Costa and Murphy (eds.) Bourdieu, Habitus and Social Research: The Art of Application, Palgrave MacMillan

Davidson, C., 2009, Transcription: Imperatives for Qualitative Research, International Journal of Qualitative Methods, 35-52

De Haan, H., 1993, Images of Family Farming in the Netherlands, Sociologica Ruralis 33:2 
Deci, E., Koestner, R., Ryan, R., 1999, The undermining effect is a reality after allExtrinsic rewards, task interest, and self-determination: Reply to Eisenberger, Pierce, and Cameron (1999) and Lepper, Henderlong, and Gingras (1999), Psychological Bulletin, 125:6 692-700

Defra, 2012, Dynamic deadweight in Environmental Stewardship - Towards a better understanding of the added benefits of the scheme, Report compiled by GHK, in consultation with Land Use Consultants

Defra, 2018, Health and Harmony: the future for food, faring and the environment in a Green Brexit - policy statement, Policy paper published on the gov.uk website, accessed at www.gov.uk/government/publications/the-future-for-food-farming-and-theenvironment-policy-statement-2018/health-and-harmony-the-future-for-foodfarming-and-the-environment-in-a-green-brexit-policy-statement, March 2019

Defra 2019, The guide to cross compliance in England 2019, Accessed through https://assets.publishing.service.gov.uk, April 2019

Defrancesco, E., Gatto, P., Runge, F., Trestini, S., 2008, Factors affecting farmers' participation in agri-environmental measures: A northern Italian perspective Journal of Agricultural Economics 59:1 114-131

DiCicco-Bloom, B., Crabtree, B., 2006, The qualitative research interview, Medical Education 40:4 314-321

DiMaggio, P., Mukhtar, T., 2004, Arts participation as cultural capital in the United States, 1982-2002: Signs of decline? Poetics 32:1 169-194

Ducos, G., Dupraz, P., Bonnieux, F., 2009, Agri-environmental contract adoption under fixed and variable compliance costs Journal of Environmental Planning and Management 52:5 669-687

Dwyer, J., J. Mills and 9 others. 2007, Understanding and influencing positive behaviour change in farmers and land managers - a project for Defra, CCRI, Macaulay Institute

Ekroos, J., Olsson, O., Rundlöf, M., Wätzold, F. and Smith, H. G., 2014, Optimizing agri-environment schemes for biodiversity, ecosystem services or both? Biological Conservation 172:1 65-71

Engel, S., Pagiola, S., Wunder. S., 2008, Designing Payments for Environmental Services in Theory and Practice - An Overview of the Issues, Ecological Economics 65:1 663-674

Epley, N., Dunning, D. 2000, Feeling "holier than thou": Are self-serving assessments produced by errors in self- or social prediction? Journal of Personality and Social Psychology, 79:6 861-875 
Espinosa-Goded, M., Barreiro-Hurle, J. and Ruto, E., 2010, What Do Farmers Want From Agri-environmental Scheme Design? A Choice Experiment Approach Journal of Agricultural Economics, 61:2 259-273

Evers, C., Wu, E., 2006, On generalising from single case-studies: epistemological reflections, Journal of Philosophy of Education, 40:4 511-526

European Commission, 2015, Agri-Environment Measures, Online fact sheet published on the EC website, accessed at www.ec.europa.eu/agriculture/envir/measures_en February 2019

European Parliament Briefings, 2016, How the EU budge is spent - Common Agricultural Policy Pillar I, accessed online at http://www.europarl.europa.eu/RegData/etudes/BRIE/2016/586622/EPRS_BRI(2016 )586622_EN.pdf, October 2019

Falconer, K., 2000, Farm-level constraints on agri-environmental scheme participation: a transactional perspective, Journal of Rural Studies 16:1 379-394

Fereday, J., Muir-Cochrane, E., 2006, Demonstrating Rigor Using Thematic Analysis: A Hybrid Approach of Inductive and Deductive Coding and Theme Development, International Journal of Qualitative Methods 5:1

Finlay, L., 2002, “Outing” the Researcher: The Provenance, Process, and Practice of Reflexivity. Qualitative Health Research, 12:4 531-545

Fisher, R., 2013, 'A gentleman's handshake': The role of social capital and trust in transforming information into useable knowledge, Journal of Rural Studies, 31:1 1322

Freidman, B., 1978, Crowding Out or Crowding In? The economic consequences of financing government deficits, The National Bureau of Economic Research, Brookings Papers on Economic Activity 3:1 593-654.

Garth, S., Egalitarian Habitus: Narratives of Reconstructing of Reconstruction in Discourses of Aspiration and Change, Appearing in Chapter 2, Costa and Murphy (eds.) Bourdieu, Habitus and Social Research: The Art of Application, Palgrave MacMillan

Garzon, I., 2006, Reforming the Common Agricultural Policy: History of a paradigm change, Palgrave Macmillan

Gawronski, B., Payne, B. K., (eds) 2010, Handbook of Implicit Social Cognition: Measurement, Theory and Applications, Guilford Press, New York

Gay, S., Osterberg, B., Baldock D., Zdanowicz, A., Recent evolution of the EU Common Agricultural Policy (CAP): state of play and environmental potential, Impact of Environmental Agreements on the Common Agricultural Policy, Document no. MEACAP WP6 D4b 
Gilbert, L. S.,2002, Going the distance: 'Closeness' in qualitative data analysis software International Journal of Social Research Methodology, 5, 215-228

Godin, G., Conner, M., Sheeran, P., 2010, Bridging the intention-behaviour gap: The role of moral norm, British Journal of Social Psychology 44:4 497-512

Grant, W., and 9 others, 2016, The Implications of 'Brexit' for UK Agriculture, Farmer Scientist Network, a report for Yorkshire Agricultural Society, accessed at http://eprints.uwe.ac.uk/29034/1/YAS_FSN_Brexit_-_Full_Report.pdf March 2019

Grenfell, M., James, D., 1998, Bourdieu and Education: Acts of Practical Theory, Routledge

Gunningham, N., Sinclair, D., 2005, Policy Instrument Choice and Diffuse Source Pollution, Journal of Environmental Law, 17:1 51-81

Halfpenny, P., 2014, Positivism in the twentieth century, Appearing in Chapter 28, Ritzer, G., Smart, B. (eds.), Handbook of Social Theory, SAGE Publishing

Hanley, N., 2001, Policy on Agricultural Pollution in the European Union, Appearing in Chapter 6, Shortle, J., Abler, D., (eds.) Environmental policies for agricultural pollution control, CABI Publishing

Hardy, C., 2008, Hysteresis, Appearing in Chapter 4, Grenfell, M. (ed.) Pierre Bourdieu, Key Concepts, Acumen Publishing

Hartley, J., 2004, Case-study research. In Catherine Cassell and Gillian Symon (Eds.), Essential guide to qualitative methods in organizational research London: Sage.

Harvey, F., 2018, Government promises profitable farming post-Brexit, The Guardian, available online at https://www.theguardian.com/environment/2018/jun/06/government-promisesprofitable-farming-post-brexit, Accessed October 2019

He, S., Wang, K., 2015, China's New Generation Migrant Worker's Urban Experience and Wellbeing, Mobility, Sociability and Wellbeing of Urban Living, 6791

Helm, D., 2017, Agriculture after Brexit, Oxford Review of Economic Policy, 33:1 124-123

Hiedanpaa, J., Bromley, D., 2014, Payments for ecosystem services: durable habits, dubious nudges, and doubtful efficacy, Journal of Institutional Economics 10:2 175195

Hilgers, M., Mangez, E., 2015, Introduction to Pierre Bourdieu's theory of social fields, Appearing in Chapter 1, Hilgers, M., Mangez, E., (eds.) Bourdieu's Theory of Social Fields: Concepts and Applications, Routledge 
Hodge, I., Reader, M., 2010, The introduction of Entry Level Stewardship in England: Extension or dilution in agri-environment policy? Land Use Policy, 27:2 270-282

Hollis, M., 1977, Models of Man: Philosophical thoughts on social actions, Cambridge University Press

Hollis, M., E., Nell, 1975, Rational economic man: a philosophical critique of neoclassical economics, Cambridge University Press

Huttunen, S., Peltomaa J., 2016, Agri-environmental policies and 'good farming' in cultivation practices at Finnish farms, Journal of Rural Studies, 44:1 217-226

Hynes, S., Garvey, E. 2009, Modelling Farmers' Participation in an Agrienvironmental Scheme using Panel Data: An Application to the Rural Environment Protection Scheme in Ireland, Journal of Agricultural Economics, 60:3 546-562

Ilbery, B., Bowler, I., 1998 From agricultural productivism to post-productivism. In Ilbery, B. (ed.) The Geography of Rural Change. Longman, London, pp.57-84

Institute for European Environmental Policy (IEEP), 2000, Preparing for the Implementation of Agri-Environment Schemes in Central and Eastern Europe, Seminar Proceedings, Published by the IEEP, accessed at www.minisites.ieep.eu/assets/144/Bratislavaseminarproceedings.pdf, February 2019

Institute for European Environmental Policy (IEEP), 2009, Provision of public goods through agriculture in the European Union, Report compiled by Cooper, T., Hart, K., Baldock, D., Document number 30-CE-0233091/00-28 accessed at https://ieep.eu/publications/the-provision-of-public-goods-through-agriculture-inthe-european-union, March 2019

Jenkins, R., 1982, Pierre Bourdieu and the Reproduction of Determinism. 16:2, 270281

Jenkins, R., 1992, Pierre Bourdieu, Routledge

Joint Nature Conservation Committee (2017), UK Biodiversity Indicators, Supplementary Data, Published at https://www.gov.uk/government/statistics/biodiversity-indicators-for-the-uk, accessed May 2019)

Jones, J., 2012, Verification of the calculations, methodology and costings used in determining payments for MESME additions to the Environmental Stewardship Scheme in 2012, Report for DEFRA by CUMULUS research consultants, report number LM0416

Juntti, M., Potter, C., 2002, Interpreting and Reinterpreting Agri-Environmental Policy: Communication, Trust and Knowledge in the Implementation Process, Sociologica Ruralis 42:3 215-232 
Karali, E., Brunner, B., Doherty, R., Hersperger, A., Rounsevell, M., 2013, The effect of farmer attitudes and objectives on the heterogeneity of farm attributes and management in Switzerland, Human Ecology, 41:6 915-926

Kawulich, B., 2005, Participant Observation as a Data Collection Method, Forum: Qualitative Social Research, 6:2 Article 43

Kennett, J., 1973, The Sociology of Pierre Bourdieu, Educational Review 25:3 237249

Kleijn, D., Sutherland, W., 2003, How effective are European agri-environment schemes in conserving and promoting biodiversity, Journal of Applied Ecology 40:1 947-969

Kristensen, L., Primdahl, J., 2006, The relationship between cross-compliance and agri-environment schemes, A research paper for the cross-compliance network

Krosnick, J., Presser, S., 2010, Question and Questionnaire Design, Appearing in Wright, J., Marsden, P., (eds.) Handbook of Survey Research (2 ${ }^{\text {nd }}$ Edition), Elsevier

Kuhfuss, L., Preget, R., Thoyer, S., Hanley, N., Le Coent, P., 2016, Nudges, Social norms and Permanence in Agri-environmental Schemes, Land Economics 92:4 641655

Kvale, S., 1996, InterViews: An Introduction to Qualitative Research Interviewing, SAGE publications

Lapadat, J., Lindsay, A., 1999 Transcription in Research and Practice: From Standardization of Technique to Interpretive Positionings, Qualitative Inquiry 5:1 64-86

Lastra-Bravo, X., Hubbard, C., Garrod, G., Tolon-Becerra, A., 2015, What drives farmers' participation in EU agri-environment schemes? Results from a qualitative meta-analysis, Environmental Science and Policy, 54:1 1-9

Latacz-Lohmann, U., Hodge, I., 2003, European agri-environmental policy for the $21^{\text {st }}$ Century, Australian Journal of Agricultural and Resource Economics 47:1 123139

Le Coeur, D., Baudry, J., Burel., F., Thenail, C., 2002 Why and how we should study field boundary biodiversity in an agrarian landscape context, Agriculture Ecosystems and Environment 89:1 23-40

LeCompte, M., Goetz, J., 1982, Problems of reliability and validity in ethnographic research, Review of Educational Research, 52:1 31-60

Lellatchitch, A., Mayrhofer W., Meyer, M., 2003, Career fields: a small step towards a grand economic theory?, The International Journal of Human Resource Management 14:5 728-750 
Lowe, P., Murdoch, J., Marsden, T., Munton, R., Flynn, A.,1993 Regulating the new rural spaces: the uneven development of land Journal of Rural Studies 9 205-222

Lowe, P., Ward, N., Potter, C., 1999, Attitudinal and institutional indicators for sustainable agriculture. In: Brouwer, F., Crabtree, B. (eds.), Environmental Indicators and Agricultural Policy. CABI, Wallingford, pp. 263-278

Roberts, M., Lubowski, R., 2007, Enduring impacts of land retirement policies: evidence from the conservation reserve program Land Economics 83:1 516-538

Macpherson, I., Brooker, R., Ainsworth, P., 2010, Case-study in the contemporary world of research: Using notions of purpose, place, process and product to develop some principles for practice, International Journal of Social Research Methodology, 3:1 49-61

Macgregor, C., Warren, C., 2006, Adopting sustainable farm management practices within a Nitrate Vulnerable Zone in Scotland: The view from the farm, Agriculture, Ecosystems and Environment 113:1-4 108-119

Marsden, T.K., Munton, R., Whatmore, S., Little, J., 1989, Strategies for copng in capitalist agriculture: an examination of the responses of farm families in British agriculture, Geoforum 20:1 1-14

Marsden, T.K., Murdoch, J., Lowe, P., Munton, R., Flynn, A., 1993. Constructing the Countryside UCL Press, London.

Mason, J., 1996, Qualitative researching. London: Sage

Mathijs, E.,2003, Social capital and farmers' willingness to adopt countryside stewardship schemes Outlook on Agriculture, 32:1 13-16

Maton, K., 2003, Reflexivity, relationism and research: Pierre Bourdieu and the epistemic conditions of social scientific knowledge, Space and Culture 6:1 52-65

Maton, K., 2006, A question of autonomy: Bourdieu's field and approach and higher education policy, Journal of Education Policy 20:6 687-704

Maton, K., 2008, Habitus, Appearing in Chapter 3, Grenfell, M. (ed.) Pierre Bourdieu, Key Concepts, Acumen Publishing

Mauerhofer, V., Hubacek, K., Coleby, A., 2013, From polluter pays to provider gets: distribution of rights and costs under payments for ecosystem services. Ecology and Society 18:4 Article 41

Mayrhofer, W., Lellatchitch, A., Meyer, M., Streyrer, J., Schiffinger, M., Strunk, G., 2004, Going beyond the individual: some potential contributions from a career field and habitus perspective for global career research and practice, Journal of Management Development, 23:9 870-884 
Mays, N., Pope, C., 2000, Qualitative research in health care: Assessing quality in qualitative research British Medical Journal 320:7226 50-52

McGuire, J., Wright Morton L., Cast, D., 2013, Reconstructing the good farmer identity: shifts in farmer identities and farm management practices to improve water quality, Agriculture and human values 30:1 57-69

Merton, R., 1968, Social Theory and Social Structure, Free Press

Meyer, C., Matzdorf, B., Muller, K., Schleyer, C., 2014, Cross compliance as payments for public goods? Understanding EU and US agricultural policies, Ecological Economics 107:1 185-194

Michel-Guillou, A., Moser, G., 2006, Commitment of farmers to environment protection: From social pressures to environmental conscience, Journal of Environmental Psychology 26:3 227-235

Mills, C., 1959, The Sociological Imagination, Oxford University Press

Mills, J., Ingram, J., Reed, M., Short, C., Gibbon, D., Dwyer, J., 2008 Evaluation of key factors that lead to successful agri-environmental co-operative schemes. Final Report for Welsh Assembly Government. Gloucester: Countryside and Community Research Institute

Moore, R., 2008, Capital, Appearing in Chapter 6, Grenfell, M. (ed.) Pierre Bourdieu, Key Concepts, Acumen Publishing

Morris, C., 2006, Negotiating the boundary between state-led and farmer approaches to knowing nature: An analysis of UK agriOenvironment schemes, Geoforum 37:1 113-127

Moxey, A., White, B., Ozanne, A., 2008, Efficient Contract Design for AgriEnvironment Policy, Journal of Agricultural Economics, 50:2 187-202

Murchison, J., 2010, Ethnography Essentials: Designing, conducting and presenting your research, Jossey-Bass Publishers

Naidoo, R., 2004 Fields and institutional strategy: Bourdieu on the relationship between higher education, inequality and society, British Journal of Sociology and Education 25:4 457-471

National Audit Office (NAO), 2010, Tackling diffuse water pollution in England, NAO ISBN: 9780102965346

Natural England, 2009, Agri-environment schemes in England, Published by Natural England, document number NE194. Accessed at www.publications.naturalengland.org.uk/publication/46002 February 2019

Natural England, 2013, Entry Level Stewardship: Environmental Stewardship Handbook, $4^{\text {th }}$ edition, published by Natural England, Accessed at 
publications.naturalengland.org.uk/publication/2798159 March 2019

Natural England, 2015, Evolution of agri-environment schemes in England, Published by Natural England, document number NE373, Accessed at http://publications.naturalengland.org.uk/publication/3567470 September 2019

Nederhof, A., 1985, Methods of coping with social desirability bias: A review, European Journal of Social Psychology, 15:3 263-280

Nowicka, M., 2015, Habitus: Its Transformation and Transfer through Cultural Encounters in Migration, Appearing in Chapter 6, Costa and Murphy (eds.)

Bourdieu, Habitus and Social Research: The Art of Application, Palgrave MacMillan

O'Keefe D., 2002, Persuasion theory and research London: Sage Publications

Oliver, D., Serovich, J., Mason, T., 2005, Constraints and Opportunities with Interview Transcription: Towards Reflection in Qualitative Research, Social Forces, 84:2 1273-1289

Olsen, R., 2005, The problem of respondent attrition: survey methodology is key, Monthly Labor Review 63:1

Opdenakker, R., 2006, Advantages and disadvantages of four interview techniques in qualitative research, Forum: Qualitative Research, 7:4 Article 11

Oreszczyn, S., A. Land, 2000, The meaning of hedgerows in the English landscape: Different stakeholder perspectives and the implications for future hedge management Journal of Environmental Management 60:1 101-118

Ovenden, G., Swash, A, Smallshire, D., Agri-environment schemes and their contribution to the conservation of biodiversity in England, Journal of Applied Ecology, 35:6 955-960

Padel, S., 2001, Conversion to organic farming: a typical example of the diffusion of an innovation, Sociologica Ruralis 41:1 40-61

Pannucci, C., Wilkins, E., 2010, Identifying and Avoiding Bias in Research, Plastic Reconstructive Surgey, 126:2 619-625

Pariliamentary Publications, 2011, The Common Agricultural Policy after 2013, accessed online at https://publications.parliament.uk/pa/cm201011/cmselect/cmenvfru/671/67104.htm September 2019

Parsons, T., 1951, The Social System, Psychology Press

Patton, M., 2002, Qualitative research and evaluation methods, Sage, Thousand Oaks, CA 
Pe'er, G., Dicks, L. V., Visconti, P., Arlettaz, R., Baldi, A., Benton, T. G., Collins, S., Dieterich, M., Gregory, R. D., Hartig, F., Henle, K., Hobson, P. R., Kleijn, D., Neumann, R. K., Robijns, T., Schmidt, J., Shwartz, A., Sutherland, W. J., Turbe, A., Wulf, F., Scott, A. V., 2014, AGRICULTURE POLICY EU: agricultural reform fails on biodiversity Science 344:6188, 1090-1092

Peerlings, J., Polman, N., Farm choice between agri-environmental contracts in the European Union, Journal of Environmental Planning and Management, 52:1 593612

Pretty, J., 1998, The living land: agriculture, food and community regeneration in rural Europe, London: Earthscan Publications

Potter, C.,1998, Against the Grain: agri-environmental policy reform in the US and $E U$. CAB International, Wallingford

Quillerou E.,Fraser, R.,Fraser, I.,, 2010. Adverse Selection in the Environmental Stewardship Scheme: Evidence in the Higher Level Stewardship Scheme? 84th Annual Conference, March 29-31, 2010, Edinburgh, Scotland 91676, Agricultural Economics Society

Reay, D., 2015 Habitus and the psychosocial: Bourdieu with feelings, Cambridge Journal of Education 45:1, 9-23

Reeves, S., Kuper, A., Hodges, D., 2008, Qualitative research methodologies: ethnography, The BMJ, 337:1020

Reidsma, P., Tekelenburg, T., van den Berg, M., Alkemade, R., 2006, Impacts of land-use change on biodiversity: An assessment of agricultural biodiversity in the European Union

Renting, H. and 7 others, 2009, Exploring Multifunctional Agriculture: A review of conceptual approaches and prospects for an integrative transitional framework, Journal of Environmental Management, 90:1 112-123

Rey, T., 2007 Bourdieu on Religion: Imposing Faith and Legitimacy, Routledge

Rhodes, R., de Bruijn, G.-J., 2013, How big is the activity intention-behaviour gap? A meta-analysis using the action control framework, British Journal of Health Psychology, 18:2

Ribisl, K., Walton, M., Mowbray, C., 1996, Minimizing participant attrition in panel studies through the use of effective retention and tracking strategies: review and recommendations, Education and Program Planning 19:1 1-25

Riley, M., 2008, Experts in their fields: farmer-expert knowledges and environmentally friendly farming practices, Environment and Planning A: Economy and Space, 40:6 1277-1293 
Riley, M., 2016, How does longer term participation in agri-environment schemes [re] shape farmers' environmental dispositions and identities?, Land Use Policy 52, 62-75

Ritchie, J. Spencer, L. (1994) Qualitative Data Analysis for Applied Policy Research In: Bryman, A., Burgess, R., (eds.), Analysing Qualitative Data, Routledge, London, 173-194

Robbins, D., 2003, The Need for an Epistemological 'Break', Appearing in Chapter 3 ,

Grenfell, M., D., James (eds.), Bourdieu and Education: acts of practical theory, Routledge

Robbins, D., 2008, Theory of Practice, Appearing in Chapter 8, Grenfell, M. (ed.) Pierre Bourdieu, Key Concepts, Acumen Publishing

Rogers E., 1983, Diffusion of innovations, New York Free Press

Ruto, E., G. Garrod 2009, Investigating farmers' preferences for the design of agrienvironmental schemes: a choice experiment approach, Journal of Environmental Planning and Management, 52:5 631-647

Rye, J., 2006, Rural youths' images of the rural, Journal of Rural Studies 22:4 409421

Sandelowski, M., 1995, Sample size in qualitative research, Research in Nursing Health 18:2 179-183

Saunders, F., 2016, Complex shades of green: gradually changing notions of the 'good farmer' in a Swedish context, 56:3, 391-407

Scheper, J., Holzschuh, A., Kuussaari, M., Potts, S., Rundlof, M., Smith, H., Kleijn, D., 2013, Environmental factors driving the effectiveness of European agrienvironmental measures in mitigating pollinator loss - a meta-analysis, Ecology Letters 16:1 912-920

Schneider, M., 2006 The Theory Primer: A Sociological Guide, Rowman and Littlefield Publishers

Schofield, J., 1992, Increasing the generalizability of qualitative research. Appearing in Hammersley, M., Social research: Philosophy, Politics and Practice Open University and Sage, London

Seabrook, M.F. Higgins, C.B., 1988, The role of the farmer's self-concept in determining farmer behaviour, Agricultural Administration and Extension, 30:1 99108

Sewell, W., 1992 A Theory of Structure: Duality, Agency, and Transformation, American Journal of Sociology 98:1, 1-29. 
Sheeran, P., Webb, T., 2016, The Intention-Behaviour Gap, Social and Personality Psychology Compass, 10:1 503-518

Sheeran, P., 2002 Intention - Behavior Relations : A Conceptual and Empirical Review. Eur. Rev. Soc. Psychol. 12, 1-36

Simon, H., 1959, Theories of decision-making in economics and behavioural science, The American Economic Review, 49:3, 253-283

Sippel, R., 1997, An experiment on the pure theory of consumer's behaviour, Economic Journal, 107:444, 1431-44

Smallshire, D., Robertson, P., Thompson, P., 2004, Policy into practice: the development and delivery of agri-environment schemes and supporting advice in England, International Journal of Avian Science, 146:2, 250-258

Srivastava, A., Thomson, S., 2009,Framework Analysis: A Qualitative Methodology for Applied Research Note Policy Research. JOAAG, 4:2 72-79

Sullivan, A., 2002, Bourdieu and Education: How useful is Bourdieu's theory for researchers? Netherlands Journal of Social Sciences 38:2 144-166

Sutherland, L-A., 2013, Can organic farmers be 'good farmers'? Adding the 'taste of necessity' to the conventionalized debate, Agriculture and Human Values 30:3 429441

Sutherland, L-A., Darnhofer, I., 2012, Of organic farmers and 'good farmers': Changing habitus in rural England, Journal of Rural Studies 28, 232-240

Sutherland, L-A., Mills, J., Ingram, J., Burton R., Dwyer, R., Blackstock, K., 2013, Commercialisation and trust in agri-environmental information and advisory services in England, Journal of Environmental Management 118:30 96-105

Swanwick, C., Hanley, N., Termansen, M., 2007, Scoping study on agricultural landscape valuation Report to DEFRA, Final Report submitted October 2007

Thomas, E., Riley, M., Spees, J., 2020, Knowledge flows: Farmers'social relations and knowledge sharing practices, Land Use Policy 90:1, 104254

Thomas, L., 2002, Student retention in higher education: the role of institutional habitus, Journal of Education Policy 17:4 423-442

Thompson, J., 1991. Editor's Introduction, In Bourdieu, P., Language and Symbolic Power, Cambridge, MA: Harvard University Press.

Thomson, P., 2008, Field, Appearing in Chapter 4, Grenfell, M. (ed.) Pierre Bourdieu, Key Concepts, Acumen Publishing 
Throop, J., Murphy, K., 2002, Bourdieu and phenomenology: A critical assessment, Anthropological Theory, 2:2 185-207

Titmuss, R., 1970, The Gift Relationship: From Human Blood to Social Policy, The New Press

Tummons, J., 2014, Using Software for Qualitative Data Analysis: Research Outside Paradigmatic Boundaries, in (ed.) Big Data? Qualitative Approaches to Digital Research. Studies in Qualitative Methodology, Volume 13, Emerald Group Publishing Limited, pp.155 - 177

Ulber, L., Klimek, S., Steinmann, H.-H., Isselstein, J., Groth, M., 2011, Implementing and evaluating the effectiveness of a payment scheme for environmental services from agricultural land, Environment Conservation 38:4 464472

Van Maanen, H., 2009, How to Study Art Worlds: On the Societal Functions of Aesthetic Values, Amsterdam University Press

Van Oudenaran, J., 2004, Uniting Europe: An Introduction to the European Union, Rowman and Littlefield Publishers

West, B., Blom, A., 2017, Explaining the Interviewer Effects: A Research Synthesis, Journal of Survey Statistics and Methodology, 5:2 175-211

Wacquant, L., 2011, Habitus as topic and tool: Reflections on becoming a prizefighter, Qualitative Research in Psychology, 8:1 81-92.

Wainwright, A., 1997, Can sociological research be qualitative, critical and valid? The Qualitative Report 3:2 1-17

Walther, M., Repatriation to France and Germany: A Comparative Study Based on Bourdieu's Theory of Practice, Springer Gable

Watkins, C., Williams, D., Lloyd, T., 1996, Constraints on farm woodland planting in England: a study of Nottinghamshire farmers, Forestry 69:2

Webb, J., Schirato, T., Danaher, G., Understanding Bourdieu, Sage Publications

Wheeler, R., Lobley, M., Winter, M., Morris, C., 2018, "The good guys are doing it anyway": The accommodation of environmental concern among England and Welsh farmers, Environmental Planning E: Nature and Space, 1:4 664-687

Whitby, M., 2000, Challenges and Options for the UK Agri-Environment: Presidential Address, Journal of Agricultural Economics 51:3 317-332

Whitby, M., Lowe, P., 1994, The Political and Economic Roots of Environmental Policy in Agriculture in Whitby, M. (ed.) Incentives for Countryside Management: The Case of Environmentally Sensitive Areas, Wallingford: CAB International: 1-24 
Wilson, G. A., 2001, From Productivism to Post-productivism ... and Back Again? Exploring the (un)changed natural and mental landscapes of European agriculture, in Transactions of the Institute of British Geographers, 26:1 77-102

Wilson, G.A., Hart, K., 2000 Financial imperative or conservation concern? EU farmers' motivations for participation in voluntary agri-environmental schemes Environment and Planning A, 32:1 2161-2185

Wilson, G. A. and Hart, K. 2001, Farmer Participation in Agri-environmental Schemes: Towards Conservation-Oriented Thinking? Sociologia Ruralis, 41:1 254274

Wilson, G. A., 2007, Multifunctional Agriculture, a Transition Theory Perspective, CABI Publishing

Wright, R., 2015, 'Now We're the Musicians': Using Bourdieu's Concepts of Habitus, Capital and Field, to Analyse Informal Learning in Canadian Music Education, Appearing in Chapter 6, Burnard, P., Hofvander, Y., Söderman, J. (eds.), Bourdieu and the Sociology of Music Education, Ashgate Publishing

Woods, M., Macklin, R., Lewis, G. K. 2015, Researcher reflexivity: exploring the impacts of CAQDAS use. International Journal of Social Research Methodology, 19:4, 385-403

Wynne Jones, S., 2017, Understanding farmer co-operation: Exploring concepts of social relatedness and emergent affects, Journal of Rural Studies, 53:1 259-268

Yarwood, R., Evans, N., 2006, A Lleyn Sweep for Local Sheep? Breed Societies and the Geographies of Welsh Livestock, Environment and Planning A: Economy and Space 38:7 1307-1326

Yin, R., 1984, Case-study Research: Design and Methods, SAGE Publications 


\section{Appendices}

Appendix A - Screenshots of NVivo coding process

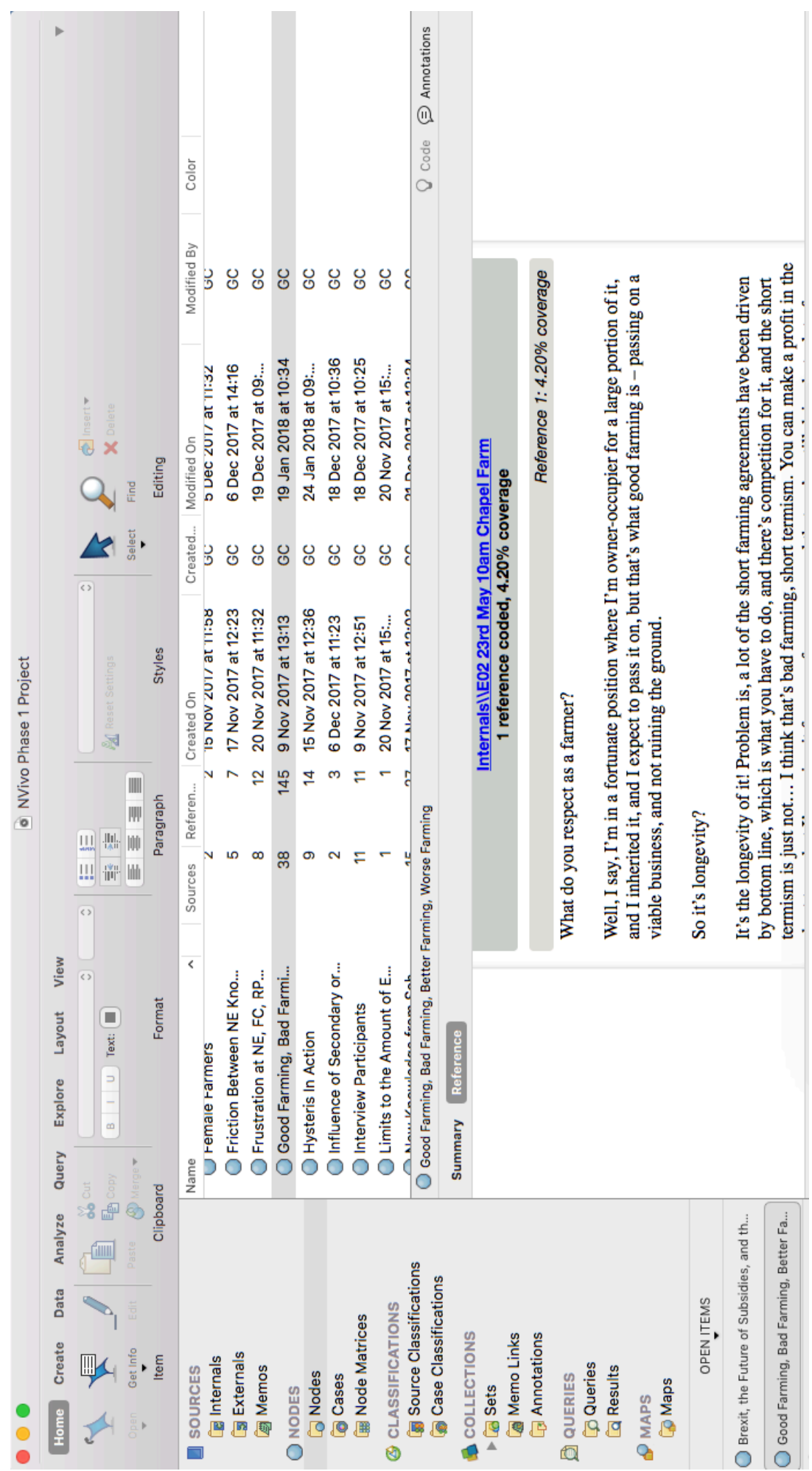




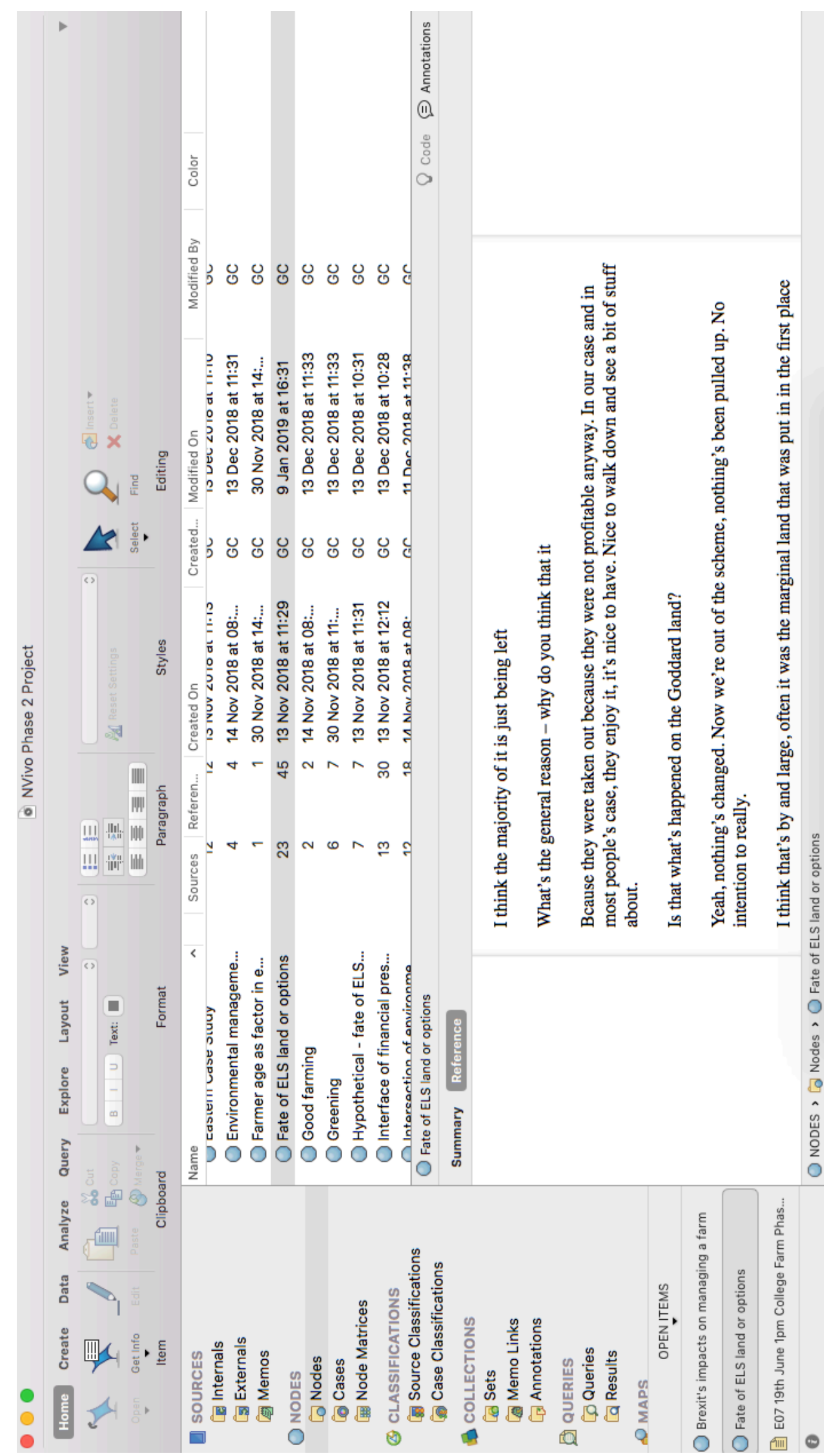


Appendix B - Interviewee details

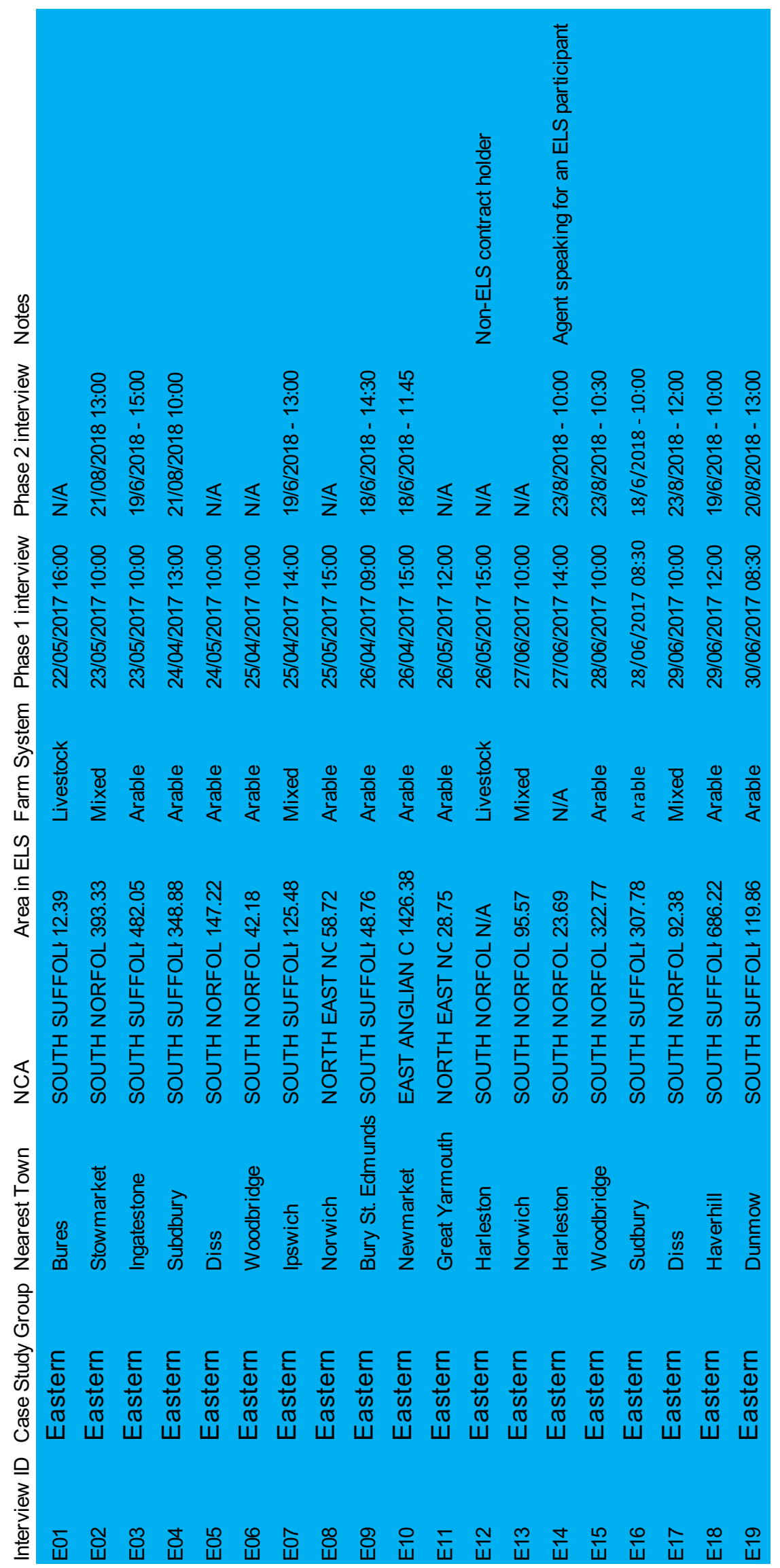




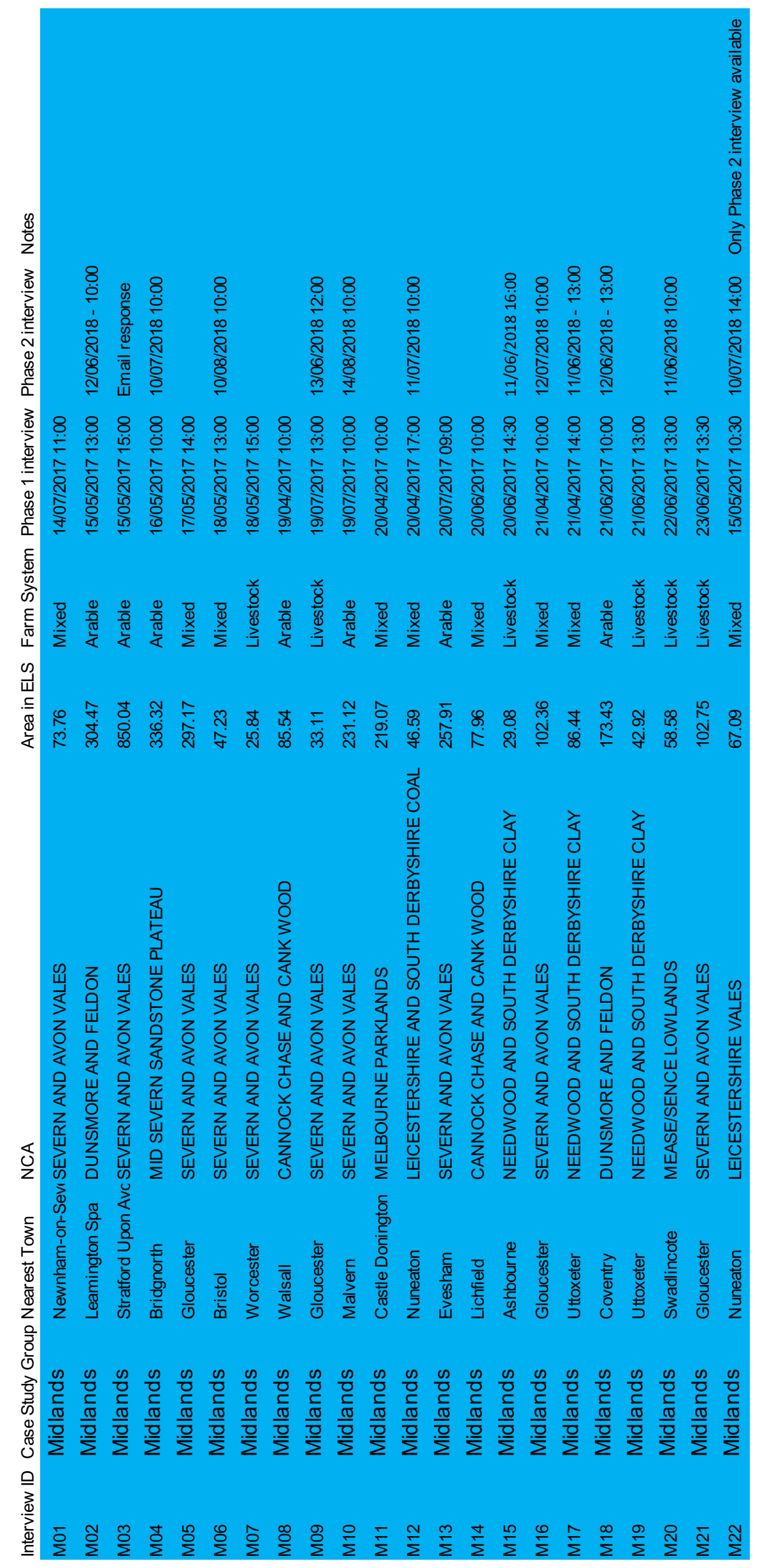


Appendix C - Phase 1 interview schedule

The following is the schedule used in the phase 1 interviews. Each question is followed by the sorts of prompts used in the interviews, or variations on question wordings used when the initial question was not clearly understood. An explanation for each question is also given.

1. Can you please tell me about your farm? How big, what products etc.

As recommended by Kvale (1996), straight-forward, introductory questions were used to allow both the interviewer and interviewees to warm to each other's presence. Prompts included non-contentious details about their holding and about the ELS contract.

2. What were the main options in your contract?

Why did you choose the options you did?

Did they fit well with your farm management system?

Do you recall the environmental objectives for the different options?

As the interviews implicated the different options in the farmers' contracts (how the farmer feels about them, how they look, whether they believe the options capable of reproducing capital), it was important to allow the farmers to self-identify what their options where, and what they understood their environmental objectives to be.

\section{What were your main reasons for getting into ELS}

Were you encouraged by anyone else to get into the scheme?

Were there any nearby farmers applying/participating? And if so, did this impact your decision to apply? In what way?

AESs are reliant on the voluntary participation of farmers (Lastra-Bravo et al. 2015), and so it was valuable to understand what the (de)motivational factors were that determined the interviewee's decision to participate. The question was included 
to introduce this theme to the interview. Specifically, the question allowed the farmers to self-identify what their motivations were, whether the environmental objectives of the scheme played a part in their decision to apply and whether they perceived there to be any prestige associated with participation. The latter prompts were included to prompt the farmers to reflect on the extrinsic social motivations (i.e. aside from the intrinsic economic contributions the scheme may make to their farm enterprise, or the capacity for the scheme to help achieve certain environmental objectives in which the farmers may be invested) that potentially encouraged their participation. The question also introduced an important theme to the interview setting - namely the impact one manager's behaviour has on another.

\section{Your ELS contract is coming to an end in the next few months. How have you felt} about the scheme, and its management requirements?

Have your options been successful in achieving their objectives [recall answers given for Q2]?

Did you have to do anything different to your previous management to get into scheme?

Have you found any of the management obligations at all challenging or interesting, or has it just been a question of following the instructions?

The usage of common sense language is important to ensure the full comprehension of the question, and as a linguistic tactic to help pacify the high-pressure interview environment into one resembling a more informal conversation (Bryman 2015). The question aimed to develop a key theme for the interview. Namely a retrospective analysis of the farmer's regard for the scheme as their involvement with it draws to a close.

The latter prompt was designed to help understand whether the farmers were able to bring their expertise to bear when carrying out the managerial obligations mandated by their contract. The ability for farmers to engage their skills and knowledges (as opposed to following a set of simple managerial instructions) when fulfilling AES option requirements has been highlighted as an important factor to ensure the farmers 
are able to reproduce cultural capital through scheme participation (Burton and Paragahawewa 2011).

5. Do you take time to think about the way nearby farmers manage their land?

Do you know about crop rotation and production of your neighbours? Do you know about your neighbour farm's workforce?

Can you easily tell which farmland of the nearby farms is under scheme management?

Do you respect it when you see environmentally managed land (scheme participation etc)?

As has been articulated, a main theme of the research is to understand if farmers associate AES participation (or environmentally sensitive land management more generally) with the reproduction of cultural capital. A crucial mechanism through which this process will happen, as per Bourdieu's theory, is the social visibility of the behaviour in question. This visibility maps onto the concept of 'roadside' farming (Burton 2004, Seabrook and Higgins 1988) and the question was designed to assess how visible the farmers believed different scheme options are, whether they believed there is a widespread practice of analysing nearby farmer's management styles, and whether there is an attitude within the agricultural community that responds favourably to those farmers who are engaging with ideas of environmental management.

6. Do you think other farmers can tell which of your land is under scheme management?

Which of your options do you think are most visible to other farmers?

Do you think your neighbours take time think about the way you manage your land? Are you proud to know they can see you're doing your bit for the environment?

As above, the concept of roadside farming, and the visibility of scheme options is of central importance to the research, and to understanding if scheme participation is 
capable of generated cultural capital for the participating farmers. This question is, in effect, the inverse of the previous question, and was designed to allow the farmers to speculate on which of their options are obvious to other farmers, and how they believe nearby farmers react to their participation in the scheme. The responses helped illuminate whether the farmers believe they were able to reproduce capital through scheme participation.

7. What do you expect to do with the land coming out of the ELS contract

Do you think you will look to put the land into the next AES scheme, put it back into production, or continue to manage the land as is under ELS, or leave it out of production?

[repeat above question for the different options in the farmer's contract] Why? What would be the main motivations for doing X [new CS contract, putting the land back into production etc] with the land covered by your current ELS contract? [if relevant] Has witnessing the environmental improvement [recall previously cited examples] from the scheme changed your attitude to environmental management? What could get you to keep the land under scheme management?

The importance of the land falling out of scheme contract coverage has been explained over the previous two chapters. The above question was designed to introduce this major theme of the research into the dialogue, and asks the farmers what their management plans are for the land that is due to become free from contractual obligations. Given the different options that are liable to exist in any one contract, iterations of the questions needed to be asked for each of the main options. The prompts were designed to understand what the motivational factors were that lead to those decisions being taken - specifically if the farmers believe the rules of the game in the agricultural field mean that continued environmental management is an expedient way of generating cultural capital.

8. For you, what is 'good farming?' 
In terms of being a 'good farmer', how important is it to manage the land for the environment?

As previously discussed, the concept of the good farmer is being used as a shorthand to capture those behaviours and artefacts that are capable of reproducing capital for the farmers without needing to lean on arcane or academic Bourdieusian definitions. It is being introduced here, therefore, to allow the farmers to self-identify which behaviours and practices fall under its rubric. The initial question is framed around 'good farming' to avoid awkward questions based on abstract concepts (e.g. "what is the good farmer" or "who is the good farmer"). The prompt is included to ensure that their environmental attitudes is included in their analysis of the good farmer.

In Bourdieusian terms, the question is designed to get an account, given by a farmer, of the rules of the game at play in the agricultural field. What the rules are that dictate which behaviours and artefacts are valued and why.

9. Do you think good farming has changed? Is good farming done the same way?

What practices are becoming more acceptable?

What practices are becoming less acceptable?

Are you doing any other environmental management outside of the scheme? Do you think conversations about environmental management are more common than before?

The question is designed to look into the theme of the changing or changed environmental attitudes in the farming community. The question was designed to elicit the farmer's diachronic sense of the farming community, and their beliefs about what behaviours and acts used to be commonplace/acceptable and what behaviours and acts are increasingly becoming more or less desirable/expected. For the same reasons described above, the question was framed around 'good farming' to avoid potentially awkward abstract questions such as "do you think the good farmer has changed...". 
In terms of project's Bourdieusian framework, the question was designed to understand how much the rules of the game within the agricultural field have changed over time, and to what extent the individual's habitus has accommodated the changes. These changed rules will bring with them a changed set of behaviours and objects capable of reproducing capital for the farmers in the agricultural field, and so the question was also designed to draw out the farmer's account of what strategies they believe will be effective in securing favour from the community. The Bourdieusian concepts of field, habitus, hysteresis and capital are all be implicated in the above questions.

\section{What has caused the change in good farming?}

Have the different agri-environment schemes had an impact? What sort of impact? Has the general understanding and education around environmental damage changed farmers' ideas about what their environmental responsibilities are?

The above question was included to develop the theme of the changing/changed sense of environmental responsibility in the agricultural community as introduced in the previous question. The opening question is specifically open-ended so as to allow the farmers to self-identify (i.e. without being lead into a particular answer) what they believe the cause(s) of the change are. The follow-up prompts were designed to add depth and texture to the initial response, and to ensure the different potential causes are sufficiently touched upon.

Again, the question and prompts were aimed at drawing out a description of the changed/changing rules of the game of the agricultural field, and the reasons behind those changes. The responses were able indicate the extent to which the changes have been integrated into the farmer's behaviours and beliefs, and how happily the changed rules of the field have been received.

\section{Is there anything else you'd like to say about your ELS experience, or about} changes in farm culture in general? 
The question was included to allow the farmers to raise any issue or idea they have that believe to be pertinent to the research. As described above, the project has an inductive element, and in case no emergent themes emerged organically over the course of the interview, this question was included to provide one final opportunity for the interviewees to raise ideas or themes of their own.

12. We'd like to arrange an interview for this time next year, would it be okay to contact you around then? It's been a very interesting discussion and it would be incredibly valuable for the research project to see how these themes have developed.

As above, an important part of the research design is to arrange follow-up interviews to take place after the interviewee's ELS contracts have finished. This question was included to attend to this feature of the methodology. 
Appendix D - Phase 2 interview schedule

The presentation will mirror that of Appendix C: Each question is followed by the sorts of prompts used in the interviews, or variations on question wordings used when the initial question was not clearly understood. An explanation for each question is also given.

1. What management changes have happened since our interview last year?

Since your ELS contract finished, what has become of the practices you had to do through your ELS contract?

The question introduces the key topic of phase 2 interviews. This open-ended question will be used first, to see which management changes the interviewee volunteers first - i.e. without leading the inquiry by referencing the predictions they made in the previous interviews. Prompts will be offered, depending on the responses given - questions about the motivations for applying to the CS, about the nature of the contract, about the reasons not going for a contract etc.

\section{In our last interview, you predicted you would X [relevant management expectations for land coming out of ELS]?}

(Repeat for each different management expectation for the different ELS options)

As above, a central motivation behind the inclusion of follow-up interviews is to verify the predictions managers made about the land coming out of ELS. Asking this question can help short-circuit the potentially problematic biases that may have otherwise influenced the land manager's predictions about how they plan to manage their land. The question is included in case the specific predictions made in the previous interviews are not referenced in the answers to question 1, and also to prompt a more thorough reflection on the management changes that have taken place (i.e. beyond the changes at the forefront of the interviewee's mind offered in their response to question 1). 
3. Are farmers willing to maintain some environmental management practice on their land if they stop remunerated for it?

Why would they, or why wouldn't they?

Under what conditions are they most likely to keep up with an ELS option, once their contracts come to an end?

As per the literature review, the idea of crowding in/out has been applied to the study of farmers' willingness to maintain environmental management techniques on the farm in a post-scheme scenario. In offering financial remuneration for the adoption of agri-environmental practices, do subsidies suffocate farmers' own intrinsic environmental motivations, promoting the sense that environmental management should only be done in the presence of financial support (crowding out); or do they spread new information and ideas about different management techniques, thus catalysing a long-term changes in the environmental profile of the farmer's management (crowding in). The above question was included as a means of capitalising on a valuable opportunity to inspect what the motivations are in the adoption of certain practices in the immediate fallout of an ELS contract's conclusion.

4. Do you know any farmers who have gone into CS and why do you think they did that?

Do you think it's a respectable way to go about farming?

5. Do you know any farmers who have maintained their ELS options without going into CS, and if so, why do you think they did that?

Do you think it's a respectable way to go about farming?

6. Do you know any farmers who have put their old ELS options back into production and why do you think they did that? 
Do you think it's a respectable way to go about farming?

Questions 4-6 and their follow ups re-introduce the concept of respect. As in the phase 1 interviews, respect functioned as a conduit through which Bourdieu's tools could be easily applied. What levels of respect are associated with the adoption of the above management approaches, and what level of cultural capital can each expect to reproduce for the farmer in question. Follow up questions were used to gauge the respect and cultural capital associated with the respective management decisions.

\section{Defra have indicated some of the changes they expect to make with the Brexit} process and agri-subsidies. Are you happy with the idea of being paid for public goods as opposed being subsidised to produce food?

Why do you/do you not like the idea of being paid for public goods? If not for public goods, what would you prefer to be subsidised for?

The impact Brexit is having on farmers' agri-environmental decisions was made clear throughout the phase 1 interviews, and was identified as having an important bearing on the research questions of the project. The question was designed to drive at the nature of those changes, the perceptions the farmers have on how it will affect their management decisions.

The question was developed with the project's NE supervisor, who raised the potential relevance and value of including the topic of 'public goods' in the phase 2 interviews. Public goods refers to those things that are non-excludable (whereby if it is available to one person, others are not excluded from its benefits or from future access) and non-rival (whereby the consumption of the good by one person does not impact the supply of the good available for others) (IEEP 2009). In the context of agriculture, this could mean water quality, soil quality, flood risk mitigation, climate change mitigation, biodiversity, food security, rural economic resilience or animal welfare. Are farmers willing, in other words, to be paid to provide those services for 
the country or would they prefer to be paid for managing their farm solely in the name of food production? The concept was included because of the clear relevance it has in the context of this project: how do the rules of the game mesh with business models that are not solely predicated on agricultural production; have the changes in the subsidy structure been integrated into the managers' habituses?

\section{For you, what is bad farming?}

With regards to environmental management, what do you think bad farming is? In terms of his environmental profile, what does the bad farmer do?

One of the emerging themes of the phase 1 interviews was the loss of cultural capital associated with environmental negligence. The concept of the bad farmer was developed to help fill this explanatory gap. It was, however, not included systematically in the interview schedule of the first round of interviews, and so its inclusion, as an open-ended question about the make-up of bad farming, was intended to facilitate a more robust means of tracing the contours of the bad farmer, and its interface of environmental disregard. When the interviewee's initial depictions of bad farming, or the bad farmer may, were not relevant to environmental management practices (but rather about poor managerial decisions, or lack of technical expertise) prompts were used to stimulate reflections on the extent to which environmental mismanagement, or environmentally damaging behaviour strays into the territory of bad farming. As with the phase 1 interview schedule, the question "what is bad farming" was preferred over the alternative "what is the bad farmer" (or similar) because of the potential awkwardness associated with introducing the abstract concept of 'the bad farmer'. 
Appendix E - interview request letter
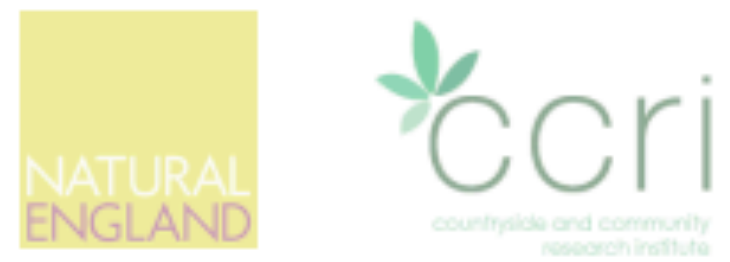

$5^{\text {n }}$ May 2017

\section{RE: Understanding your experiences of the ELS tier of the Environmental Stewardship} scheme

In the next few months your ELS contract is due to finish, and I am writing to you to request an interview to discuss your perspective on the scheme, and on the rural environment in general. The research is intended to help understand participants' ELS experiences, what impact it has had on the attitudes of the farming community towards the environment and what the land management plans are for the land coming out of scheme management.

I am conducting the research for my PhD studies undertaken at the Countryside and Community Research Institute (CCRI). The studentship is part-funded by Natural England, although their role in the research is strictly advisory. The interview will last around one hour, and would be conducted at a time and place most convenient to you. Participation in the research is voluntary, and should you wish to reject any further participation in the project (or if you have any other questions) please feal free to contact me through any of the contact details, below. Your involvement would, however, be of great value to the research, and may also be a represent a welcome chance to share your experiences of the scheme and your beliefs about the state of farming today.

In keeping with the CCRI's policy on ethics and privacy, the information you provide will be covered by the 1998 Data Protection Act. All responses will be kept anonymous and will not be used for any purpose other than for this study.

Over the coming weeks I will make further contact to arrange an interview. In the meantime, let me thank you for the time taken to read this letter, and in advance for your continued involvement in the research project.

Yours Faithfully

George Cusworth

PhD Researcher 